\title{
الحجية السلبية للحكم الجنائي الأجنبي \\ دراسة تحليلية مقارنة في القانون المصري والفرنسي
}

الدكتور

خالد صفوت ناجي عبد القادر بهنساوي

مدرس القانون الجنائي - كلية الحقوق

جامعة بني سويف 



\section{مقدمة عامة}

\section{حق الاولة في العقاب:}

ينشـأ حـق الدولــة في العقـاب بمجـرد وقـوع الجريمــة كـرد فعـل علـي

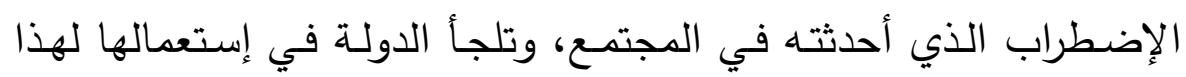

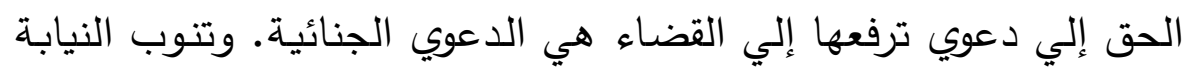
العامة عن المجتمع وتمثله في مباشرة الدعوي الجنائية(').

\section{أهمية الحكم بين إجراءات الدعوي:}

للحكم أهميـة أساسية بين إجراءات اللدعوي الجنائية، ذلك أن غايتها

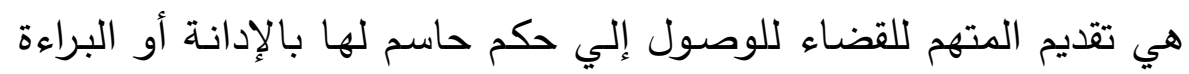

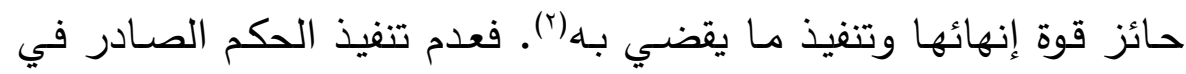
الدعوي يجعل كل الإجراءات التي اتخذت فيها فئهي عبثاً لا طائل منها. ومن ثم نستطيع القول بأنه متي وصلت الدعوي العمومية إلي صدور

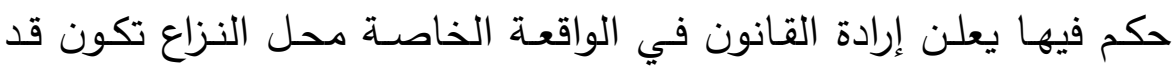

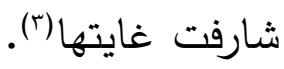

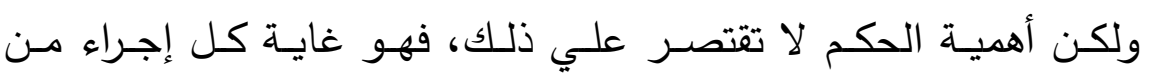

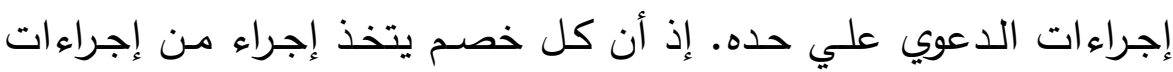
الدعوي إنما يتجـه نحو هدف نهائي هو إستخلاص حكم يطابق وجهة

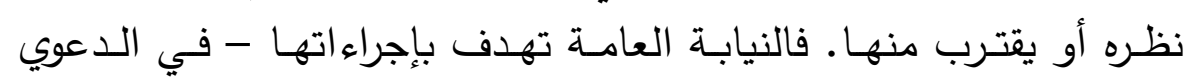

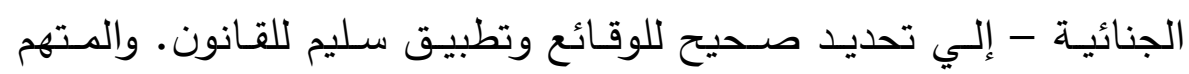

(1) د/ عبد الرعوف مهدي، شرح القواعد العامـة للإجراءات الجنائية، دار النهضـة العربية،

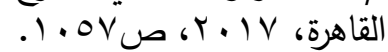

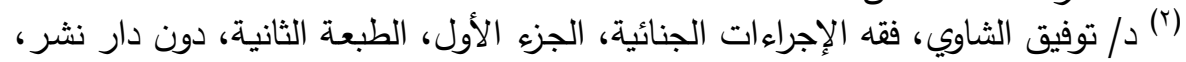

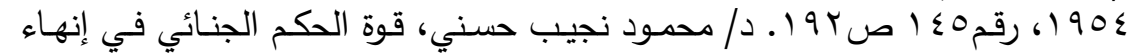

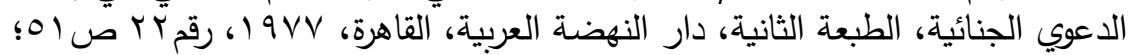

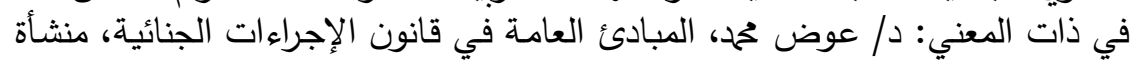

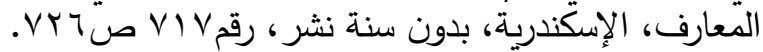

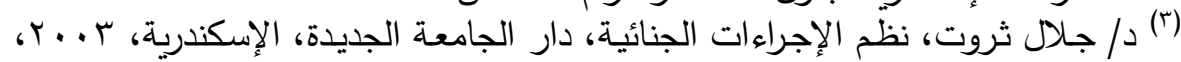


يسعي بإجراءاته إلي إستخلاص حكم يقرر براءته أو يُقضـي عليه بأقل عقوبة يسمح بها القانون ('). ولكن أهمية الحكم لا تقتصر علي كونـه غاية الدعوي وغاية كل إجراء

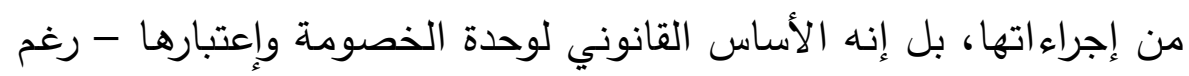

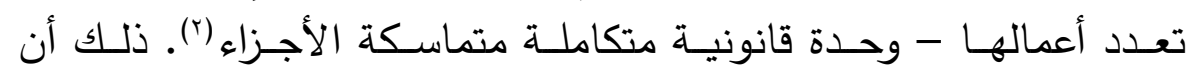

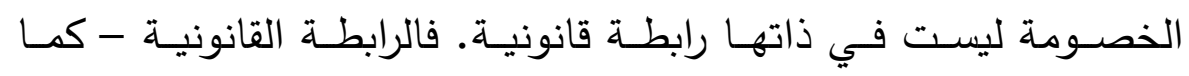

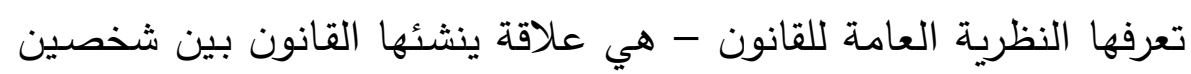

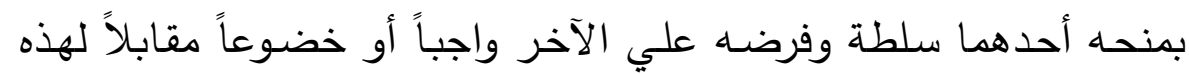

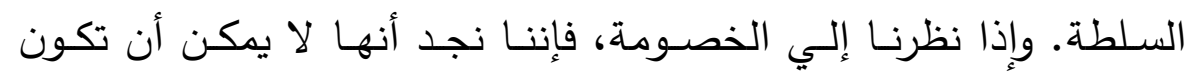

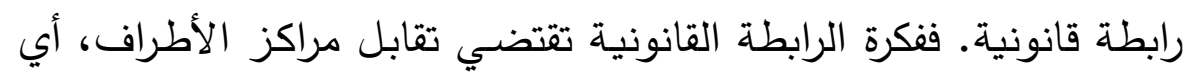

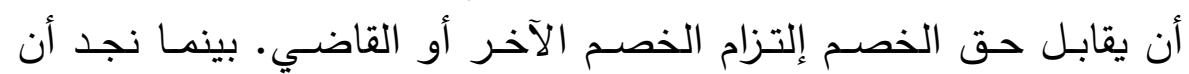

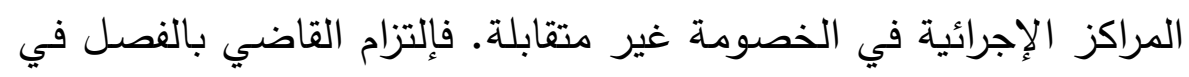
الدعوي مصدره القانون مباشرة، ويرجع إلي طبيعة وظيفته وليس إلتزاماً

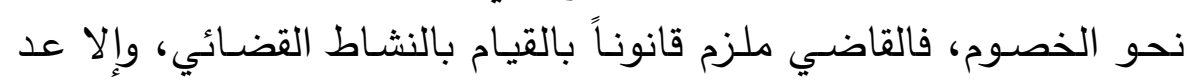

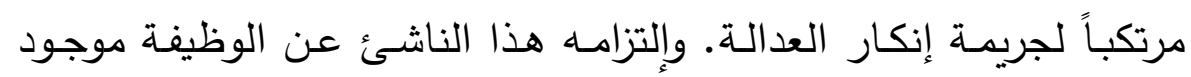

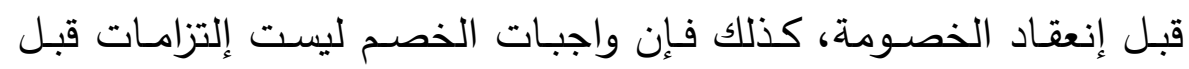

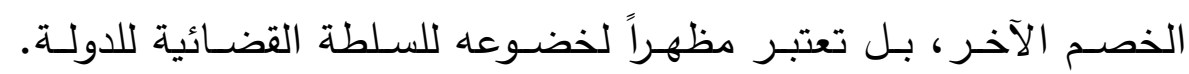

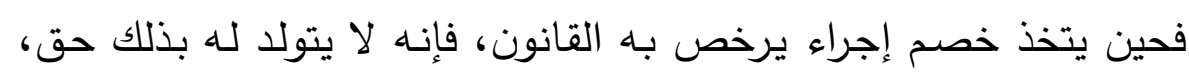
وإنما يصبح - بالنسبة لخصمه - في وضع إجرائي معين.

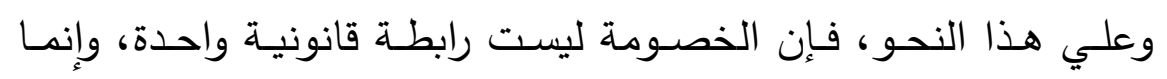

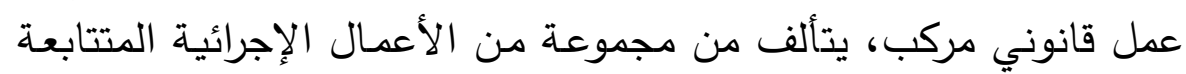

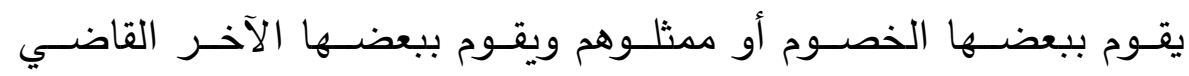

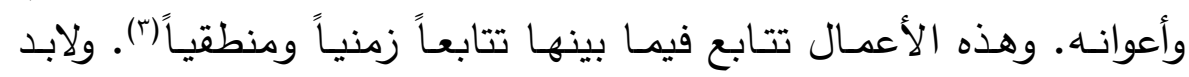

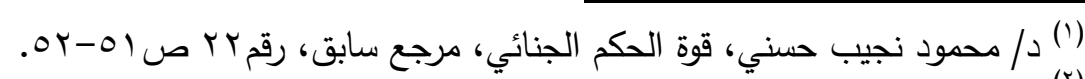

$$
\begin{aligned}
& \text { () ذات الموضع السابق. }
\end{aligned}
$$

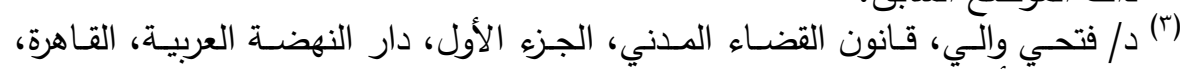

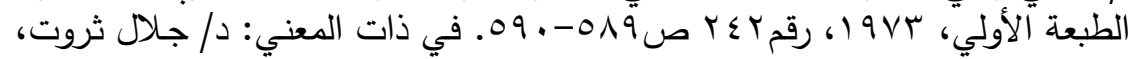

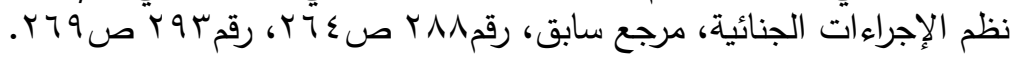


لهذه الأعمـال مـن رابطـة تصـل بينهـا، هذه الرابطـة هـي وحدة الغايـة.

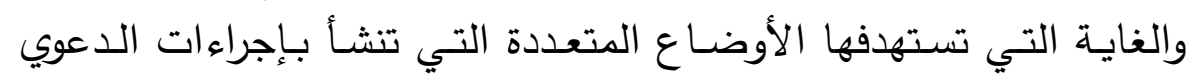

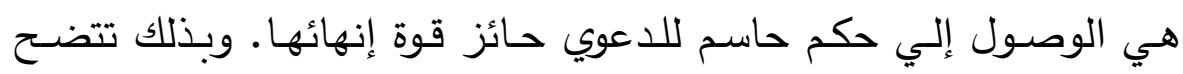
أهمية الحكم في الدعوي، فهو غايتها وأسـاس وحدة الخصـومة المتولدة عنها (')

\section{أسباب إنقضاء الاعوي الجنائية:}

أسـباب إنقضــاء الـدعوي الجنائيـة ذات طبيعـة إجرائيـة لأنهـا عقبـات

$$
\text { إجرائية تحول دون مباشرة الدولة حقها في العقاب. }
$$

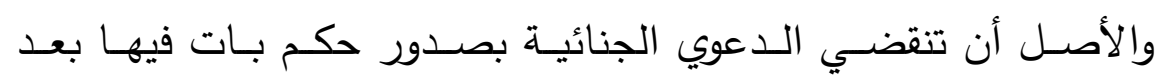

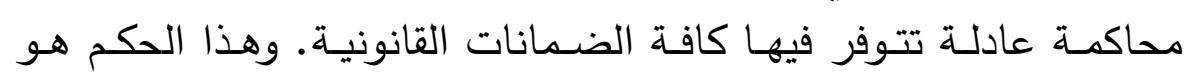
الذي يستنفد جميع طرق الطعن فيه. فهو الذي يحوز قوة الأمر المقضي

غير أن هناك أسباباً تطرأ علي الدعوي قبل رفعها أو تطرأ عليها بعد

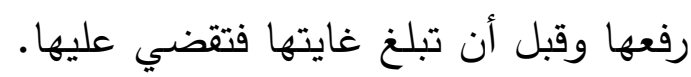

وأسباب الإنقضـاء عديدة(r)، منها مـا هو عـام يسري علي كل دعوي

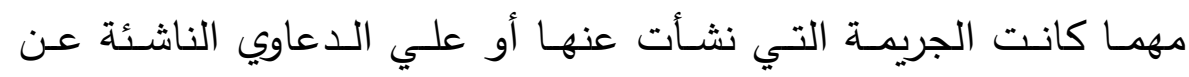

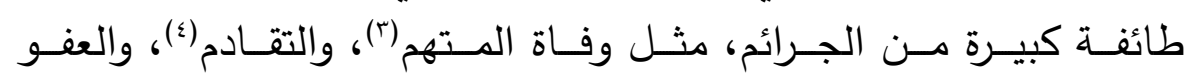

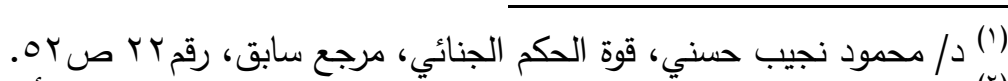

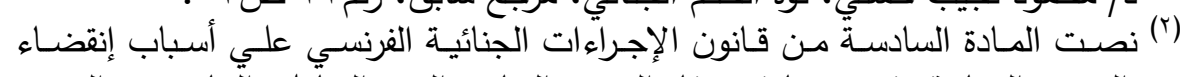

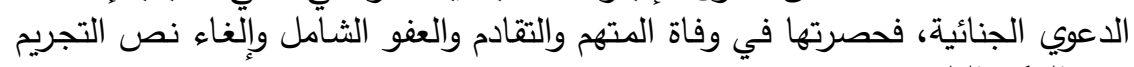

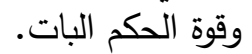

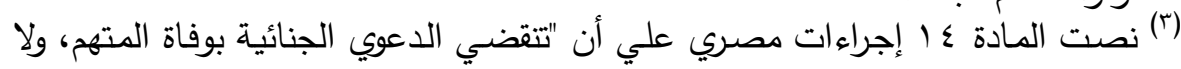

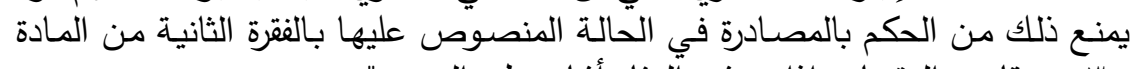

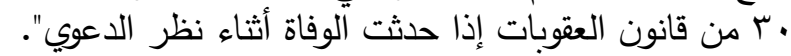

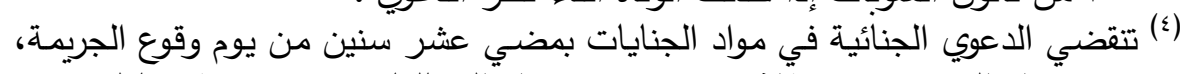

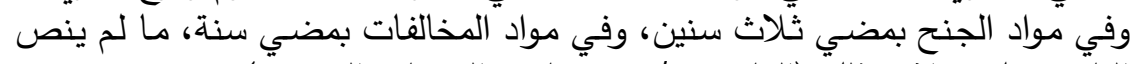

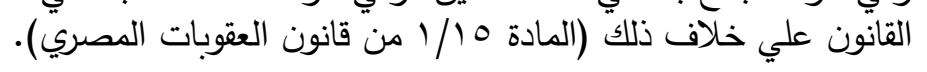




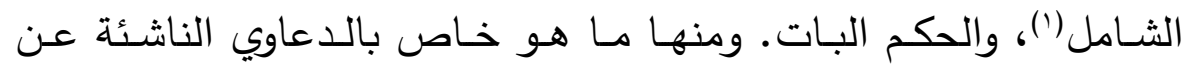

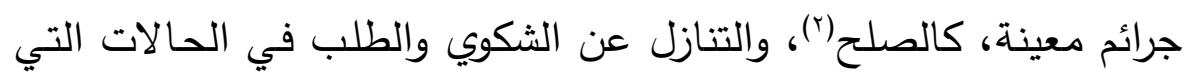
يعلق فيها القانون لصحة رفع الدعوي أو تحريكها تقديم شكوي أو طلب. آثار الحكم الجنائي البات:

وتتميز آثار الحكم الجنـائي البات بأمرين (َ): أحدهما إيجـابي والآخر سلبي.

ويتمثل الأمـر الأول في القوة التنفيذيـة للحكم، وذلك بصـلاحيته سـنداً

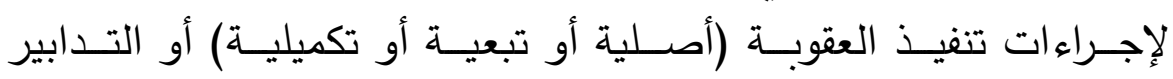
الإحترازية فيمن قضي عليه بها، وهي بذلك ذات طابع إيجابي (๕). ويتمثل الأمـر الثاني في قوتـه في إنهاء الـدعوي الجنائيـة، وخـروج

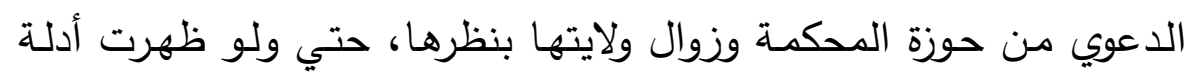

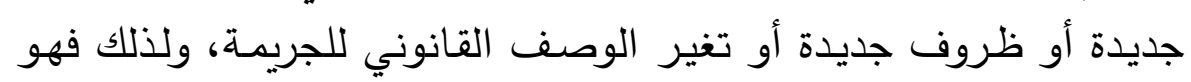

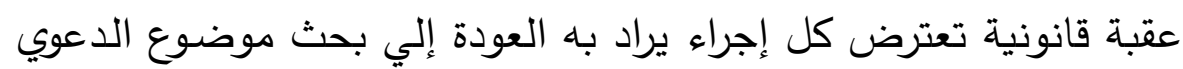

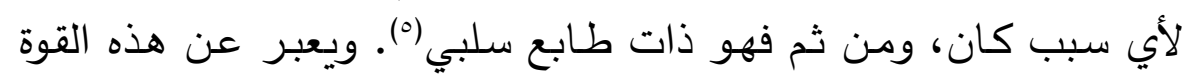
بمبدأ "عدم جواز محاكمة الشخص عن ذات ومن الفعل مرتين". مبدأ عدم جواز محاكمة الشخص عن ذات الفعل مرتين:

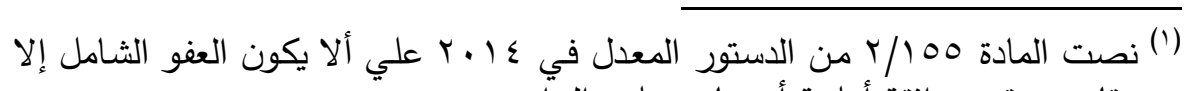

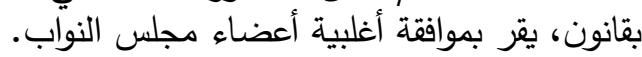

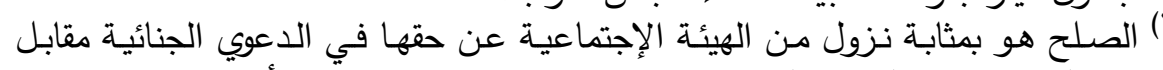

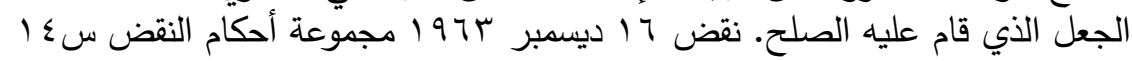

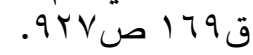

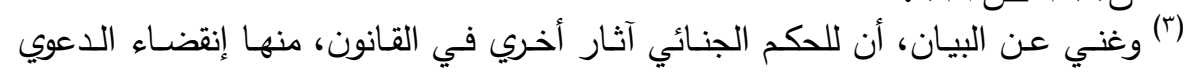

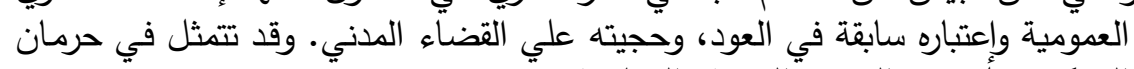

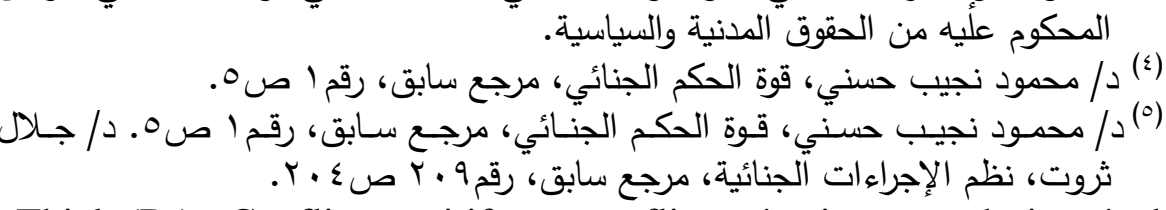

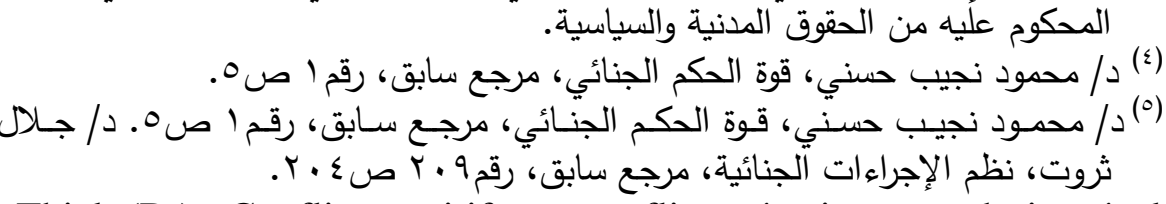

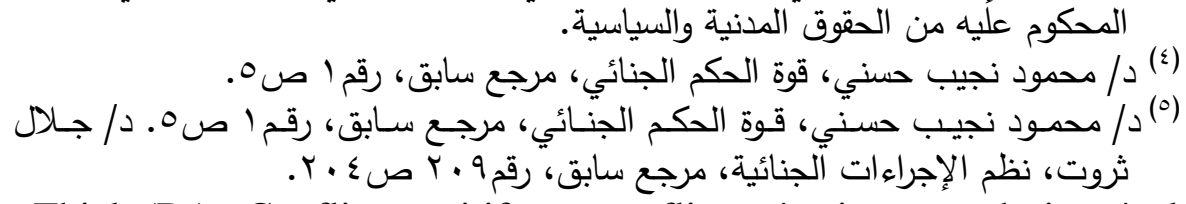

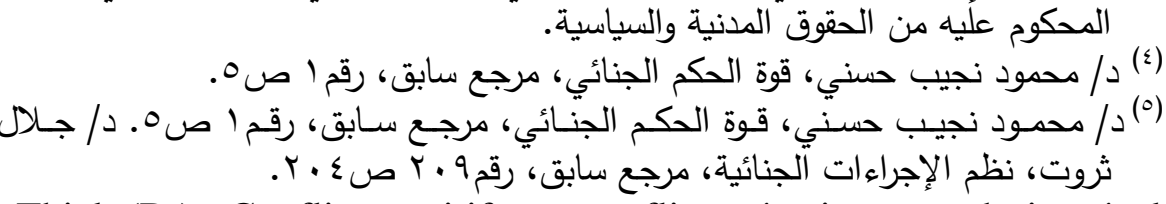
(r) Thiel (D.): Conflits positifs et conflits négatives en droit pénal international, thèse, université de Metz, $r \cdots, n^{0} \uparrow q, p^{\top} \cdot$. 
Non bis in idem يتمثل هذا المبدأ - ويطلق عليه بالتعبير اللاتيني - في أنـه إذا حـوكم مـتهم مـن أجل فعل وصل وصدر في شـأنه حكم أنهي

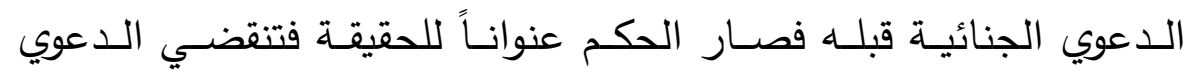

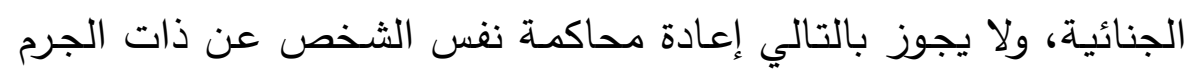

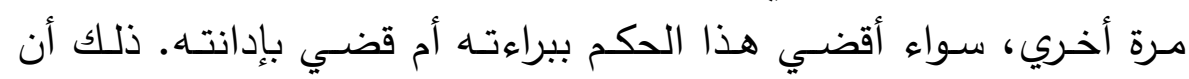

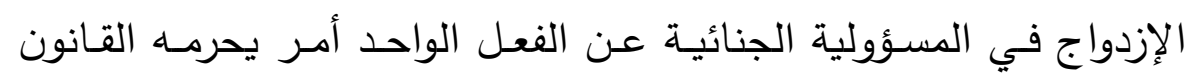

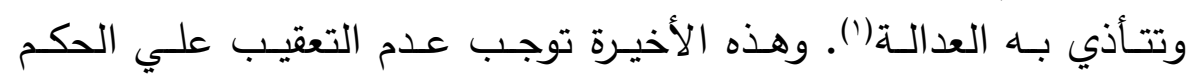

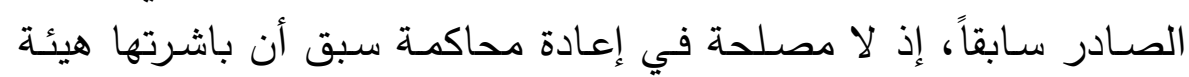

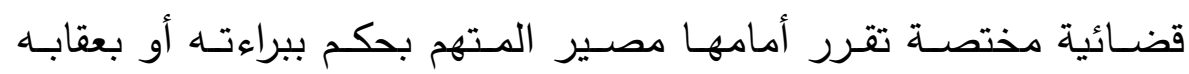

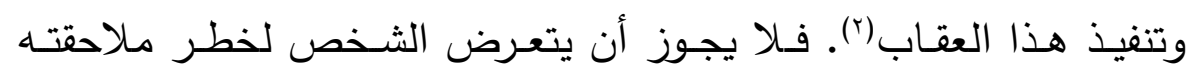

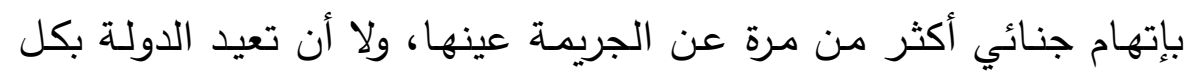

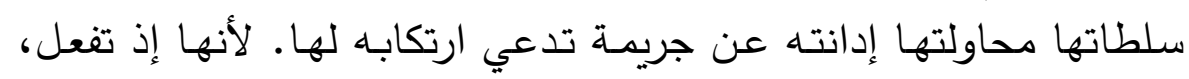

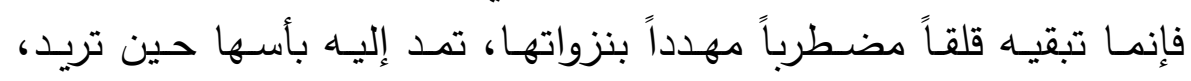

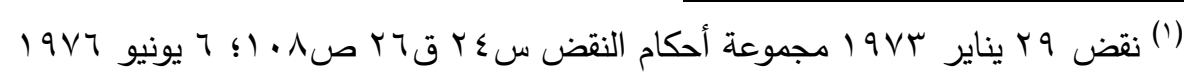
س

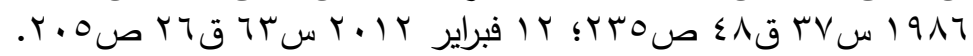

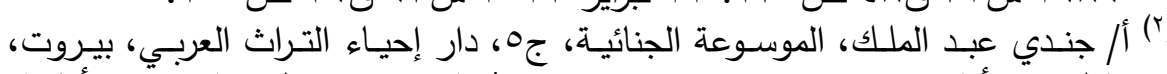

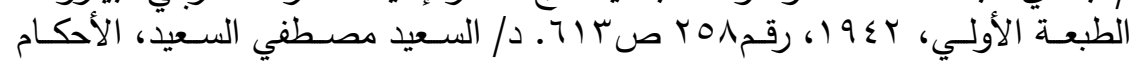

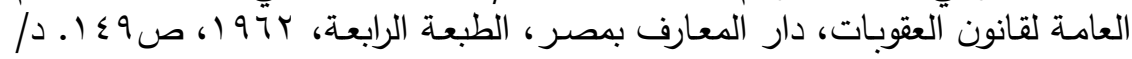

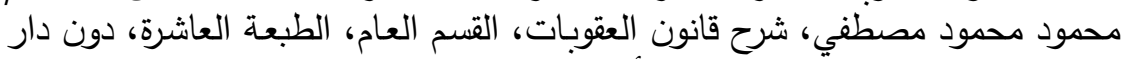

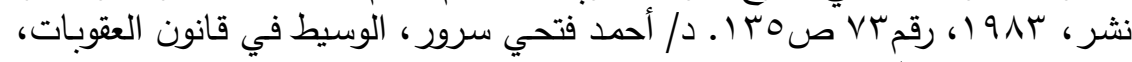

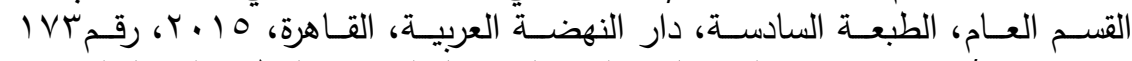

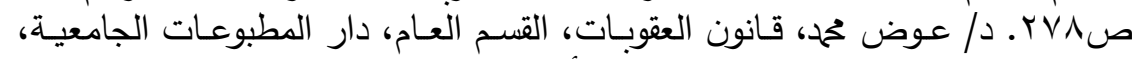

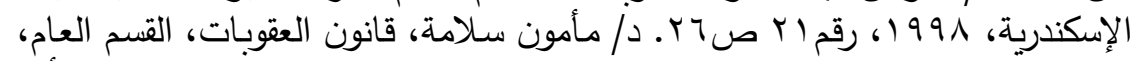

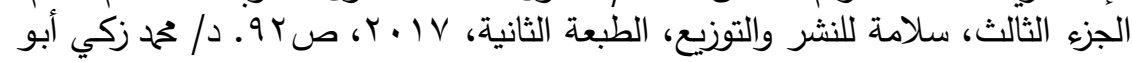

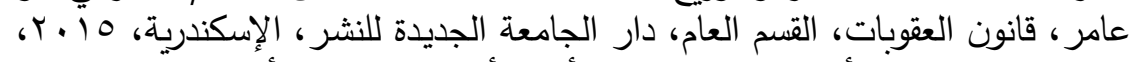

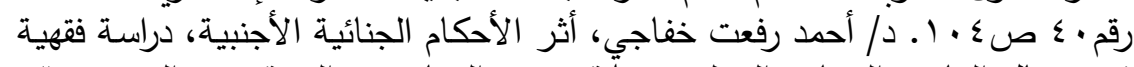

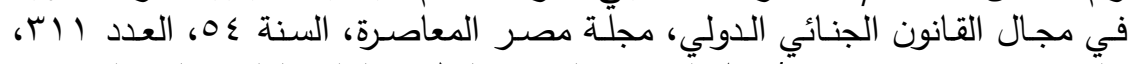

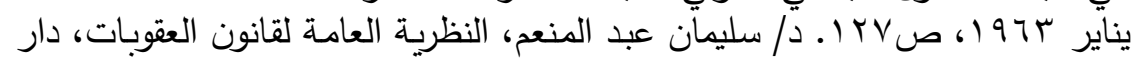

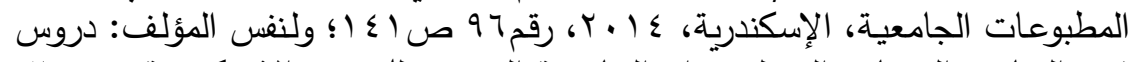

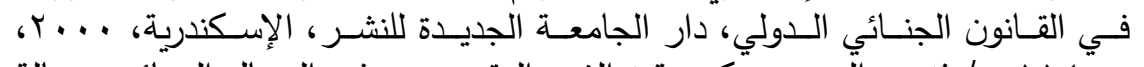

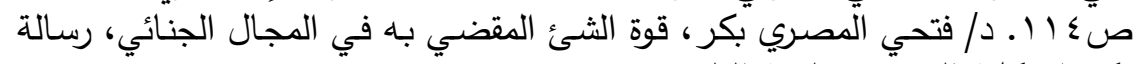

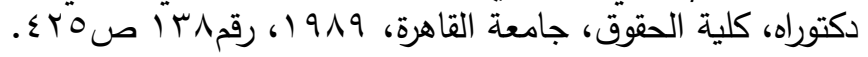


ليغدو محاطاً بألوان من المعاناة لا قبل له بها، مبدداً لموارده في غير

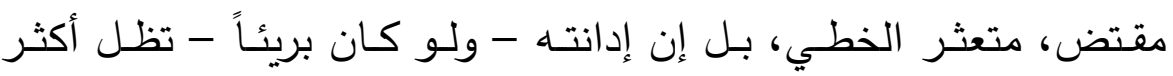

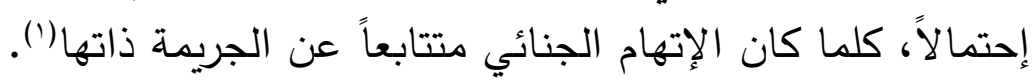

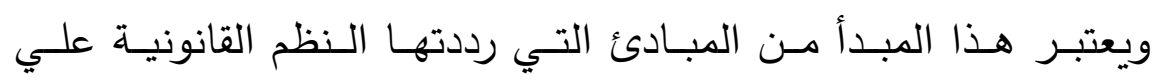

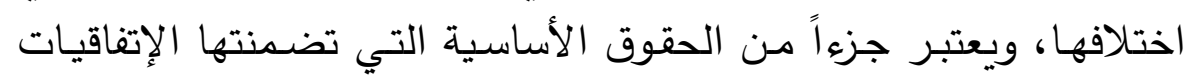

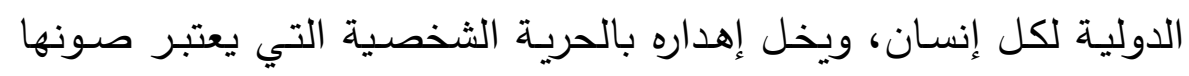

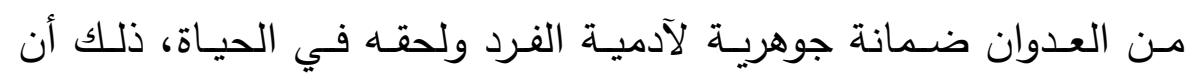

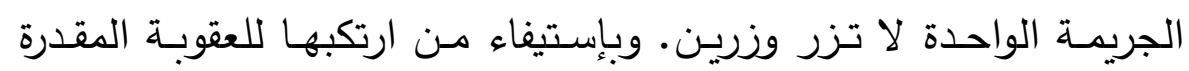

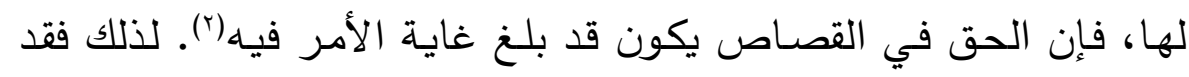

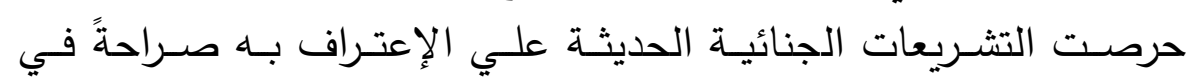
قوانينها، من ذلك التشريع المصري والفرنسي.

فقد اعترف المشـرع المصـري بقوة الحكم الجنـائي في إنهاء الـدعوي

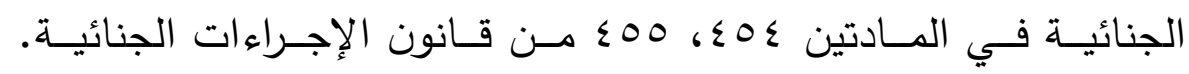
فأولاهما تنص علي أن "تنقضي الدعوي الجنائية بالنسبة للمتهم المرفوعة الداء

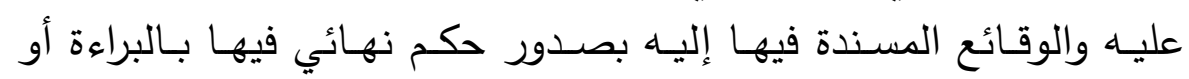

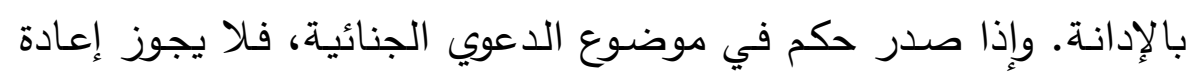
نظرها إلا بالطعن في هذا الحكم بالطرق المقررة في القانون". وثانيتهما تقرر أنه "لا يجوز الرجوع إلي الدعوي الجنائية بعد الحكم فيها نهائياً

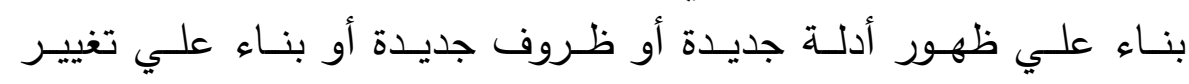

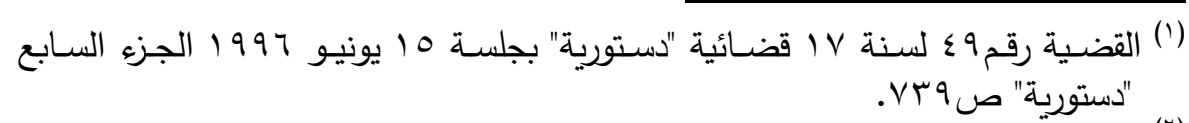

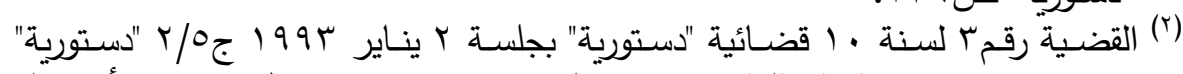

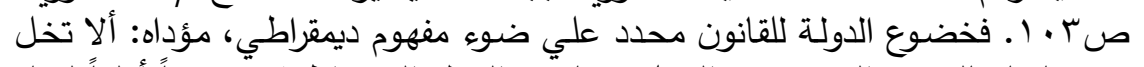

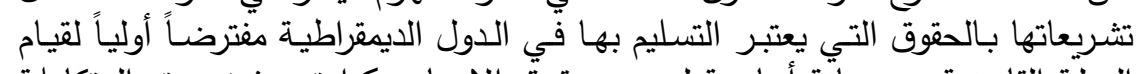

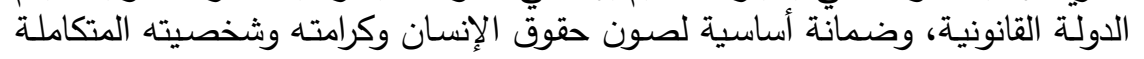

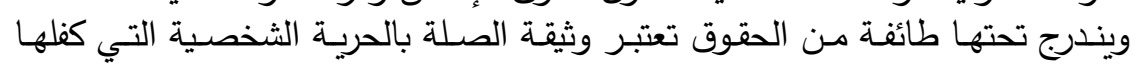

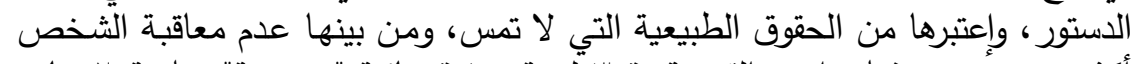

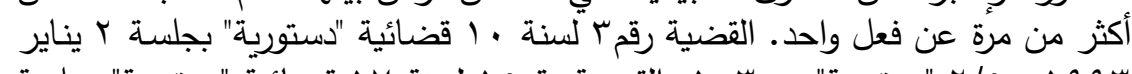

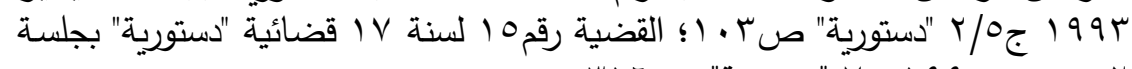

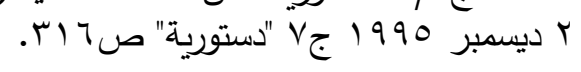




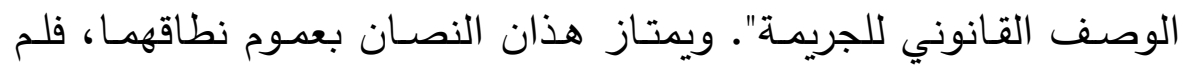

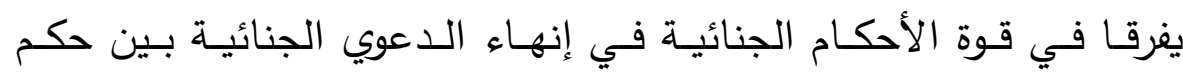

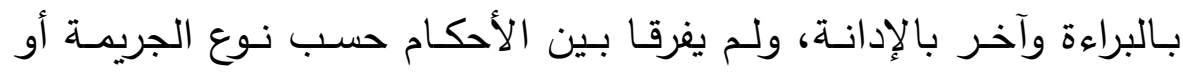

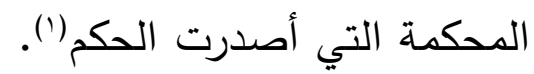

كما أقر قانون الإجراءات الجنائية الفرنسي هذا المبدأ في الفقرة الأولي

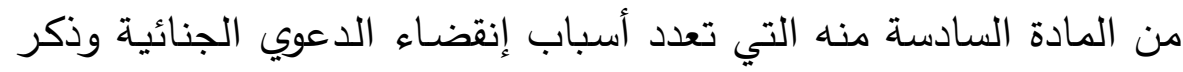

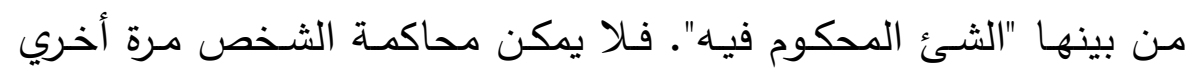
عن نفس الوقائع التي حوكم عنها من قبل. ويؤكدها بعد ذلك في المادة

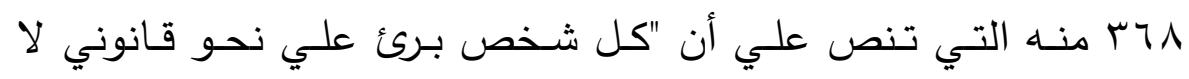

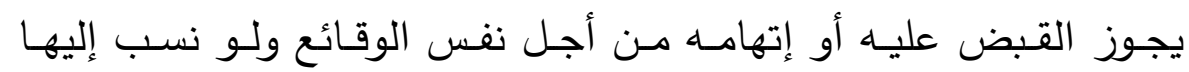

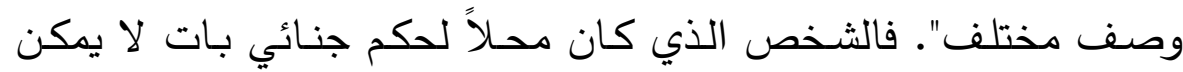

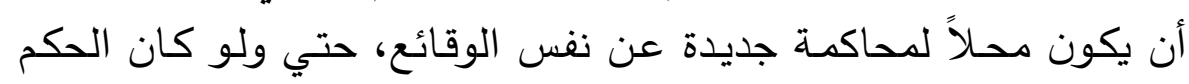

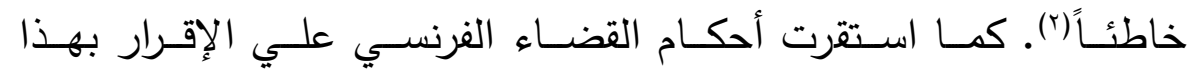

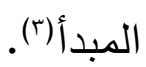

\section{مبدأ إقليمية قانون العقوبات ونتائجه:}

من مظاهر سيادة الدولة علي إقليمها، إنطباق قانون العقوبات الوطني

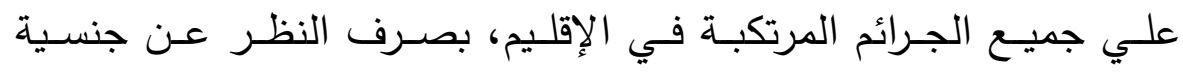

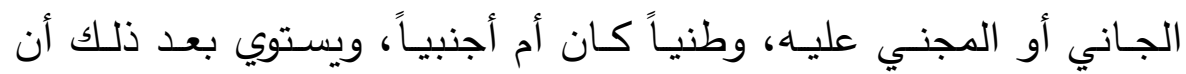

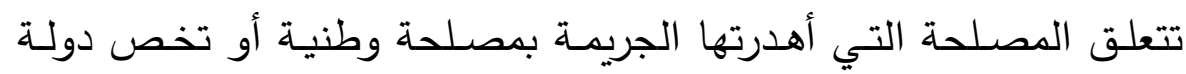
أجنبية، وهو المبدأ المعروف بمبدأ "إقليمية قانون العقوبات".

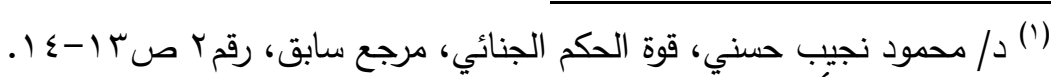

(r) Jean Pradel: Droit pénal, Tome III, procedure pénale, Édition Cujas, Paris, Deuxième édition, 1911, n ${ }^{0} 40 \leqslant$, p. 710 . Thiel (D.): op.cit. $\mathrm{n}^{0} 79, \mathrm{p} .{ }^{7}$.

(5) crim. 7 mars $110 \mathrm{~V}$, D. 1 1NOV, I, $11 \cdot$; crim. 10 oct. 1909, J.C.P.

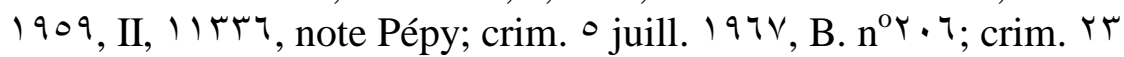

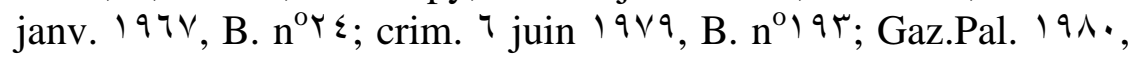
I, $17 \varepsilon$; crim. $r \leqslant$ mars 1999, B. $n^{\circ} 0 \leqslant$ 


\section{وينجم عن هذا المبدأ نتيجتان:}

الأولي: لها طابع إيجابي، ومؤداه تطبيق القانون الجنائي تطبيقاً شاملاً

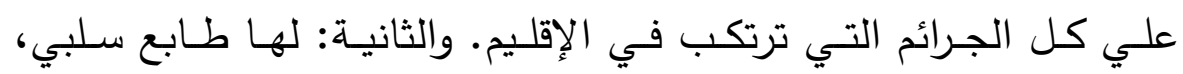

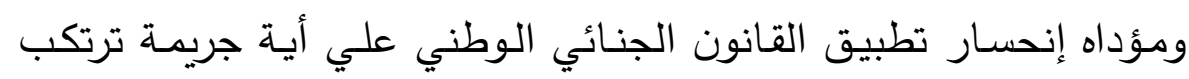
خارج إقليم الدولة.

وتطبيـق مبـدأ الإقليميـة يـؤدي بصـورة مطلقــة إلـي إقليميـة الأحكـام

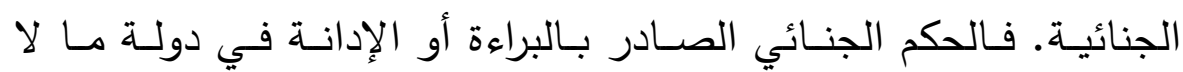

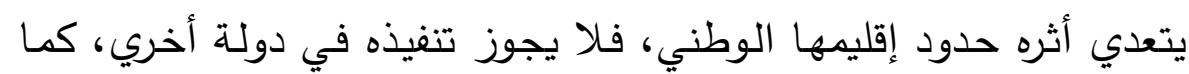

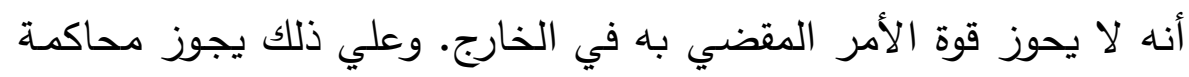

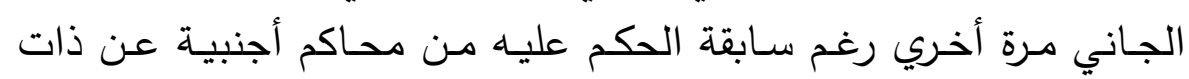

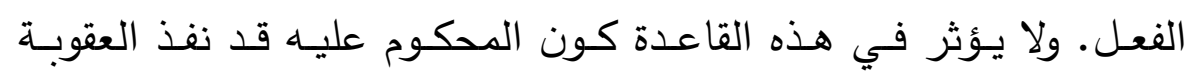

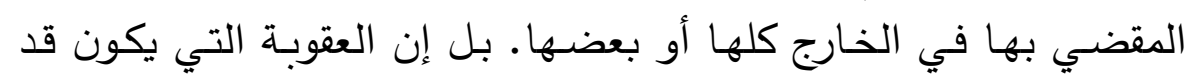

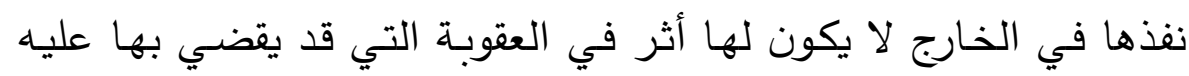

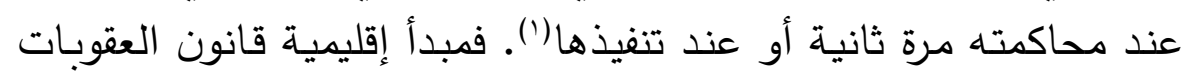
يؤدي إلي تلازم بين السلطتين التشريعية والقضائية في المجال الجنائي،

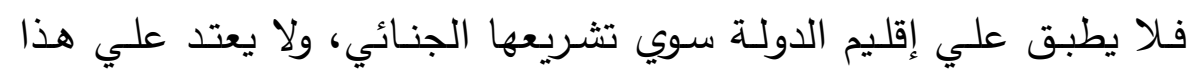

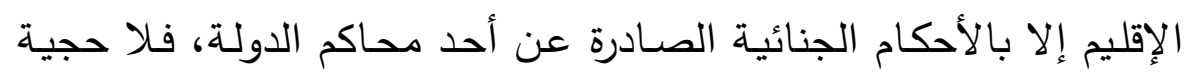
لتشريع جنائي أجنبي، ولا حجيـة لحكم جنائي صـادر عن محاكم دولـة الألة أخري.

ولاشك أن كافة الأحكام الجنائية الوطنية تتمتع علي إقليم الدولة بقوتها في إنهاء الدعوي الجنائية، متي توافرت فيها الثـروط اللازمـة لإعمال

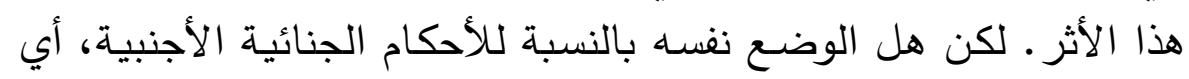

(1) Donnedieu De Vabres: Les principes modernes du droit pénal international, Paris, $194 \wedge$, p. ${ }^{1}$.

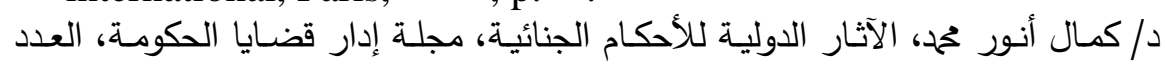

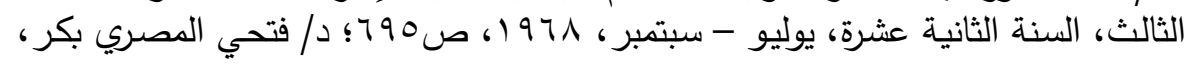
مرجع سابق، رقم 
الصادرة من القضاء الأجنبي؟ بمعني آخر هل يمكن المساواة بين الحكم الجنائي الأجنبي والحكم الجنائي الوطني في إحداث ذات الأثر؟ الهن التوسع في تحديد نطاق تطبيق قانون العقوبات من حيث المكان:

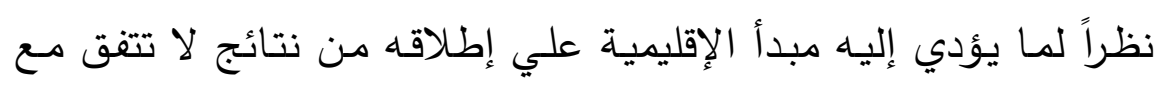

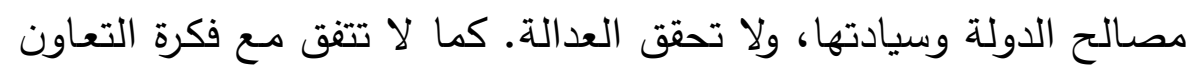

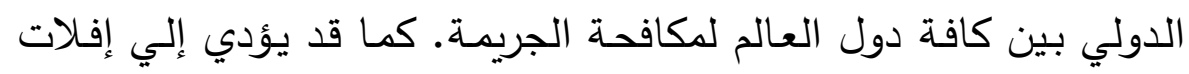

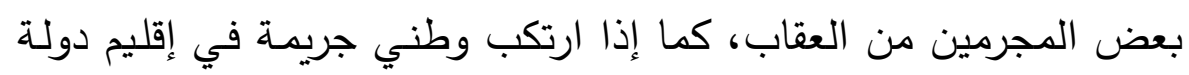
أخـري ثم عـاد إلـي دولتـه، فـلا تسـتطيع الأخيـرة محاكمتـه وفقـاً لمبـدأ

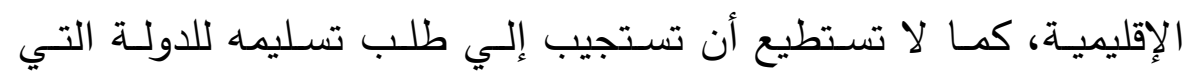

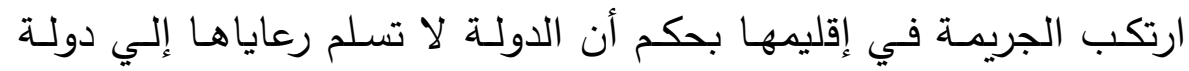

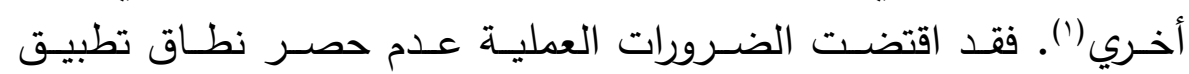
القانون علي إقليمها وحده. ومن ثم لجأت التشريعات - في حدود متباينة

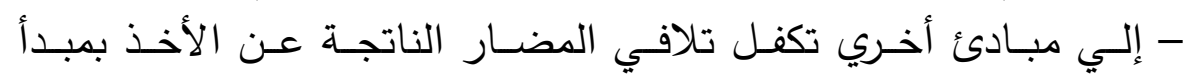

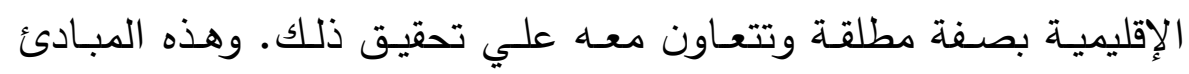
هي: مبدأ العينية ومبدأ الثخصية (الإيجابية والسلبية) ومبدأ العالمية.

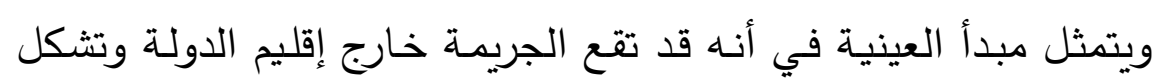
إعتداء علي حق من حقوقها أو حقوق رعاياها، وقد تكون من الخطورة

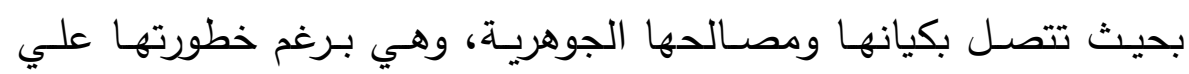

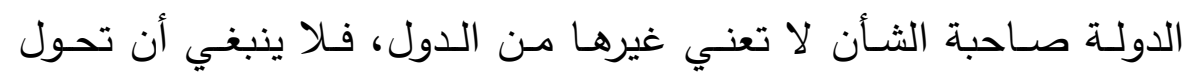

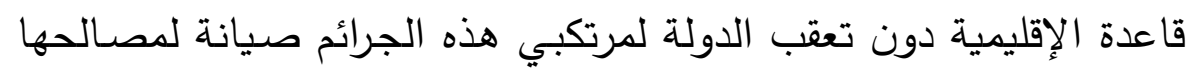

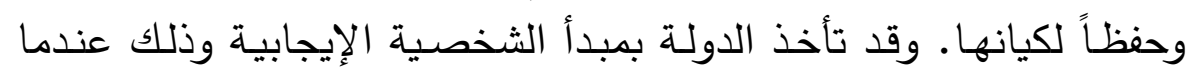

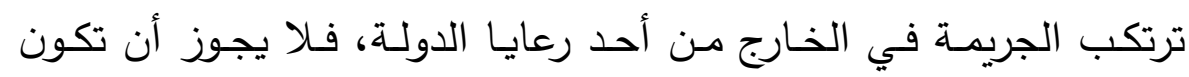

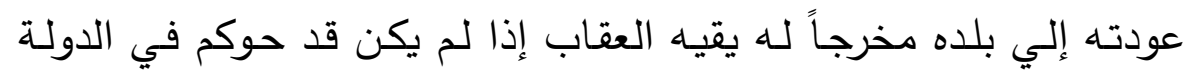

(1) Dans le même sens, voir: Jean Pradel: Droit pénal, Tome I, Introduction générale, Droit pénal général, Édition Cujas, Paris, 1911, n⿳亠人r, p. 190. Huet (A.) et Koering-Joulin (R.): op.cit.

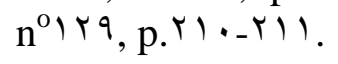


التي ارتكبـت فيهـا الجريمـة، الأمسر الذي يقتضـي بسط سلطان القـانون

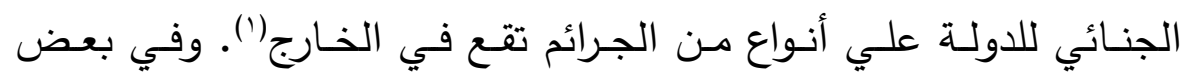

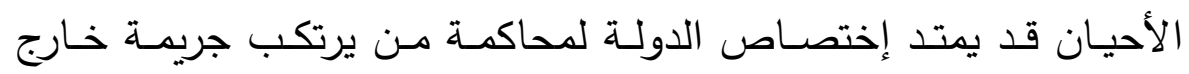
الدولة تقع علي أحد من ينتمون إلي جنسيتها، وهو ما يطلق عليه مبدأ الشخصية السلبية.

وتأخذ بعض التشريعات الجنائية بمبدأ العالميـة، ذلك أن الأفكار في

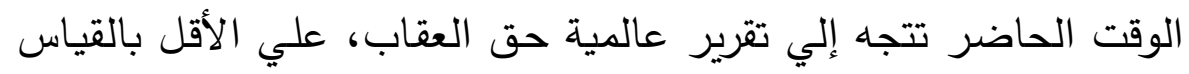

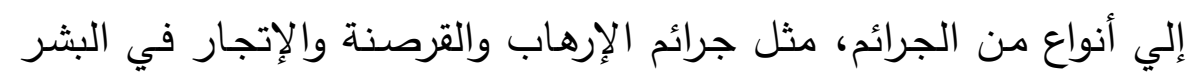

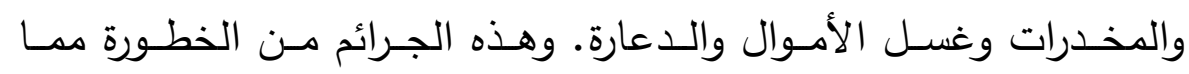

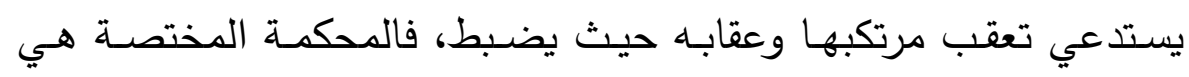

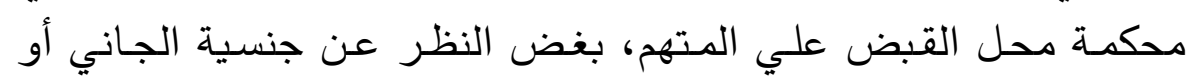

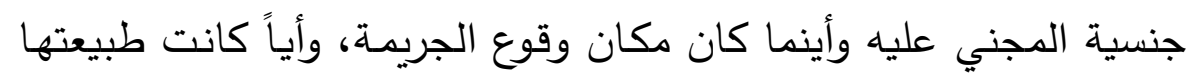

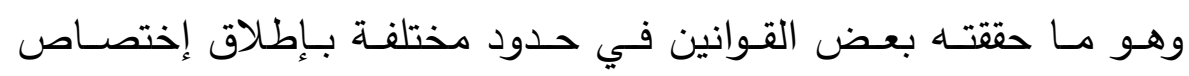
محاكمها الجنائية وتشريعها الجنائي علي مها يقع في الخارج من جرائم

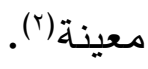

ولكل دولة الحق والحرية في تحديد مبادئ الإختصـاص الجنائي الدولي

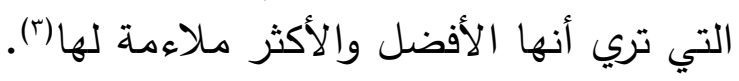

أساس مشكلة الحجية السلبية للأحكام الجنائية الأجنبية:

ترتب علي تعدد معـايير الإختصـاص القضـائي وتماثلها في المجـال

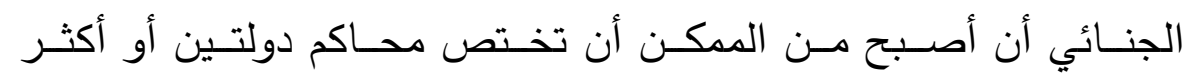

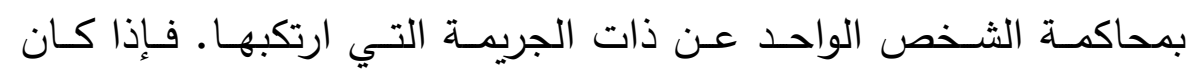

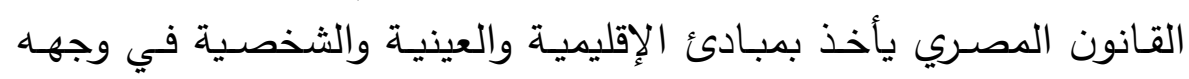

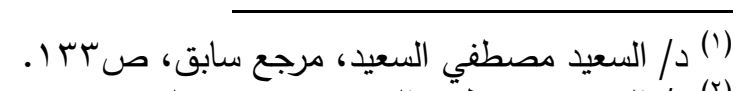

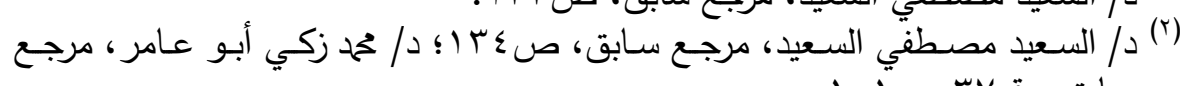

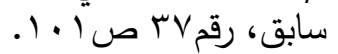

Jean Pradel: Tome I, Droit pénal général, op.cit. $n^{\circ} \backslash \wedge r$, p. 197.

(v) C.P.J.I. $\vee$ sép. $19 r v$, affaire du lotus, R.D.I.P. $194 \wedge$, p. ${ }^{4} \uparrow$ l) et s., note John Fischer Williams. 
الإيجـابي في الوقـت الـذي يأخـذ فيـهـ القـانون الفرنسـي بـذات المبـادئ

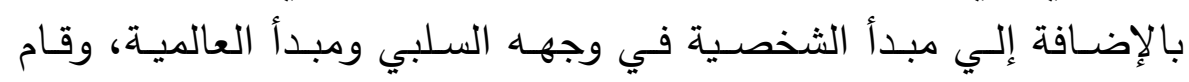

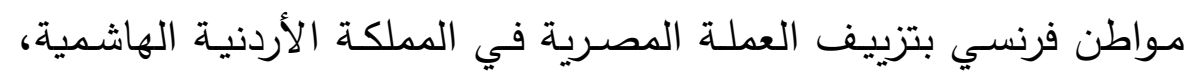

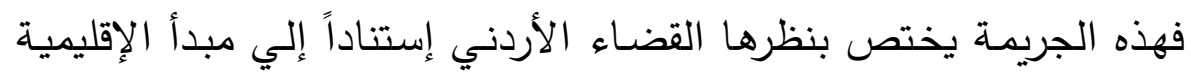

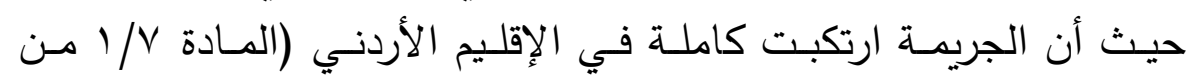
قانون العقوبات الأردني)، كما يختص بها القضـاء الفرنسي إستناداً إلي الإني

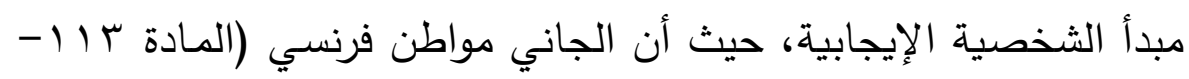

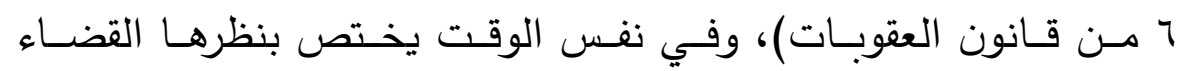

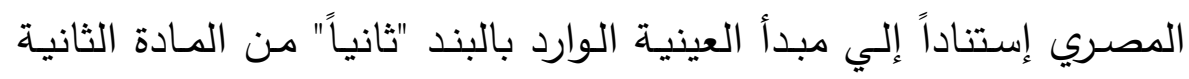

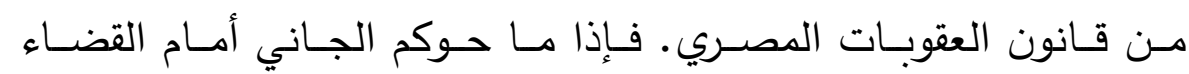

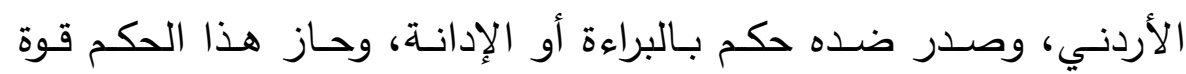

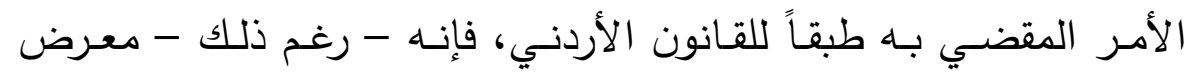

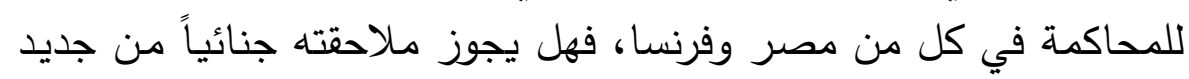

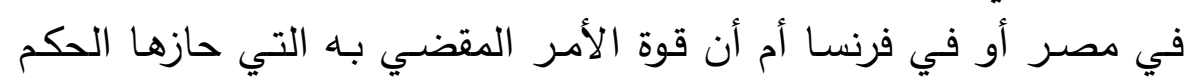

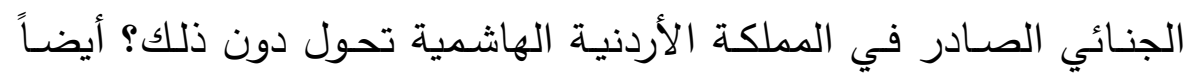

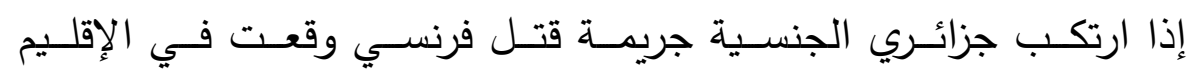

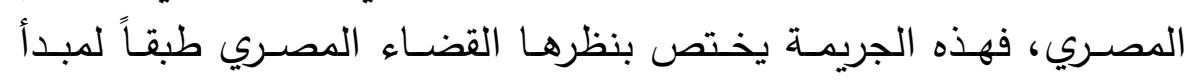

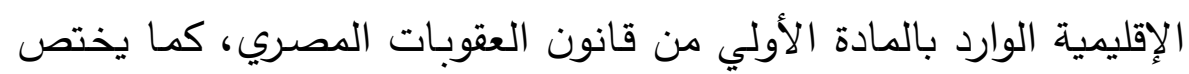

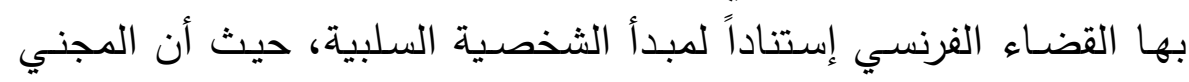

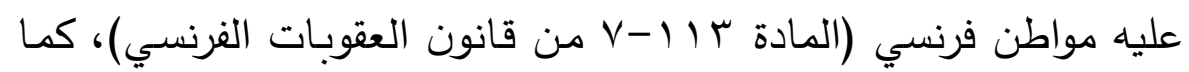

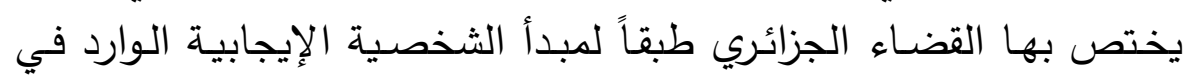

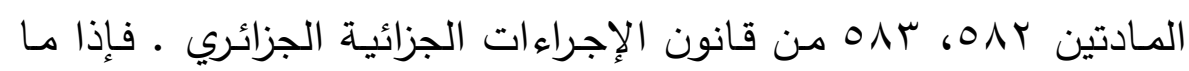

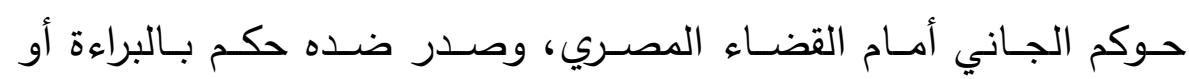

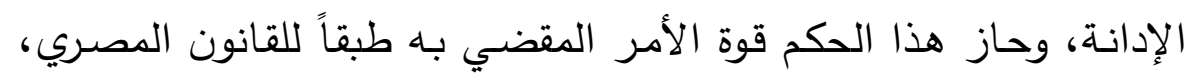

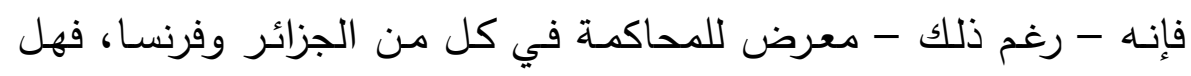

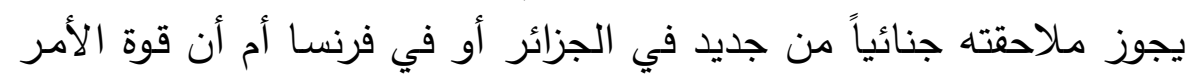


المقضـي بـه التي حازهـا الحكم الجنـائي الصـادر في مصـر تحول دون

ذلك؟

ومفاد ذلك أن تعدد معايير الإختصـاص القضـائي في المجال الجنائي

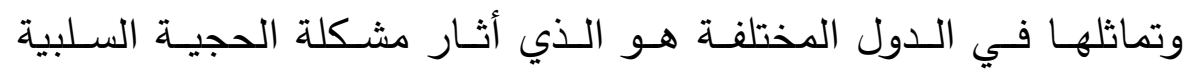

لنأحكام الجنائية الأجنبية.

\section{منهج البحث: - 2 - من}

حتي تكون هذه الدراسـة متكاملـة مـن مختلف جوانبها فسـعتمد علي

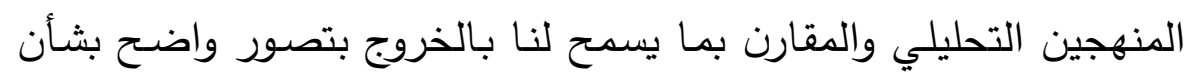

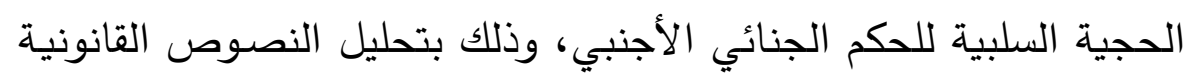
التي عالجت مسألة الإعتراف بهذه الحجية أمام القضـاء الوطني في كل التئل

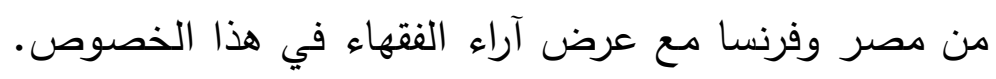
خطة البحث:

لم يشأ المشرع المصري أو الفرنسي أن يهدر الحجية السلبية للأحكام

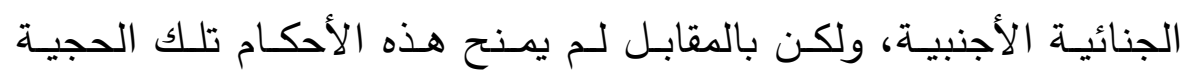

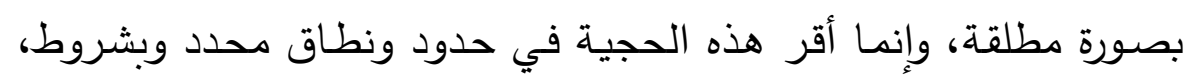

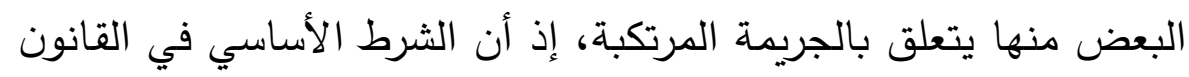

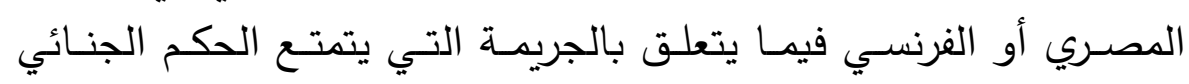

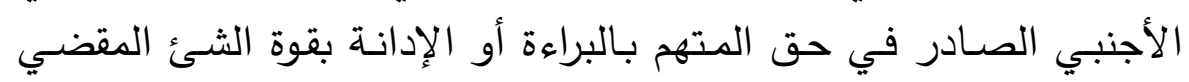

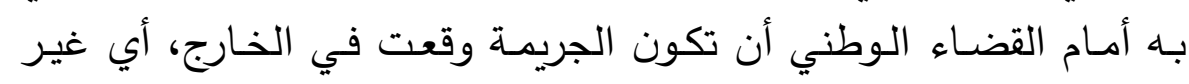

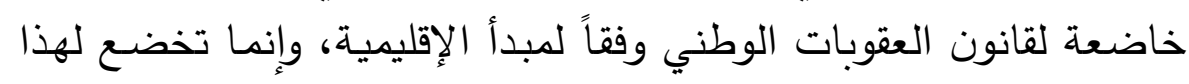

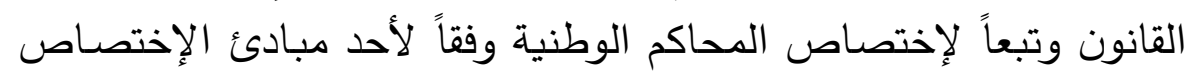

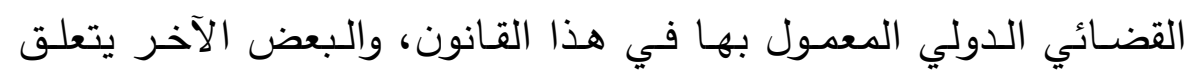

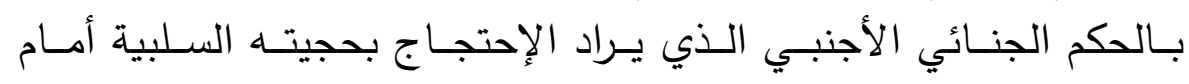
القضاء الوطني.

وإذا كان من المستقر عليه الآن، أن معظم التشريعات الجنائية تعترف

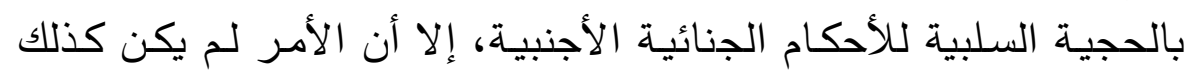




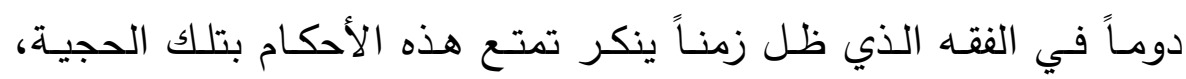

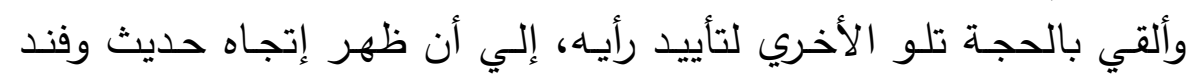
تلك الحجج وأدلي بحجج تؤكد ضرورة الإعتراف بالحجية السلبية للأحكام الجنائية خارج نطاق إقليم الدولة التي صدرت فولهن فيها.

هذا مـا سوف نتناولـه بالدراسـة في هذا البحث التي سنمهد لها ببيان

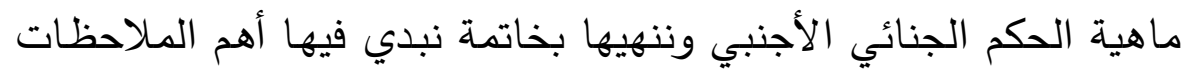

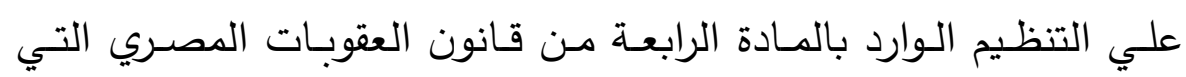
عالجت مسألة الحجية السلبية للأحكام الجنائية الأجنبية. وعلي هدي ما تقدم ستكون خطة البحث علي النحو التالي: مبحث تمهيدي: ماهية الحكم الجنائي الأجنبي. الفصـل الأول: موقف الفتـهـ مـن الإعتـراف بالحجيـة السـلبية للأحكـام الجنائية الأجنبية.

الفصل الثاني: الثرط الخاص بمكان وقوع الجريمـة "وقوع الجريمـة في الخارج".

الفصل الثالث: الثروط المتعلقة بالحكم الجنائي الأجنبي. خاتمة. 


\section{مبحث تمهيدي \\ ماهية الحكم الجنائي الأجنبي}

تمهيد:

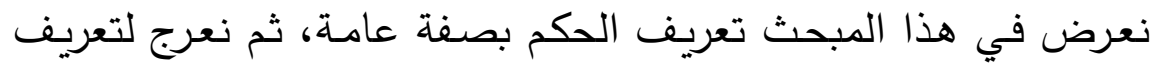

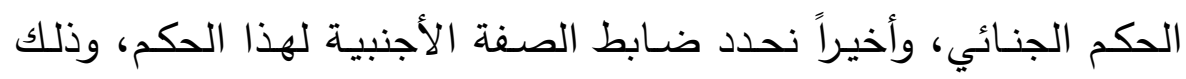

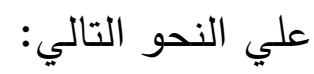

أولاً: تعريف الحكم بصفة عامة:

عرفت محكمة النقض المصرية الحكم بأنه "القرار الصـادر من محكمة

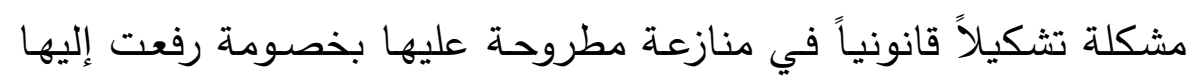

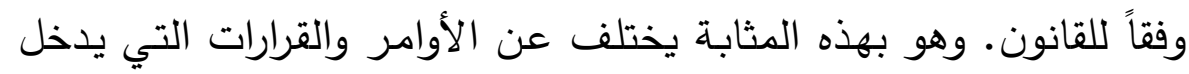

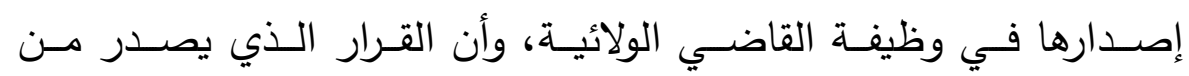

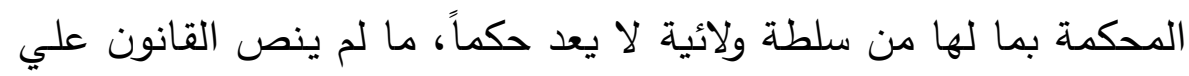
خلاف ذلك"(')

وهو تعريف منتقد (؟) إستناداً لإفتقاره إلي الدقة، فبعض عناصره تزّيد لا

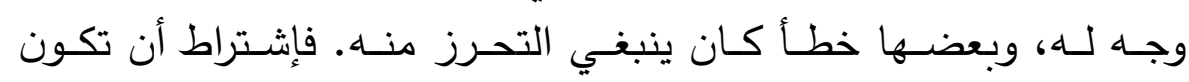

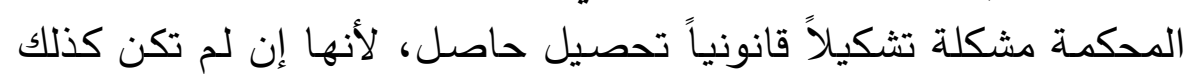

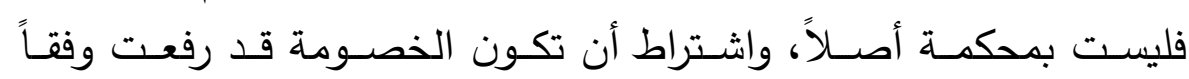

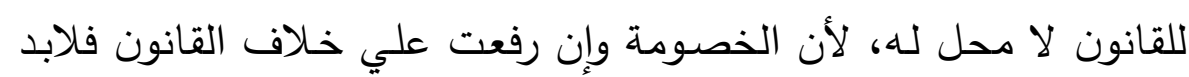

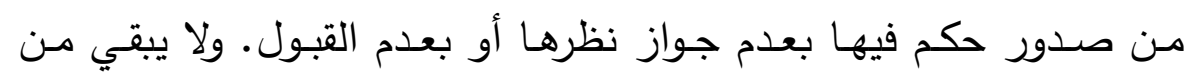

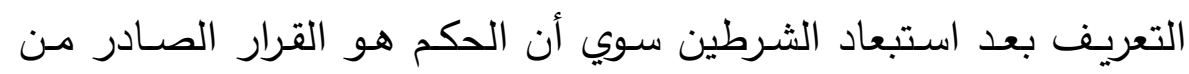
محكمة في خصومة مطروحة عليها.

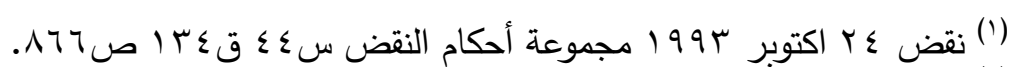

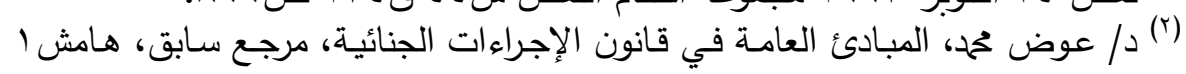

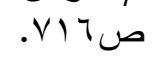




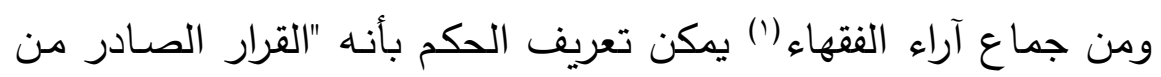

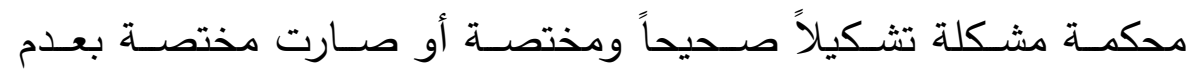
الإعتراض علي إختصاصها في الوقت المناسب في خصسومة مطروحة

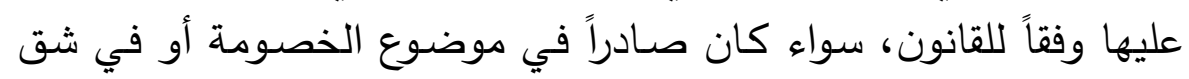
منه أو في مسألة متفرعة عنها.

ويبين من هذا التعريف أن الحكم، يتميز بما يلي: أولاً: أنه يصدر من محكمة تتبع جهة قضائية. ثانيـاً: انـه يصـدر بمـا للمحكمـة مسن سـلطة قضـائية، أي يصـدر في خصومة.

ومن ثم، فإن القرار الصـادر من هيئة غير قضـائية لا يعد حكماً ولو الصو

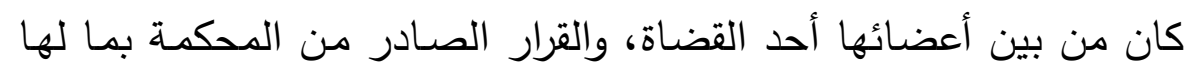

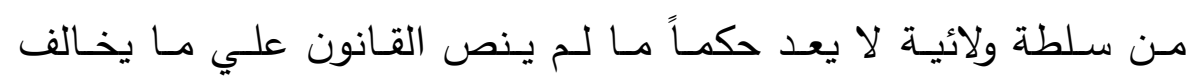
ذلك (r).

ويكثف هذا التعريف عن إتجاه الرأي السائد في الفقه إلي الجمع بين

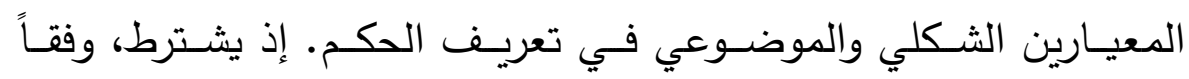

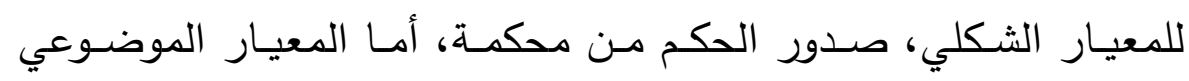
فيتمثل في وجوب صدور الحكم في خصومة رفعت وفق قواعد القانون.

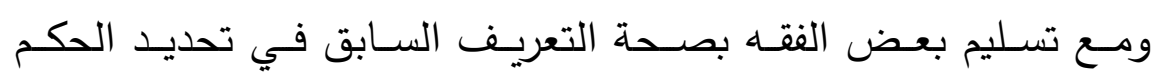

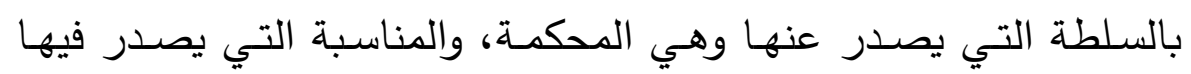

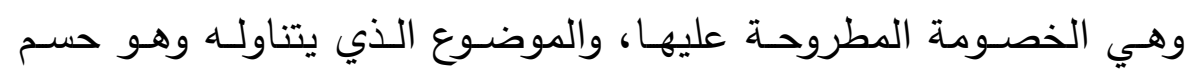

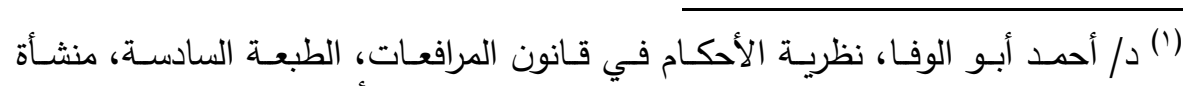

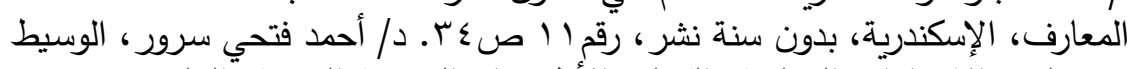

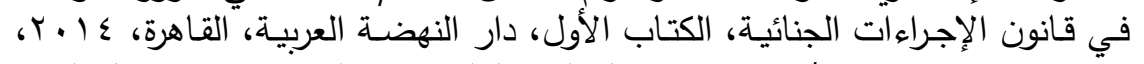

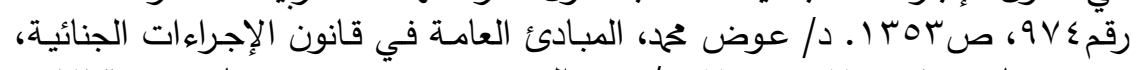

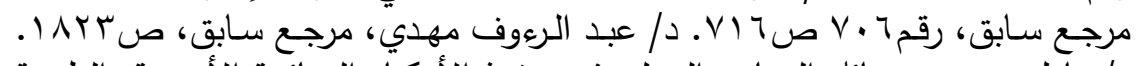

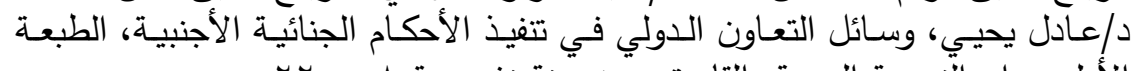

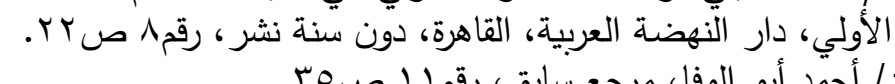

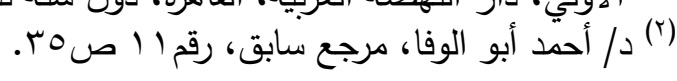


الخصـومة كلها أو في جزء منها، إلا أنسه يعيب علي هذا التعريـف مـا

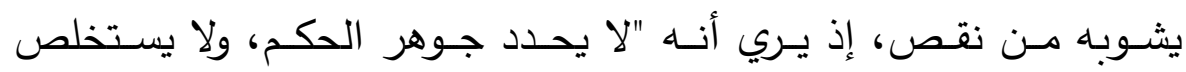

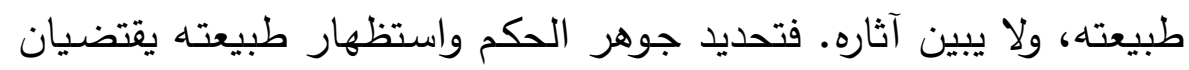

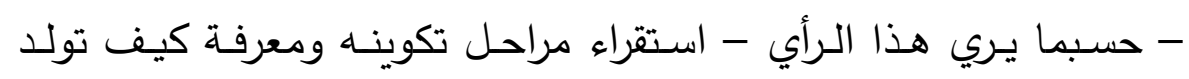

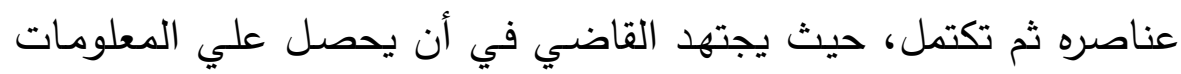

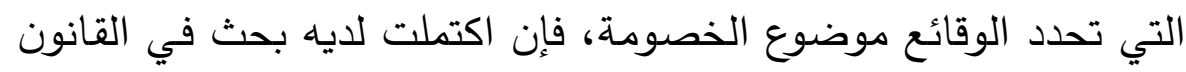

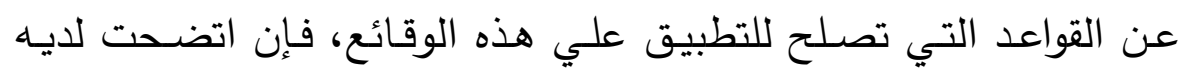
هذه القواعد اجتهد في تفسيرها، وجوهر التفسير هو تحديد نطاق تلك هلك

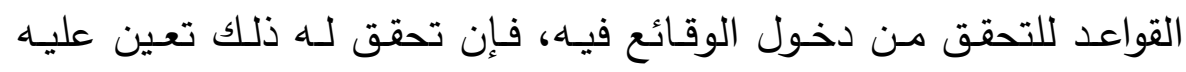

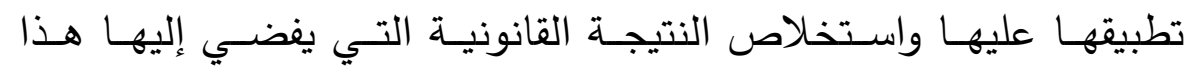

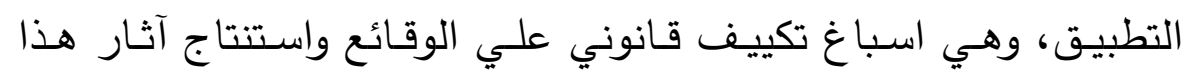
التكييف التي تتمثل في تحديد سلوك معين يلتزم أطراف الدعوي بـه كما

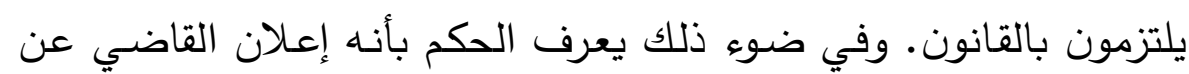

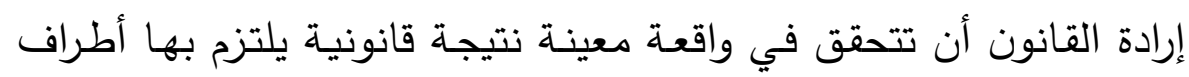

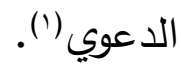

\section{ثانياً: تعريف الحكم الجنائي:}

تؤكد غالبية الفقه الجنائي علي أن يعد الحكم جنائياً متي كان صادراً

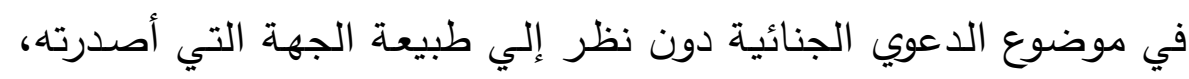

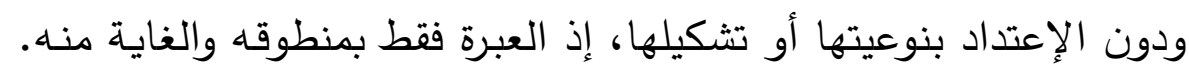

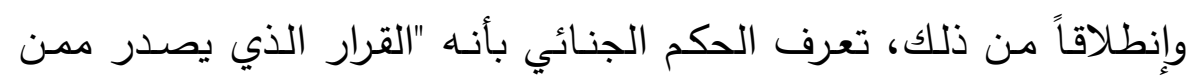

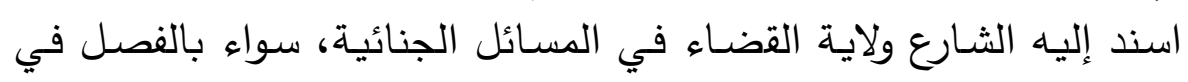

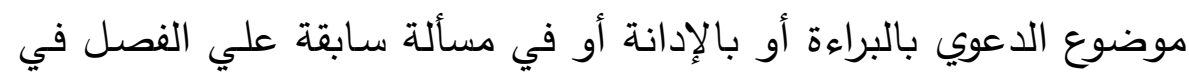
الموضوع. والحكم الصـادر في الموضوع هو بطبيعته نهاية المطاف في

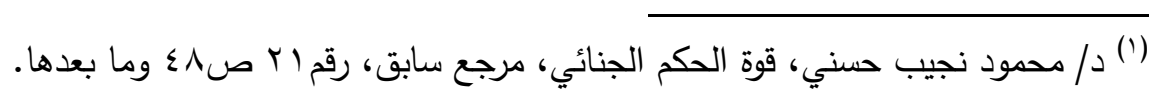


الــعوي الجنائيـة متـي اسـتنفدت جميـع طـرق الطعـن فيـه كمـا رسـها

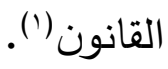
وتطبيقاً لذلك، يعد حكماً جنائياً ذلك الحكم الذي يفصل في موضوع الدعوي الجنائيـة ويصدر بعقوبـة أو تدبير إحترازي مـن محكمـة جنائيـة.

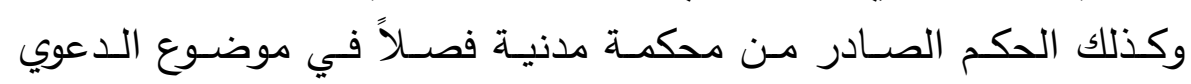

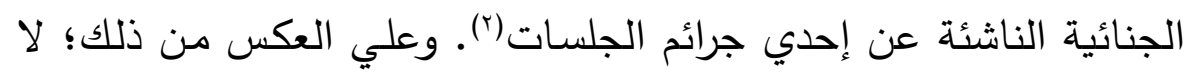

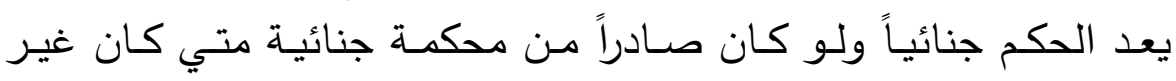

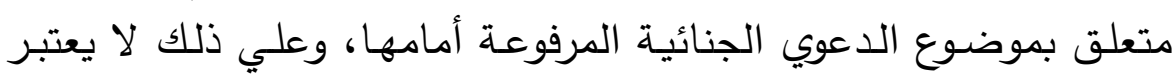

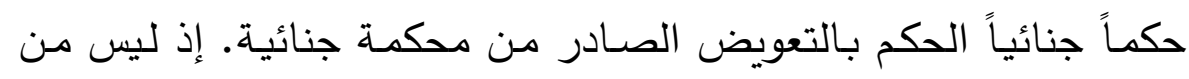
شأن صفة الجهة التي أصدرته أن تؤثر في طبيعته فيبقي الحكم مدنياً علي الرغم من صدوره من محكمة جنائية(؟).

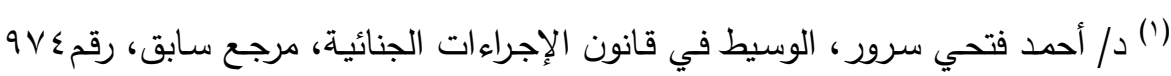

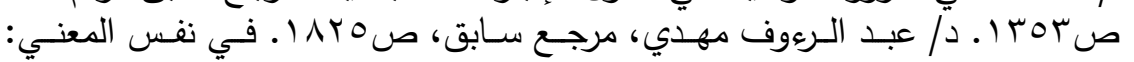

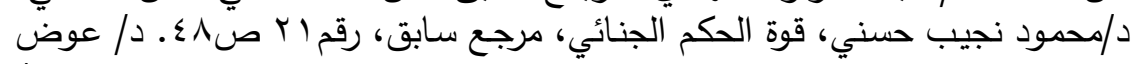

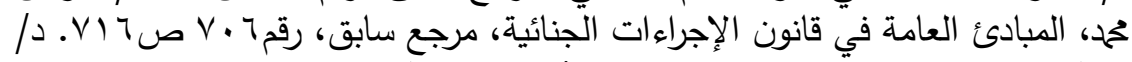

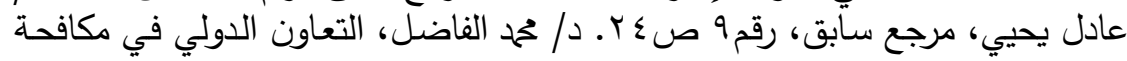

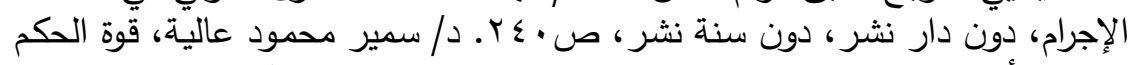

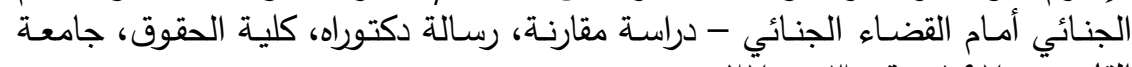

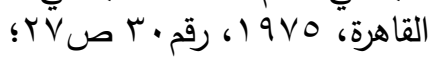

J.-L. colombini: La prise en considération du droit étranger (pénal et extra pénal) dans le jugement pénal, thèse, université de Lausanne, $19 \wedge \mathrm{r}, \mathrm{n}^{\circ}$, p. 17.

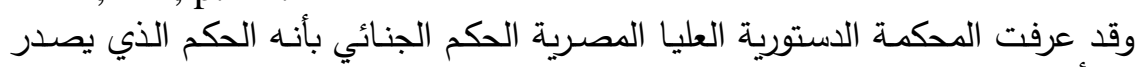

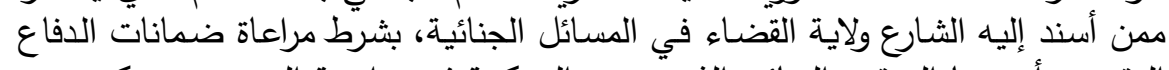

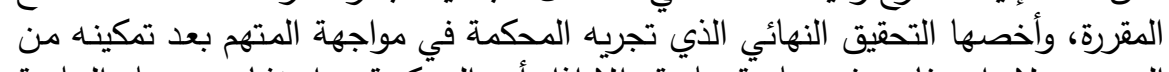

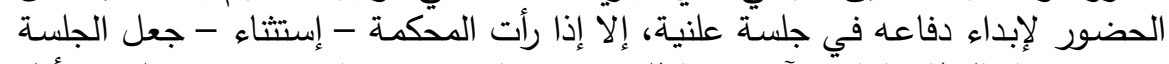

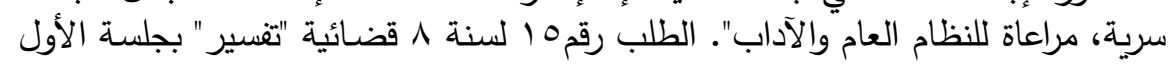

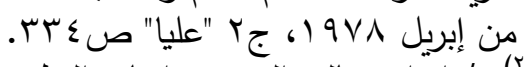

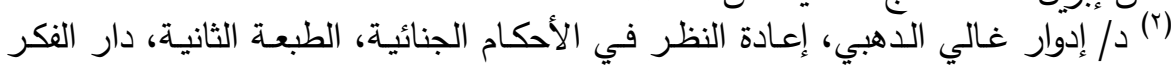

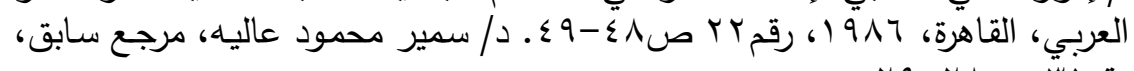

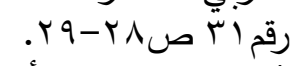

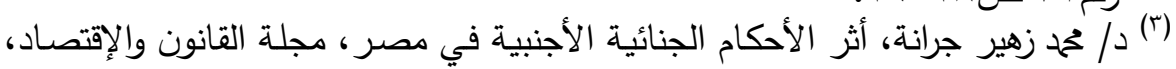

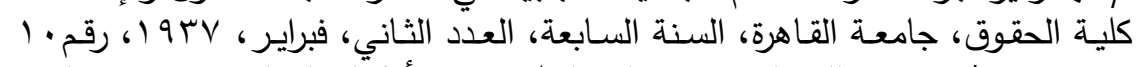

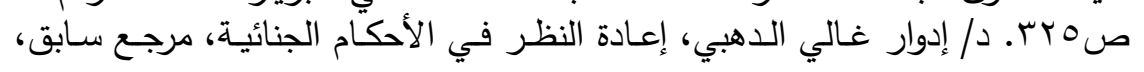


وطبقاً للمادة ع • r من قانون الإجراءات الجنائية المصري يتخذ الحكم في الموضوع إحدي صورتين: الصورة الأولي: الحكم بالبراءة، وذلك إذا كانت الواقعة غير ثابتة أو لم تثبت في حق المتهم أو كان القانون لا يعاقب عليها. الصورة الثانية: الحكم بالإدانة وإصدار العقوبة، وذلك إذا ثبتت الواقعة وكان معاقباً عليها.

فإن كان الحكم صادراً بالبراءة فإنه يعد كاشفاً ومقرراً لأصل البراءة في

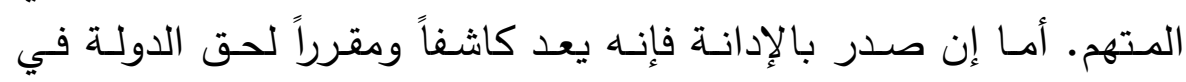

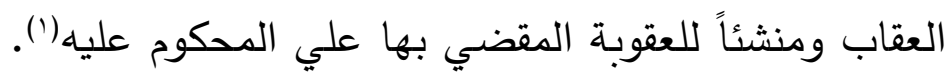

ثالثاً: ضابط الصفة الأجنبية للحكم الجنائي:

ثمــة إخـتلاف جـوهري بـين الحكم الجنـائي الـوطني والحكم الجنـائي

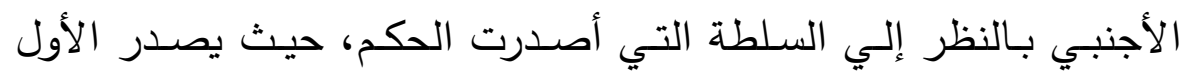

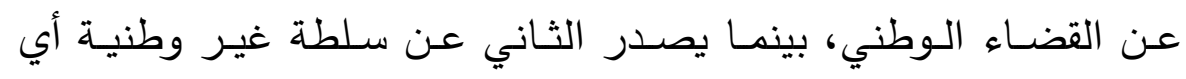

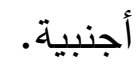

وقد ذهب رأي(؟) في الفقـه إلي تعربـف الحكم الجنـائي الأجنبـي بأنـه

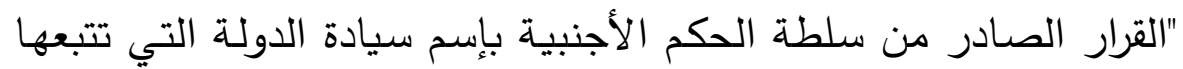

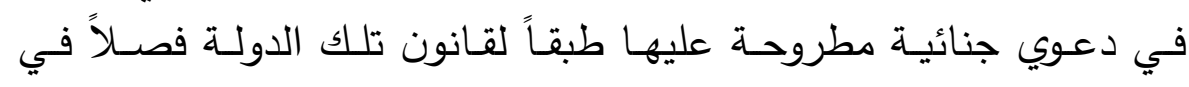

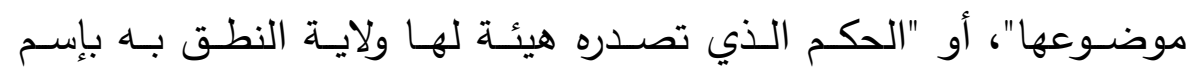

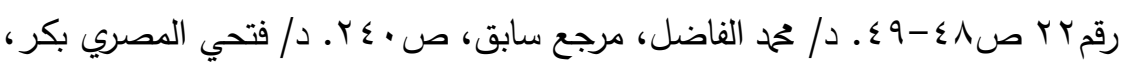

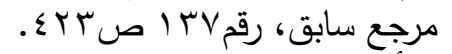

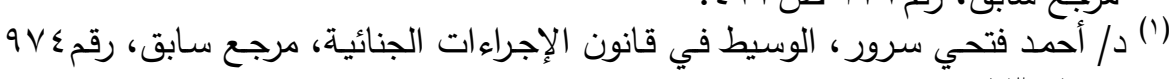

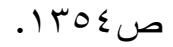

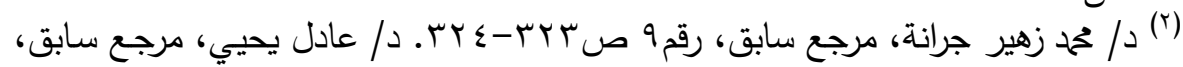

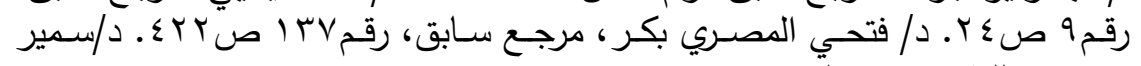

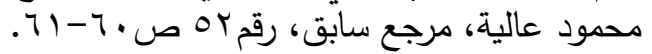

Lombois (C.): Droit pénal international, Deuxième édition, Dalloz,

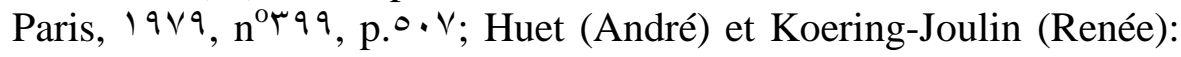
Droit pénal international, presses universitaires de France, Paris, $199 \leqslant, n^{0} 10 \leqslant$, p. $r \leqslant 7$. 


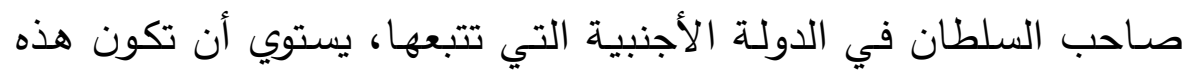

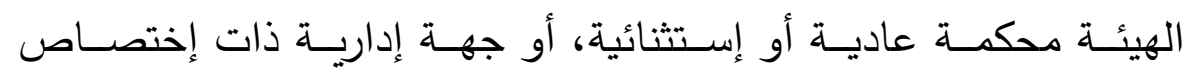

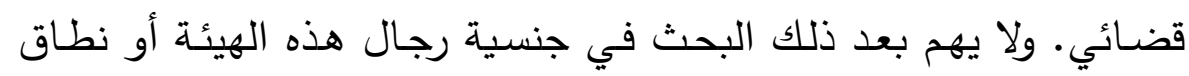
الإقليم الذي يمتد إليه حكمها". ويري أصحاب هذا الإتجاه إلي أنه يكفي

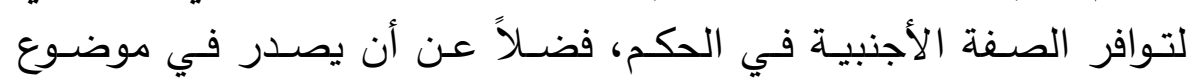

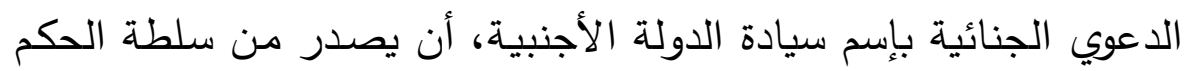

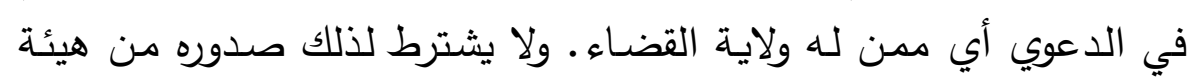
ذات تشكيل قضائي، وإنما يكفي صدوره من هيئة لها ولاية إصدار الحكم

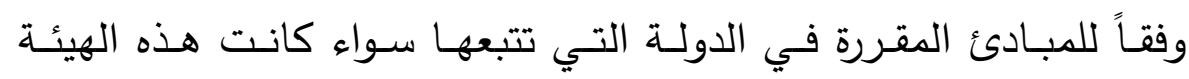

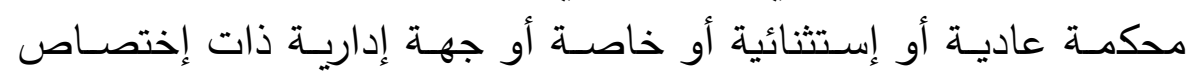
قضائي

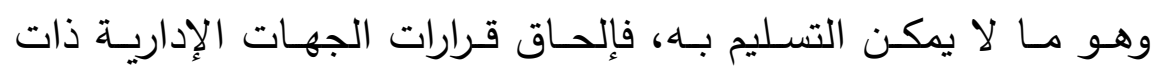

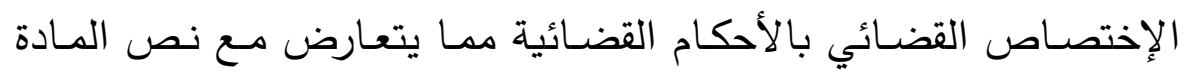

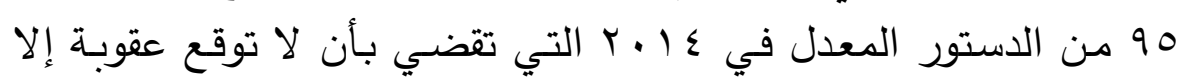

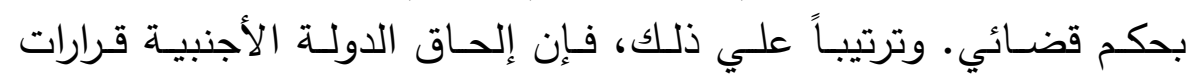

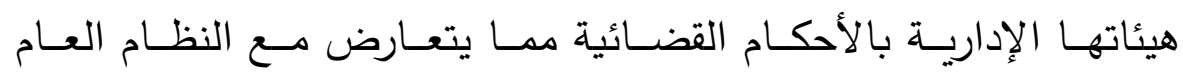

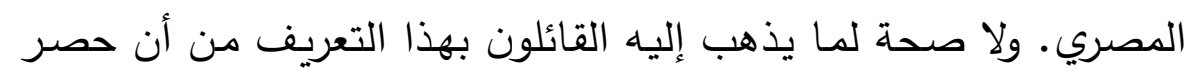

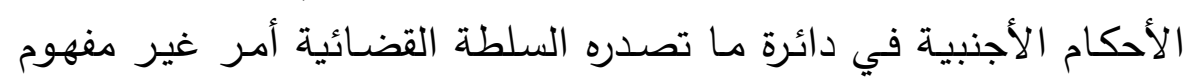

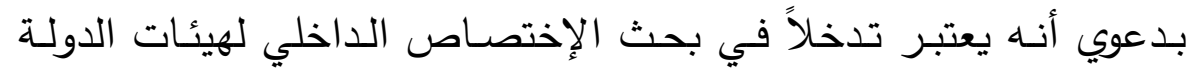

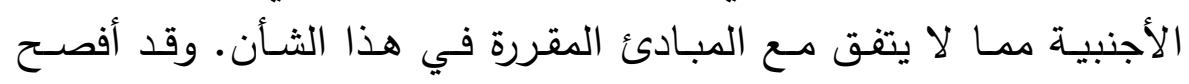

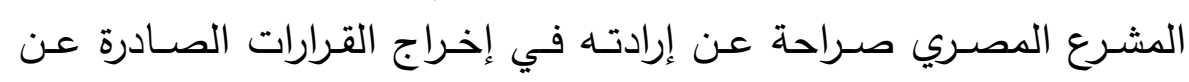

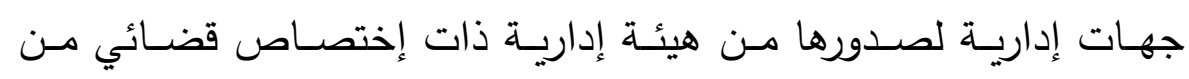

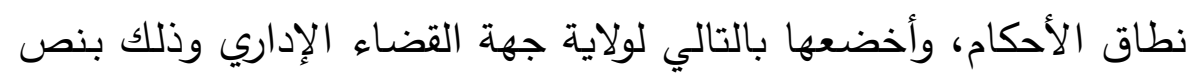

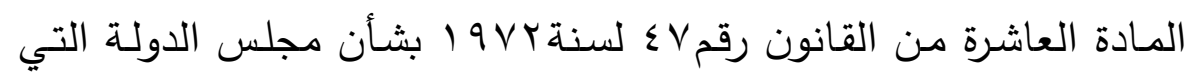

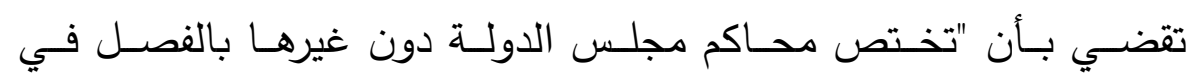

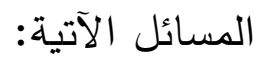


ثامنـاً: الطعـون التي ترفـع عـن القرارات النهائيـة الصـادرة مـن جهات إداريـة ذات إختصاص قضائي ....".

والواقع أن ضـابط الصـفة الأجنبيـة للحكم الجنـائي يتمثل في صدوره

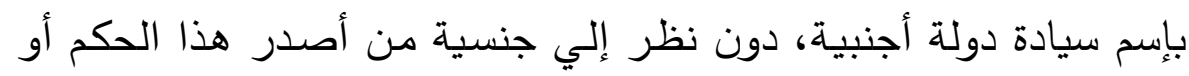

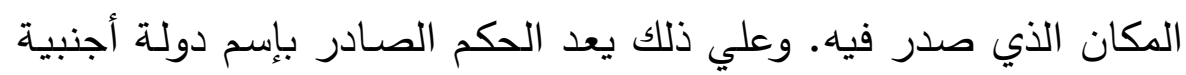

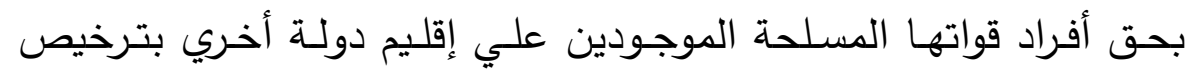
منها أجنبياً بالنسبة لهذه الأخيرة، رغم صدور هذات الهودين الحكم في إقليم هذه إنه

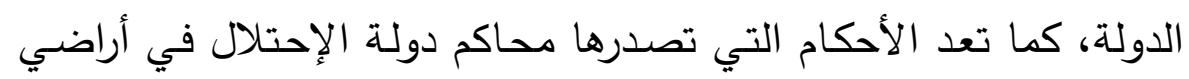

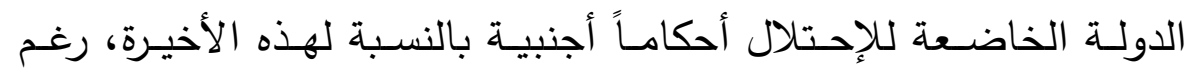

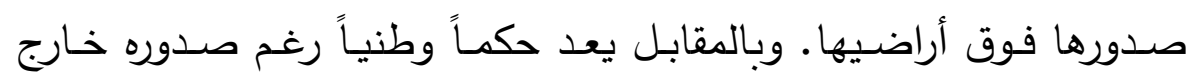

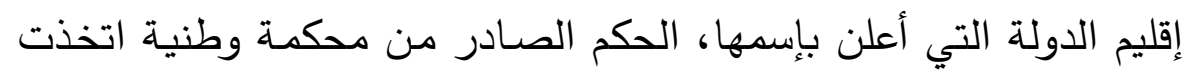

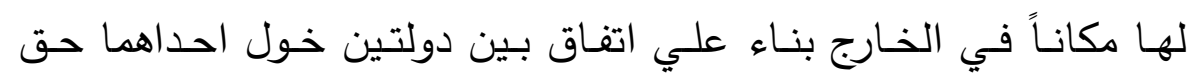
إقامة محكمة في الثانية لمحاكمة متهمين محددين (').

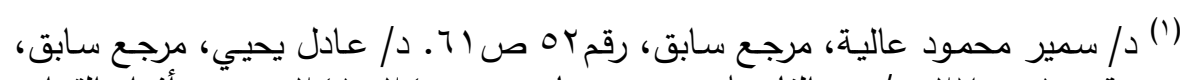

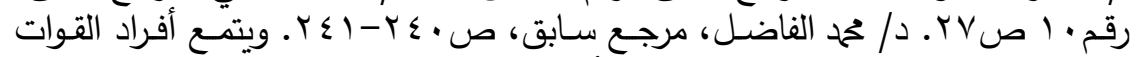

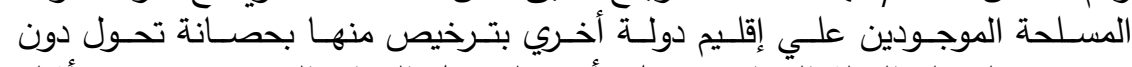

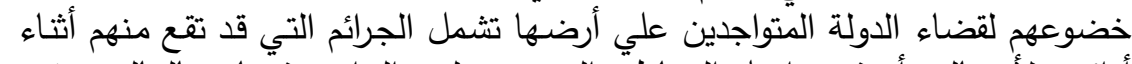

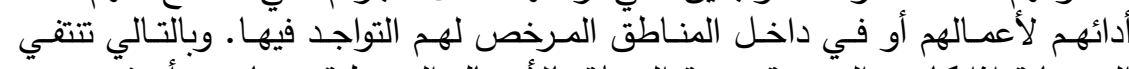

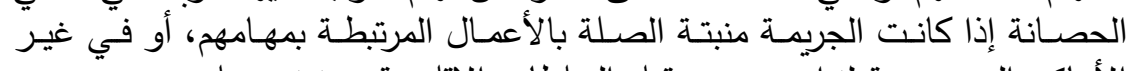

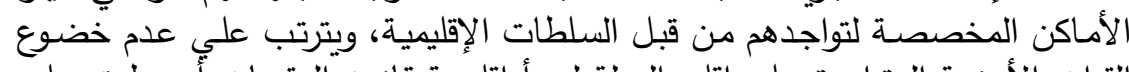

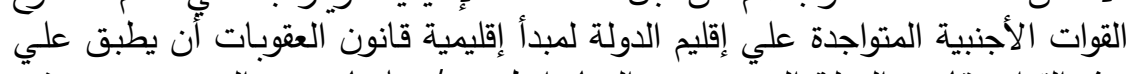

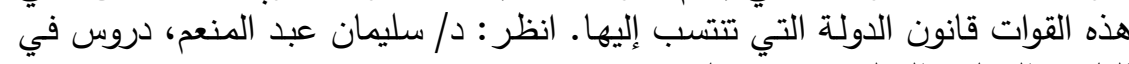

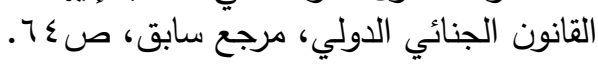




\section{الفصل الأول}

موقف الفقه من الإعتراف بالحجية السلبية للحكم الجنائي الأجنبي

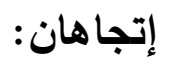

ثـار جـدل فقهي حـول الإعتـراف بالحجيـة السـلبية للأحكـام الجنائيـة

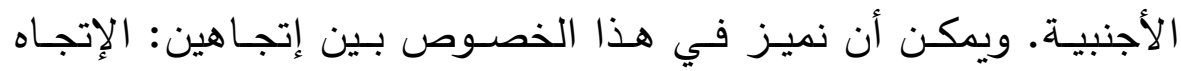

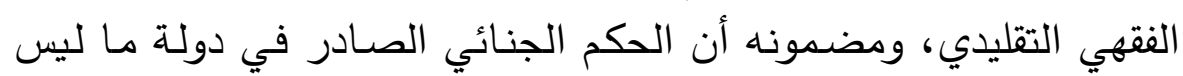

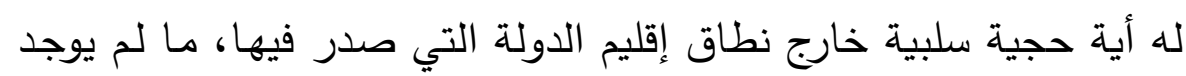

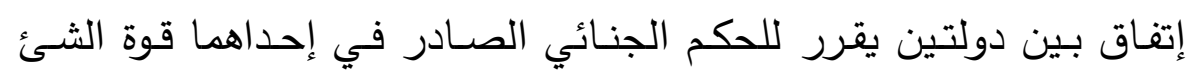

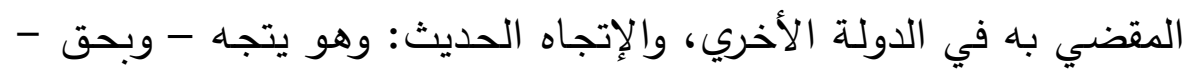

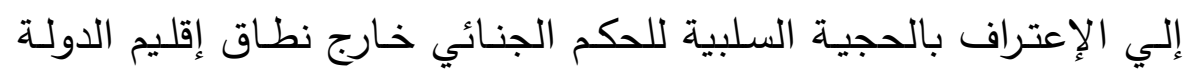

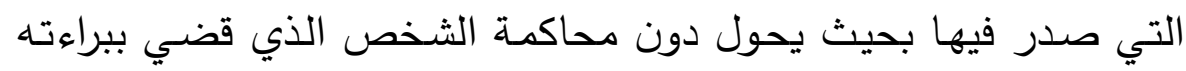

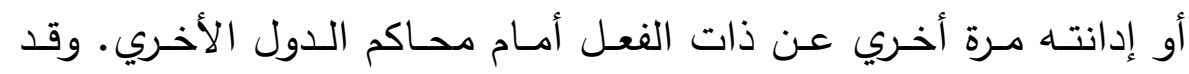

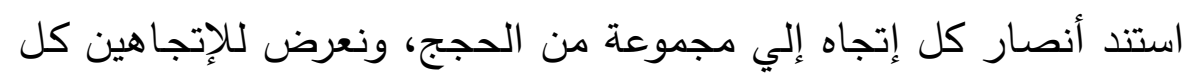
في مبحث مستقل. 


\section{المبحث الأول}

\section{الإتجاه التقليدي}

\section{"إنكار أية حجية سلبية للأحكام الجنائية الأجنبية"}

ظلـ معظم الفتـهـ زمنــاً يـرفض الإعتراف بأيـة حجيـة سـلبية للأحكـام

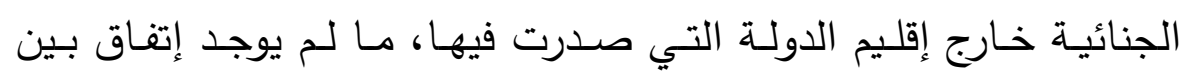
دولتين يقرر للحكم الصادر في إحداهما قوة الشئ المقضي بهـئه وقد استند أنصسار هذا الإتجاه إلي مجموعة من الحجـج تتمثل أهمها فيما يلي (')

ا- إن الإعتراف بهذه الحجيـة للأحكـام الجنائيـة الصـادرة مـن محساكم

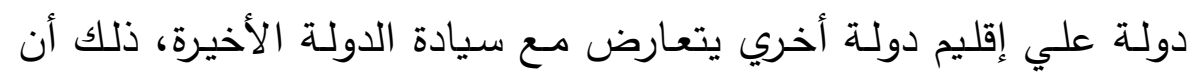

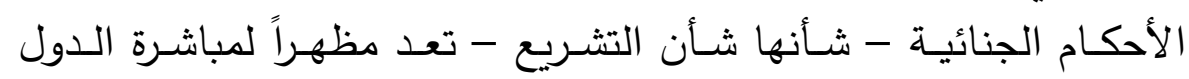

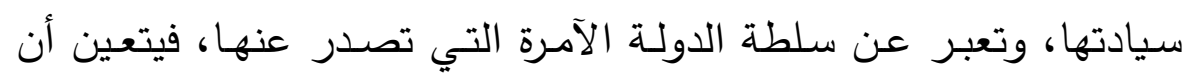

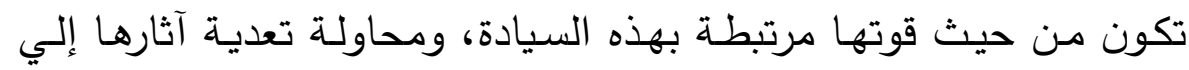

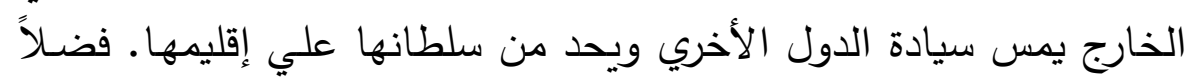

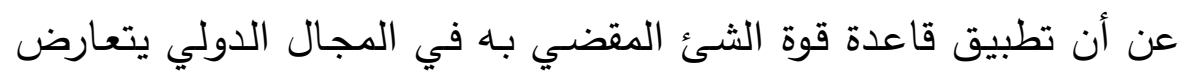

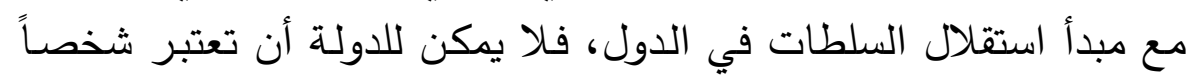

\section{(') انظر في عرض هذه الآراء والحجج:}

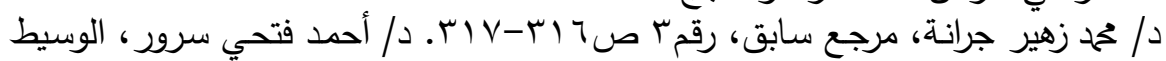

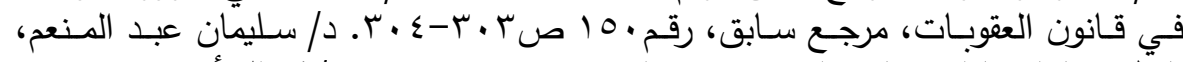

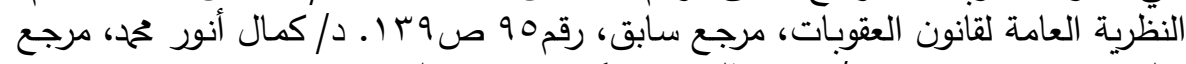

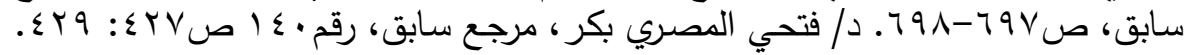

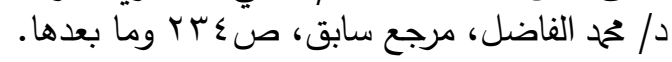

Donnedieu de vabres (H.): Les principes modernes du droit pénal international, op.cit. p. ${ }^{r} \cdot \varepsilon$; David (F.): De la reconnaissance des sentence pénale étrangèrs en France, au point de vue de la recedive et du sursis, R.I.D.P. no ${ }^{0} r$, $10^{\mathrm{e}}$ année, 19 个 , p. rro et s.; Le Calvez (J.): Compétence législative et compétence judiciaire en droit pénal, seconde partié, R.S.C. 1911, n ${ }^{\circ} r$ avril - juin, 191., p.rrv et s. Rebut (D.): Droit pénal international, Dalloz, $r \cdot 1 r, n^{o s} \wedge r$ et $s ., p .0 \leqslant$ et $s$. 
ما مجرماً إلا إذا صدر عليه حكم من محاكمها الوطنية وطبقاً لقانونها الوطني. ץ- إذا كـان تطبيـق مبـدأ إقليميـة قـانون العقوبـات يسـتلزم أن يكـون

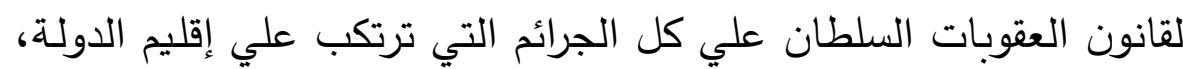

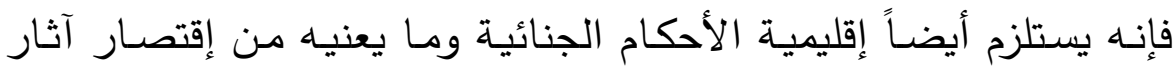
تلك الأحكام علي إقليم الدولة التي صدرت فيها بحيث لانيا يكون لها لها آثاراً إيجابية أو سلبية خارجية.

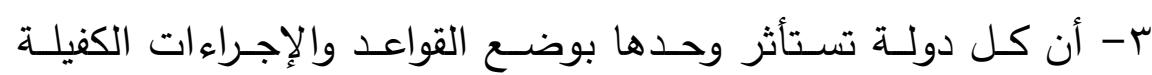

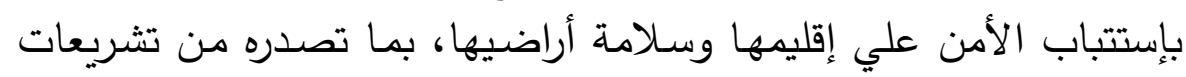

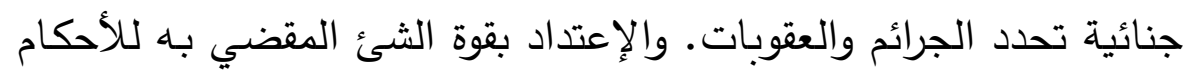

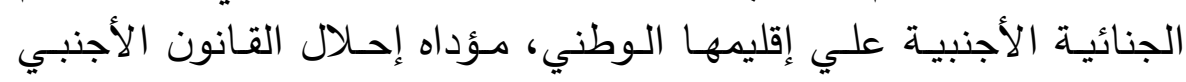

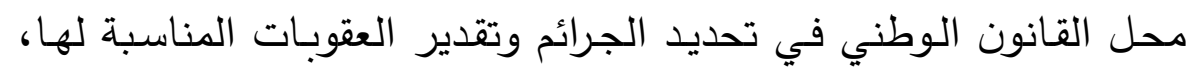

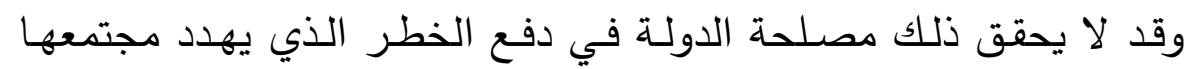

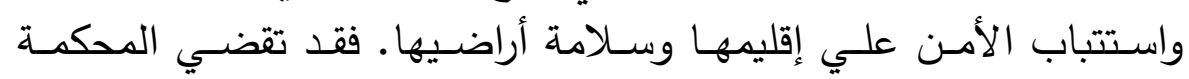

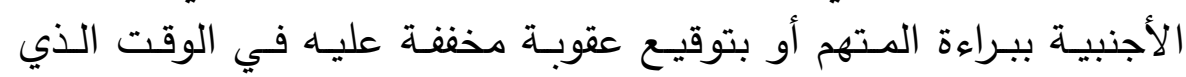

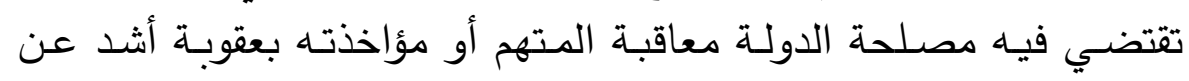
الجريمة التي اقترفها.

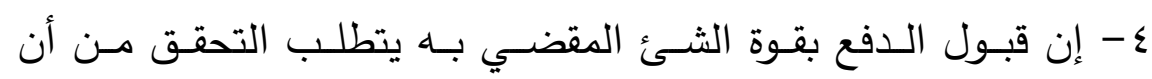

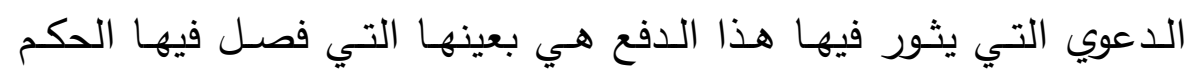
الجنائي، أي "وحدة الدعوي" فإن تخلف هذا الشرط فكانت الدعوي التي فئي

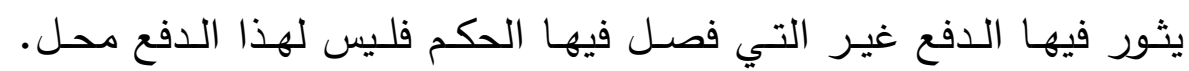

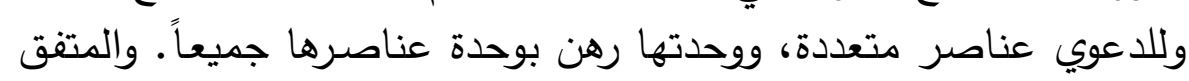

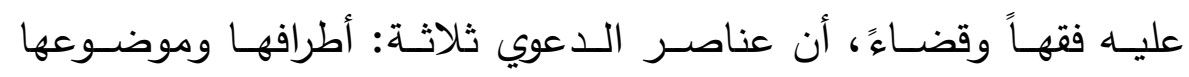

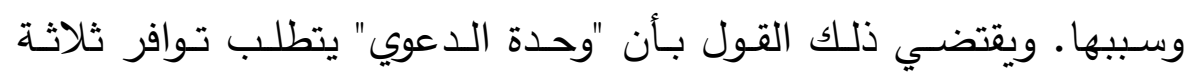
شروط: وحدة أطراف الخصومة، ووحدة موضوعها، ووحدة سببها. فلكي

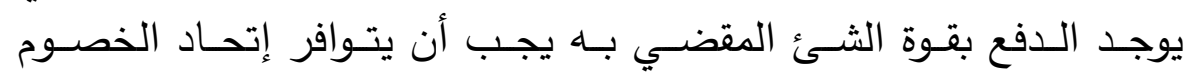

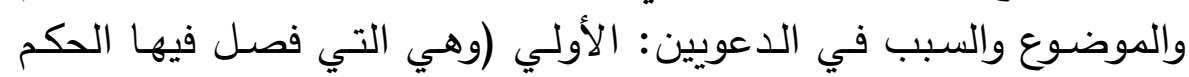
الجنائي)، والثانية (وهي التي يثور فيها الدفع بقوة الثسئ المقضي بــيه). 
وشـرط وحدة الخصـوم لا يتـوافر في الـدعوي التي صـدر فيهـا الحكم الجنـائي الأجنبـي والـدعوي الجنائيـة المطروحسة أمسام المحساكم الوطنيـة.

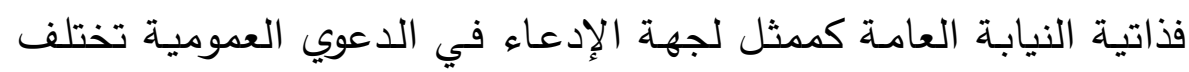

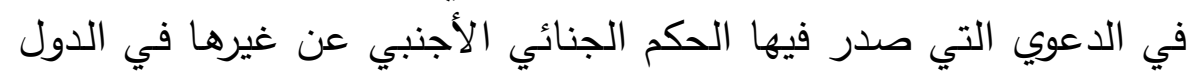
الأخري.

0- إن من الأهداف الرئيسية للأحكام الجنائية هو تحقيق الردع العام

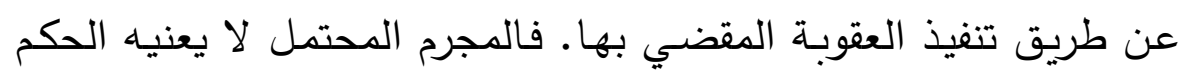

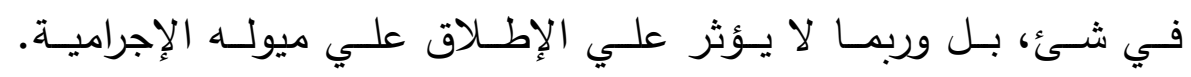

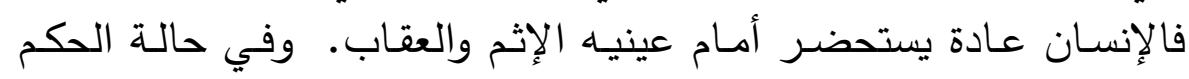

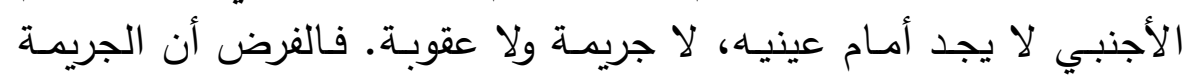

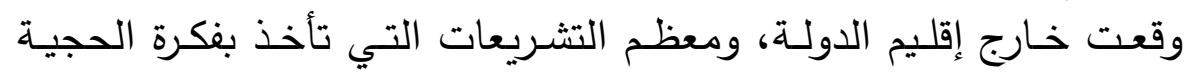

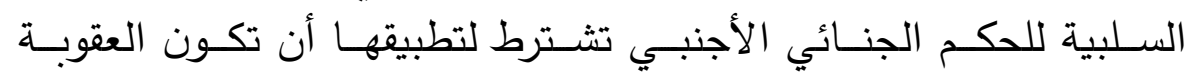

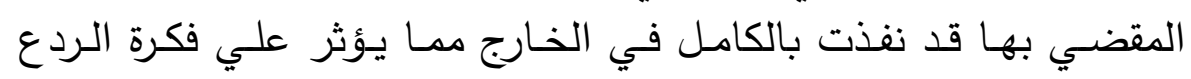
العام كغرض من أغراض العقوبة.

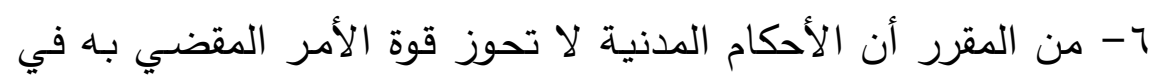

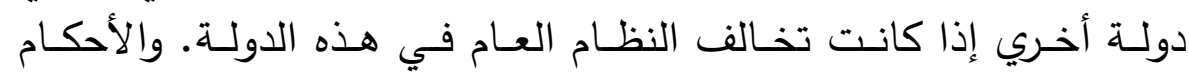

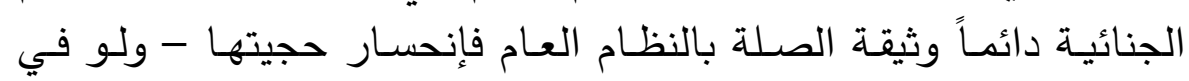

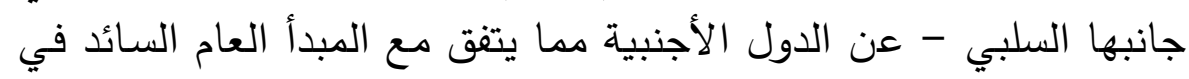

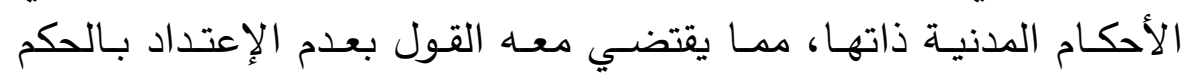
الجنائي خارج نطاق الدولة التي صدر فيها. V- هنـاك فـرق جـوهري بـين الأحكــام المدنيـة والأحكـام الجنائيـة.

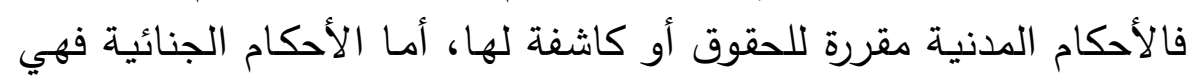

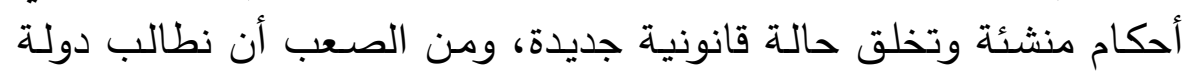

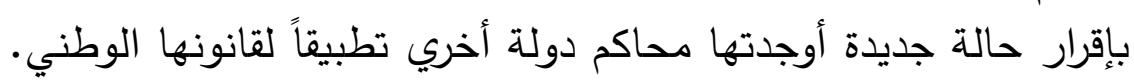

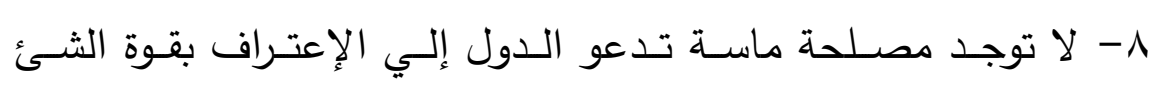
المقضي به للأحكام الجنائية الأجنبية. 


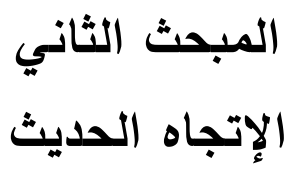

الإعتراف بالحجية السلبية للأحكام الجنائية الأجنبية

يذهب الإتجاه الحديث في الفقه(') - وبحق - إلي التأكيد علي ضرورة

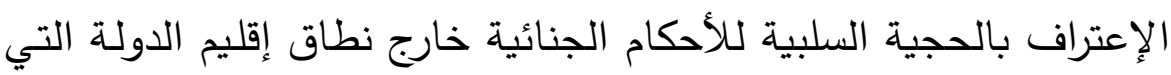

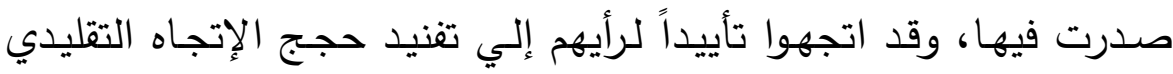

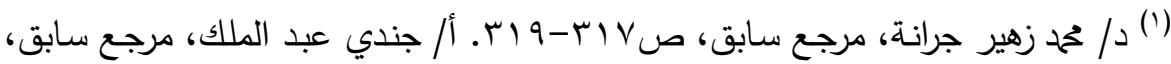

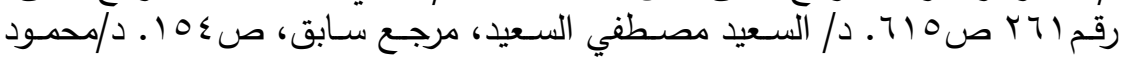

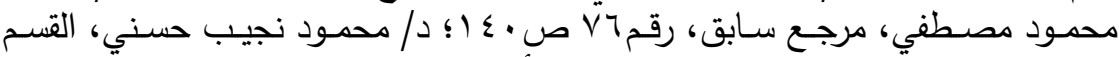

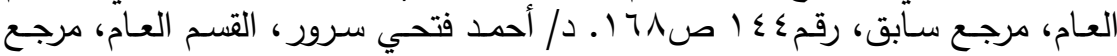

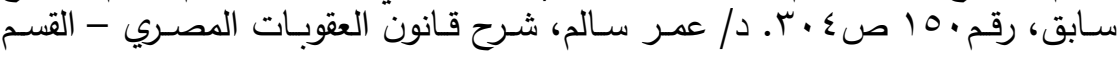

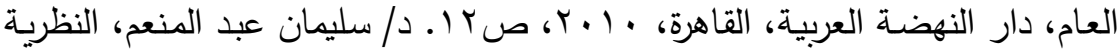

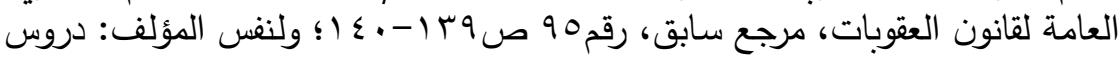

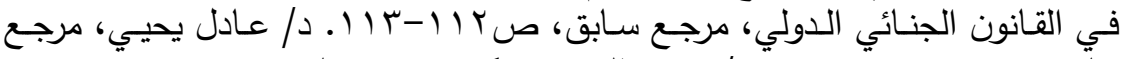

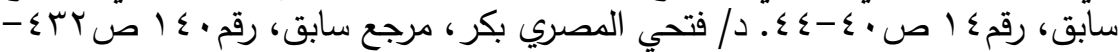

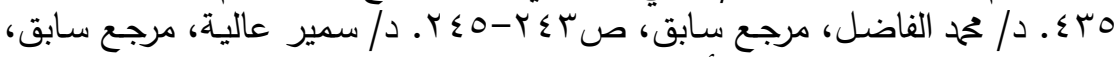

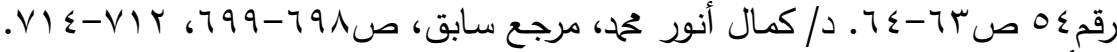

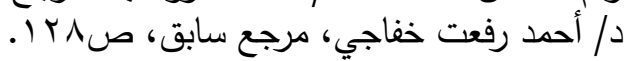

Schultz (H.): Compétence des juridictions pénales pour les infractions commises à l'étranger, R.S.C. I97v, p.r' •; Fayard (M.C.): La localisation international de l'infraction, (Etude de

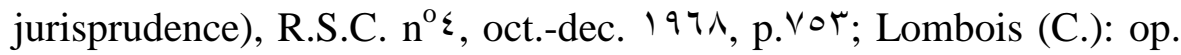
cit. $n^{0} 9$, p. ${ }^{0 .} \leqslant$; Barbe (E.): Une présentation du projet de décision cadre rélative à la reconnaissance des décision de gel des avoirs et des preuves, In. "La reconnaissance mutuelle des décisions judiciaires pénales dans l'union europénne, ouvrage collectif, Bruxelles, r..', p.^ ${ }^{\wedge}$; Ropers (J.-L.): Le marché commun et les effets internationaux des jugements répressifs, J.C.P. 197 r, doctrine, $n^{\circ}$ । $\vee \vee$; Kunter (N.): Les consequences positives directes ou supplementaires des

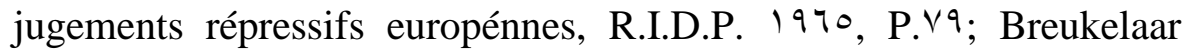
(W.): La reconnaissance des Jugements répressifs = =étrangères, R.I.D.P. numéro spécial, $19 \vee \varepsilon, \varepsilon 0^{\mathrm{e}}$ année, $\mathrm{n}^{\mathrm{o}} \mathrm{r}$ et $\varepsilon$, P.0 07 . Jofé: De l'application par le juge d'un Etat des lois pénales étrangères, Revue de droit pénal et criminologie, 1949 , p. $\vee \diamond \leqslant$ et $s$. 
المنكـر لهـذه الحجيـة، وأضـافوا إليهـا حججـاً أخـري. وهـذا هـو الإتجـاه الأولي بالإتباع.

\section{أولاً: تفنيد حجج الإتجاه التقليدي:}

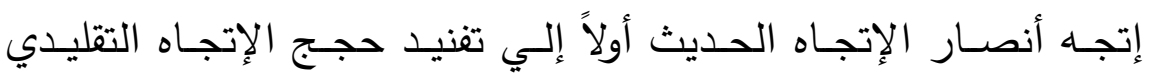

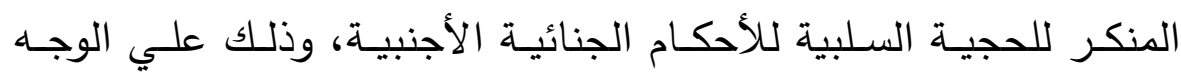
الآتي:

أ- أن القول بـأن الإعتراف بالحجيـة السلبية للحكم الجنـائي الأجنبي

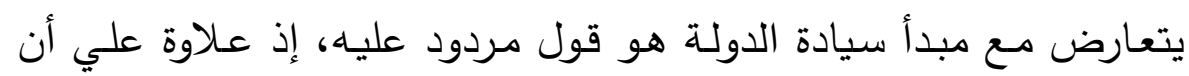

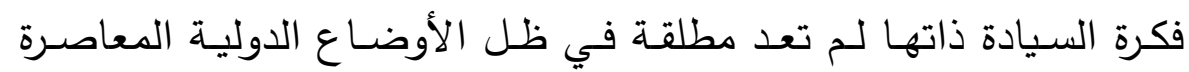

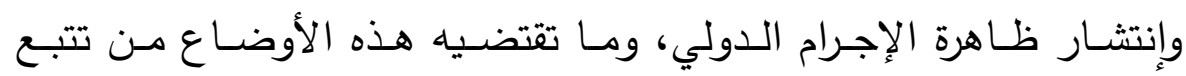
المجرمين أينما كانوا، حتي لا يفلت مجرم من العقاب. وإذا كان حقاً أن الحكم الجنائي يعتبر مظهراً من مظاهر مباشرة الدولة

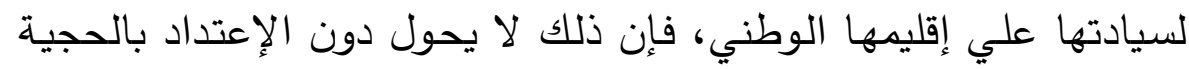

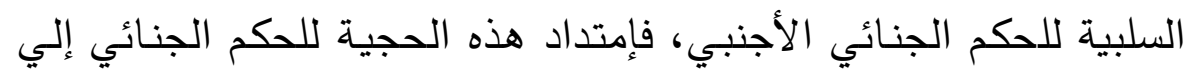

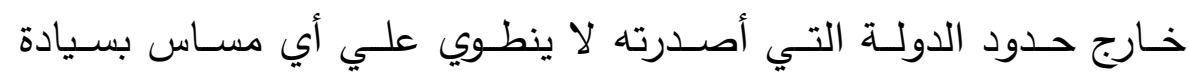

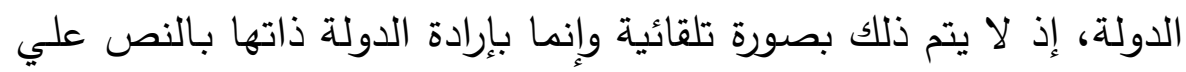

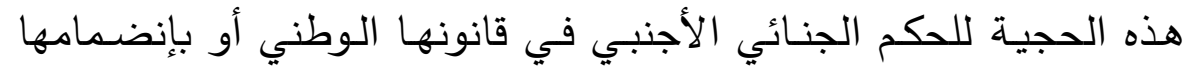

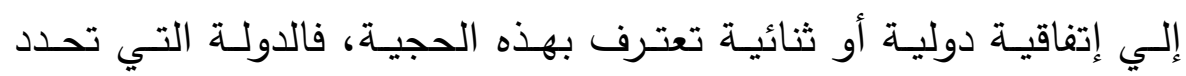

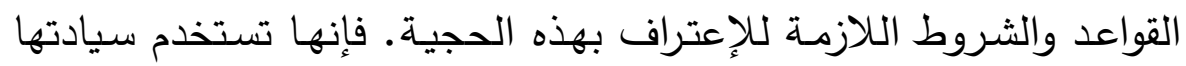

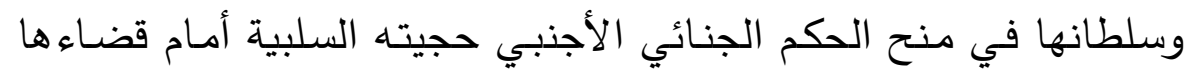
الوطني وتكسبه من هذه الحجية القدر الذي ترتضيه.

ب- إن القول بـأن مبدأ إقليميـة قانون العقوبـات يحول دون الإعتراف

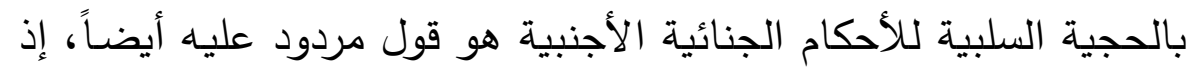

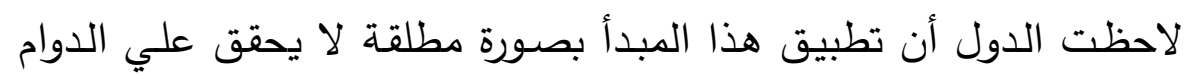

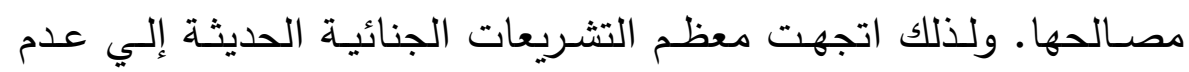
تبني هذا المبدأ وحده عند تحديد النطاق المكاني لقانونها العقابي، بل 
تبنـت إلـي جانبـه مبادئ أخري مـن شـأنها أن تمـد نطـاق تطبيق قـانون

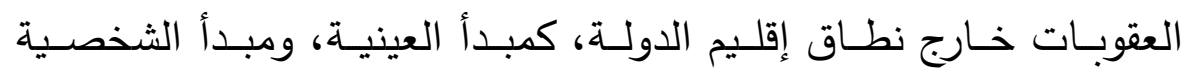

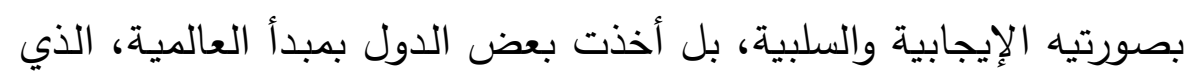

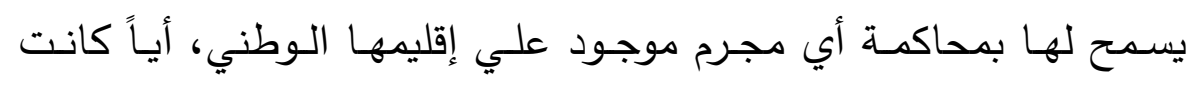

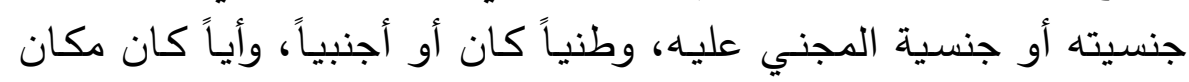
ارتكاب جريمته. وهذا المسلك يستوجب أن تمتد حجية الأحكام الجنائية التي تصدرها محاكم الدولة خارج نطاق إقليمها.

ج- إن القـول بـأن عـدم الإعتـراف بالحجيــة السـلبية للحكم الجنـائي الأجنبي يستند إلي إنتفاء "وحدة الخصدوم" في الدعوي التي صدر فيها

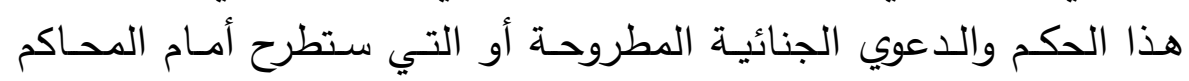

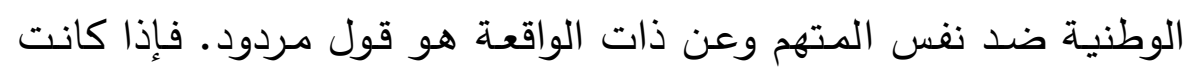

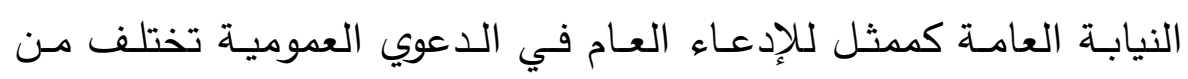

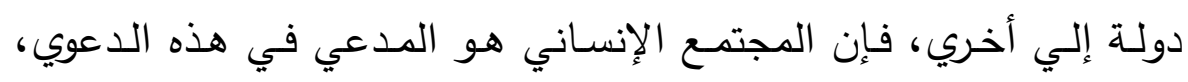

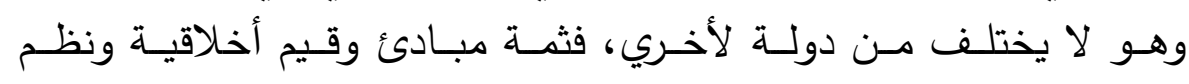

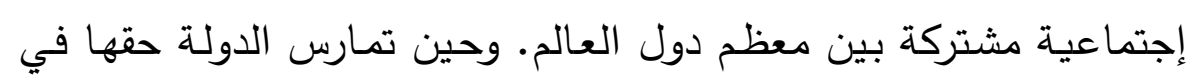

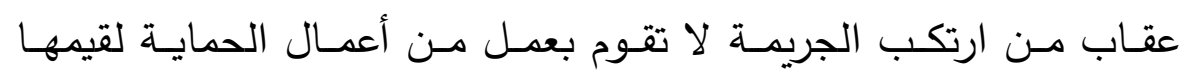

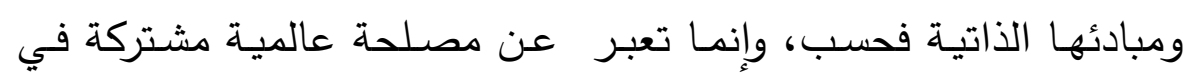

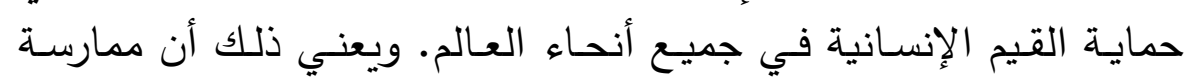

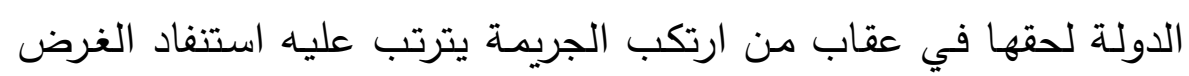

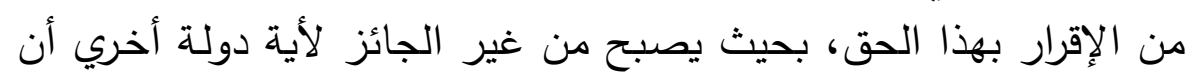

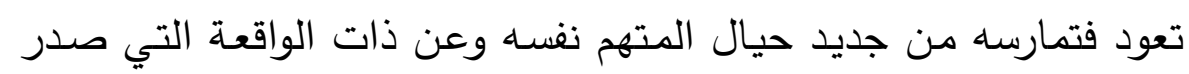

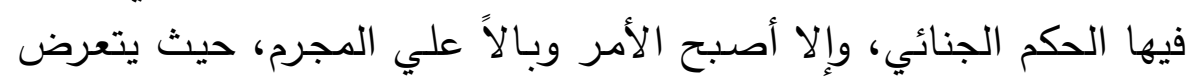

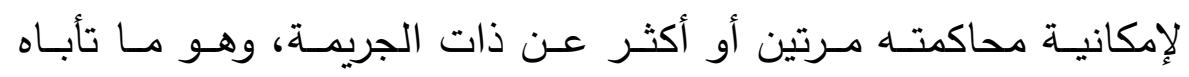
العدالة.

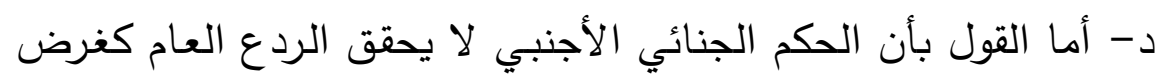

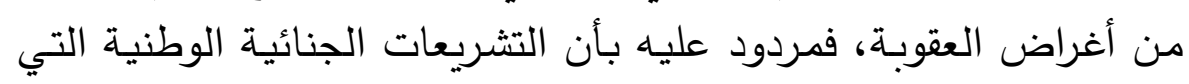

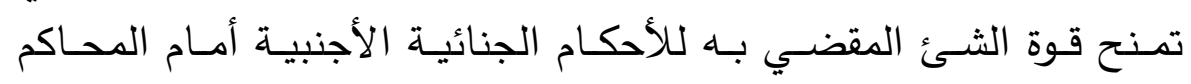


الوطنية، تشترط أن تكون العقوبـة المقضـي بها قد نفذت بالكامل، وهو

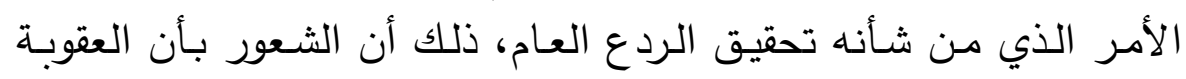

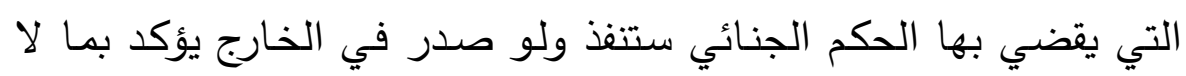

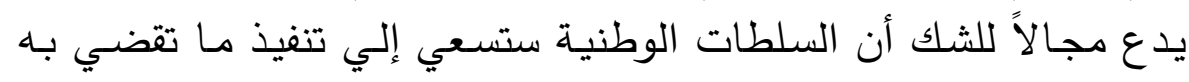
المحاكم الوطنية من عقوبات، وهو ما يقود في النهاية إلي تحقيق الردع تلفيل العام.

هـ- أما القول بأن الأحكام المدنية لا تحوز قوة الثئ المقضي بـه في

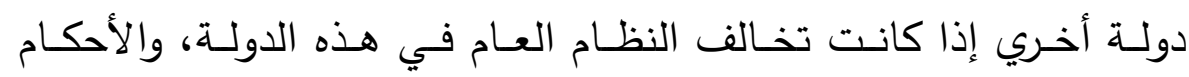

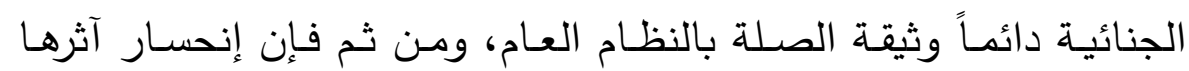

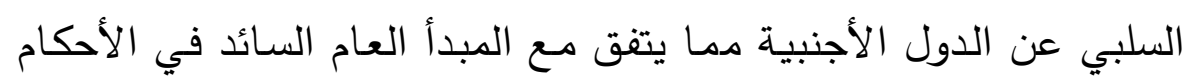

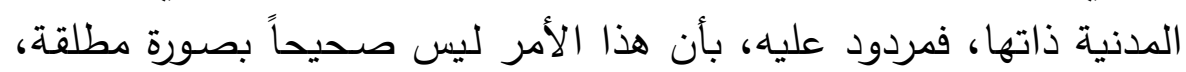

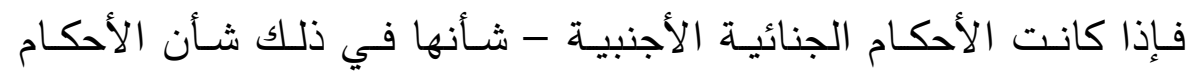
المدنية الأجنبية قد تصطدم - في بعض الحالات - بالنظام العام السائد

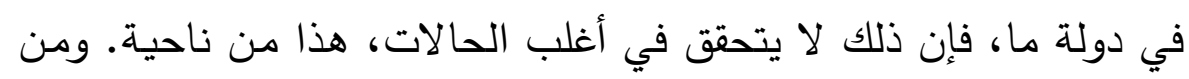

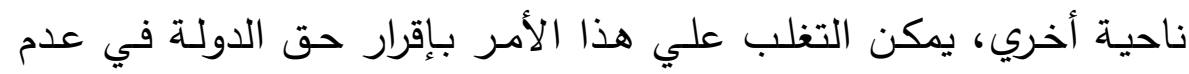

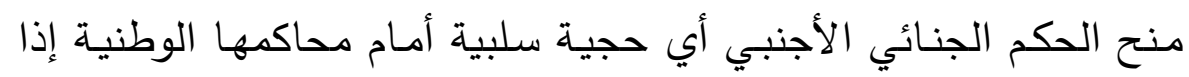
كان يتعارض مع النظام العام السائد بها.

و - أمـا القول بـأن هناك فـارق جوهري بين الأحكام المدنيـة والأحكام الجنائية، فالأولي مقرة أو كاشفة للحقوق، أمسا الثانية فهي أحكام منشئة الأنة

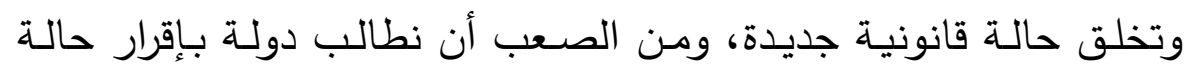

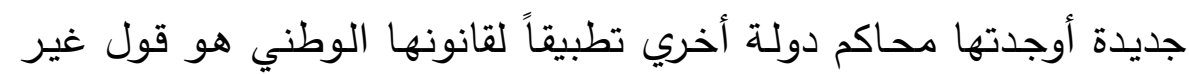
صحيح علي إطلاقه، فمن الأحكام المدنية ما هو منشئ للحقوق، كالحكم الهري

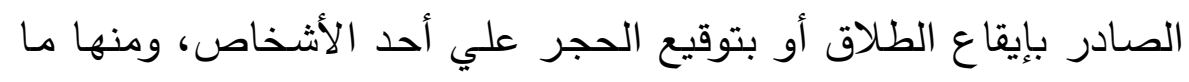

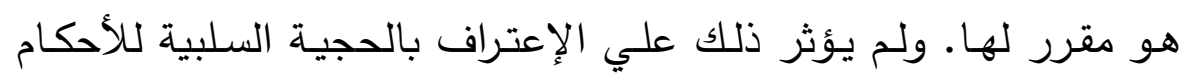

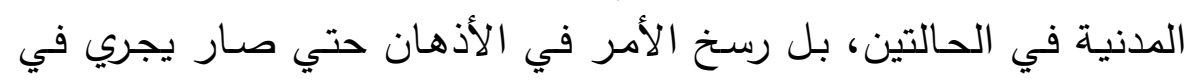

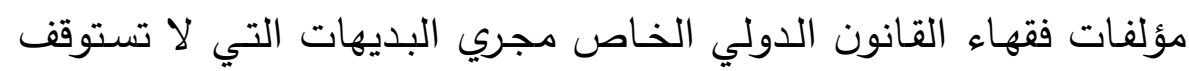

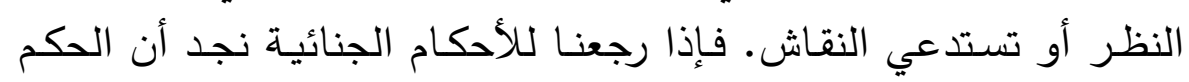


الصادر بالبراءة هو كاشف لأصل البراءة في الإنسان وليس منشئاً لها،

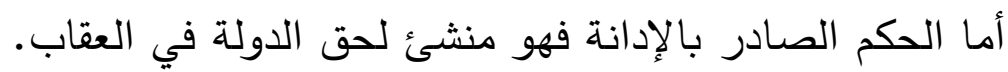

ولذلك لا نري داعياً للتفرقة بين الأحكام المدنية والأحكام الجنائية في مسألة الإعتراف بالحجية السلبية للحكم الأجنبي، فالأولي كالثانية تماماً من هذه الناحية.

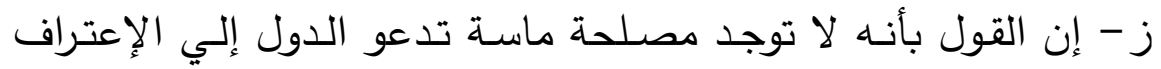

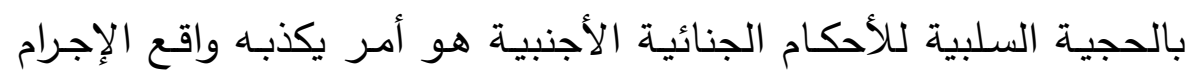

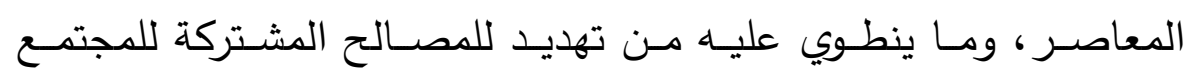

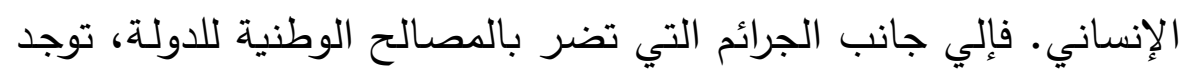

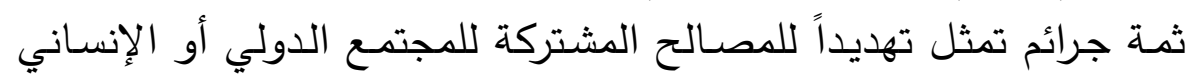

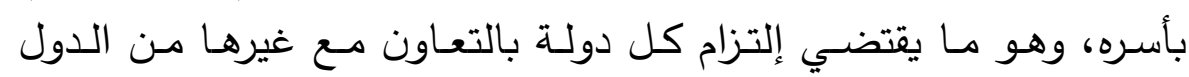

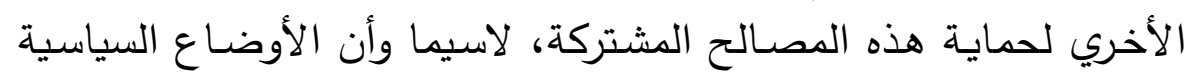

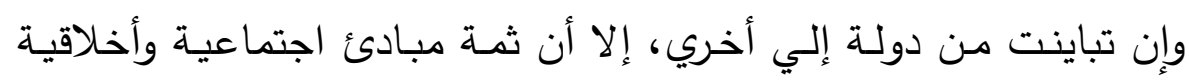

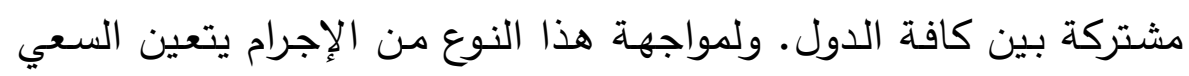
- بقدر المستطاع - لإيجاد إطار قانوني عالمي واحد يكرس فيـه مبدأ

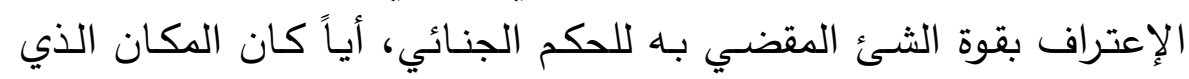

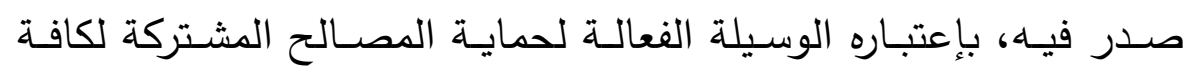

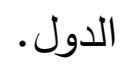

ثانياً: الحجج الأخري التي استند إليها أنصار هذا الإتجاه: إلي جانب تفنيد الحجج التي استند إليها أنصـار الإتجاه المنكر للحجية

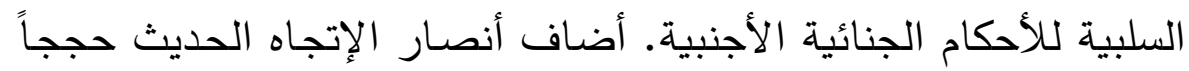
أخري لتأييد رأيهم تتمثل فيما يلي:

1- المقتضيات الإجتماعية الحاضرة وإنتشار ظاهرة الإجرام الدولي في

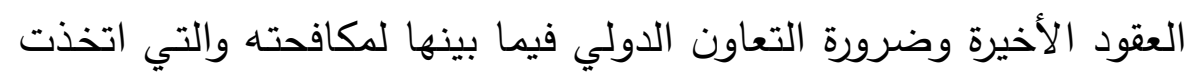
أشكالاً جديدة في عالم متطور ومتنوّع، والحد منها بصفة وفئة عامة، والجرائم

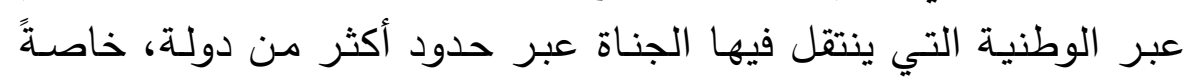


بعد أن تيسرت سبل النقل والمواصـلات بين الدول وقربت المسافات التي

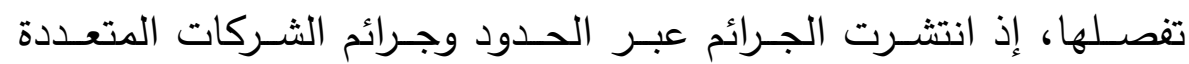

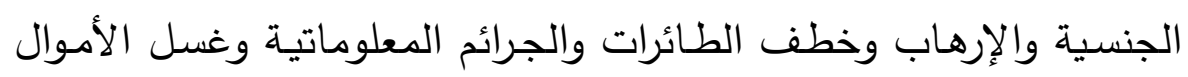

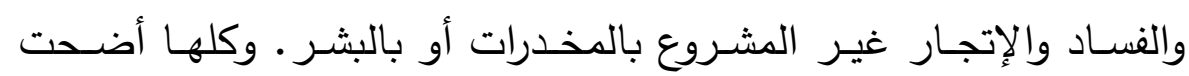

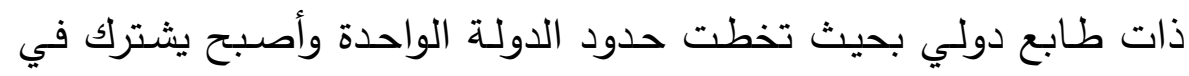

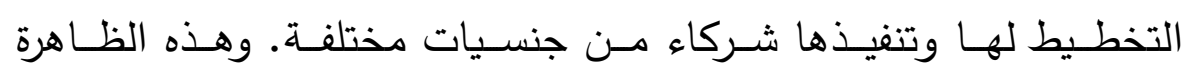
تستوجب منح الحكم الجنـائي قوة الثـئ المقضـي بـه خـارج نطساق إقليم

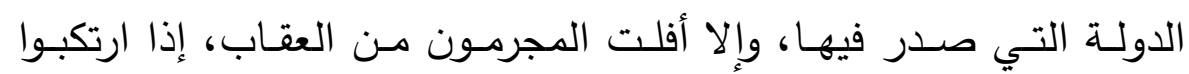

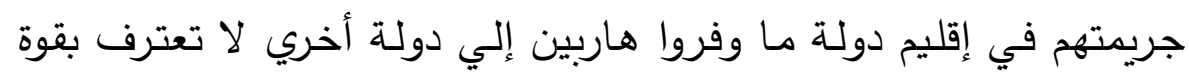

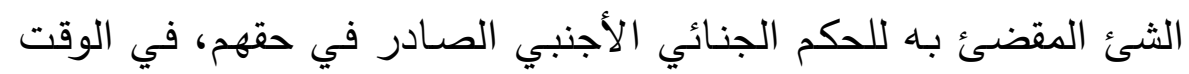
الذي لا ينعقد لمحاكمها الوطنية الإختصاص بنظر الجرائم التي ارتكبوها

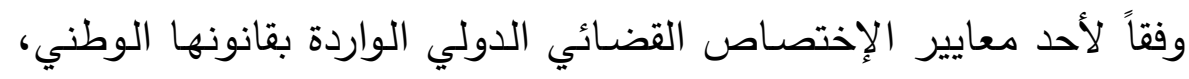

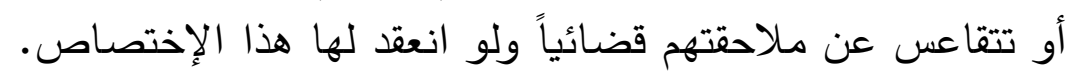

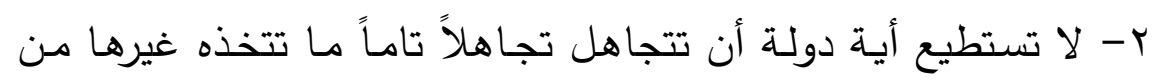
الدول من إجراءات وما يصدره قضاؤها من أحكام وخصوصـاً إذا اتصلت دولت تهاه بأمور تتعدي إليها أو بأشخاص يقيمون في إقليمها. r- تتجلي أهميـة الإعتراف بالحجيـة السلبية للحكم الجنـائي الأجنبي

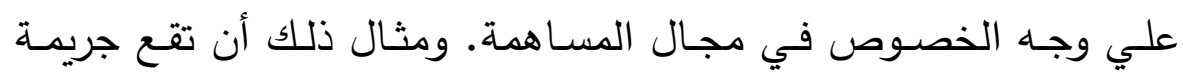
أصلية علي إقليم دولة مـا، بينما تتحقق أفعال المساهمة علي إقليم دولة التها أخري: فالدولة التي تخول محاكمها الإختصـاص بنظر أفعال المساهمة

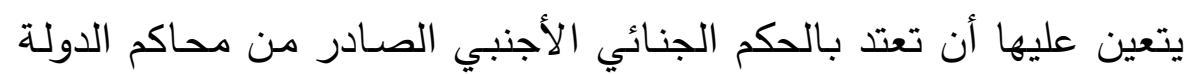

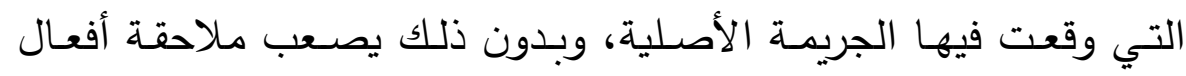

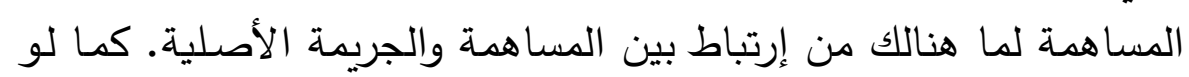

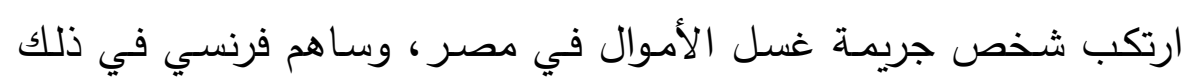

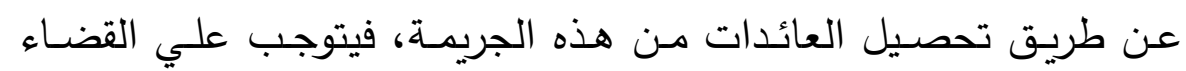
الفرنسي أن يؤجل الحكم علي المساهم إلي أن يصدر الحكم علي الفاعل هله الأصلي من طرف القضاء المصرئ. 
ع - إن المصـلحة الوطنيـة ذاتهـا تسـتلزم مـنح الحجيـة السـلبية للحكم

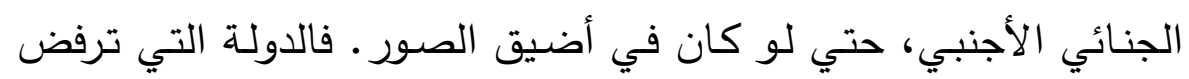

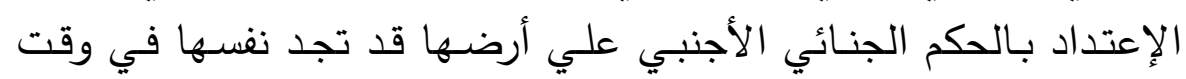

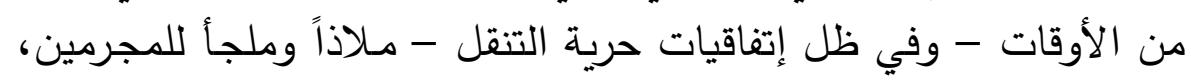

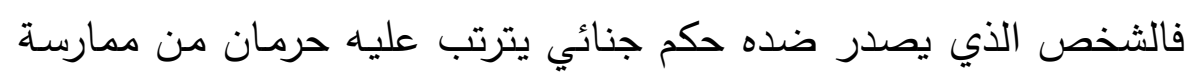

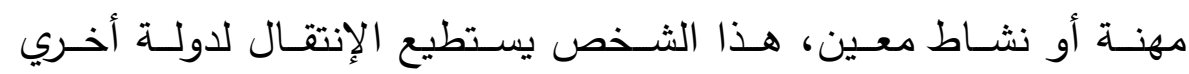

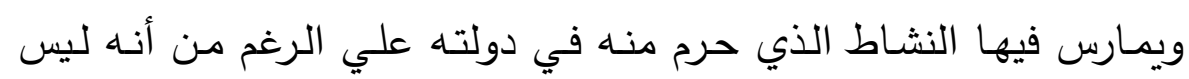
أهلاً لمباشرة هذا النشاط.

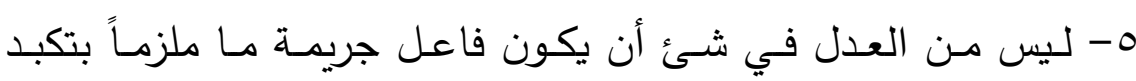

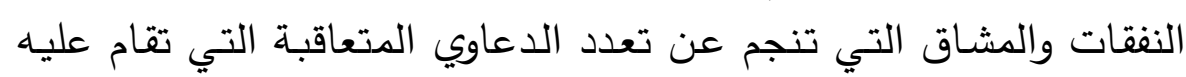

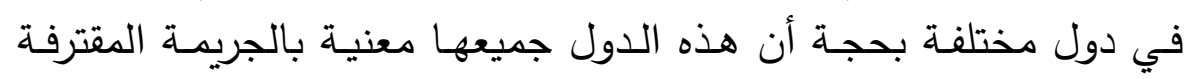

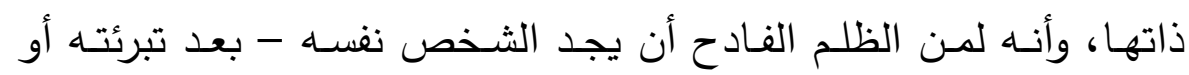

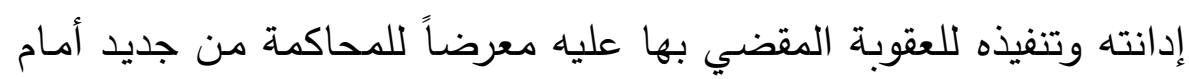
محاكم دولة أخري. 


\section{الفصل الثاني}

\section{الشرط الخاص بمكان وقوع الجريمـة "وقوع الجريمة في الخارج"}

النصوص القانونية: - n

نصــ المـادة الرابعـة مـن قـانون العقوبـات المصـري علي أن "لا تقـام

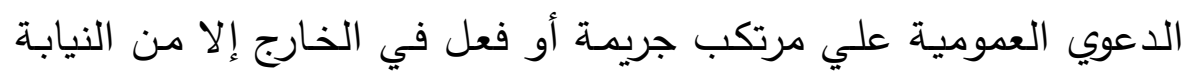

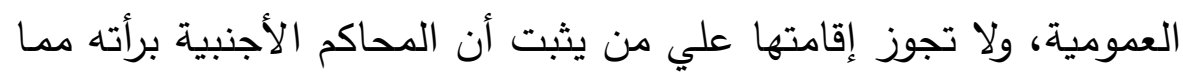

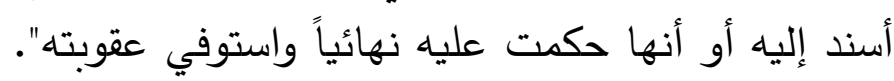

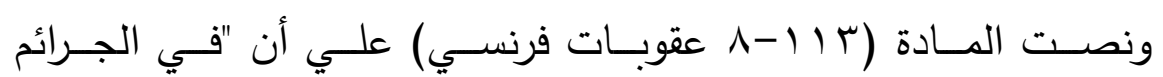

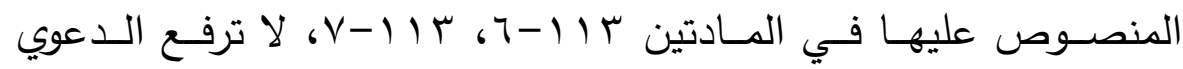
الجنائية إلا بطلب من النيابة العامة، ويجب أن يسبق هذا الطلب تقديم

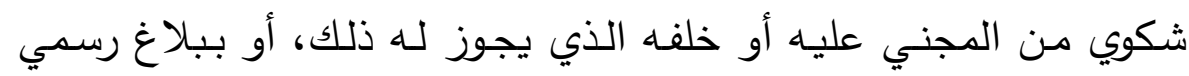

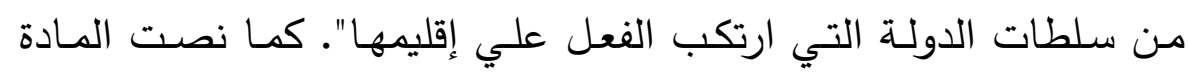

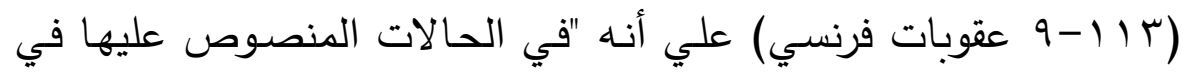

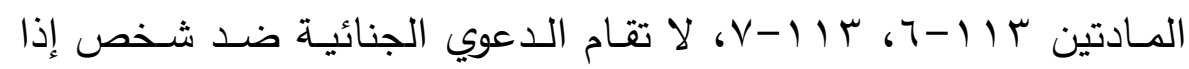

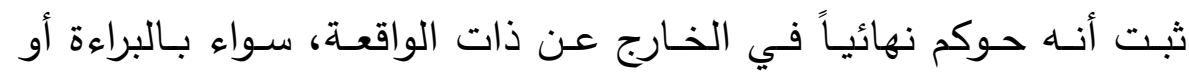

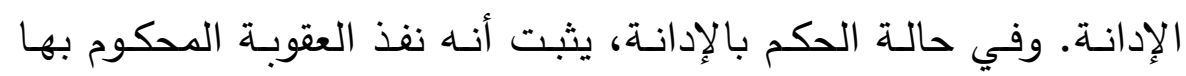
ضده أو أنها قد سقطت بالادنقادم". ومسن هذه النصـوص يتضـح أن المشرع في فرنسـا ومصـر أورد قيدين

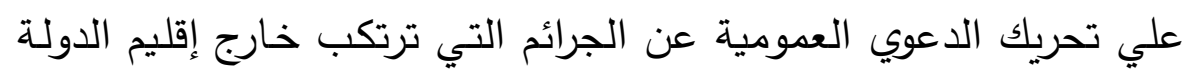
وتختص بنظرها المحاكم الوطنية.

القيد الأول: وهو قيــ إجرائي ويتمثل في الجهـة التي تملك تحريك الدعوي الجنائية فقد حصرها في النيابة العامة (').

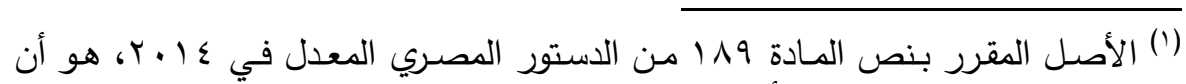

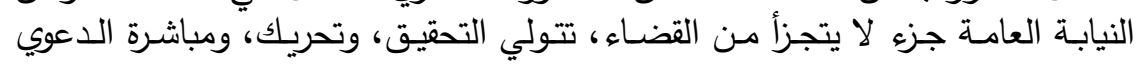


والثاني: وهو قيد موضوعي خاص بحظر تحريك هذه الدعوي إذا ثبت أن المحاكم الأجنبية قد برئت المتهم مما أسند إليه أو قضت بـت بإدانته وأنها

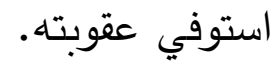

كما يخلص من هذه النصوص أن مجال تطبيق هذين القيدين يقتصر

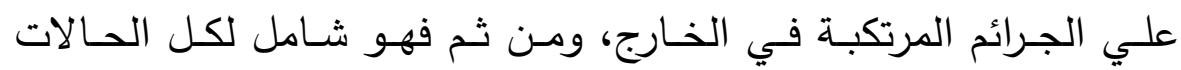

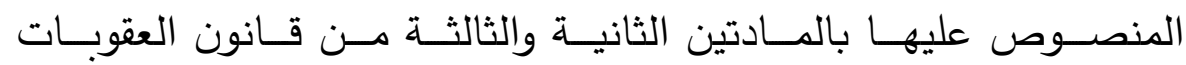

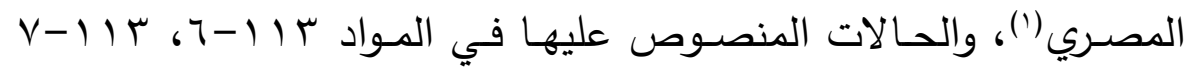

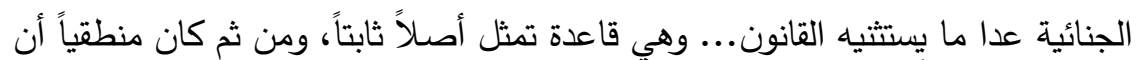

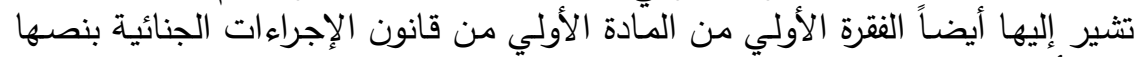

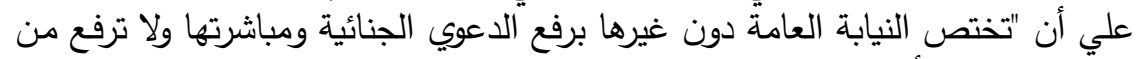

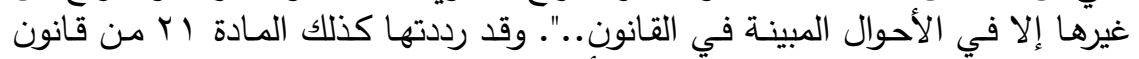

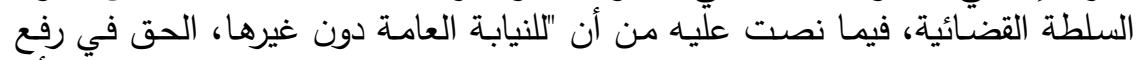

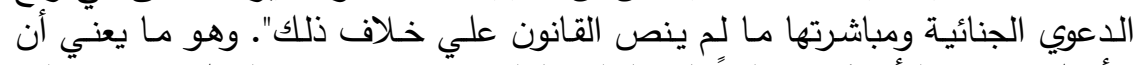

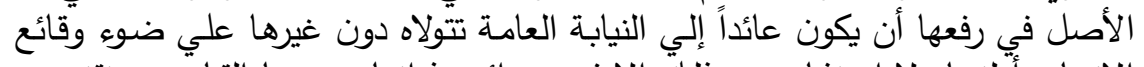

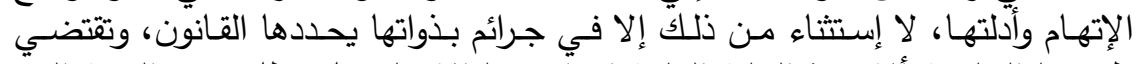

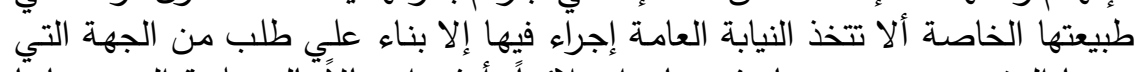

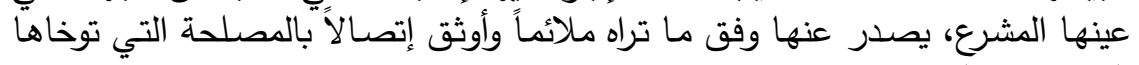

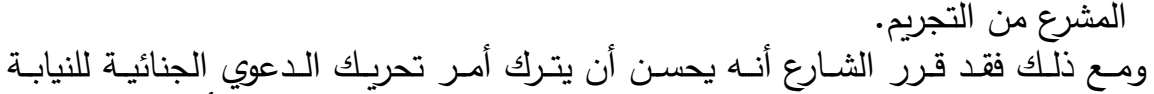

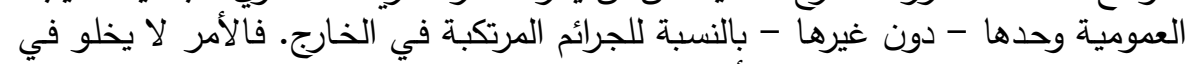

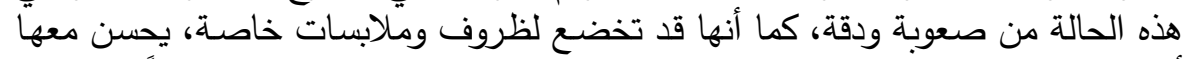

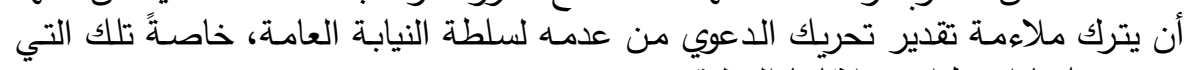
يترتب عليها إضطراب علاقاتتا الدولية.

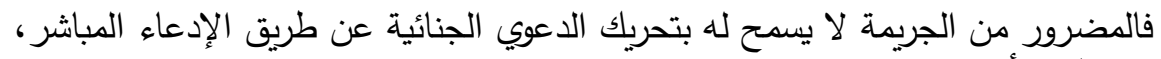

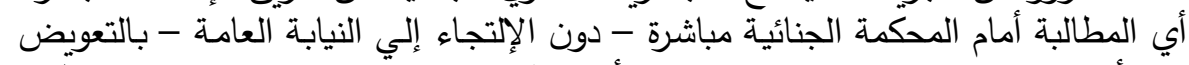

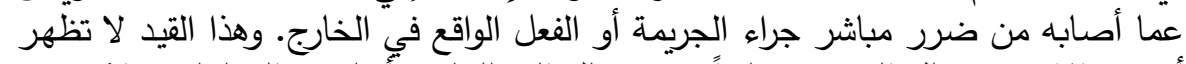

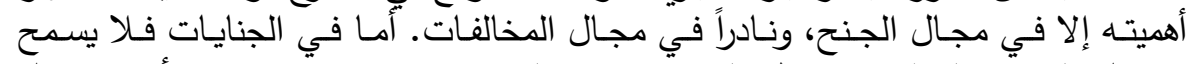

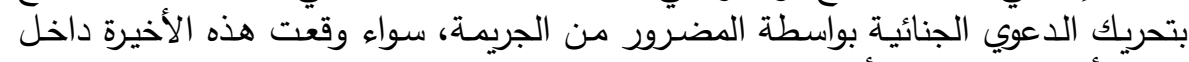

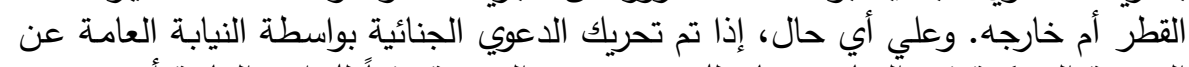

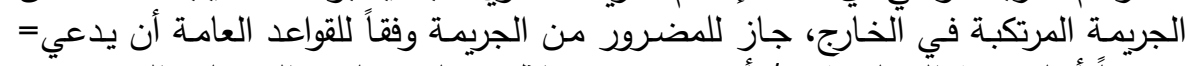

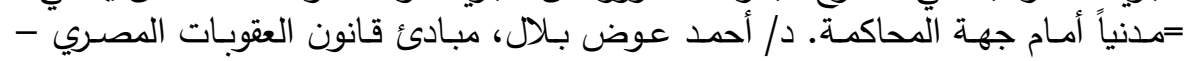

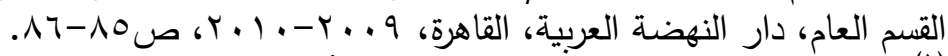

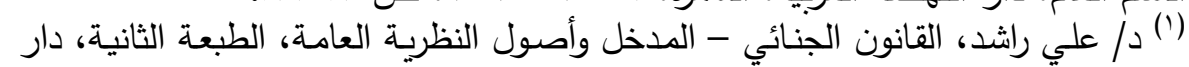

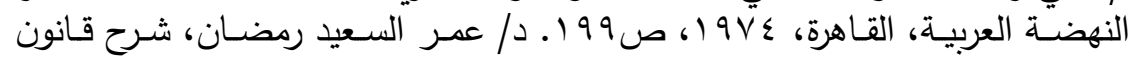

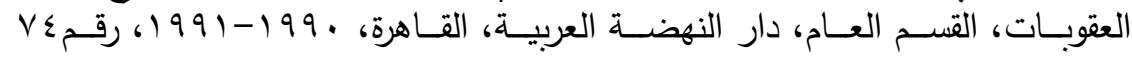




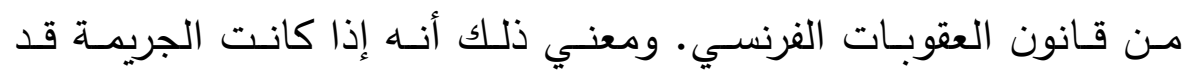
ارتكبت داخل الإقليم الوطني، فلا مجال لهذا التطبيق. فالتشريع الجنائي الوطني هو الذي يطبق دون غيره علي من يرتكب في إقليم الدولة فعلاً

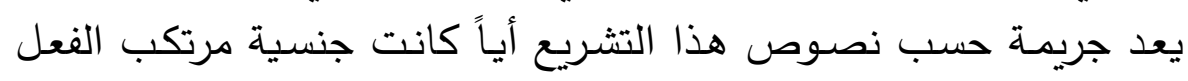
أو المجني عليه وهو أمر تقتضيه سيادة الدولة علي إقليمها وهو الوسيلة التودئ

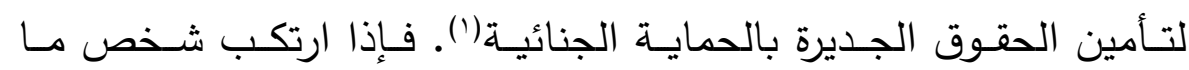

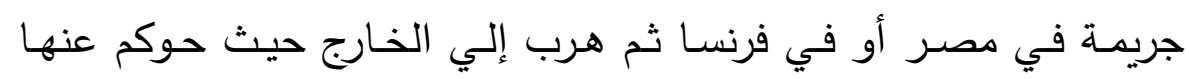

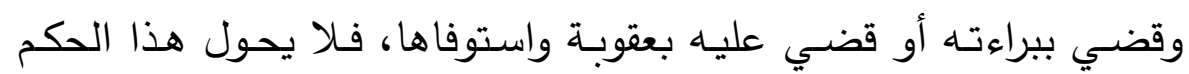

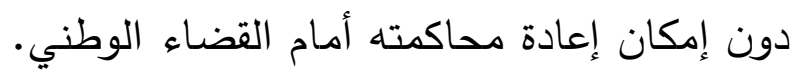

ولذلك علي المحاكم المصرية والفرنسية وهي بصدد تطبيق النصسوص

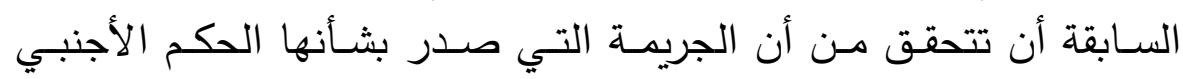

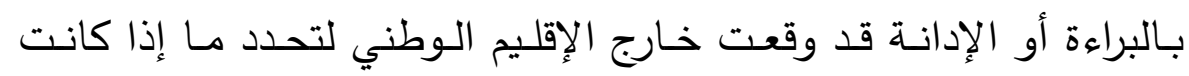

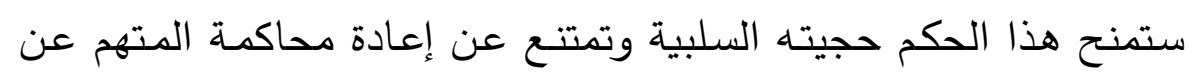

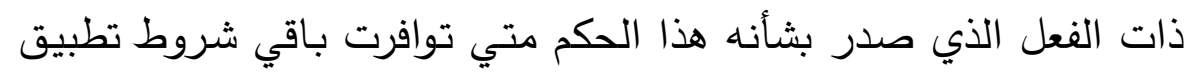

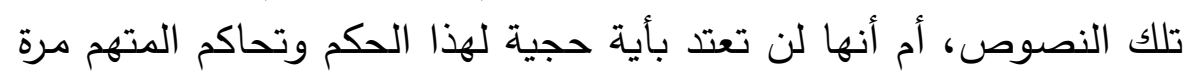

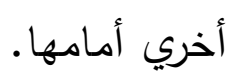

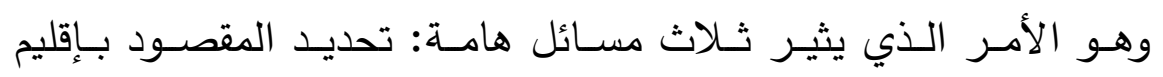

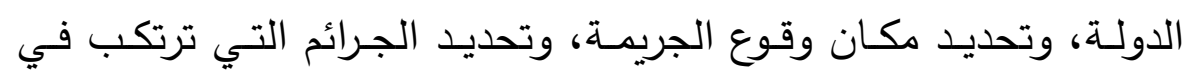

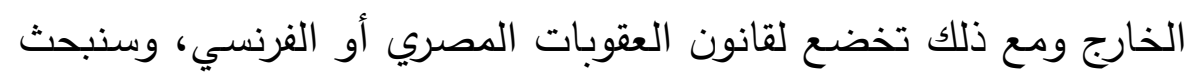

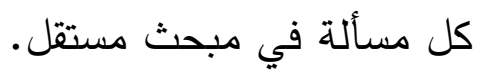

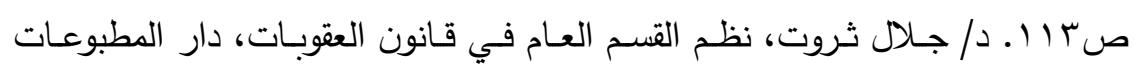

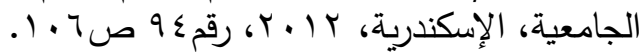

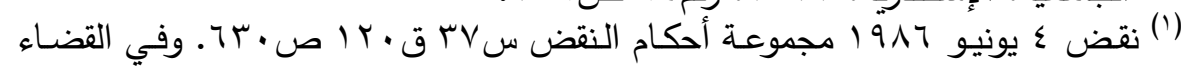

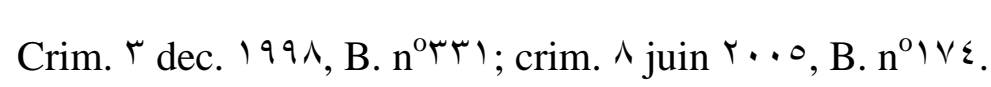

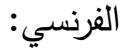




\section{المبحث الأول}

\section{تحديد المقصود بإقليم الدولة}

تقوم الدولـة علي أسـاس مجموعـة مـن الأفراد يمارسـون نشـاطهم علي

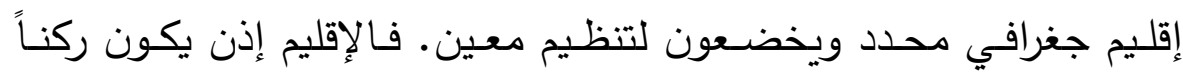
أساسياً مـن أركان الدولـة. وهو يعد شرطاً لإستقلال السلطة السينة السياسية. ذلك أن الإقليم هو المجال أو النطاق التي تباشر فيه الدولة الدئلة سيادتها. ولا تهتم التشريعات الجنائية - عادة - بتعريف إقليم الدولة أو تحديده،

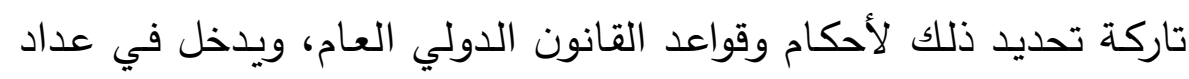

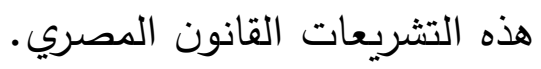

وإقليم الدولة لا يقف عند حد اليابسة، أي الأرض، بل يمتد كذلك إلي الي

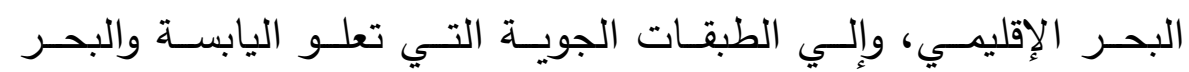
الإقليميس('). وعلي ذلك، فالإقليم يشتمل علي إقليم أرضسي وإقليم مـائي

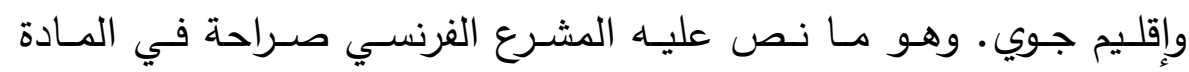
سا 1 - ا مـن قانون العقوبـات في قولـه "يشمل إقليم الجمهوريـة المجـال البحري والجوي المرتبطين به". أولاً: الإقليم الأرضي (البري):

الأرض هي العنصر الأول من إقليم كل دولة، وتمارس الدولة سيادتها

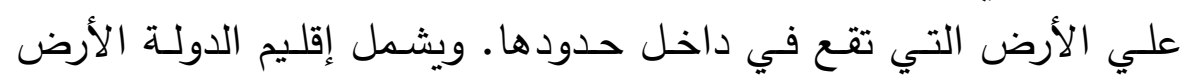

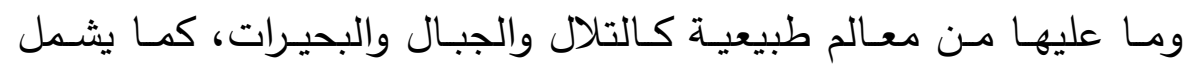

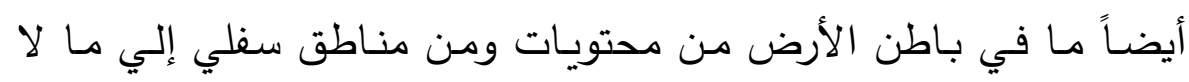

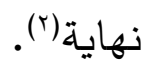

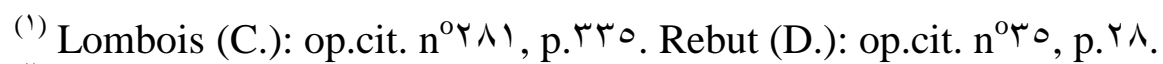

( ) Pradel (J.): Tome I, Droit pénal général,op.cit. $n^{\circ} \backslash \wedge \varepsilon, p .19 \vee$; Bouloc (B.): Droit pénal général, $r{ }^{\mathrm{e}}$ édition, Dalloz, Paris, $\uparrow \ldots q$,

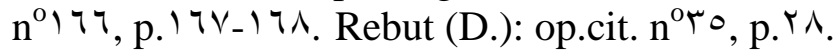

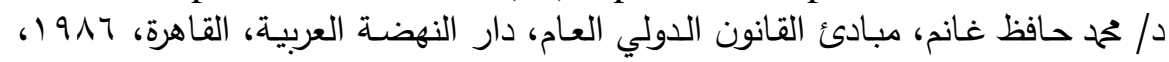

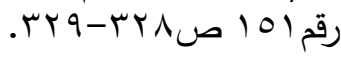




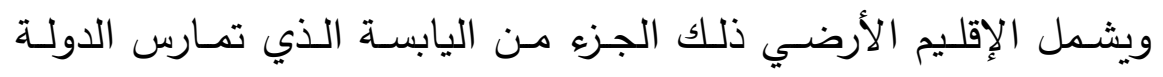

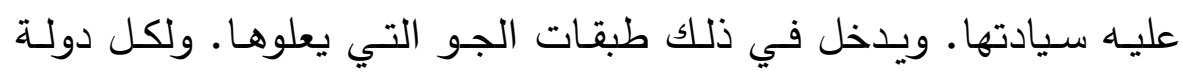
حدود تعين نطاق إقليمها الأرضي.

واعترف القانون الدولي منذ نشوئه بسيادة الدولة علي المياه الداخلية،

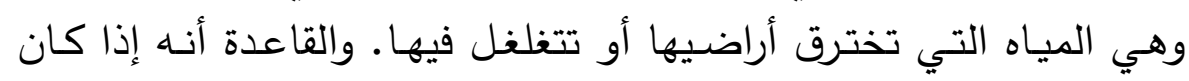
البحر أو البحيرة يقع في أراضي دولة واحدة فهو يعتبر جزعاً من إقليمها

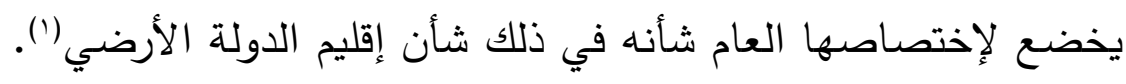

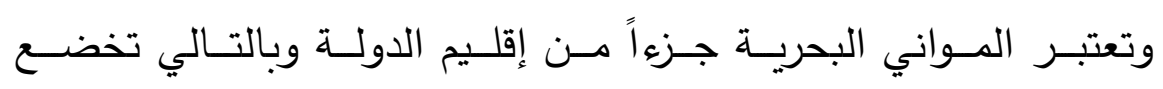

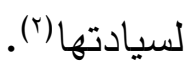
ولا يشترط في الإقليم الأرضسي أن يكون متصـلاً، بـل يمكن أن يكون متقطعاً تفصل أجزاءه المختلفة بحار أو جبال أو أنهار (r). ثانياً: الإقليم البحري (المائي): وهو ما يطلق عليه البحر الإقليمي، وهو عبارة عن مساحة من البحر

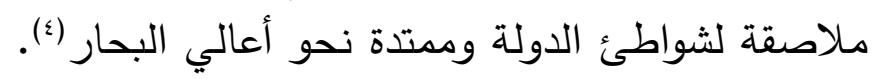

France métropolitaines, départements d'outre-mer (DOM) (Guadeloupe, Guyanne, Martinique, Réunion, Saint Pierre et Miquelon), et des territoires d'outre-mer (TOM) (Nouvelle Calédonie, Polynésie, les Terres australes et antarctiques, Territoire de Mayotte, Wallis et Futuna).

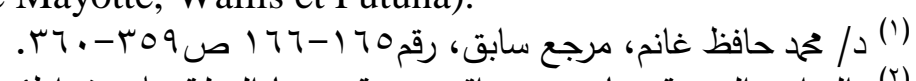

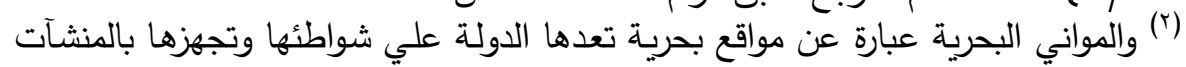

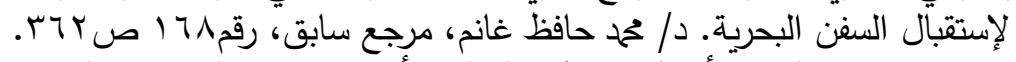

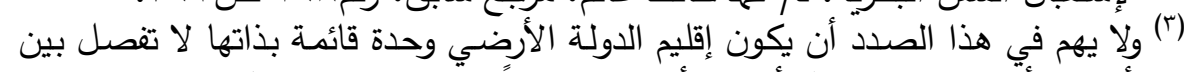

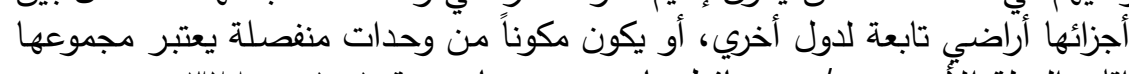

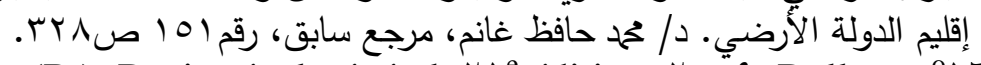

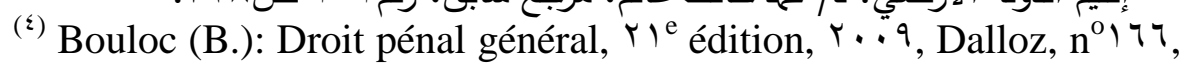
p. 174 .

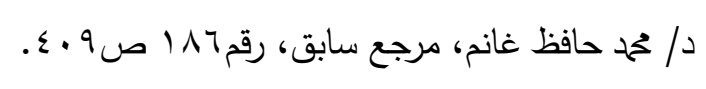


ولا توجد في الوقت الحالي قاعدة من قواعد القانون الدولي العام تحدد بدقة إتساع البحر الإقليمي لكل دولة.

وكانت مصر تحدد إتساع بحرها الإقليمي بثلاثة أميال بحريـة، ثم عدل

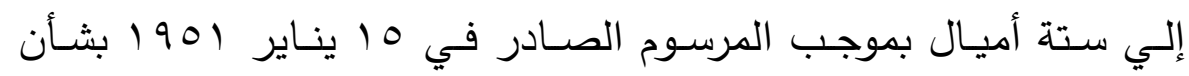

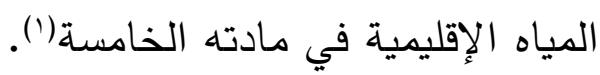

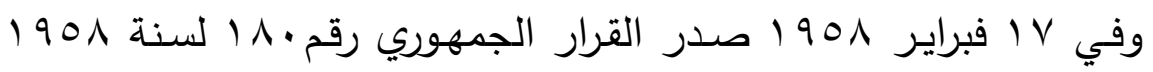

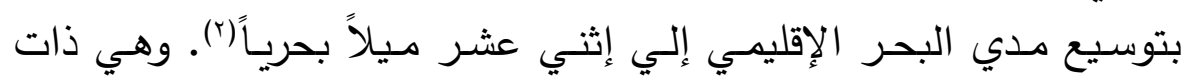

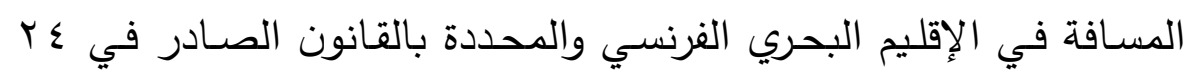

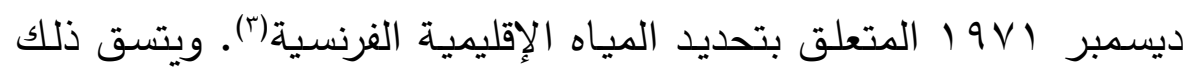

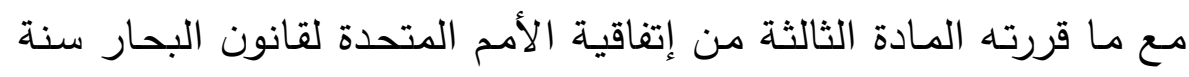

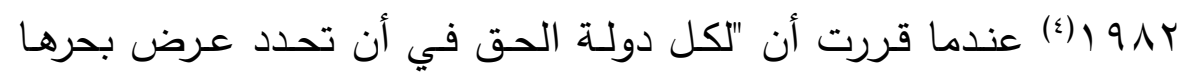

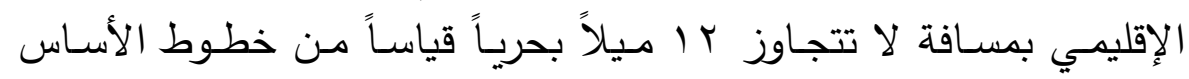
المقررة وفقاً لهذه الإتفاقية".

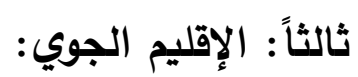

يثـــل إقلـيم الدولــة الطبقـات الهوائيــة التـي تعلـو إقليمهــا الأرضــي والمائي

(') نصت المادة الثانية من المرسوم الصـادر في 10 يناير 1901 علي أن "تكون المياه

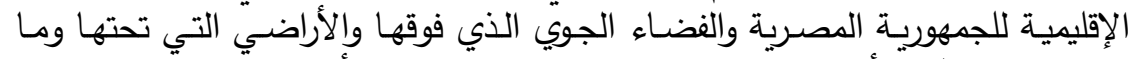

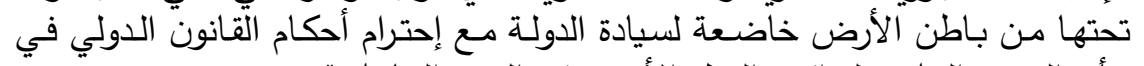

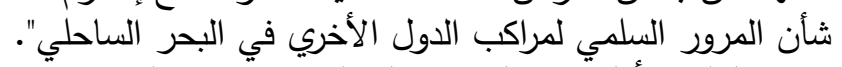

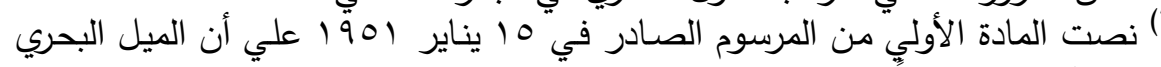

( ${ }^{\top}$ Pradel (J.): Tome I, Droit pénal général, op.cit. $n^{\circ} \wedge \wedge \varepsilon, p .19 \vee$;

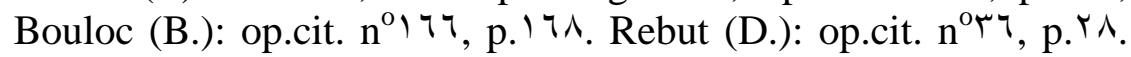

Voir: En juris. crim. ' mai 1990, B. $\left.n^{0} 17\right)$.

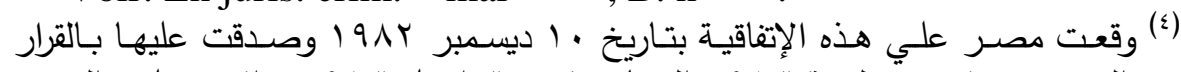

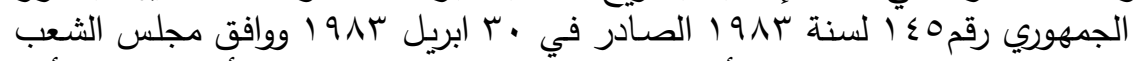

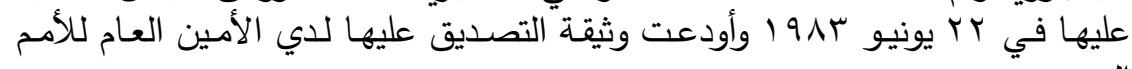


وفي V ديسمبر سنة ؟ ؟ 1 ابرمت إتفاقية شيكاغو الخاصـة بالطيران المدني الدولي. والمبدأ الأساسي الذي تقوم عليه هو الإعتراف بسيادة

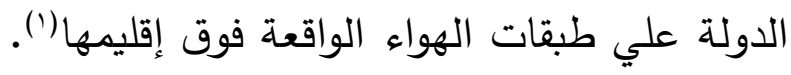
الإمتداد الحكمي لإقليم الدولة: تقتصـر سـلطات الدولـة - وفقـاً لمبـدأ الإقليميـة - علـي مـن يرتكـب الجريمـة علي إقليمها بالمعني السـابق تحديده. ولكن تطبيق هذا المبدأ

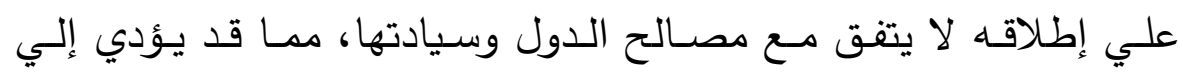
إفلات بعض المجرمين من العقاب، ولهذا فإن الدول لم تحصر سيادتها

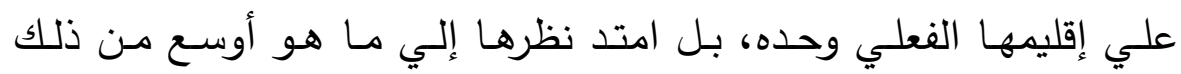

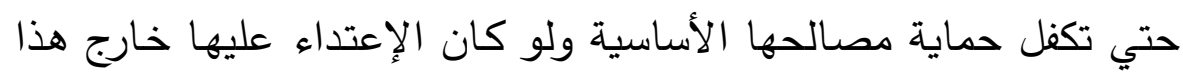

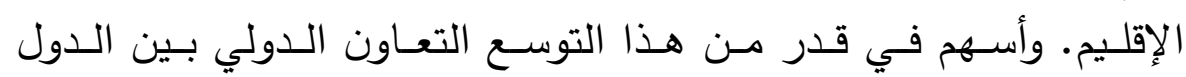

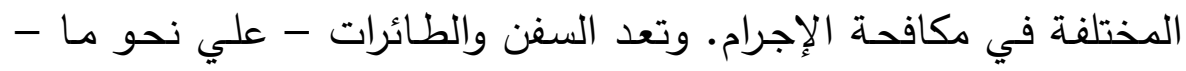
إمتداداً لإقليم الدولة، ويقتضي الأمر التمييز بينهما.

وممـا لاشكك فيـه خضـوع الجرائم الواقعـة علي متن السفينة أو الطـائرة

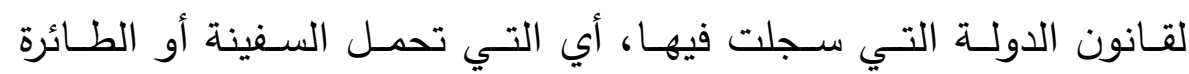

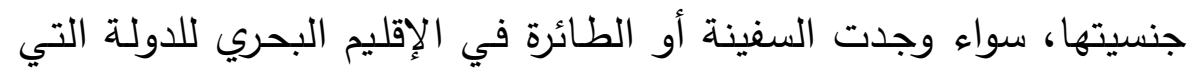

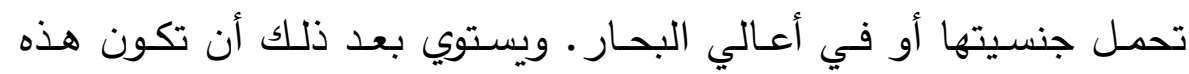

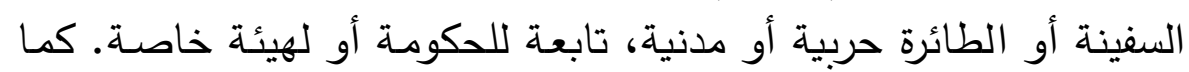

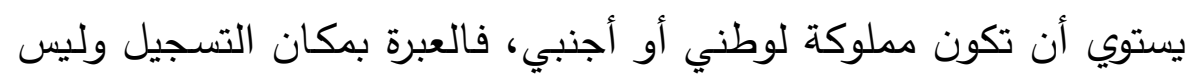

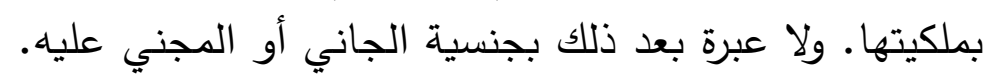
ولكن تنشـأ الصـوبة بالنسبة للسفن والطـائرات التي توجد في الميـاه

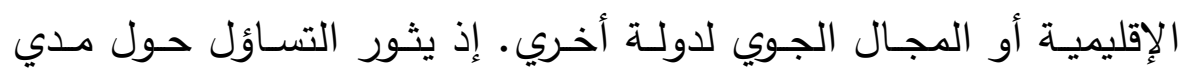

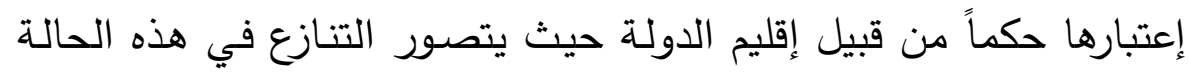
بين قانون دولة العلم وقانون دولة الإقليم.

(') انظر المـادة الأولي من الإتفاقية ونصها "تعترف الدول المتعاقدة أن لكل دولـة، علي الفضاء الهوائي الذّي يعلو إقليمها، سيادة كاملة مقصورة الإنفية عليها". 
إذا كانت السفينة وقت وقوع الجريمـة علي ظهرها في الإقليم البحري

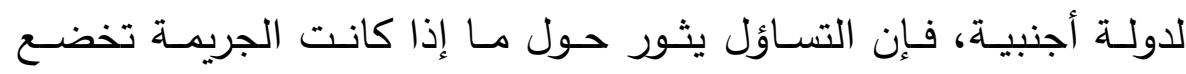

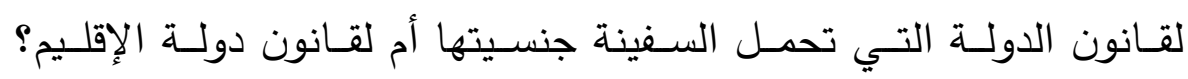
ويقتضي الأمر التفرقة بين ما إذا كانت السفينة حربية أو مدنية.

فـإذا كانـت السـفينة حربيـة، فقـد اتجـهـ العـرف الـدولي إلـي خضـوعها

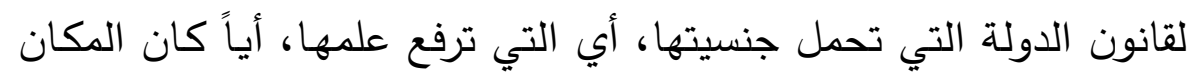

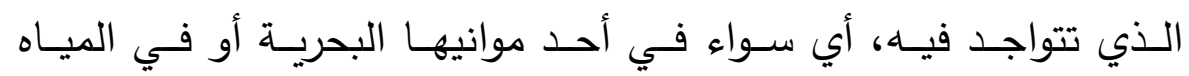

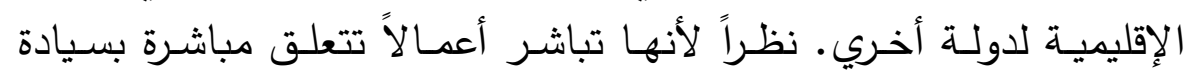

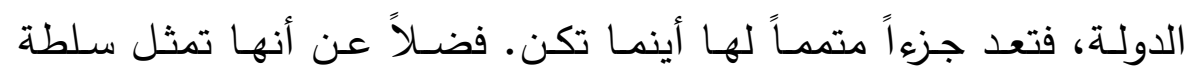

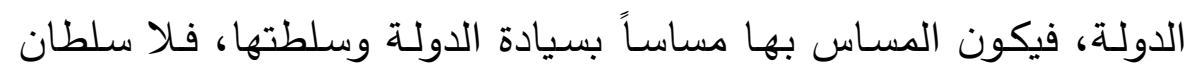

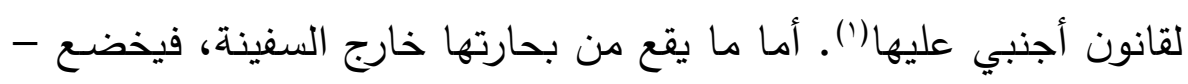

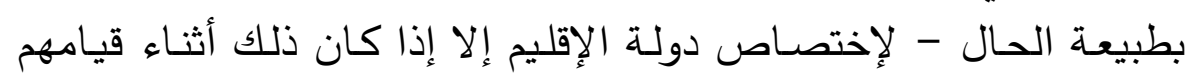

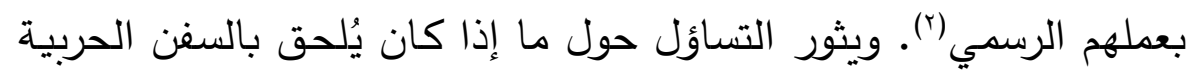

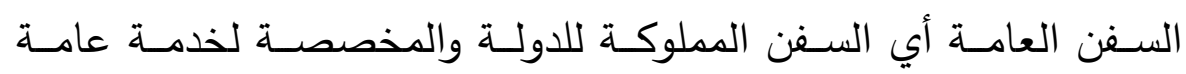

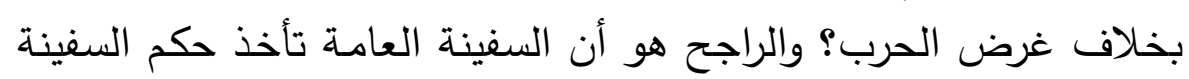

(') Pradel (J.): Tome I, Droit pénal général, op.cit. $\mathrm{n}^{\circ} \wedge$, p. $19 \vee$; Bouloc (B.): op.cit. $n^{0} \backslash \uparrow \vee$, p. $1 \uparrow \uparrow$; Lombois (C.): op.cit. $n^{\circ} \uparrow \wedge$, p.rro.

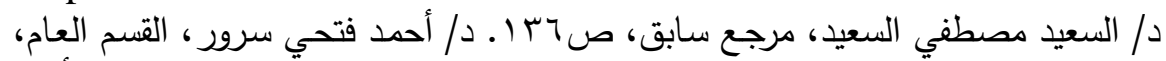

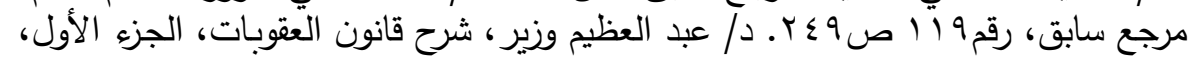

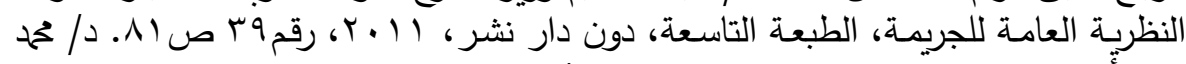

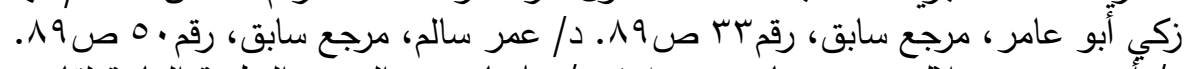

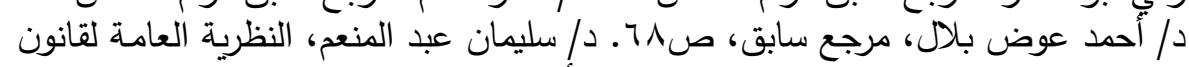

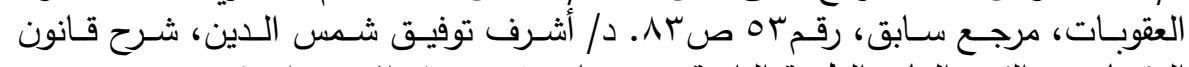

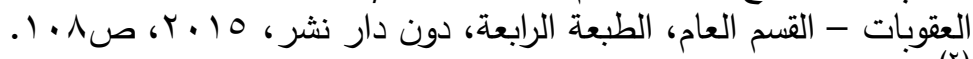

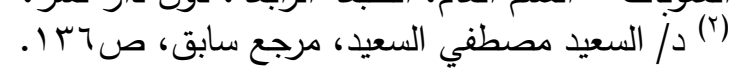

Zlataric (B.): Droit pénal international, Revue al Qanoun wal Iqtisad, Le caire, juin $1979, n^{\circ} r, r q$ année, $\left.n^{\circ}\right)^{\circ} r, p . \vee \varepsilon$. 
الحربيـة وبالتـالي تخضـع الجرائم الواقعـة علي متنهـا لقانون الدولـة التي التي تحمل جنسيتها، أي لقانون دولة العلم (').

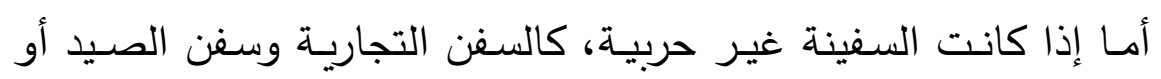
النزهة، فإن الجريمة المرتكبة علي ظهرها تخضـع بحسب الأصل لقانون

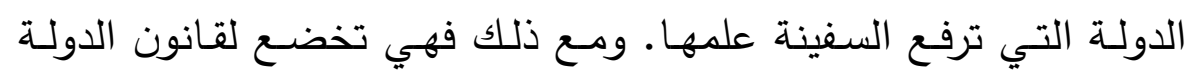
التي تتواجد في إقليمها في الحالات الآتية(؟):

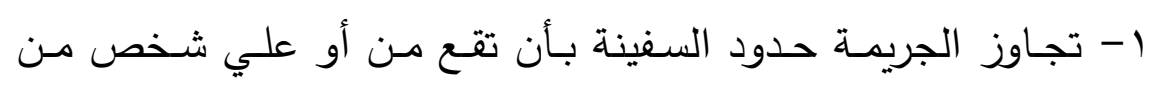
غير ركابها أو طاقمها.

ץ- إذا كان من شأن الجريمة الإخلال بسلامة الدولة أو بأمن الميناء. r- إذا طلب ربان السفينة أو من يقوم مقامسه المسـاعدة من السلطات المحلية. ع - ضرورة مكافحة الإتجار غير المشروع في المخدرات.

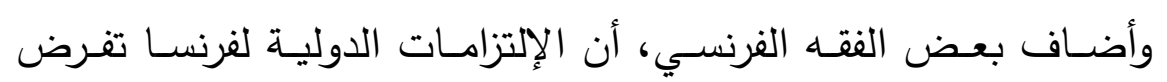

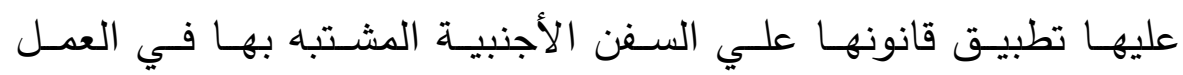

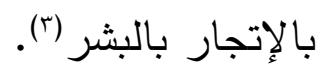
ويستنتج مدـا سـبق أن السـفينة - بحسب الأصـل - تخضــع لقـانون

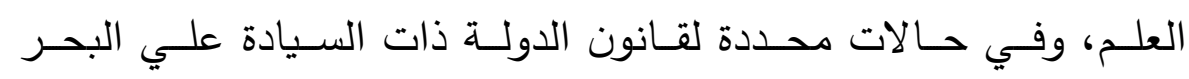
الإقليمي وفقاً لمبدأ الإقليمية.

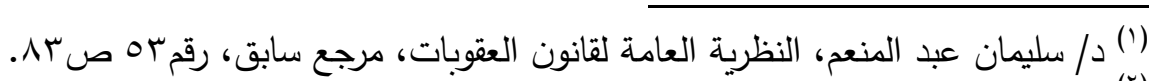

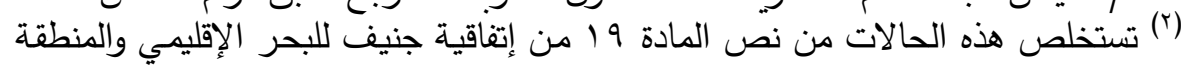

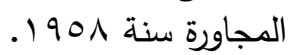

Voir: Pradel (J.): Tome I, Droit pénal général, op.cit. $\mathrm{n}^{\circ} \backslash \wedge \varepsilon$,

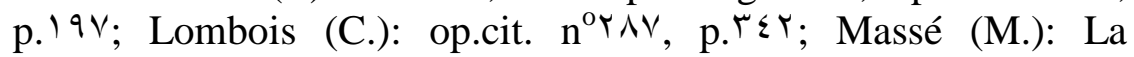
compétence pénale française dans l'espace depuis l'entrée en vigueur du nouveau code penal, R.S.C. oct.-dec. 1990 , p.^09. En juris. Alger 19 août $\wedge \wedge \mathrm{r}, \mathrm{S}$. $1 \wedge \vee \varepsilon$, II, $r \wedge r$; crim. 9 janv. $19 \mathrm{rV}, \mathrm{S}$. $19 \mathrm{rr}, \mathrm{I}, 110$.

${ }^{(r)}$ Lombois (C.): op.cit. n ${ }^{\circ} \curlyvee \wedge \vee$, p. ${ }^{r} \leqslant$. 
ولكن المشرع المصري لم يتقيد بهذه القواعد تماماً حيث قرر سريان القانون المصري علي ما يرتكب علي ظهر السفن المصريـة أينما وجدت؛

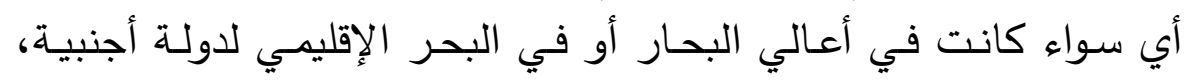

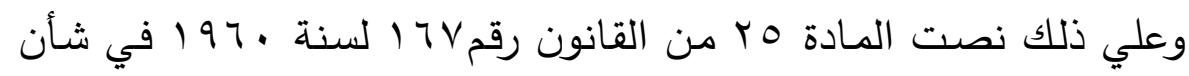

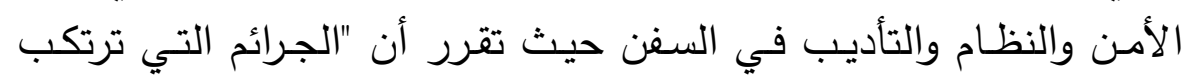
علي ظهر سفينة ترفع علم الجمهورية تعتبر أنها ارتكبت علي أراضيها".

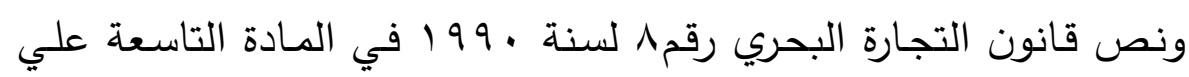

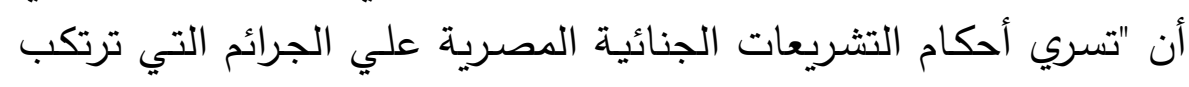
علي كل سفينة ترفع علم جمهورية مصر العربية".

وقد يحدث - في بعض الأحيان - أن تقع جريمة ما علي ظهر سفينة

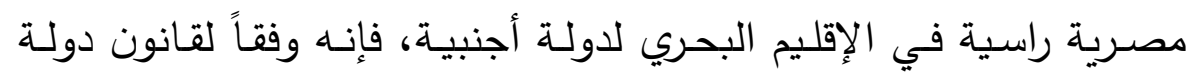

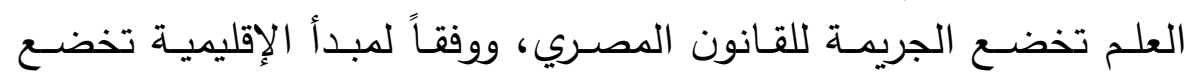

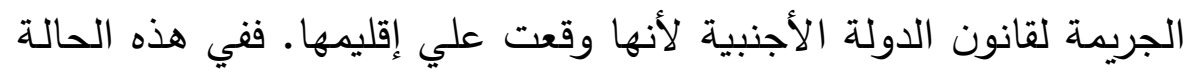

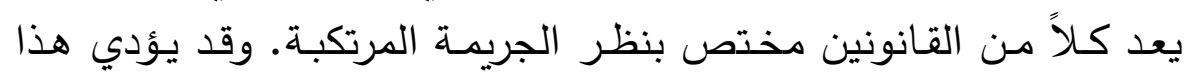

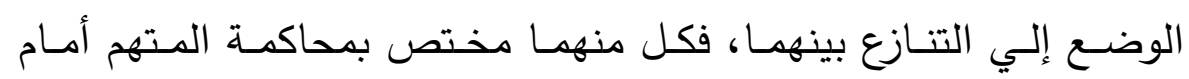

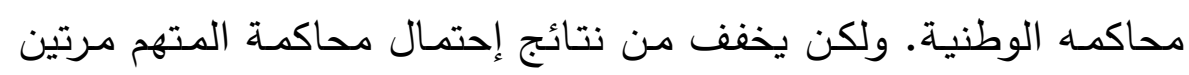

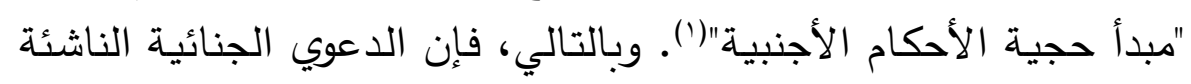

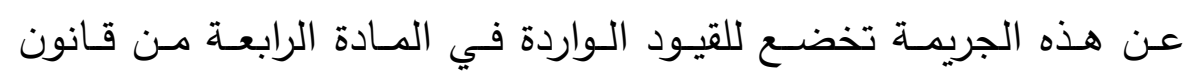
العقوبات المصري، وذلك علي التفصيل الذي سنراه فيما بعد.

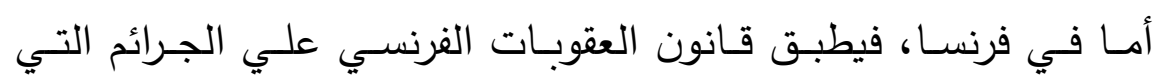

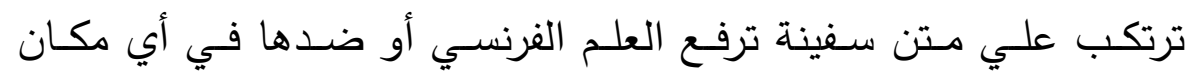
وجدت، أو علي أشخاص وجدوا عليها. ويطبق أيضـاً وحده علي الجرائم

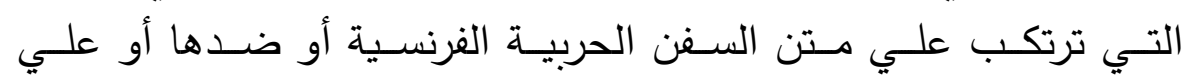

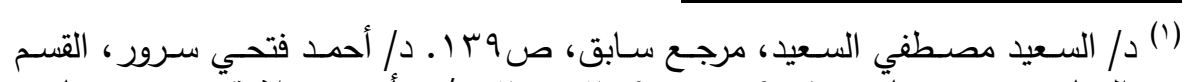

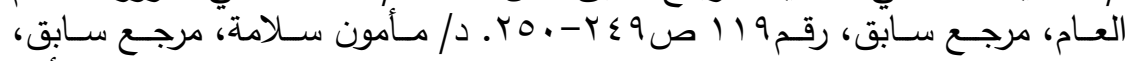

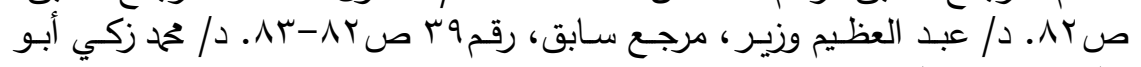

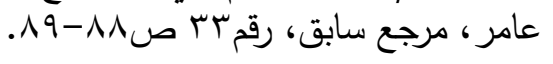


أشخاص وجدوا عليها، في أي مكان وجدت (المادة r ا ا -r عقوبات). فيخضع لإختصاص المحاكم الفرنسية الجرائم المرتكبة في عرض الته البحر

من شخص أجنبي علي سفينة تحمل العلم الفرنسي ('). ثانياً: الطائرات:

تخضع الجرائم التي تقع علي متن الطائرات لقانون الدولة التي سجلت

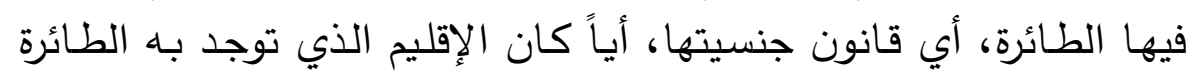
وقت ارتكاب الجريمة أو كانت تحلق فوق أعالي البحار .

وقد ابرمت إتفاقية طوكيو في ع ا سبتمبر سنة ب79 19 بثأن الجرائم والأفعال التي تحدث علي متن الطائرة والقانون الواجب التطبيق عليقئ عليها.

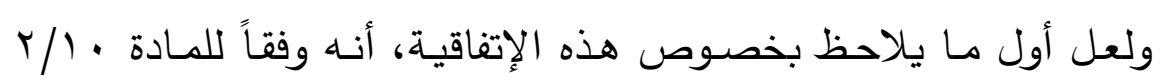

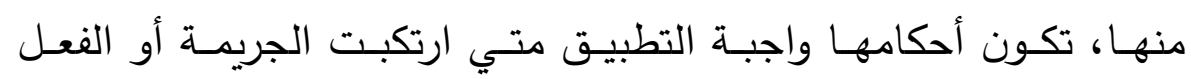

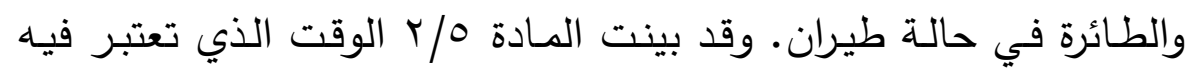

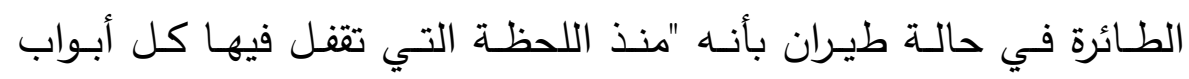

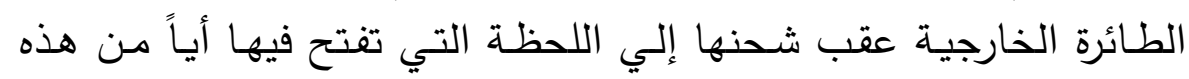
الأبواب بغرض تفريخ الطائرة".

أمــا عـن القـانون الواجـب التطبيـق، فقــ قضــت المـادة ب/ / بإنعقـاد

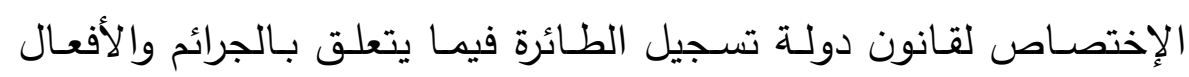

(1) crim. ० août 19r., B. noroo; crim. 9 janv. 19rv, S. 19rv.1.110. Lombois (C.): op.cit. $n^{0} \uparrow 9$, p. ${ }^{0.0}$; Pralus (M.): Etude en droit pénal international et en droit communautaire d'un aspect du principe non bis in idem: non bis, R.S.C. ( $($ $)$, juill.-sép. 1997, p. ${ }^{71}$; Pradel (J.): Le nouveau code penal (partié générale) (loi $\mathrm{n}^{\circ}$ 9r_rAr du rr juillet 199r), ALD 199r, n ${ }^{\circ} r$, p. 9 9r et s.; Massé (M.): op.cit. p.^०^. Desessard (L.): France, Les compétences criminelles concurrentes nationales et internationals et le principe non bis in idem, R.I.D.P. $r \ldots r / r$, vol. $v r$, p. 919 . Rebut (D.): op.cit. $n^{\circ} \uparrow q$, p. ${ }^{r} \cdot$. Moulier: La compétence universelle en droit international T.I, Thèse, Paris I, $r \cdots r$, p. ${ }^{\vee r}$. 
التي ترتكب علي متن الطائرة، وإن كانت منحت الأفضلية لقانون دولـة السطح في عدة حالات نصت عليها المادة الرابعة وهي: أولاً: أن يكون للجريمة أثر علي إقليم هذه الدولة.

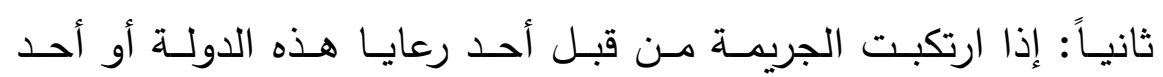

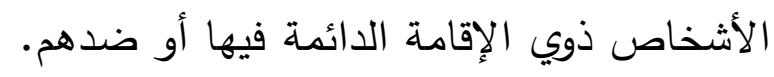
ثالثاً: إذا ارتكبت الجريمة ضد أمن الدولة. رابعاً: إذا انطوت الجريمة علي خرق للقواعد والأنظمة النافذة في هذه الدولة المتعلقة بالطيران أو تحركات الطيران. ران.

خامسـاً: إذا كانـت مباشـرة هـا الإختصـاص ضــرورياً لضـــان مراعـاة الدولة لأي من تعهداتها طبقاً لإتفاقية دولية متعددة الأطراف.

وقد نصـت الفقرة الرابعـة مـن المـادة الأولـي مـن الإتفاقيـة علي عدم

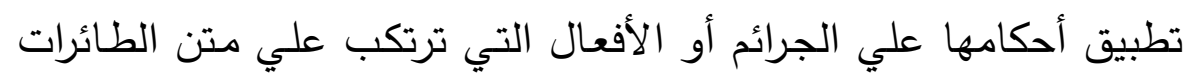
المستخدمة في الأغراض الحربية أو الجمركية أو خدمات الشرطية.

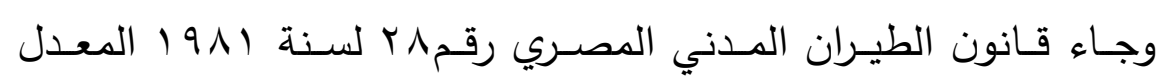

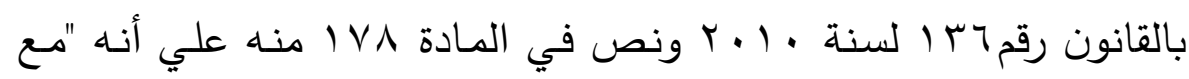

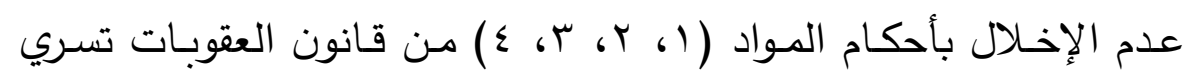

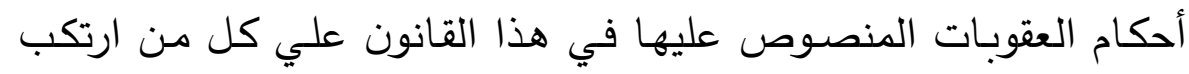
جريمة منصوص عليها فيه خارج مصر وذلك في الحالات الآتية: ا - إذا ارتكبت الجريمة ضد وسيلة من وسائل النقل الجوي مسجلة في الدولة أو تحمل علمها أو علي متنها.

r- إذا ارتكبـت الجريمـة ضــ أو علـي مستن وسـيلة مـن وسـائل النقـل

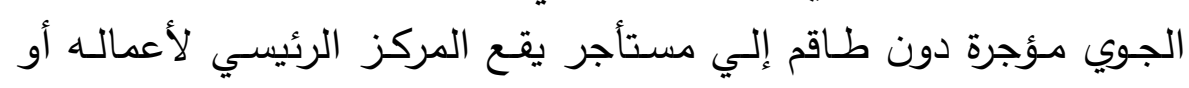
محل إقامته الدائم في الدولة دونة 
r- إذا كان من شأن الجريمـة إلحاق الضـرر بوسيلة من وسائل النقل

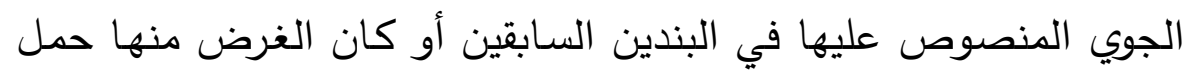

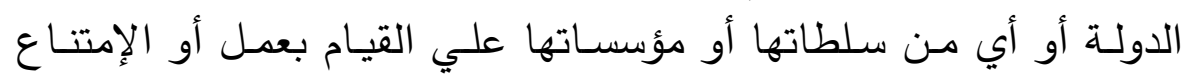

عنده

ع - إذا كان مرتكب الجريمـة أجنبياً تواجد في مصـر وذلك في حالة

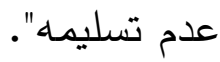

وفي فرنسا، يطبق قانون العقوبات الفرنسي علي الجرائم التي تقع علي

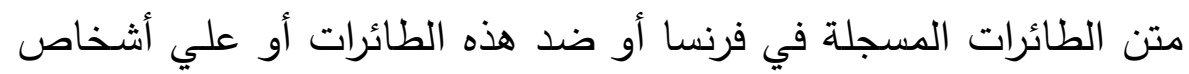
وجدوا علي متنها في أي مكان وجدت. ويطبق كذلك وحده علي الجرائم

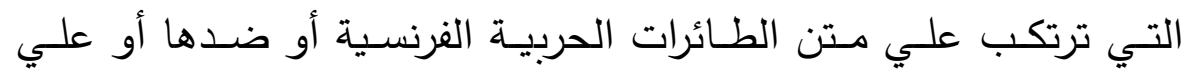

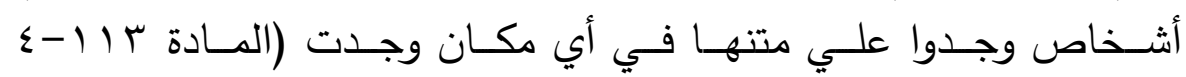

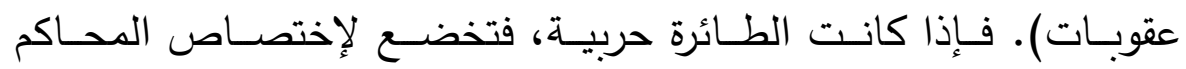

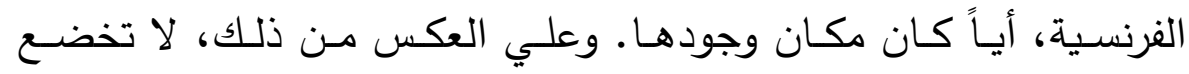

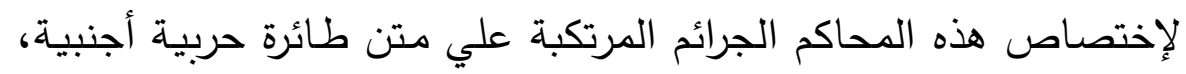
فهذه الأخيـرة تخضـع لإختصـاص محساكم دولتهـا. أمـا إذا كانـت الطـائرة مدنية فتخضع لإختصاص الدولة التي تحمل جنسيتها('). فيخضع لإختصاص المحاكم الفرنسية الجرائم المرتكبة علي الطائرات،

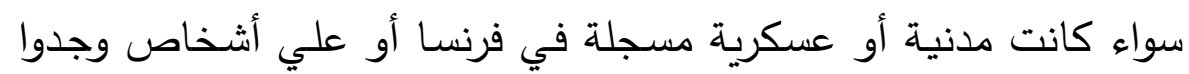

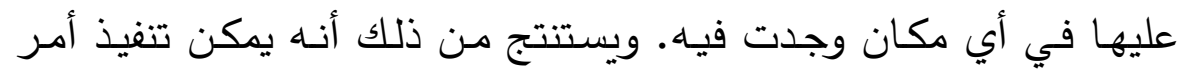
القبض الصادر من قاضي التحقيق علي متن طائرة فرنسية موجودة في

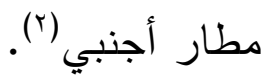

(') Lombois (C.): op.cit. $\mathrm{n}^{\text {os }}$ ^l et s., pp. ${ }^{\text {rro et } \mathrm{s} \text {; Bouloc (B.): op.cit. }}$ n ${ }^{0} 7 \vee$, p. $17 \uparrow$; Pralus (M.): op.cit. p.07l; Massé (M.): op.cit.

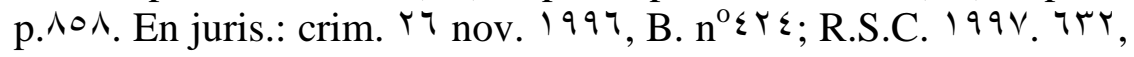
obs. Bouloc.

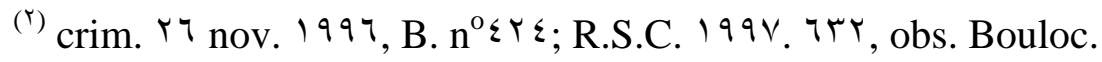




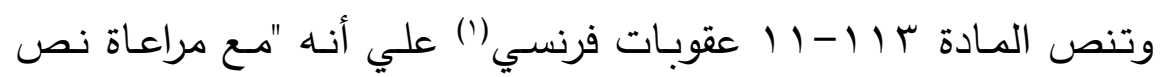

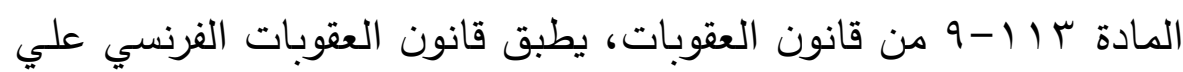

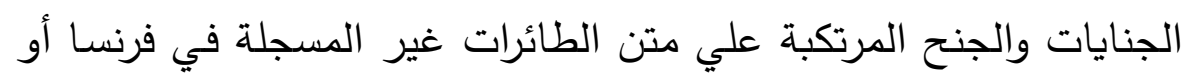
ضدها أو علي الأشخاص الموجودين علي متنها:

ا - متي كان الفاعل أو المجني عليه يحمل الجنسية الفرنسية. Y- متي هبطت الطائرة في فرنسا بعد وقوع الجناية أو الجنحة.

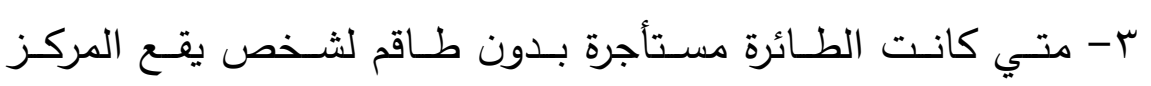
الرئيسي لأعماله أو محل إقامته الدائمة علي إقليم الجمهورية. وفي الحالـة المنصـوص عليها في البند الأول مـن هذه المـادة تحدد

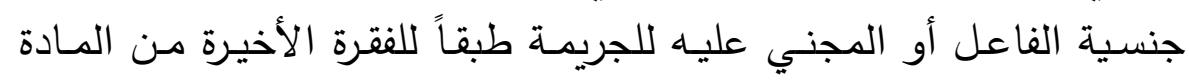
r r (1)

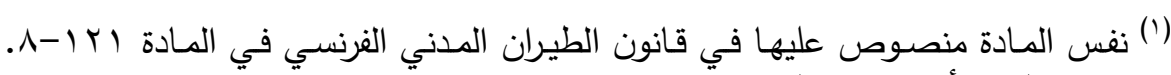
Rebut (D.): op.cit. $n^{0} \backslash \vee^{q}$, p. $\vee 9$. ويلاحظ هنا أنه لا يشترط ازدواج التجريح. 


\section{المبحث الثاني \\ تحديا مكان إرتكاب الجريمة}

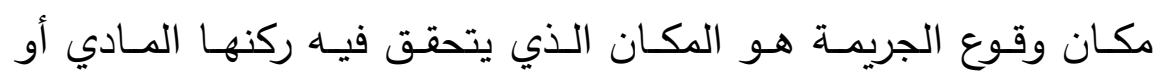

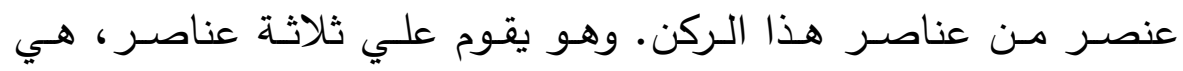

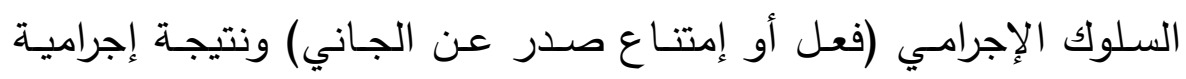
تنجم عن هذا السلوك وعلاقة سببية تربط بينهما. وقد يقع السلوك الإجرامي في إقليم دولـة وتقع النتيجـة في إقليم دولـة أخري. مما يثير التساؤل عن الإقليم الذي تعتبر الجريمـة قد وقعت فيه فيه.

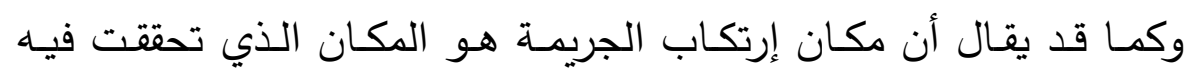
نتيجتها، فقد يقال أنه المكان الذي تحقق فيه السلوك الإجرامي لمرتكبها

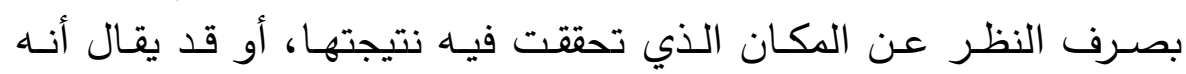
المكان الذي تحققت فيه الآتار المباشرة للفعل والتي تتكون منها رابطة

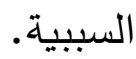

وكما يتحقق الركن المادي علي يد شخص بمفرده، فقد يتحقق أيضـاً

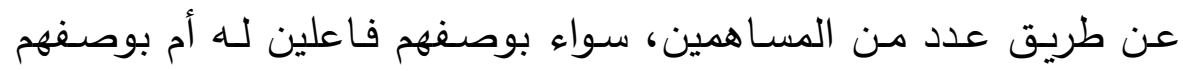

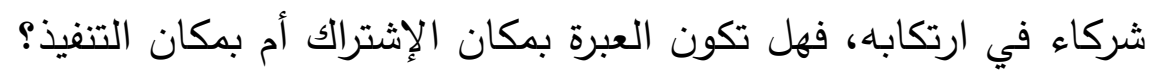
وقد حرص المشرع الفرنسي علي تحديد مكان وقوع الجريمـة بمقتضي

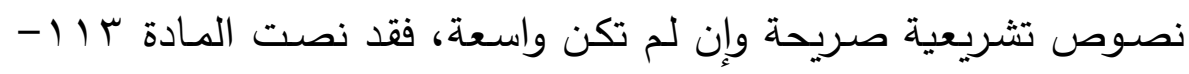

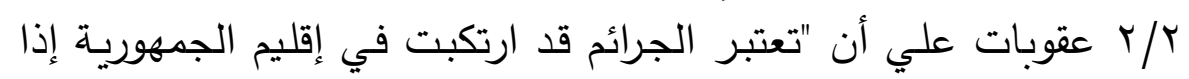

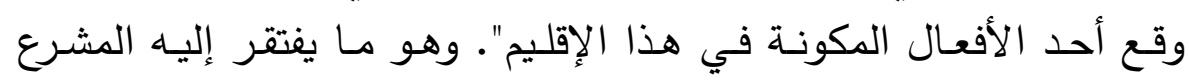

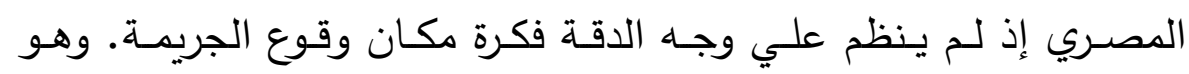
قصور تشريعي يجب تداركه لاسيما مع تعاظم ظاهرة الجرائم الدولية('). أولاً: وقوع الركن المادي للجريمة بأكمله في إقليم دولة واحدة: (1) د/ سليمان عبد المنعم، النظرية العامة لقانون العقوبات، مرجع سابق، رقمه صـو. 
كما سبق القول، يتألف الركن المادي للجريمة من عناصر ثلاثة، هي:

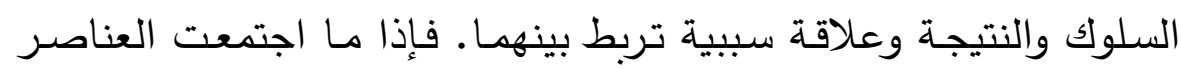

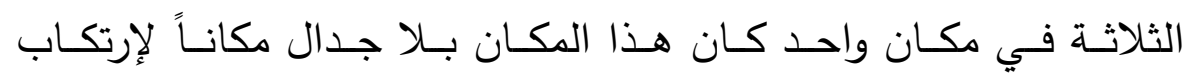
الجريمة.

ثانياً: وقوع الركن المادي للجريمة في إقليمين أو أكثر:

من المتصور أن يقع أحد عناصر الركن المـادي في إقليم دولتة بينما

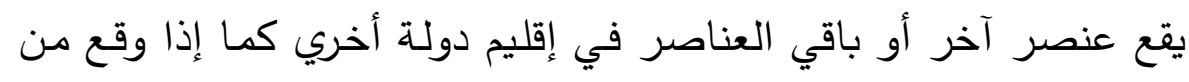
الجاني نشاط إجرامي في إقليم معين وحدثت نتيجة هذا النشاط في إقليم

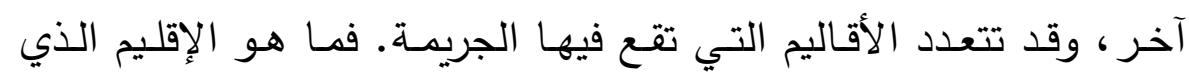
تعتبر الجريمة قد وقعت فيه؟

اختلف الفقهاء في هذا الأمر إلي ثلاثة آراء: فذهب رأي إلي الإعتداد

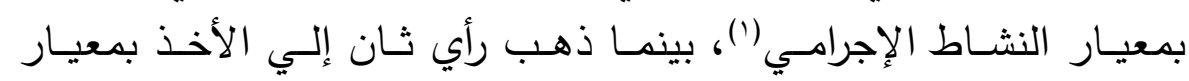
النتيجة (r) (ب).

بينما ذهب رأي ثالث - أخذ به غالبية الفقهاء(r)- إلي أن الجريمة تقع فئح

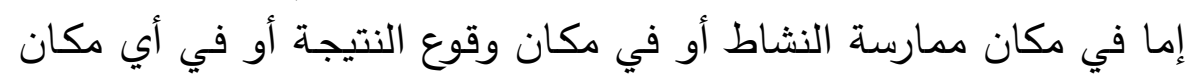

(1) Donnedieu de vabres (H.): Traité de droit criminel et de législation pénal comparée, Recueil Sirey, 19ะV, n ${ }^{0} 17$ ro. Voir aussi: Legeais: L'évolution des solutions françaises de conflits de lois en matière pénale, Mélanges Savatier, 197 , p. 00 r et $s$.

${ }^{(r)}$ Canonne (G.): Essai de droit pénal international; L'affaire du lotus, thèse, Toulouse, $1949, p .1 \% 9$ et $s$.

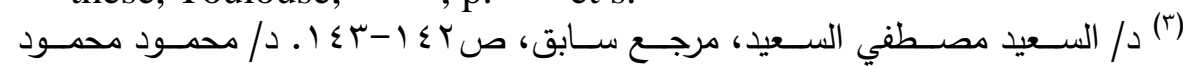

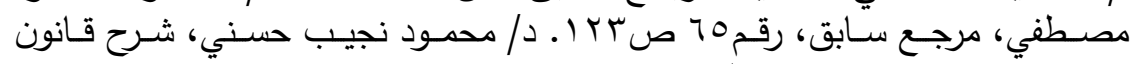

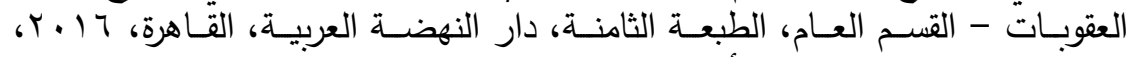

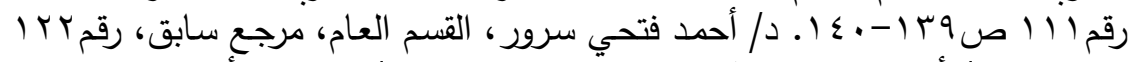

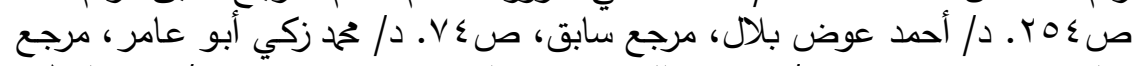

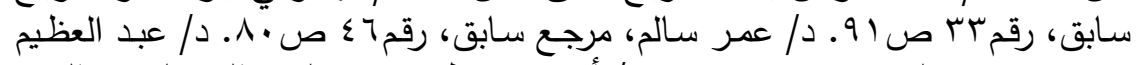

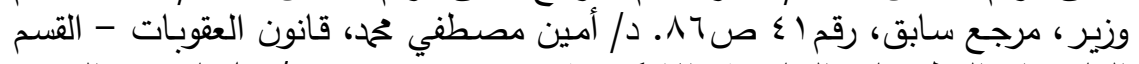

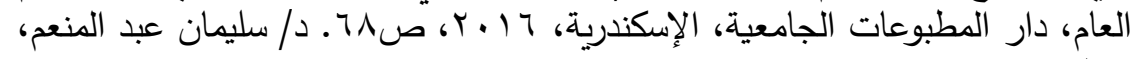

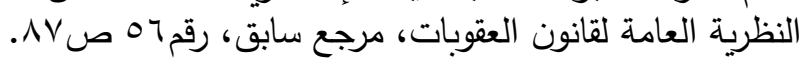


آخر تحققت فيـه أحد الآثار المباشـرة للفعل، والتي تتكون منهـا علاقـة السببية بين النشاط والنتيجة.

وهذا الإتجاه الأخير أخذ به القضـاء المصري في أحكامه عندما قضي

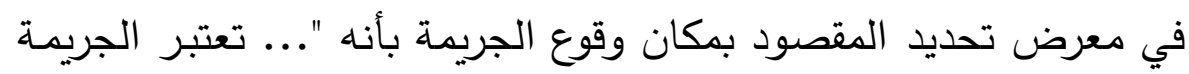

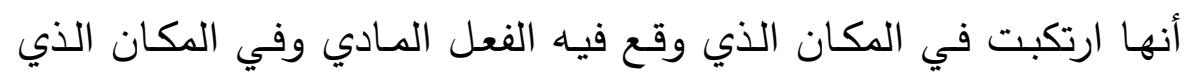

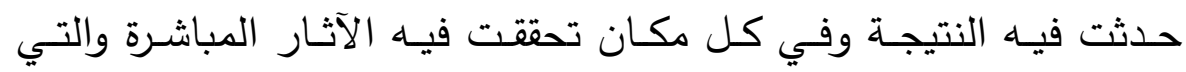
تتكون منها الحلقات السببية التي تربط بين الفعل والنتيجـة"('). وسـايره علي ذات النهج القضاء الفرنسي (ז). وقد أخذ بـه قانون العقوبـات المصـري عندما نص في المـادة الثانية/ البند "أولاً" علي أن تسري أحكام هذا القانون علي "من يرتكب في خارج

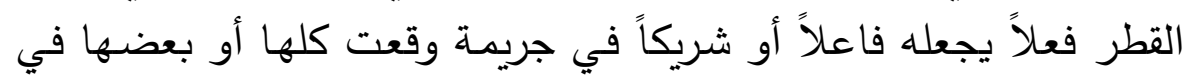
القطر المصري. كما اعتبر المشرع الفرنسي الجريمـة مرتكبة في الإقليم

Koering Joulin (R.): L'article 79 r CPP et la localisation internationale de l'infraction, thèse, Strasbourg, $19 \vee r$, p. ${ }^{r} \circ$ et $\mathrm{s}$. ; Tsarpalas: Le moment et la durée dans les infractions pénales, thèse, Paris, $197 \mathrm{~V}, \mathrm{n}^{\circ} 1 \mathrm{~V}$;

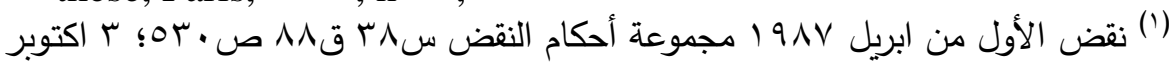

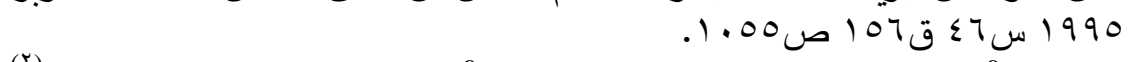

(r) crim. $\uparrow$ nov. $19 \vee \cdot$, B. n ${ }^{\circ} \uparrow \wedge 0$; crim. $1 \Upsilon$ mai $19 \vee 1$, B. n ${ }^{\circ} 10 \vee$; crim.

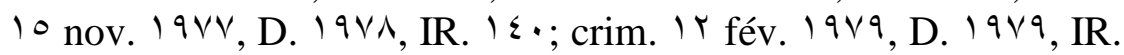
P. IVV, obs. Roujou de Boubée; R.S.C. I 9v9, p. ovo, obs. Bouzat;

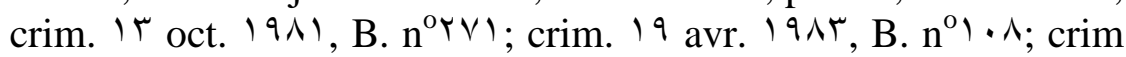

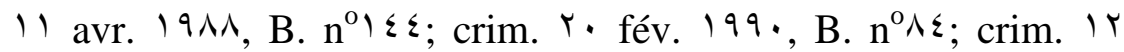

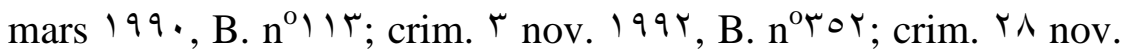

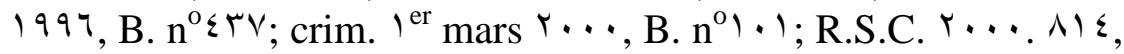
obs. Bouloc; crim. $r^{q}$ mars $r \cdots$, , B. $\left.n^{0} \backslash \leqslant\right\urcorner$; crim. $r^{q}$ janv. $r \cdots r$,

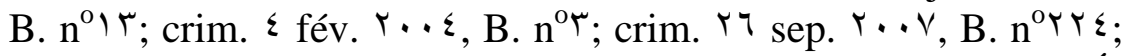
D. $r \cdots \wedge$, Jur. I $1 \vee q$, note D. Rebut; R.S.C. r.^, 19 , obs. É. Fortis, $r \uparrow \cdot$, obs. R. Finielz; Crim. $r \operatorname{dec} r \ldots q$, Dr. Penal, $r \cdot{ }^{\prime} \cdot$, comm. $\varepsilon r$, obs. M. Véron. 


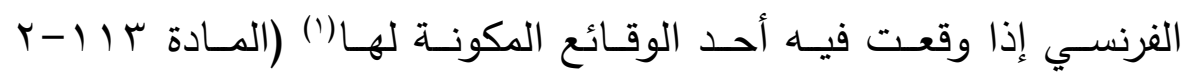
(عقوبات) ( مرنسي

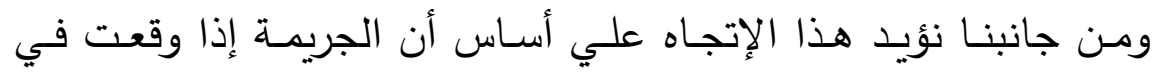

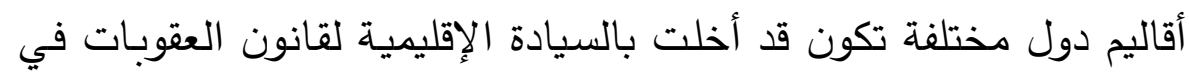
كل إقليم وقعت فيه ولو جزئياً.

والمعول عليه هو وقوع الجريمـة كلياً أو جزئياً داخل الإقليم الوطني، أياً كان مكان الجاني وقت وقوع الجريمة: فيستوي أن يكون موجوداً في الجيا الإقليم أو خارجه.

وقد يؤول الأمر - أحياناً - إلي خضوع بعض الجرائم في وقت واحد لقانون العقوبات الوطني ولقانون دولة أو دول أخري. غير أن ذلك ليس اليس

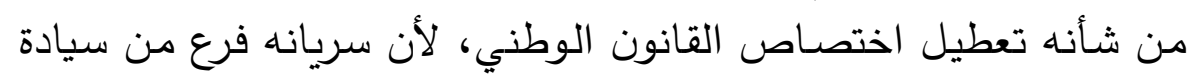

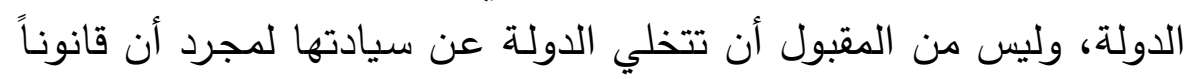

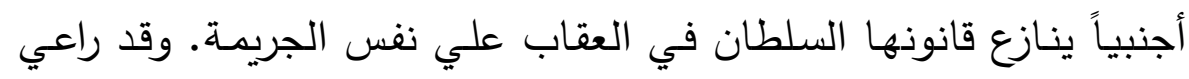

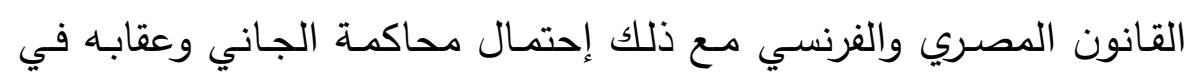

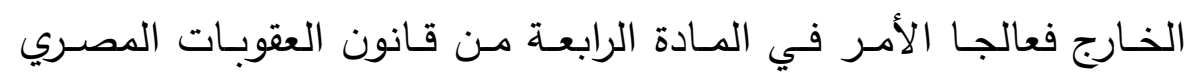
والمادة rا | (-9 من قانون العقوبات الفرنسي (r). وممـا سـبق نستنتج أنـهـ يعـد مكانـاً لوقوع الجريمــة: مكسان السـلوك أو

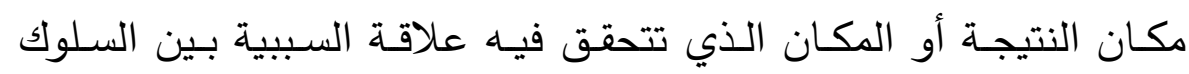
والنتيجـة. أمـا المكـان الذي يتحقـق فيـهـ مـا يسـبق السـلوك مـن أعمـال تحضيرية للجريمـة أو مـا يلي النتيجـة من أفعـال تستهدف إخفاء آثارهـا

(') Bouloc (B.): op.cit. n ${ }^{0} 14 \wedge$, p. 179 ; Pradel (J.): Tome I, Droit pénal

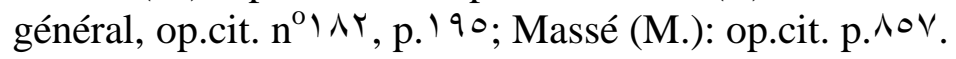
وبطبيعة الحال، يختص القانون الفرنسي وكذلك المحاكم الفرنسية بمحاكمة الفرنسي الذي

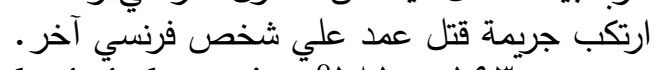

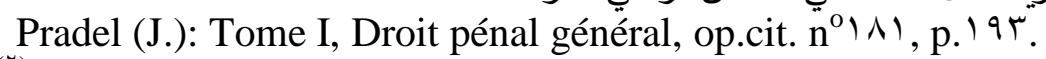

(r) Jeandidier (W.): Droit pénal général, Montchrestien, Paris, re éd. 1991, n⿳0101; Lombois (C.): op.cit. n⿳⺈9v, p.0.0.

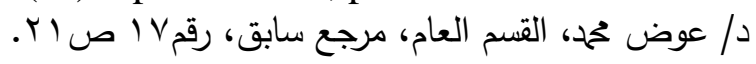


وإن اعتبرت في ذاتها جرائم مستقلة، فلا يدخل في الحسبان عند تحديد مكان وقوع الجريمة.

ثالثاً: اختلاف مكان المساهمة الجنائية عن مكان وقوع الجريمة: قد يساهم الجاني وهو في الخارج كفاعل أصلي أو كشريك في جريمة تتم في مصر •

ولا صعوبة بالنسبة إلي الفاعل الأصلي، إذ تعتبر الجريمـة - في جزء منها - قد ارتكبت في مصر ، وتقع تحت طائلة قانون العقوبات المصري إلـي كما بينا من قبل.

إنما تثور الصـوبة إذا اقتصـر الجاني وهو في الخـارج علي ممارسـة إحدي صـور الإشـتراك (التحريض أو الإتفـاق أو المسـاعدة). ففي هذه

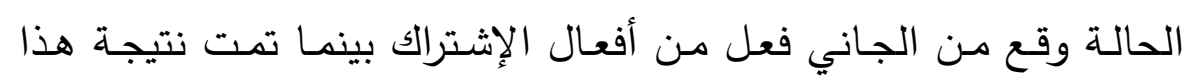

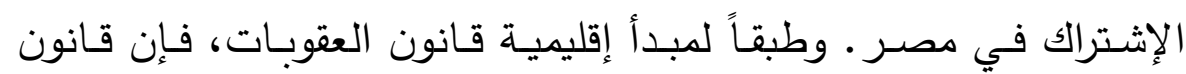
العقوبـات المصـري يسري علي أفعـال الإشتراك التي تمـت في الخـارج،

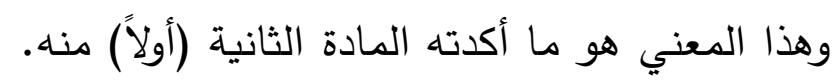

وقد يوحي ظاهر هذا النص أن المشرع قد أراد أن يضيف فرضـاً جديداً إلي مبدأ الإقليمية، بينما الحقيقة أن هذا الفرض ليس إلا تطبيقاً مباشراً

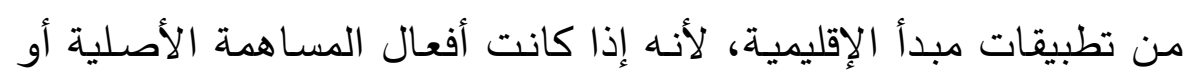

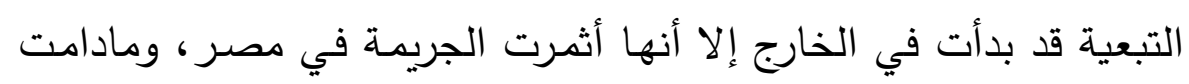
الجريمة قد وقعت في مصر، فإن القانون المصري يكون واجب التطبيق،

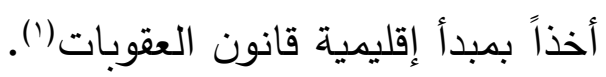

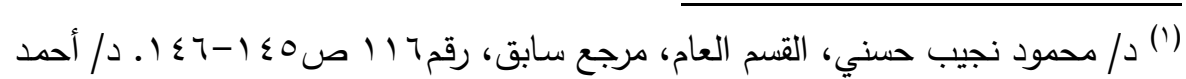

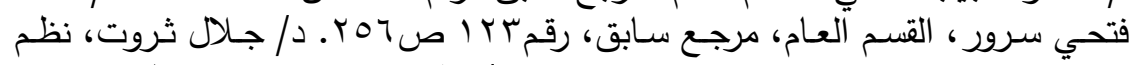

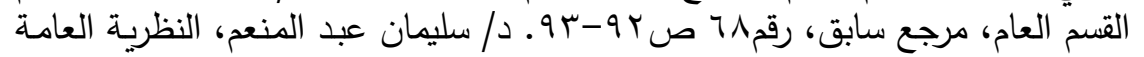

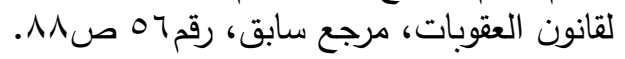


أمـا في الحالـة العكسية، أي حين يقدم الجـاني وهـو في مصـر علي المساهمة في جريمة تقع في الخارج، فلا يسري قانون العقوبات المصري إلا إذا كان الفعل الذي ارتكبه الجاني في مصر يخضـع بذاته لحكم هذا القانون بغض النظر عن النتيجة التي وقعت في الخارج. ولا يشـترط في الحـالات السـابقة أن يكـون الجـاني مصـرياً، فـالعبرة بطبيعة ما صدر منه وليس بجنسيته.

وطبقـاً للمـادة س ا | -ه مـن قـانون العقوبـات الفرنسـي يطبـق قـانون العقوبـات الفرنسي علي كل من ارتكب فعلاً في إقليم الجمهوريـة يجعله شريكاً في جناية أو جنحة وقعت في الخارج إذا كانت الجناية أو الجنحة

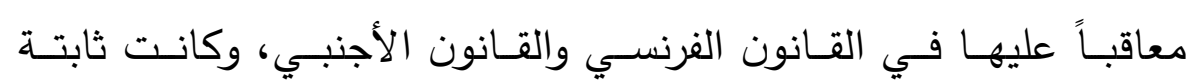
بمقتضي حكم نهائي صادر من القضاء الأجنبي('). من ذلك يتضـح أن المشرع الفرنسي يتطلب توافر ثلاثة شروط لتطبيق

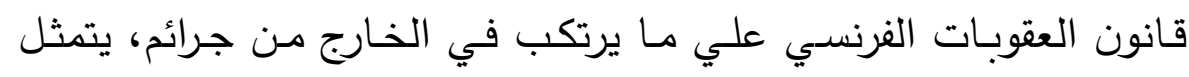
أولهها في أن تكون الواقعـة معاقباً عليها في القانون الأجنبي والقانون

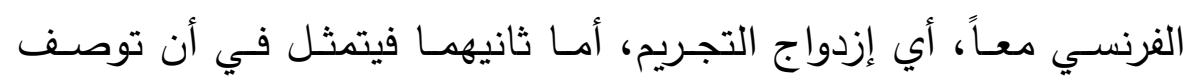

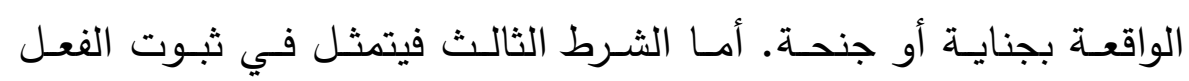

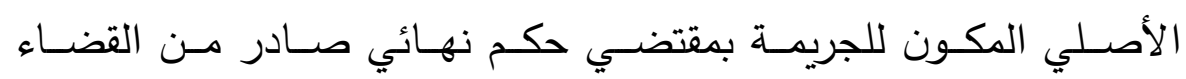

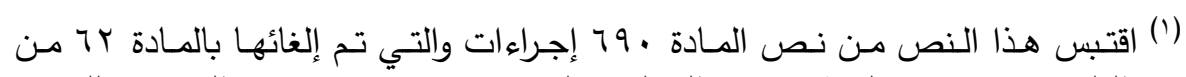

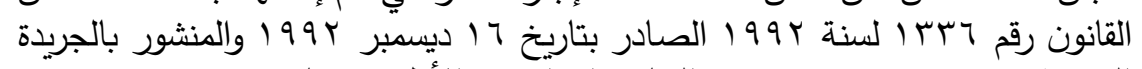

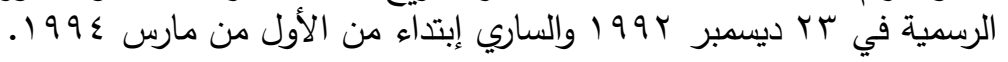

Fournier (A.): Complicité internationale et compétence des juridictions répressives françaises, Rev. crit. DIP (9४।, doctrine et chroniques, p. ${ }^{\Gamma l}$ et ss.; Le Calvez (J.): op.cit. p. r०v; Thiel (D.): op.cit. $n^{0} \circ \leqslant$, p. $₹$. Massé (M.): op.cit. p.^०१. En juris.: crim. $\uparrow$. fév. $199 \cdot$, B. $n^{\circ} \wedge \varepsilon ;$ D. 1991 , p. $r 90$, note A. Fournier. 
الأجنبي(') وعليه، فقد إعترف قانون العقوبات الفرنسي بالحجية السلبية

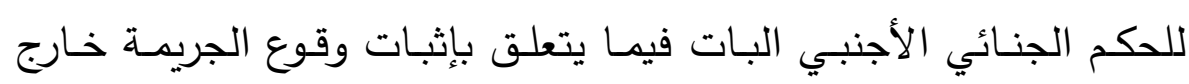

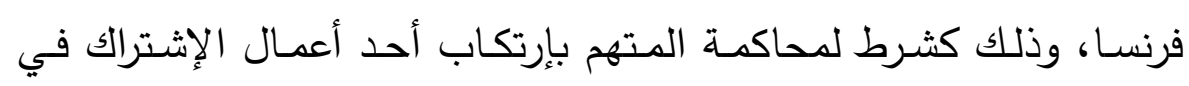
هذه الجريمة داخل فرنسا.

وبطبيعـة الحـال، إذا وقـع الفعـل الأصـلي في فرنسـا، فـإن المحساكم

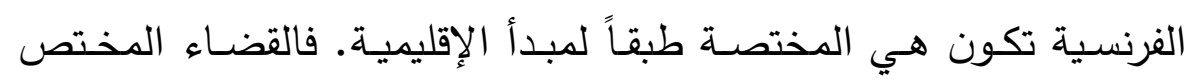

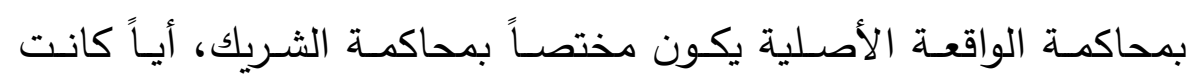
جنسيته، وأياً كان المكان الذي تمت فيه أعمال الإشتراك، داخل فرنسا لألها أو خارجها(؟). ولذلك قضـي بأن الجريمـة المرتكبـة علي الإقليم الفرنسي تمنح الإختصاص للقضاء الفرنسي بصدد الشركاء، حتي ولو كان هؤلاء يحملوا جنسية أجنبية، وتمت أعمال الإشتراك في الخارج("). ويري البعض(ء) أن موقف القانون المصري من إهمال أفعال المساهمة

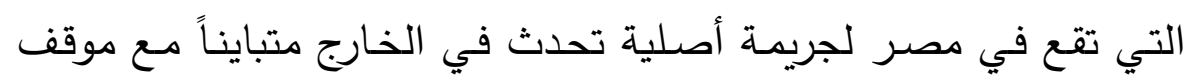
سميه الفرنسي. وهو أمر يمكن للمشرع المصري تداركه بتعديل تشريعي لاسيما وأن مثل هذا التعديل المرجو يتفق مـع ضـرورات مكافحة ظـاهرة الجريمـة عبر الوطنية التي يغلب أن تتوزع فيها الأدوار علي إقليم أكثر فئرون

(1) V. Crim. 1· fév. 1999, B. n ${ }^{\circ} 10$; D. 1999, p. ₹91, note A. Fournier; crim. $1 \cdot$ sép. $\uparrow \cdots \wedge$, Dr. pénal $r_{\cdots} \cdot 9^{\circ}$. voir aussi: Bigay (J.): Les dispositions nouvelles de compétence des juridictions françaises à l'égard des infractions commises à l'étranger, D. 19V7, chronique p. ${ }^{\circ}$. Thiel (D.): op.cit. ${ }^{\text {or }} \backslash 9$, p. $\ 11$.

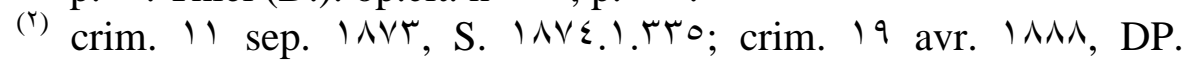

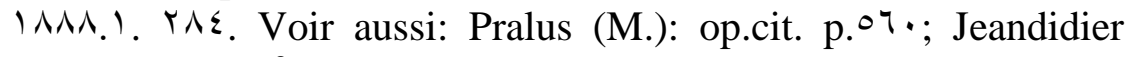
(W.): op.cit. $\mathrm{n}^{0} 101$; Massé (M.): op.cit. p.^09. Huet (A.) et Koering-Joulin (R.): op.cit. $n^{0} \backslash \leqslant 1$, p. ${ }^{r}$ q.

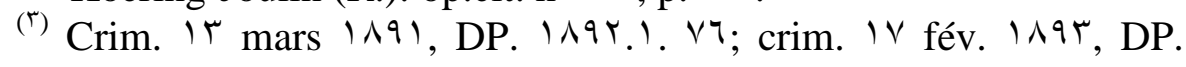

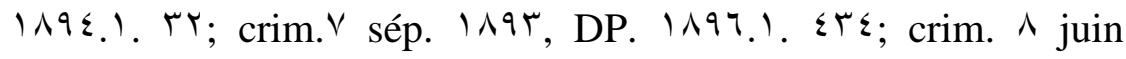
$191 \%$, DP. 191r. 1. $10 \leqslant$.

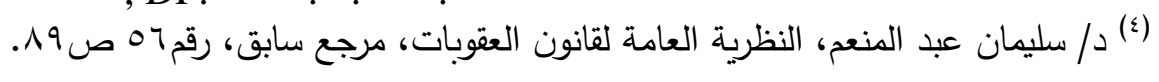


مـن دولـة. ويتجلي ذلك علي وجـه الخصـوص في مجـال جـرائم غسل

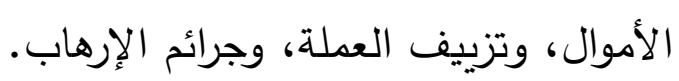

صور خاصة لمكان وقوع الجريمة:

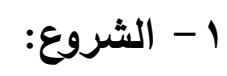

إذا وقف نشاط الجاني عند حد الشروع، ذهب رأي(') إلي أن جريمته تعتبر قد وقعت في الإقليم الذي ارتكب فيه الجاني نشاطه أي البدء في التنفيذ أو المكان الذي يريد تحقيق نتيجة نشاطه فيه.

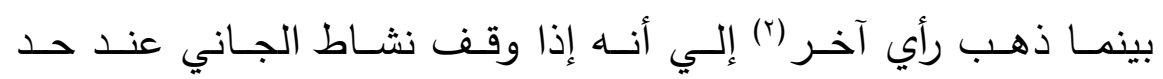
الشروع، فإن جريمته تعتبر قد وقعت في الإقليم الذي ارتكب فيه النشاط

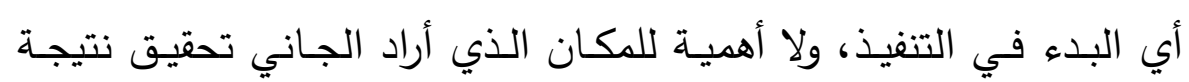
نشاطه فيه طالما أن هذه النتيجة لم تتحقق، وبالتالي لم يقع أي إخلال

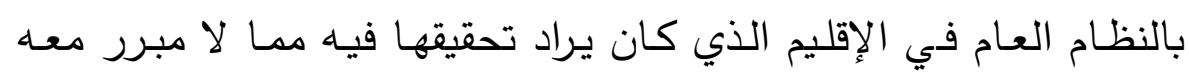
لإخضاع الشروع لقانون هذا الإقليم.

ونري أن هذا الإتجاه هو الأولي بالإتباع، خاصـةً مع إتساقه هـ المادة 1 اY إجراءات مصري والتي قضت بأنه في حالة الشروع تعتبر الجريمـة أنها وقعت في كل محل يقع فيه عمل من أعمال البدء في التنفيذ.

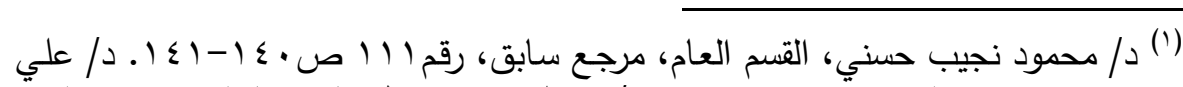

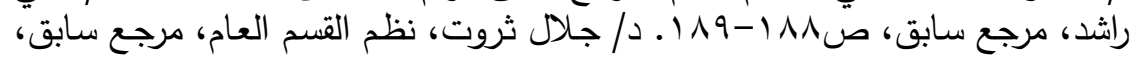

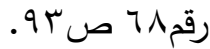

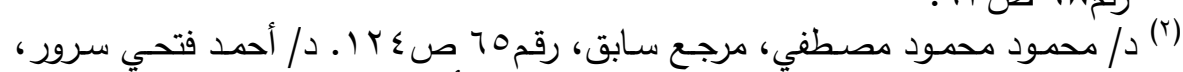

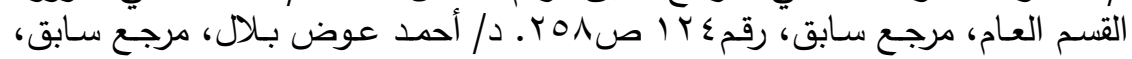

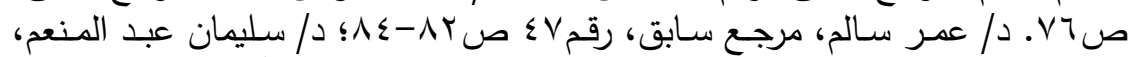

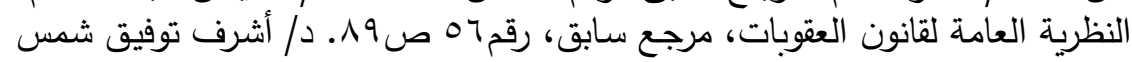

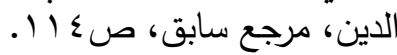

Crim. 11 avr. $19 \wedge \wedge$, B. $n^{0} \mid \leq \varepsilon$. Huet (A.) et Koering-Joulin (R.): op.cit. $\left.n^{0} \mid r\right)$, p. rIr. 


\section{r}

تتوافر أركان الجريمـة المستمرة في كل لحظة من لحظات استمرارها. ويقتضـي هذا الإستمرار الزمني امتداد نطاق إرتكابها الإقليمي إلي كل إقليم يحدث فيه هذا الإستمرار (').

فالركن المادي لهذه الجريمة ينطوي علي إستمرار زمني ومكاني في آن واحد.

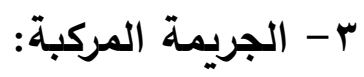

وهي الجريمـة التي يفترض القانون لوقوعها توافر أكثر من عمل ذي في

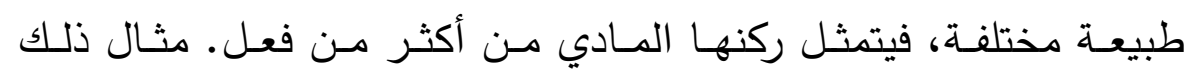

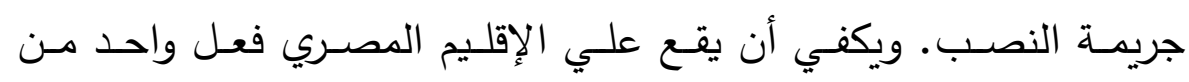
الأفعال المكونة لها لكي يسري القانون المصري علي الجريمة بأكملها.

$$
\text { ع - جريمة الإعتياد: }
$$

ثار التسـاؤل عن القـانون الواجب التطبيق إذا وقعت الأفعال المكونـة للإعتياد في أكثر من إقليم.

اختلف الفقه في الإجابة علي هذا التساؤل، فذهب رأي(') إلي أنسه إذا

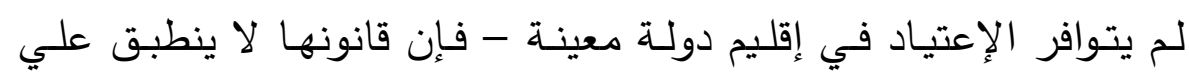

(') Bouloc (B.): op.cit. $n^{0} 17 \wedge$, p. 179 ; Pradel (J.): Tome I, Droit pénal

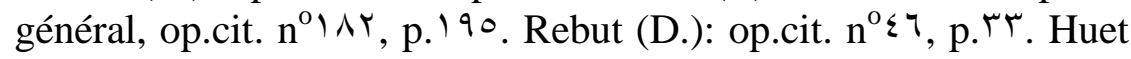
(A.) et Koering-Joulin (R.): op.cit. $n^{0} / r$, , p. ${ }^{1} / 0$. En Juris.: Pau,

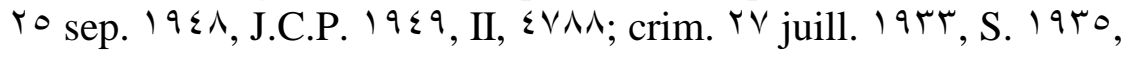
1, rᄉ.

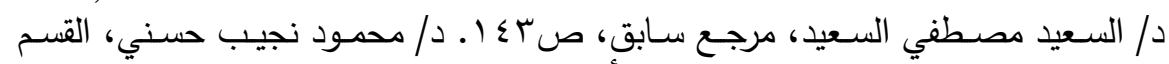

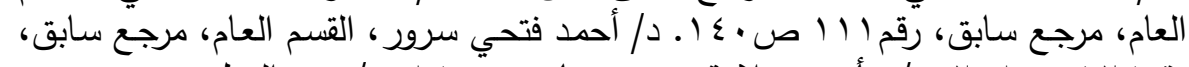

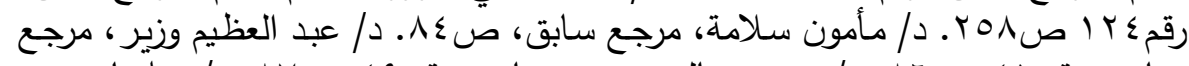

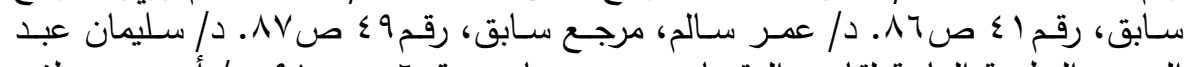

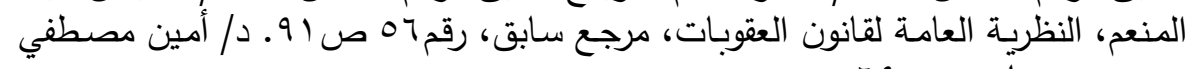

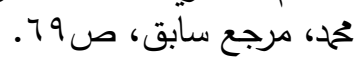


الجريمة، وأنه لا يجوز الإكتفاء بتوافر فعل واحد من أفعال الإعتياد في إقليم الدولة حتي يقال بإنطباق قانونها علي هذه الجريمة.

وذهب رأي آخر (ץ) إلي أنه يكفي أن يقع فعل واحد من أفعال الإعتياد في مصر بالإضـافة إلي الأفعال الأخري التي وقعت في الخـارج حتي إني

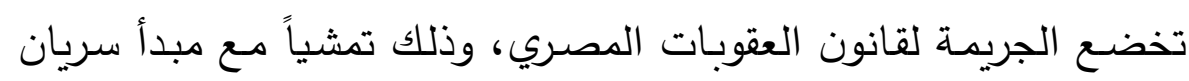
قانون العقوبات علي كل جريمة وقعت كلها أو بعضها في مصر (المادة

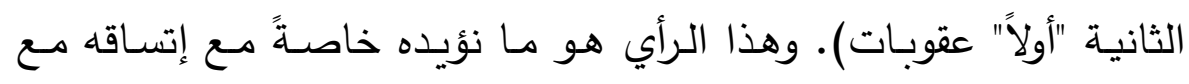

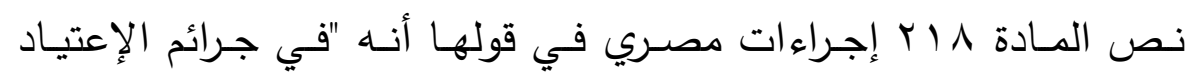

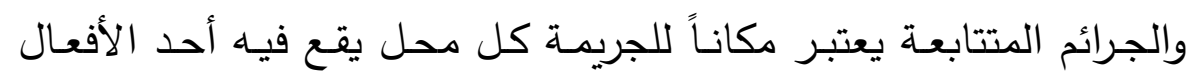

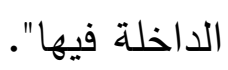

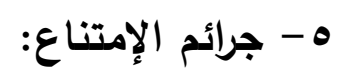

ثار التساؤل عن كيفية تحديد مكان إرتكاب جريمـة الإمتناع في حالة

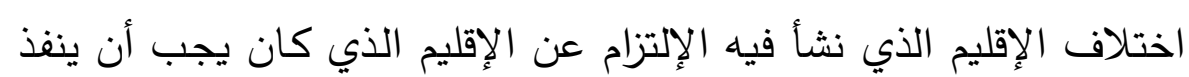
فيه الإلتزام فعلاً. ذهب رأي() إلي أن الجريمـة تعد واقعـة في أي من الإقليمين (الإقليم

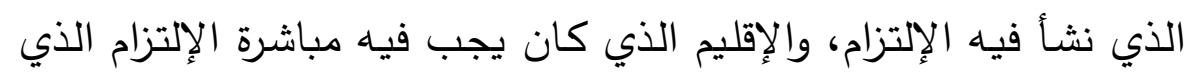
امتنع الجاني عن ادائه).

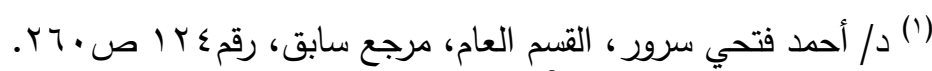

Huet (A.) et Koering-Joulin (R.): op.cit. $\left.n^{0} \mid r\right)$, p. $r i \varepsilon$. Lombois (C.): op.cit. n ${ }^{\circ} r V \cdot, p^{r} r \varepsilon$.

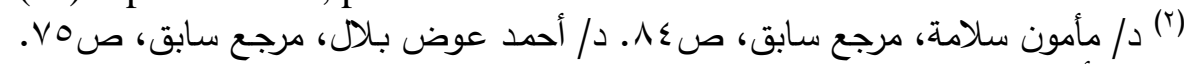

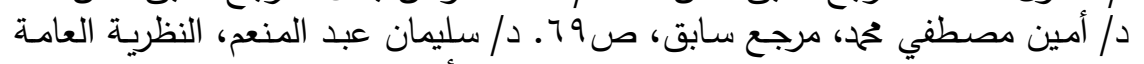

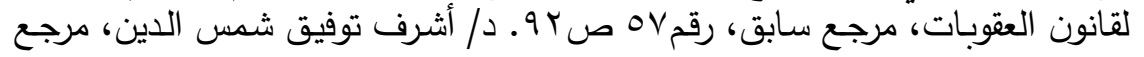

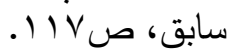

Bouloc (B.): op.cit. $n^{0} 141$, p. 179; Pradel (J.): Tome I, Droit pénal général, op.cit. n'^^r, p.190.

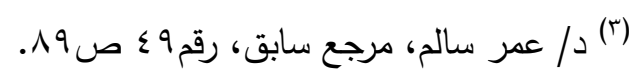




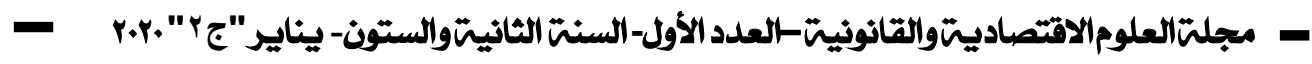

وذهـب رأي آخـر (') - وبحـق - إلـي أن مكـان وقـوع الجريمــة يتحـدد

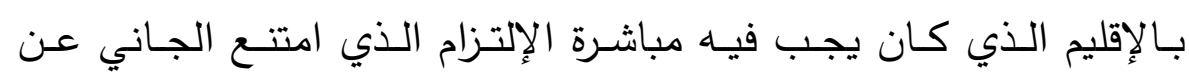

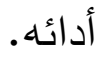

Lombois (C.): op.cit. $n^{\circ}{ }^{\circ} 09, p^{r} / r$; crim. rq mars 197r, B. n ${ }^{\circ} 10 r$;

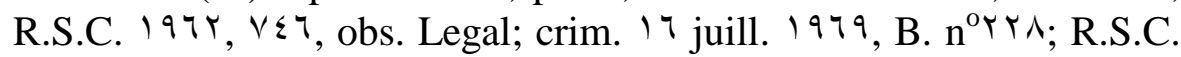
19V. 1.1. Obs. Levasseur.

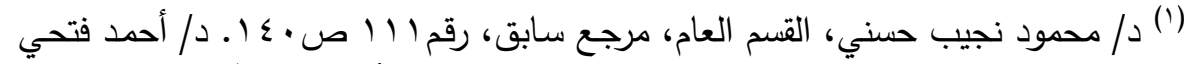

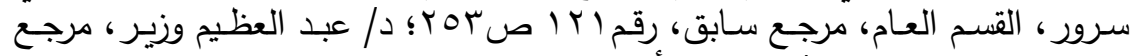

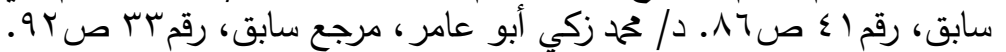

Rebut (D.): op.cit. $n^{0} \leqslant 0$, p.rr. crim. ${ }^{\top}$ juill. 1900, B. $n^{0} r \leqslant r$; crim. rV oct. 197r, B. nor 1 . 


\section{المبحث الثالث}

\section{خضوع الجريمة لقانون العقوبات الوطني}

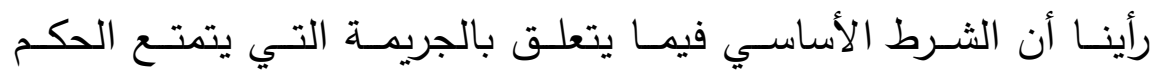

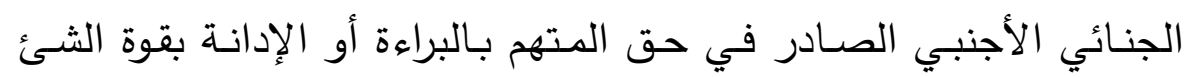

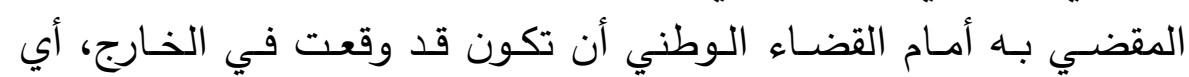

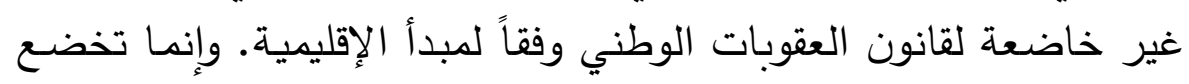

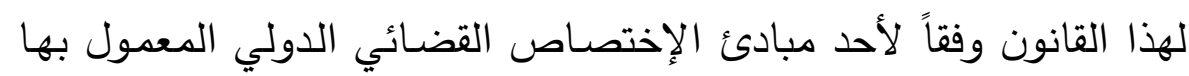

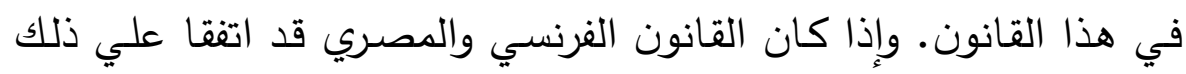

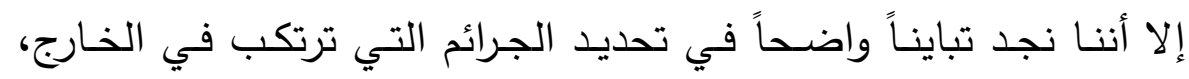

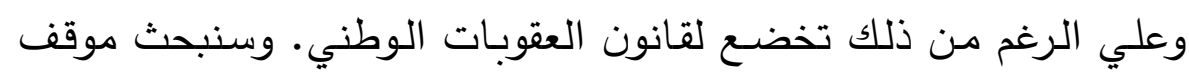
كل قانون في مطلب مستقل. 


\section{المطلب الأول \\ موقف القانون الفرنسي}

لم يقرر القانون الفرنسي الأخذ بالحجية السلبية للحكم الجنائي الأجنبي

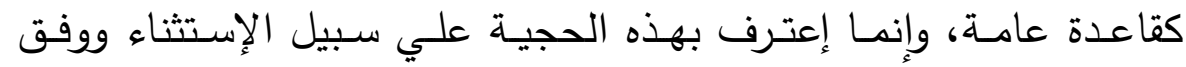

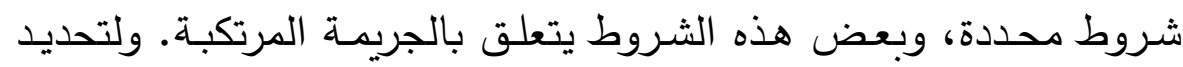

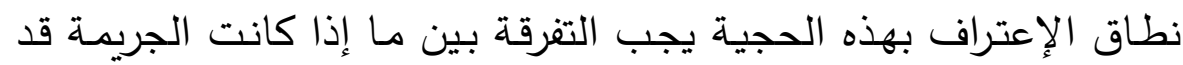
ارتكبت في إقليم الجمهورية أو ارتكبت في الخارج. 1- الجريمة المرتكبة داخل فرنسا:

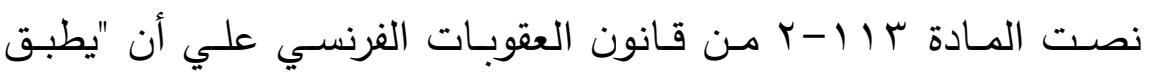
قـانون العقوبـات الفرنسـي علـي الجـرائم المرتكبـة في إقليم الجمهوريـة. وتعتبر الجريمـة قد ارتكبـت في إقليم الجمهوريـة إذا وقـع أحد الأفعـال المكونة لها في هذا الإقليم".

وعليـه، إذا ارتكبــت الجريمـة في الإقلـيم الفرنسـي وخضـعت بالتـالي

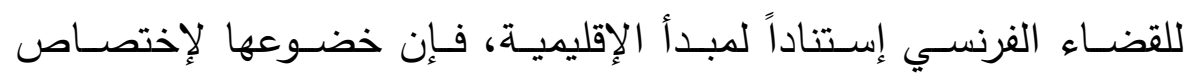

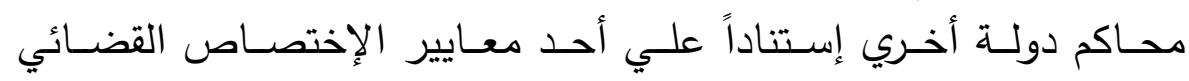

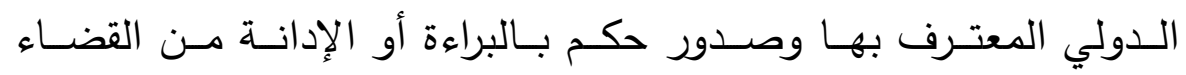

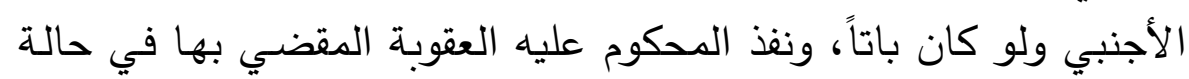

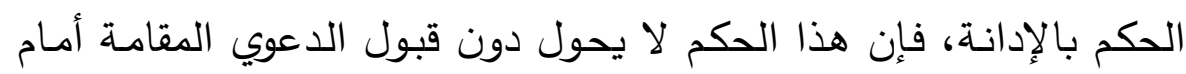

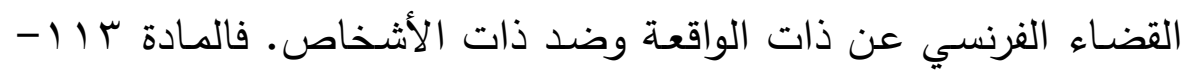
9 من قانون العقوبات الفرنسي قد حددت الحالات التي يحوز فيها الحكم

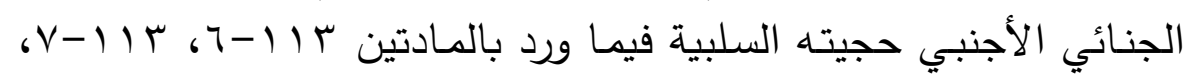

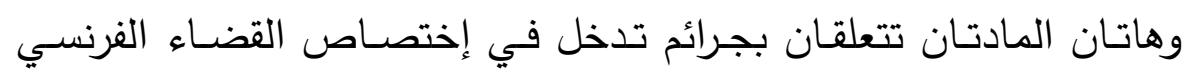
إستناداً إلي معايير أخري غير معيار الإقليمية. r- الجريمة المرتكبة خارج فرنسا: 
إذا كان المشرع الفرنسي قد أقر - من حيث المبدأ - الحجية السلبية

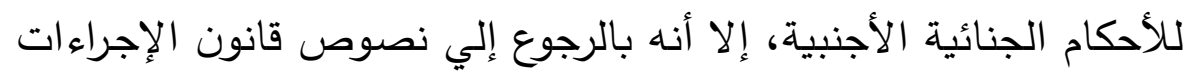

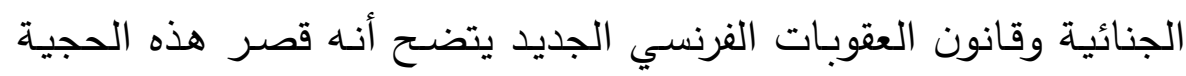
علي الجرائم التي ترتكب في الخـارج وتخضـع للقضــاء الفرنسي إستـناداً إلي مبدأ الشخصية في وجهيه الإيجابي والسلبي ومبدأ العالمية، ولم يمد

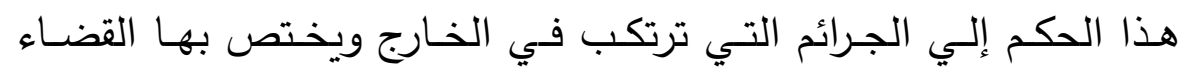
الفرنسي عملاً بمبدأ العينية، وذلك علي النحو التالي: ترني

أولاً: الجـرائم التـي يخـتص بنظرهـا القضــاء الفرنسـي طبقــاً لمبـــأ الشخصية الإيجابية: النائ

نظمت المادة r 11 -7 عقوبات مسألة سريان قانون العقوبـات الفرنسي علي الجرائم المرتكبة في الخارج من فرنسي ويختص تبعاً لذلك القضاء

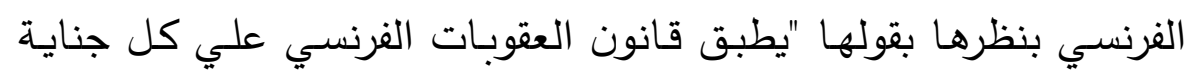

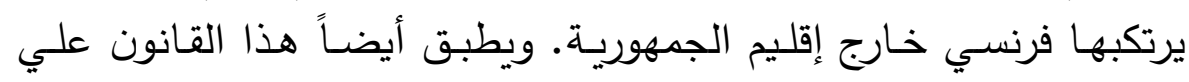

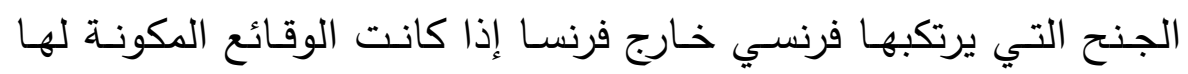

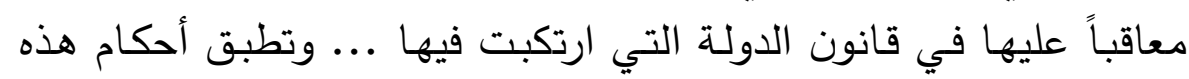

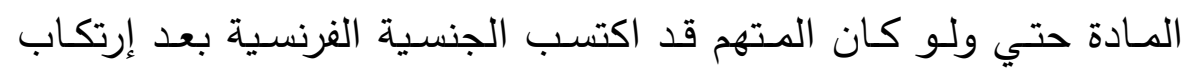
الواقعة المنسوبة إليه".

وإذا كانت الجرائم تقسم وفقاً لجسامتها إلي جنايات وجنح ومخالفـات

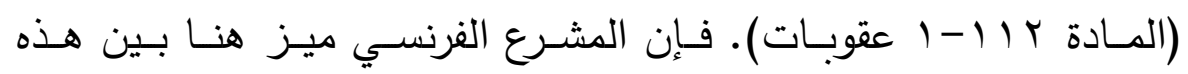

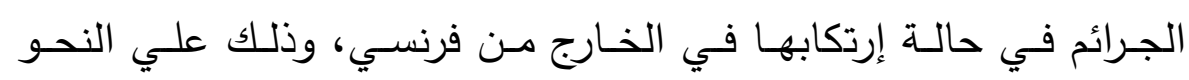
الآتي:

أ- في حالـة كـون الجربمــة المرتكبـة في الخـارج تشكل جنايـة طبقـاً للقانون الفرنسي: 
إذا ارتكـب فرنسـي جريمــة فـي الخـارج تثـكل جنايـة طبقـاً للقـانون

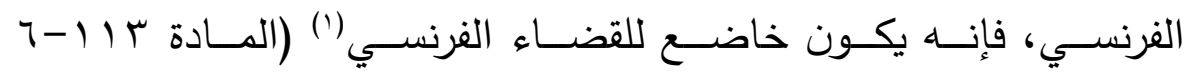

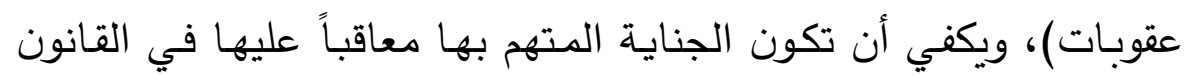

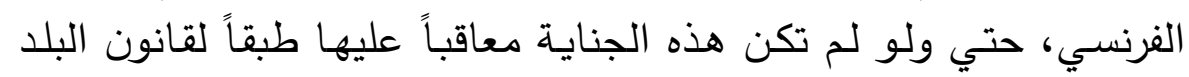

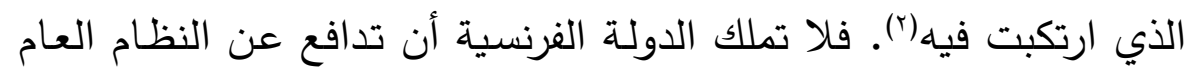

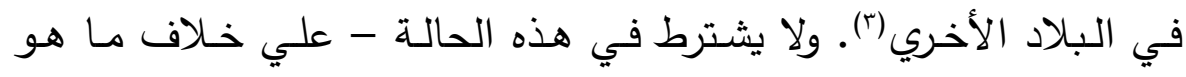

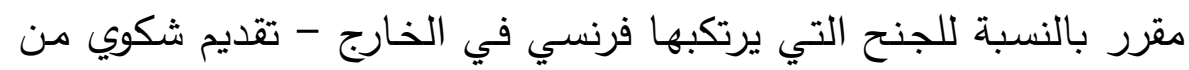

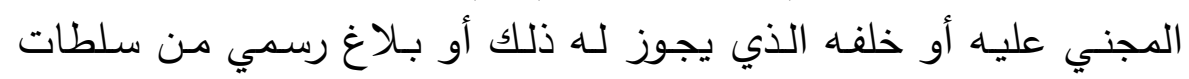
الدولة التي ارتكبت الجريمة علي إقليمها(غ).

فإذا كانت الجناية معاقب عليها في الخارج وحوكم الفرنسي عنها طبقاً

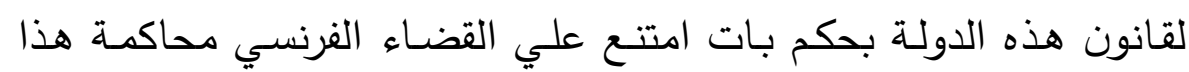

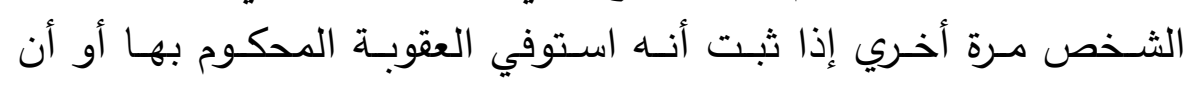

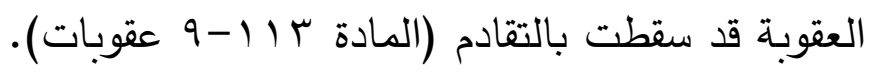

ويلاحظظ أن قـانون العقوبـات الفرنسـي يسـري علـي الثـخص الأجنبـي

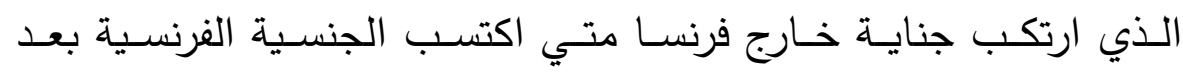

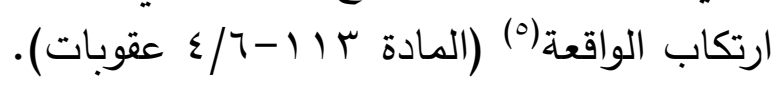

بَ- في حالـة كون الجربمـة المرتكبـة في الخـارج تشـكل جنحـة طبقـاً للقانون الفرنسي:

(') Stefani (G.), Levasseur (G.) et Bouloc (B.): procedure pénale, Dalloz, Paris, $r \cdots \wedge, r)^{\mathrm{e}}$ edition, $\mathrm{n}^{\mathrm{o}}$ or $\cdot$, p. $\leqslant 9 r$.

ويقع علي عاتق النيابة العامة إثبات توافر الجنسية الفرنسية للمدعي عليه.

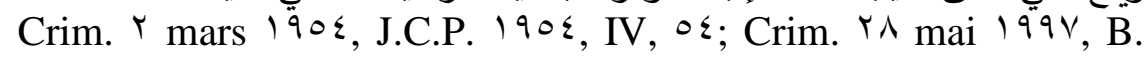
$\mathrm{n}^{\text {or }}$.

${ }^{(\top)} \operatorname{Bigay}\left(\right.$ J.): op.cit. p. ${ }^{\circ 1}$.

(r) Pradel (J.): Tome I, Droit pénal général, op.cit. $n^{0}$ ११५, p. ${ }^{r} \cdot r$. Rebut (D.): op.cit. $n^{0} \backslash r \mathrm{r}$, p.Vฯ.

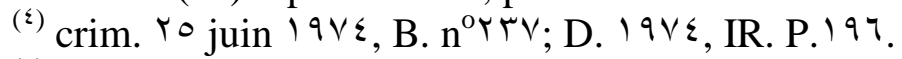

${ }^{\circ}$ crim. ${ }^{\circ}$ dec. $197 \leqslant$, J.C.P. 1970. II. I $\leqslant \leqslant 7$, note Aymond; B. $n^{0} r \varepsilon \vee$. 
لا يختص القضـاء الفرنسي بنظر الواقعة التي ترتكب من فرنسي في

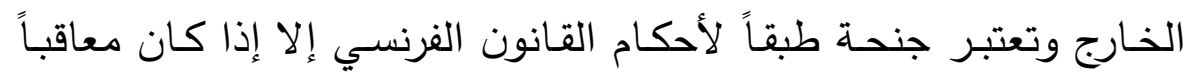

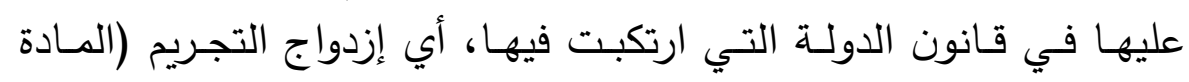

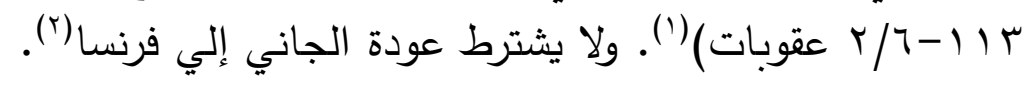

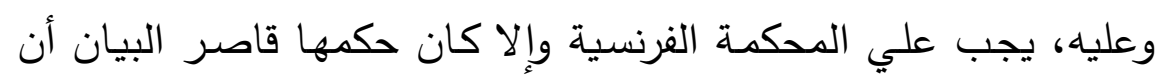
تشير إلي القانون الجنائي الأجنبي في حكمها، وأن الواقعة التي يحاكم

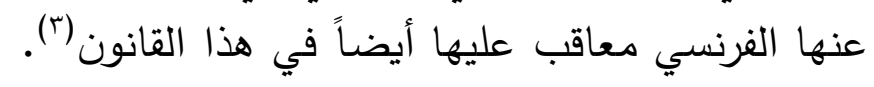

وتفسير القانون الأجنبي مسألة موضوعية غير خاضعة لرقابة محكمة

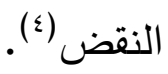

ج- في حالـة كون الجربمـة المرتكبـة في الخـارج تشكل مخالفـة طبقاً للقانون الفرنسي:

إذا ارتكب مواطن فرنسي جريمـة ما في الخارج في دولة أجنبية تشكل

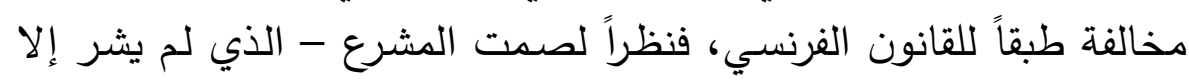
للجنايات والجنح فقط - فلا تختص المحاكم الفرنسية بمحاكمته (').

(') Colmar $r$ l juillet 190., R.S.C. 190., o9r, obs. Magnol; Gaz.Pal. 190., r, 119; crim. rv nov. 1941, B. nor19; Paris, $r \leq$ oct. 1919, Gaz.Pal. 199. Y.V. 7 ; crim. $r \varepsilon$ sép. 1997, Gaz.Pal. 199V. I, chron. crim. ro. En doctrine: Fournier (A.): Aperçu critique du principe de double incrimination en droit pénal international, in. "Le droit et les droits", Mélanges dédiés à Bernard Bouloc, vol. ', Paris, Dalloz, p. rrr; Bigay (J.): op.cit. p. ${ }^{\circ 1}$. Thiel (D.): op.cit. n ${ }^{\circ}$ \% ,

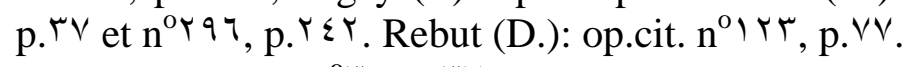

(५) Thiel (D.): op.cit. $n^{\circ}{ }^{\circ}$, p. p. ${ }^{r}$.

(r) Paris, $r \leq$ oct. $19 \wedge 9$, Gaz.Pal. 199., $r, \vee \cdot\urcorner$, note Marchi; crim. IV

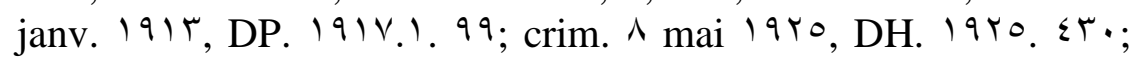
crim. 19 mai 19V1, B. n ${ }^{\text {I }} 7 \varepsilon$; J.C.P. 19Vr. II. 179 $19 \vee$, note Vitu; crim. 7 mars $19 \wedge \varepsilon$, B. $n^{\circ 9} \cdot$; crim. $\uparrow \vee$ juin $19 \wedge \varepsilon$, B. no ${ }^{\circ} \wedge \varepsilon ;$ crim. 1. oct. 1911, B. norrl; crim. 9 nov. 1911, B. n ${ }^{\circ} 410$; Crim. 14 mai $r \cdot 1 \cdot$, B. n ${ }^{0}$ r 19 .

(घ) crim. Ir nov. $199 \mathrm{~V}, \mathrm{~B} . \mathrm{n}^{\mathrm{o}} \mathrm{r} \mathrm{r}$. 
ثانيـاً: الجـرائم التـي يخـتص بنظرهـا القضـاء الفرنسـي طبقـاً لمبــأ الشخصية السلبية:

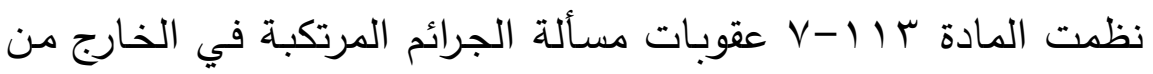
أجنبي أو فرنسي ضد شخص يحمل الجنسية الفرنسية، وذلك في قولها

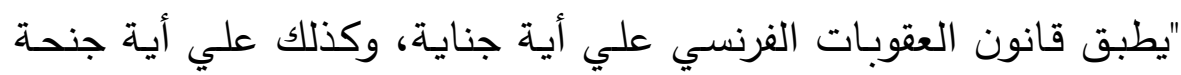

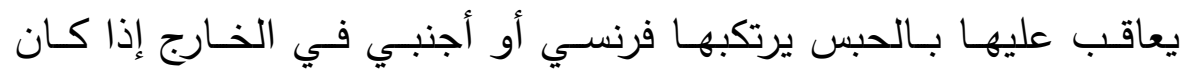
المجني عليه فرنسياً لحظة ارتكاب الجريمة".

ولتطبيق هذه المـادة اشـترط المشرع الفرنسي أن يكون المجني عليـه

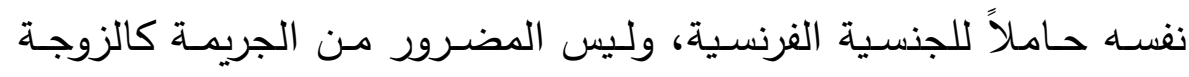
والأولاد. وتطبيقاً لذلك: قضـي بعدم إختصاص القضـاء الفرنسي بالجناية

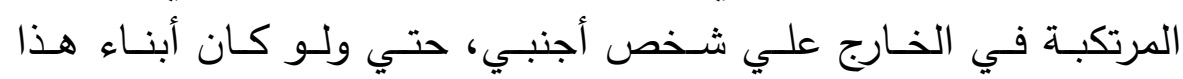
الشخص أو زوجته يحملون الجنسية الفرنسية(؟).

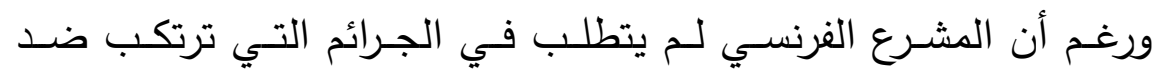

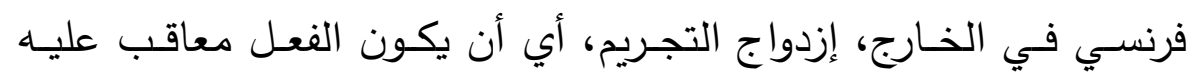

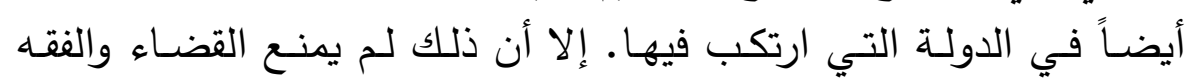
الفرنسي من اشترطه(r).

وطبقاً للمادة س | (-9 عقوبات، لا تقام الدعوي الجنائية ضد الشخص،

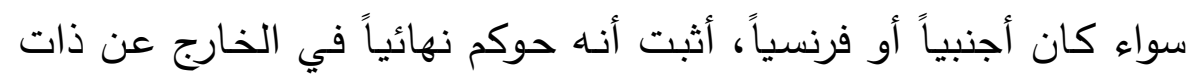

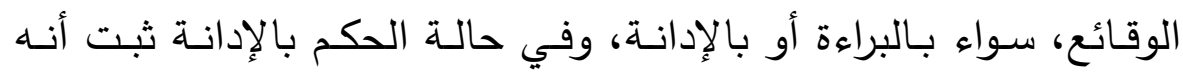

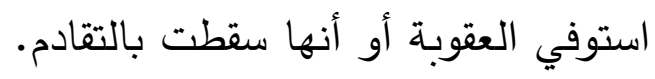

(') Stefani (G.), Levasseur (G.) et Bouloc (B.): op.cit. no orr, p. ะ१r; Pradel (J.): Tome I, Droit pénal général, op.cit. $n^{0} \backslash 9 \leqslant$, p. ${ }^{r} r$. Thiel (D.): op.cit. $n^{0} \leqslant q, p . \leqslant 7$. Rebut (D.): op.cit. $n^{0} \backslash r \cdot$, p. $v^{\prime}$.

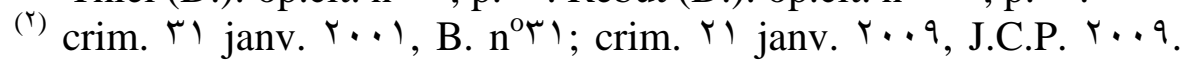
IV. ITrV.

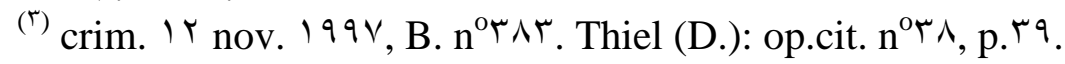


وفي جميع الأحوال، لا تقام الدعوي الجنائية إلا بنـاء علي طلب من

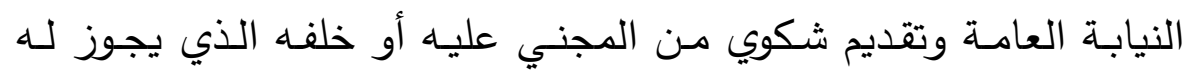
ذلك أو عن طريق بلاغ رسمي من سلطات الدولة التي وقع الفعل علي

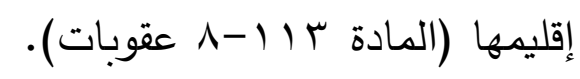

ثالثـاً: الجـرائم التـي يختص بنظرهـا القضـاء الفرنسـي طبقـاً لمبــأ العالمية:

نصـ المـادة 1119-1 إجراءات علي أن "بالتطبيق للإتفاقيات الدوليـة

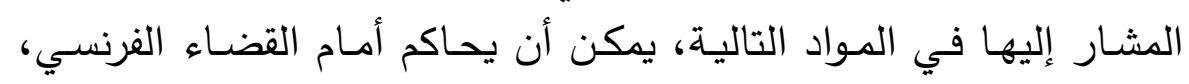

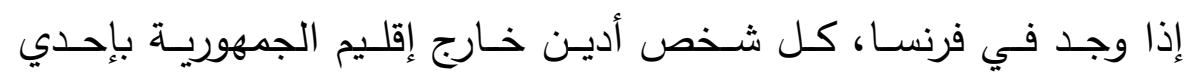

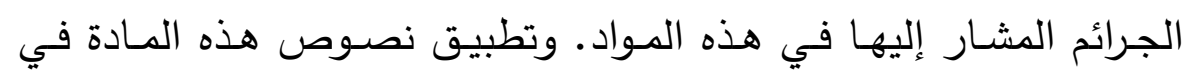

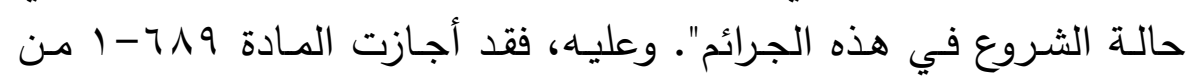

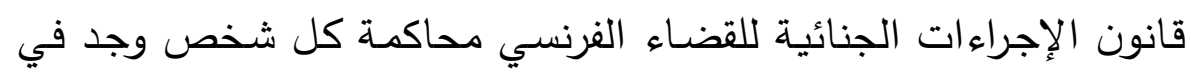

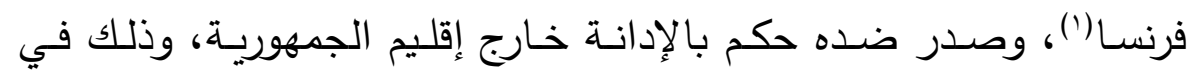

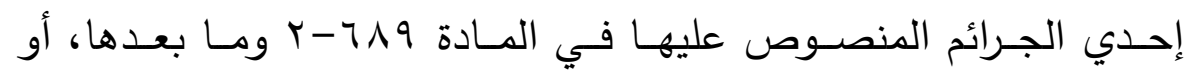
الشروع فيها إذا كان الشروع معاقباً عليه.

$$
\text { والجرائم التي أشارت إليها هذه المادة هي: }
$$

1- جرائم التعذيب والمعاملـة غير الإنسـانية التي نصت عليها إتفاقية

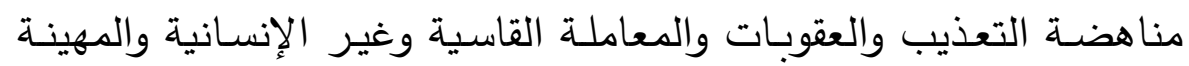

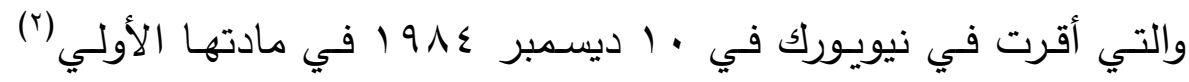

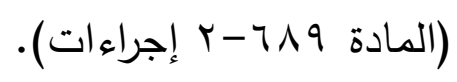

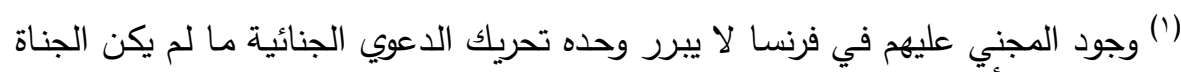

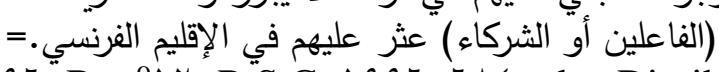

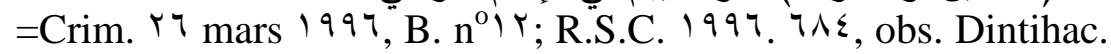
Voir aussi: Carreau (D.): La compétence universelle au regard du droit international, in. "Les droits et le droit", Mélanges dédiés à

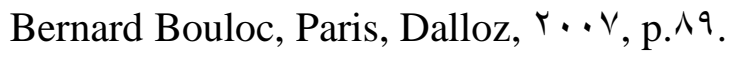

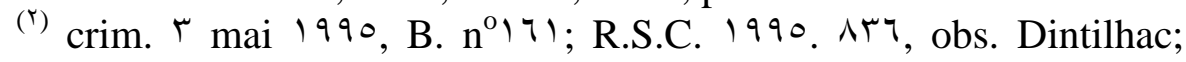
crim. 7 janv. 1991, B. $n^{\circ}$; R.S.C. 1991. ^rv, obs. M. Massé; 
r- جرائم الإرهاب التي نصت عليها الإتفاقيـة الأوروبية الموقعة في

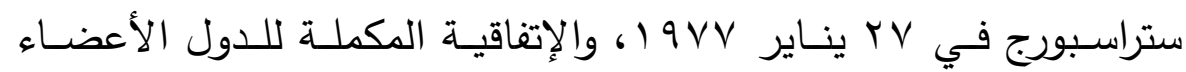

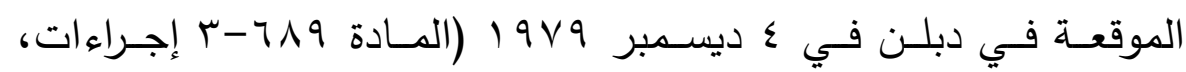

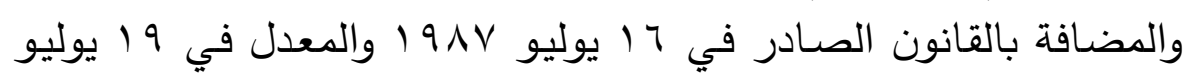
.$(1994$

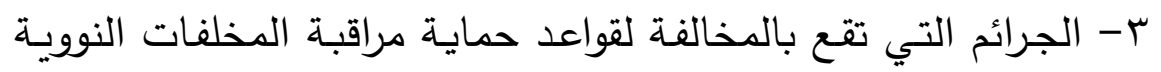

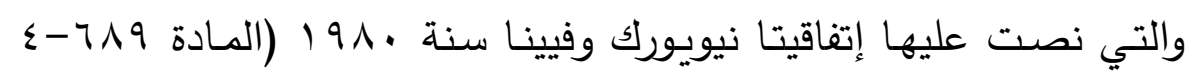

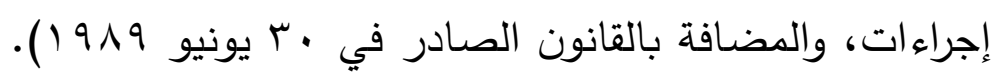

ع - الجنايات والجنح التي تقع علي أمن الملاحة البحرية ووسائل النقل

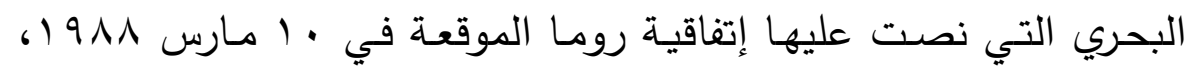

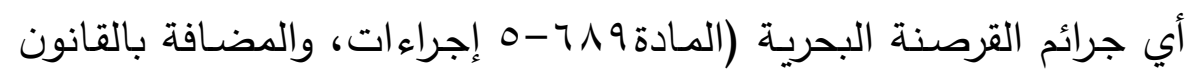

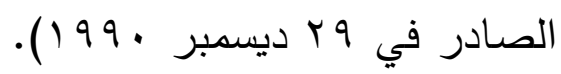

ه- تطبيقـاً لإتفاقيـة العقـاب علـي جـرائم إختطـاف الطـائرات (جـرائم

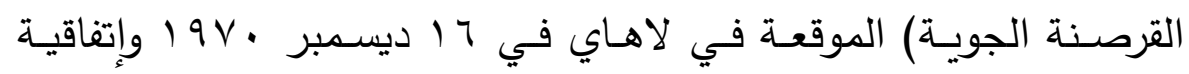

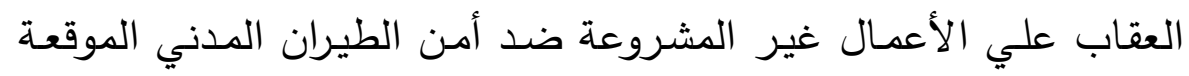

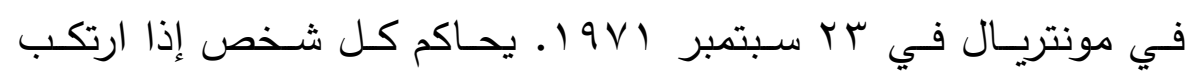

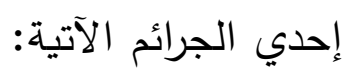

أ- إذا خطف طـائرة غير مسـلة في فرنسـا أو إرتكب أي فعل آخر يشكل تهديد للمسافرين أو للطاقم.

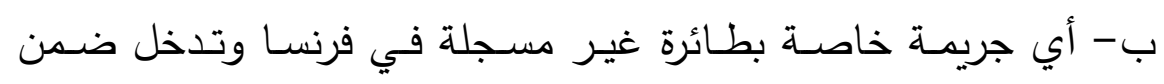

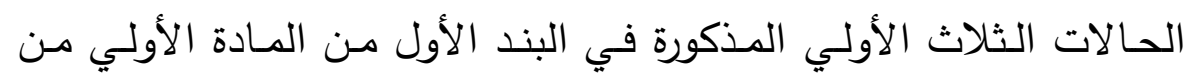

J.C.P. 1991. II. 1.10^, note Roulot; D. r..., somm. ro, obs. Y. Mayaud; crim. $r$ oct. $r \cdots r$, B. $n^{0} 190$; Rev. crit. DIP. $r \cdots r, p$. $r \cdot q$, note H. Matsopoulou; crim. 1· janv. $r \cdot . \vee, B . n^{0} \vee$; D. $r \cdots \vee$. r.॰ , obs. Girault; R.S.C. r..v. o r, obs. Giudicelli; AJ. Pénal r... . IA . 
إتفاقيـة العقاب علي الأعمـال غير المشـروعة ضـد أمن الطيران المدني

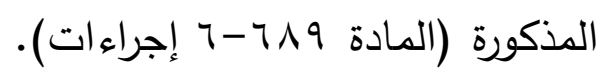

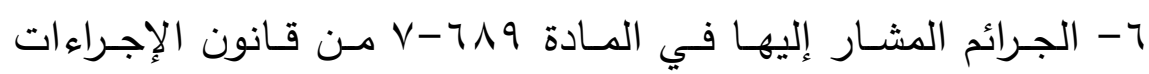

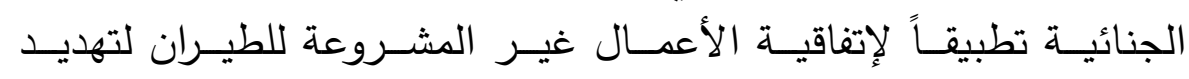

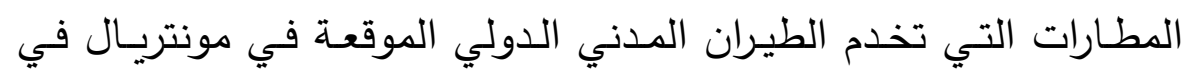

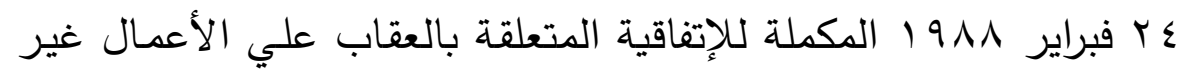

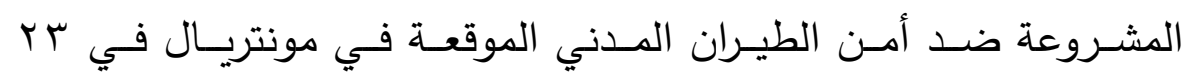

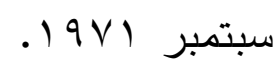

V- الجـرائم الخاصـة بحمايـة المصـالح الماليـة للمجتمعـات الأوروبيـة

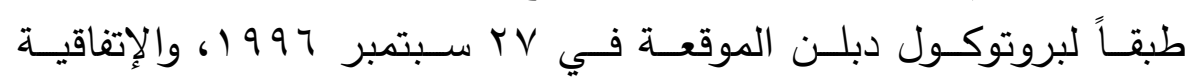

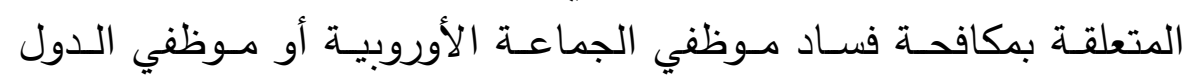

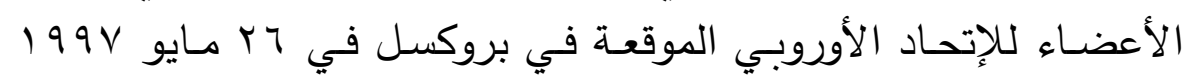

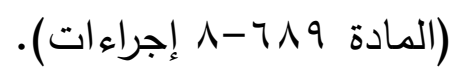

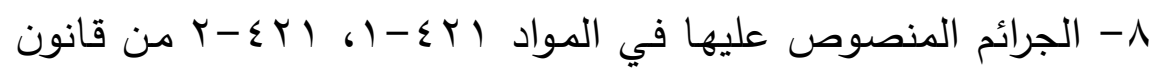

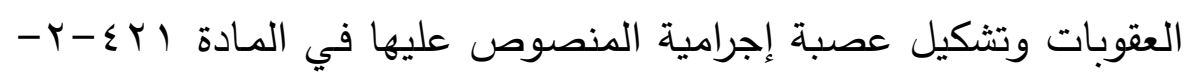

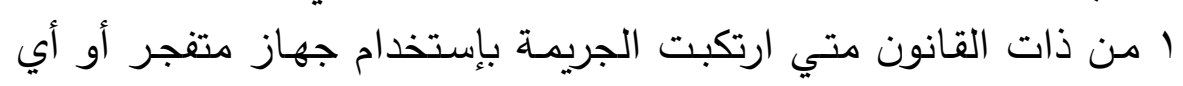

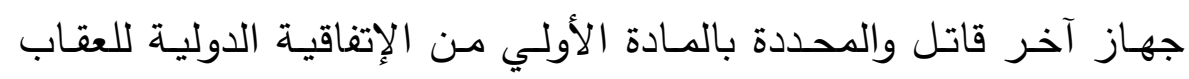

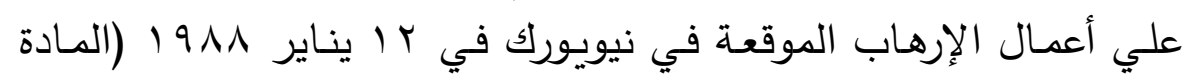

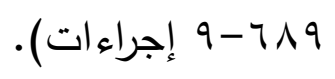

9- الجرائم المالية المتعلقة بأعمال الإرهاب المعرفة بالمادة الثانية من

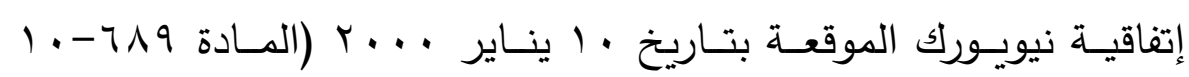

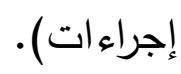

• 1- الجرائم التي تدخل في إختصـاص المحكمة الجنائية الدولية متي

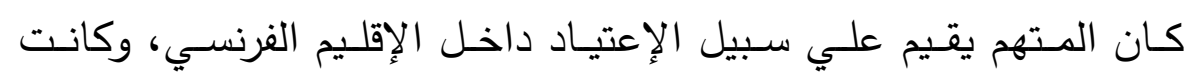

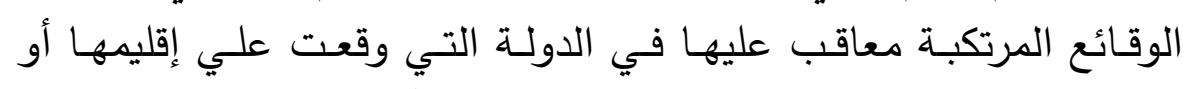
كانت الدولـة التي يحمل المـتهم جنسيتها طرفاً في الإتفاقيـة المذكورة. 
ويشـترط للمحاكمـة أن تخـتص النيابــة العامــة وحـدها برفـع الـدعوي

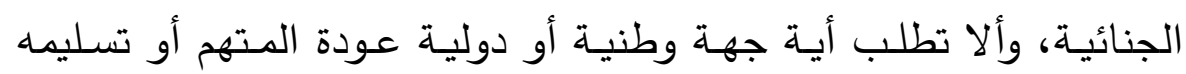

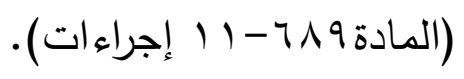

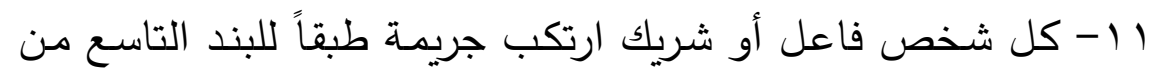

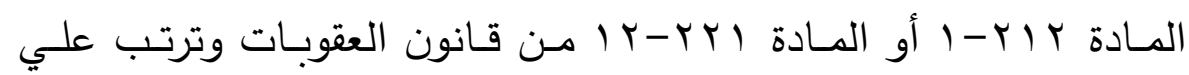

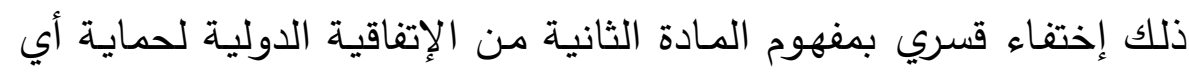

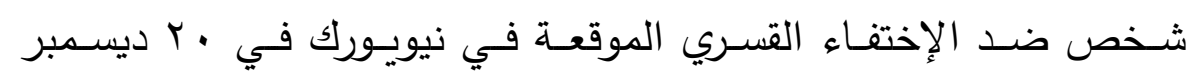

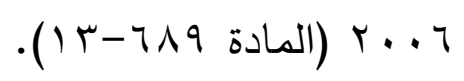

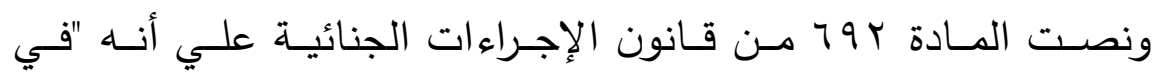

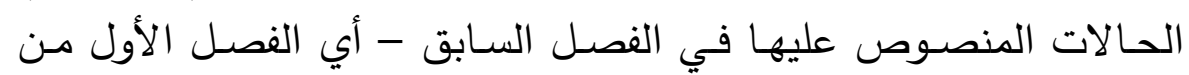

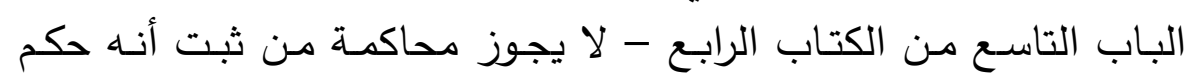

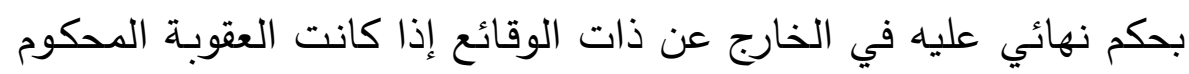

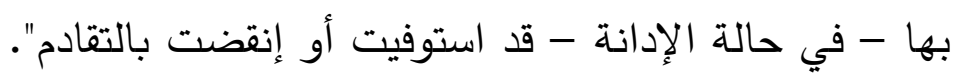

والجـرائم المشــار إليهـا سـابقاً تخضــع لإختصــاص المحـاكم الفرنسـية

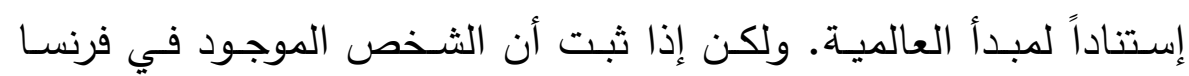
والذي ألقي القبض عليه فيها، قد حوكم في الخارج بحكم نهائي، وفي إلي إني

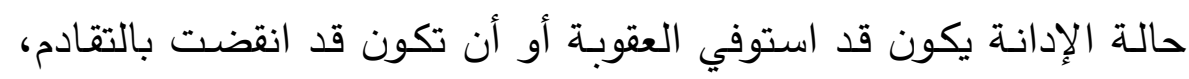
فإنه يمتنع علي القضاء الفرنسي محاكمته مرة أخري أمامها.

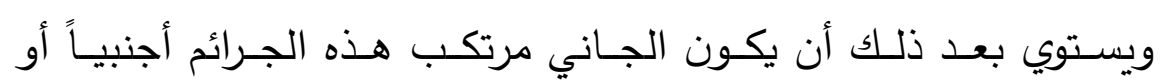

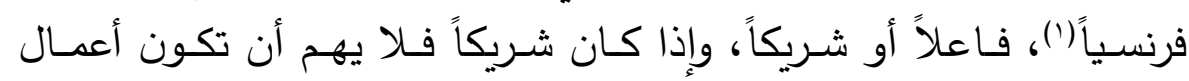
الإشتراك قد ارتكبت في فرنسا أو في الخارج.

رابعـاً: الجـرائم التـي يخـتص بنظرهـا القضــاء الفرنسـي طبقـاً لمبــأ

(1) crim. rr mai $199 \vee$, B. n ${ }^{\circ} 191$. 
نصــت المـادة r|1 1- • 1 عقوبـات علـي أن "يطبـق قـانون العقوبـات

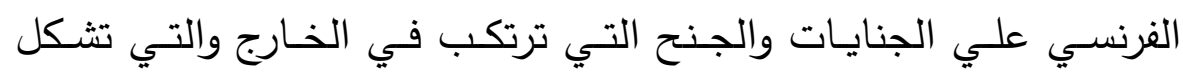
إعتداء علي المصالح الأساسية للأمسة المنصوص عليها في الباب الأول فئرل

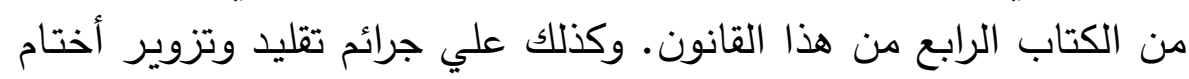

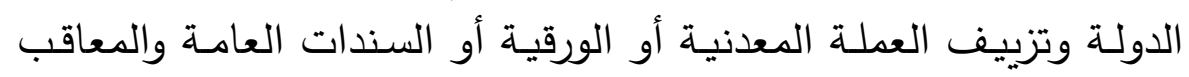
عليها بمقتضي المواد

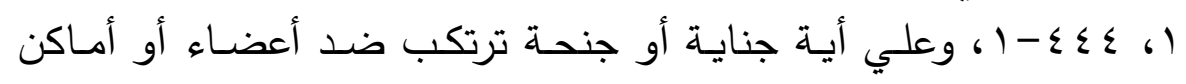

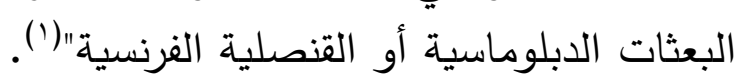

ويستوي في هذه الجرائم أن يكون الجاني فرنسياً أو أجنبياً. كما يستوي

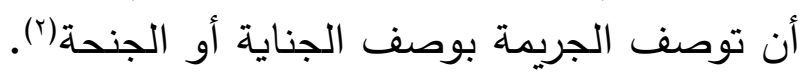

ونخلص مما سبق أن المشرع الفرنسي إعترف بالحجية السلبية للحكم الجنائي الأجنبي في ثلاث حالات فقط، وهي:

1- الحالات المنصوص عليها في المادة با |1-7 من قانون العقوبات

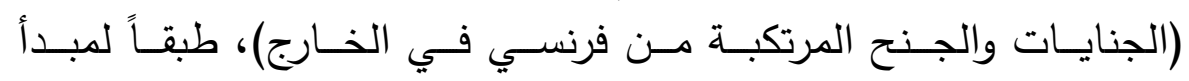
الشخصية الإيجابية.

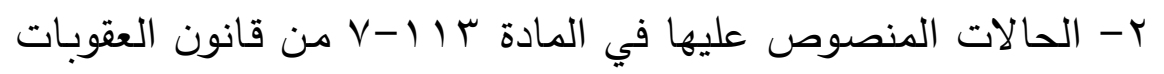

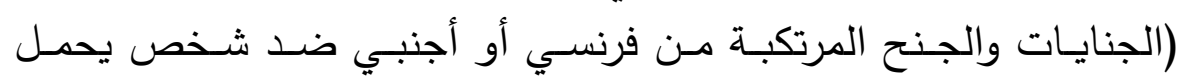
الجنسية الفرنسية)، طبقاً لمبدأ الثخصية الكية السلبية.

(') وهي ذات المادة ع 79 من قانون الإجراءات الجنائية، قبل إلغائها.

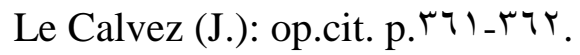

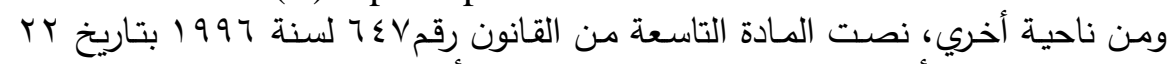

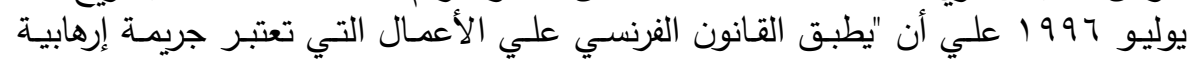

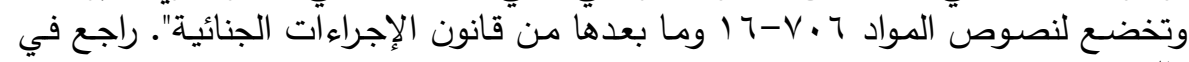
ذلك:

crim. o juin 1997, B. n ${ }^{\circ} r q$; R.S.C. 199v, p. 101, obs. Dintilhac; crim. $r \varepsilon$ sép. 199^, B. norrs.

(r) Stefani (G.), Levasseur (G.) et Bouloc (B.): op.cit. n ${ }^{\circ}$ rr , p. $\leqslant q$;

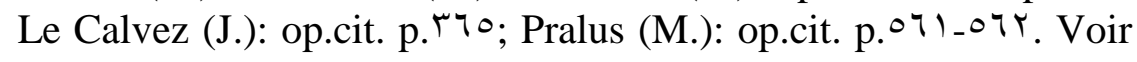
aussi: crim. $r \wedge$ juill. 1900 , J.C.P. 1900 . II. $\wedge \vee \leqslant \wedge$. 
r- الحالات المنصوص عليها في الفصل الأول من الباب التاسع من

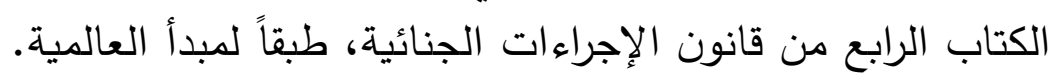

وبالتالي، لا يعترف المشرع الفرنسي بالحجية السلبية للأحكام الجنائية

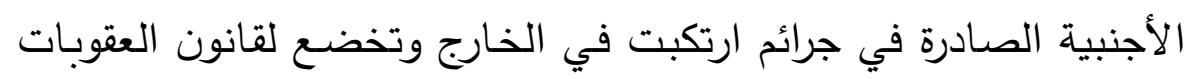

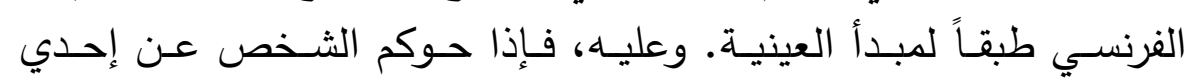

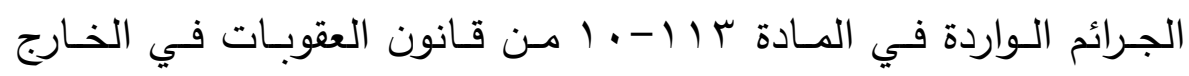

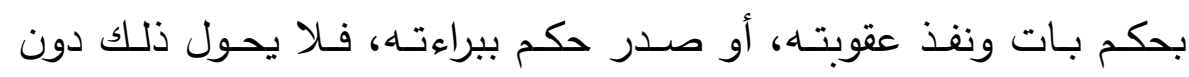

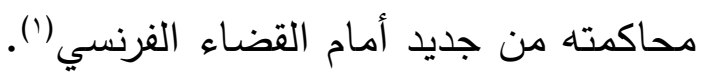

(1) Thiel (D.): op.cit. $n^{\circ} \uparrow \wedge$, p. ${ }^{\top q}$. Desessard (L.): op.cit. p. ${ }^{9} 9$. Rebut (D.): op.cit. $n^{0} \backslash 1 \varepsilon$, p. $V Y-V T$.

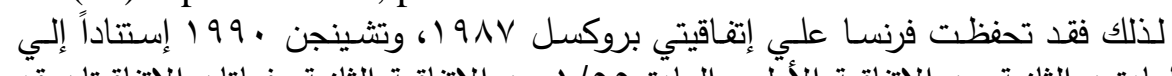

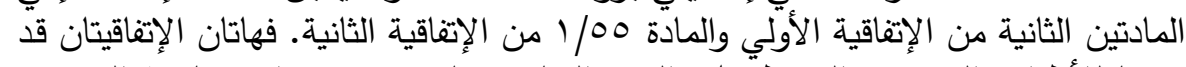

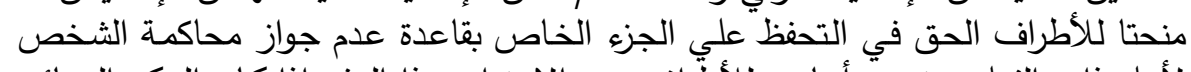

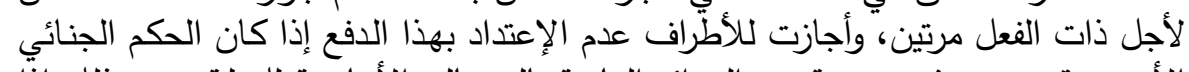

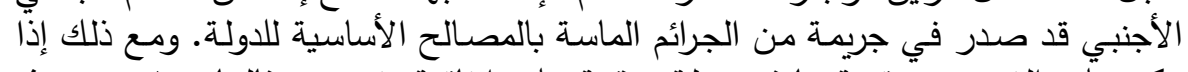

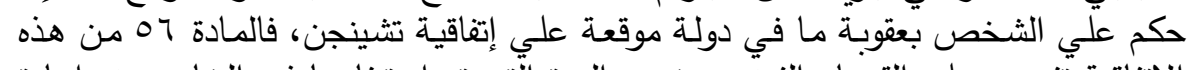

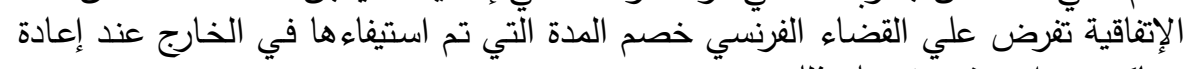
Rebut (D.): op.cit. n ${ }^{0} 11 \leqslant$, p. VY-VY. محاكمته. راجع في تثنصيل ذلك: 


\section{المطلب الثاني \\ موقف القانون المصري}

لــم يقـرر القـانون المصـري الأخـذ بالحجيــة السـلبية للحكـم الجنـائي الأجنبي كقاعدة عامـة، وإنما إعترف بهذه الحجية علي سبيل الإحس الإستثناء ووفق شـروط محددة، وبعـض هذه الشـروط يتعلق بالجريمـة المرتكبـة.

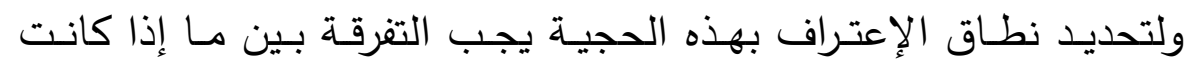
الجريمة قد ارتكبت في إقليم الجمهورية أو ارتكبت في الخارج. 1- الجربمة المرتكبة داخل مصر :

نص المشرع المصري في المادة الأولي من قانون العقوبات علي مبدأ إقليمية هذا القانون بالقول "تسري أحكام هذا القانون علي كل من يرتكب في القطر المصري جريمة من الجرائم المنصوص عليها فيه". وعليـه، إذا ارتكبــت الجريمـة في الإقلـيم المصـري وخضـــت بالتـالي

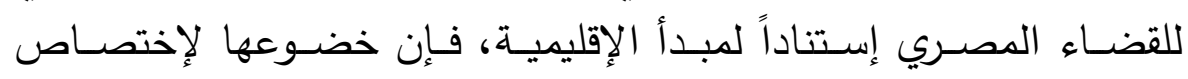

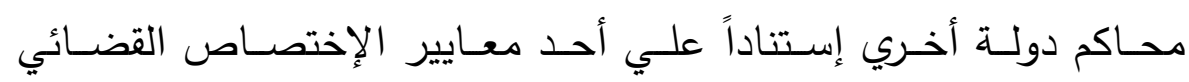

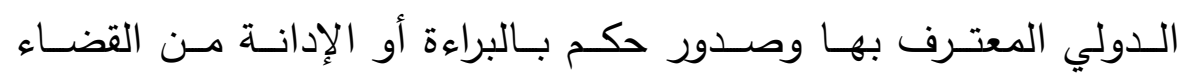

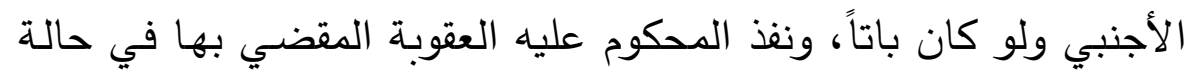

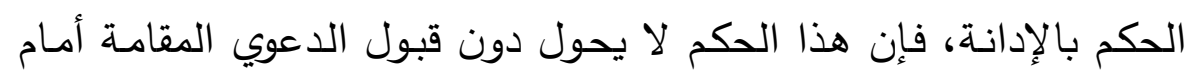
القضاء المصري عن ذات الواقعة وضد ذات الأثخاص. r- الجربمة المرتكبة خارج مصر :

إذا كان المشرع المصري قد أقر - من حيث المبدأ - الحجية السلبية

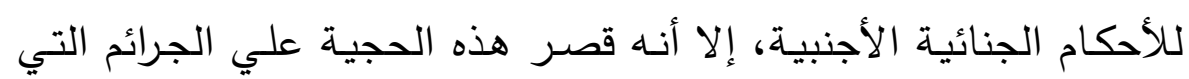

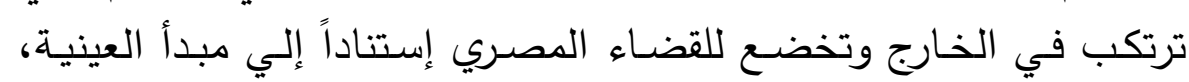
ومبدأ الشخصية الإيجابية، وذلك علي النحو التالي:

أولاً: الجرائم التي يختص بنظرها القضاء المصري طبقاً لمبدأ العينية: 
نصــ المـادة الثانيـة مـن قـانون العقوبـات المصـري علـي أن "تسـري أحكام هذا القانون أيضاً علي الأشخاص الآتي ذكرهم:

أولاً: كل من ارتكب في خارج القطر فعلاً يجعله فاعلاً أو شريكاً في الفي جريمة وقعت كلها أو بعضها في القطر المصري.

ثانياً: كل من ارتكب في خارج القطر جريمة من الجرائم الآتية: أ- جناية مخلة بأمن الحكومة مما نص عليه في البابين الأول والثاني من الكتاب الثاني من هذا القانون.

ب- جناية تزوير مما نص عليه في المادة T · r من هذا القانون. ج- جناية تقليد أو تزييف أو تزوير عملة ورقية أو معدنية مما نص

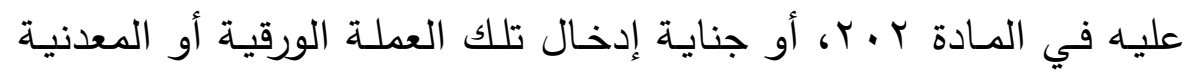

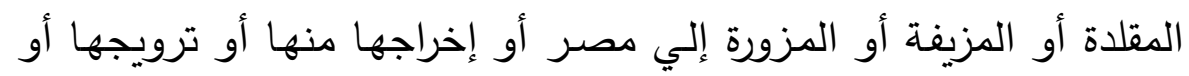

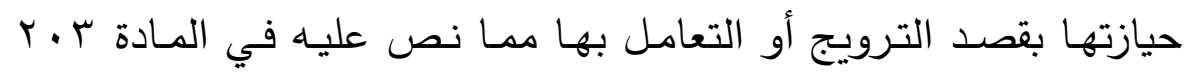

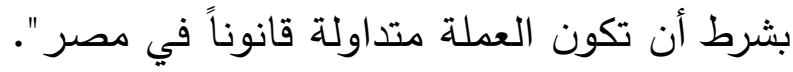

وظاهر من النص المتقدم أن المشرع المصري مد نطاق تطبيق قانون

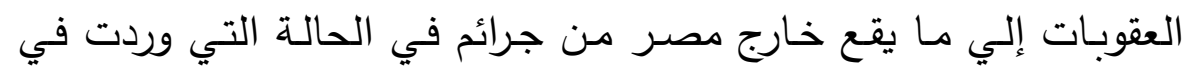

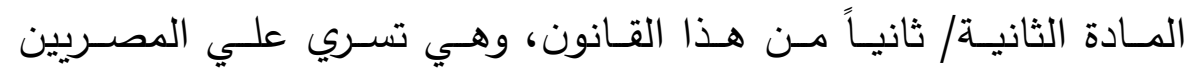

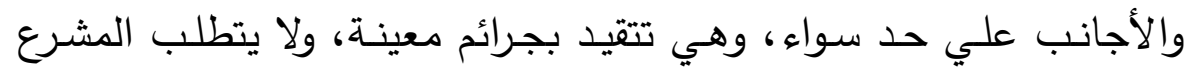

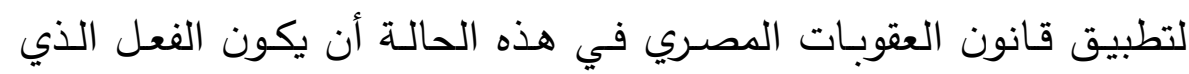
وقع في الخارج معاقباً عليه طبقاً لقانون الدولة الذي ارتكب فذه فيه. ثانيـاً: الجـرائم التـي يخـتص بنظرهـا القضــاء المصـري طبقــاً لمبــأ الشخصية الإيجابية: النيا: الجراية

نظمت المـادة الثالثة عقوبـات مسـألة سـريان قـانون العقوبـات المصـري علي الجرائم المرتكبة في الخارج من مصري ويختص تبعاً لذلك القضـاء

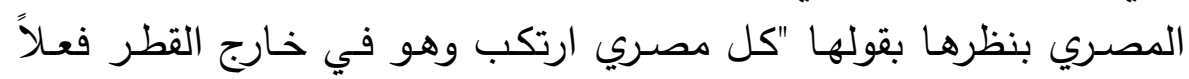




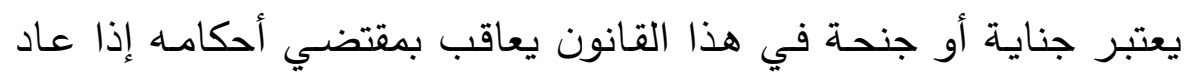
إلي القطر ، وكان الفعل معاقباً عليه بمقتضي البلد الذي ارتكبه فيه". وظاهر من النص المتقدم أن المشرع المصري مد نطاق تطبيق قانون

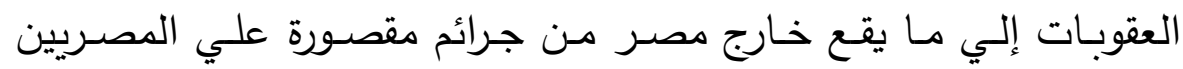

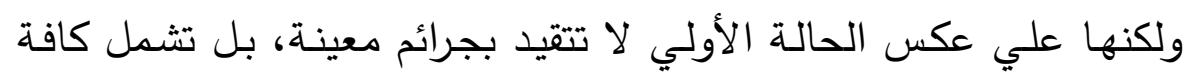

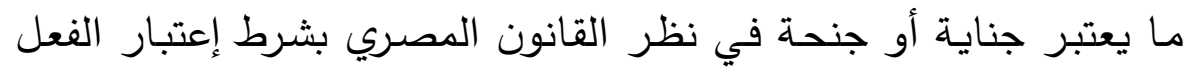

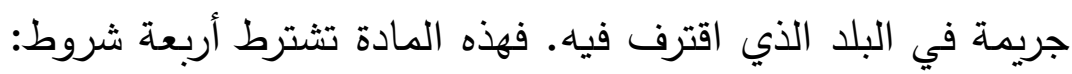

أن أن يكون الجاني متمتعاً بالجنسية المصرية.

r- أن تكون الجريمة جناية أو جنحة طبقاً للقانون المصري.

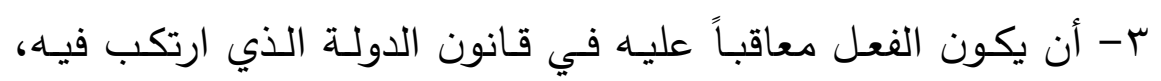
بأية عقوبة سواء بعقوبة جناية أو جنحة أو مخالفة. ع - عودة الجاني إلي الإقليم المصري.

وقد قرر المشرع المصري في المادة الرابعة من قانون العقوبات علي

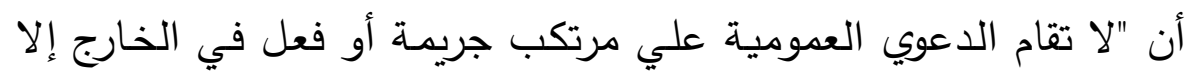
من النيابة العامـة. ولا تجوز إقامتها علي من يثبت ألن أندام المحاكم الأجنبية برأته مما أسند إليه أو أنها حكمت عليه نهائه نهائ واستوفي عقوبته"(').

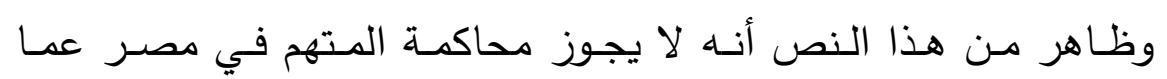

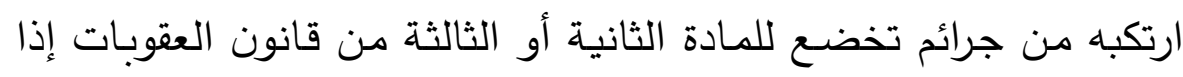

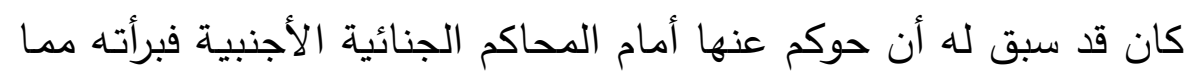
أسند إليه، أو أنها حكمت لهن انيه نوكائياً بالإدانة واستوفي عقوبته.

(1) ينتقد البعض - وبحق - مذهب المشرع المصري فيما ذهب إليه من إدراج المادة الرابعة

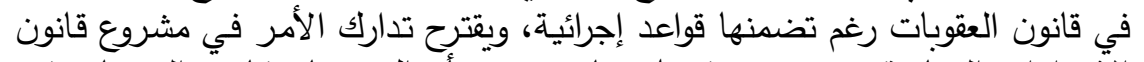

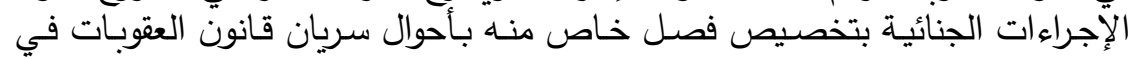

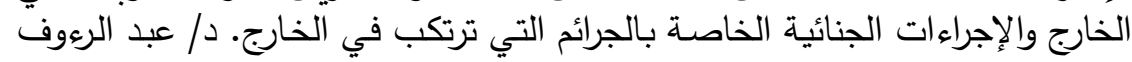

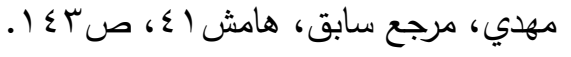




\section{الفصل الثالث}

\section{الشروط المتعلقة بالحكم الجنائي الأجنبي}

لـم يشـأ المشـرع المصـري أن يهـدر الحجيـة السـلبية للأحكـام الجنائيـة

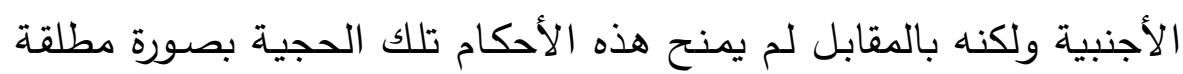

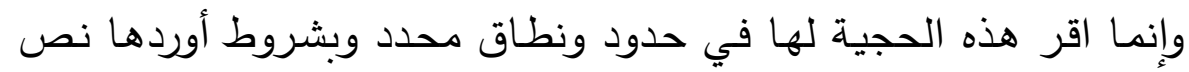
المادة الرابعة من قانون العقوبات وذلك بقولها "لا تقام الدعوي العمومية ودية

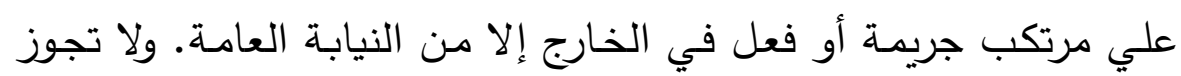

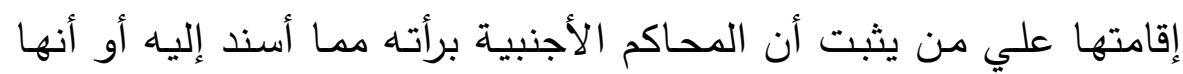

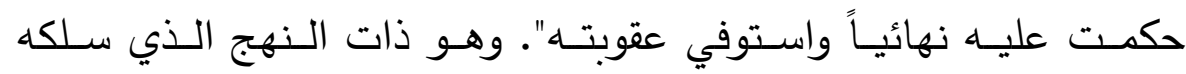

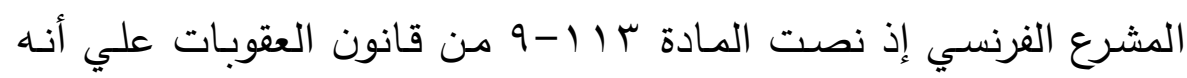

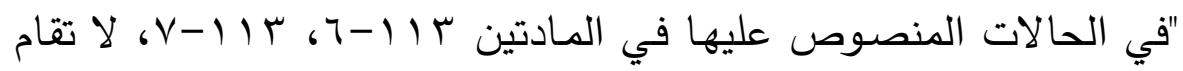

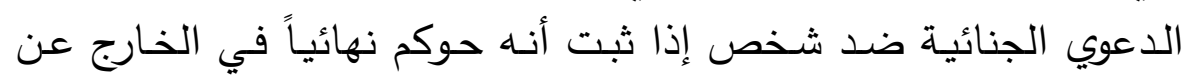

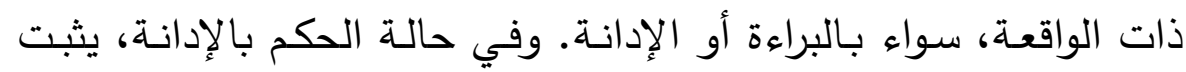

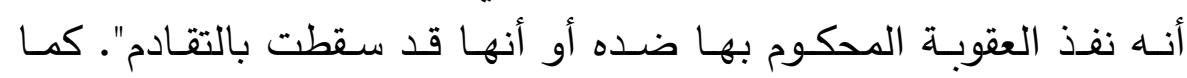

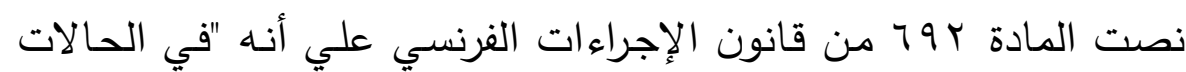

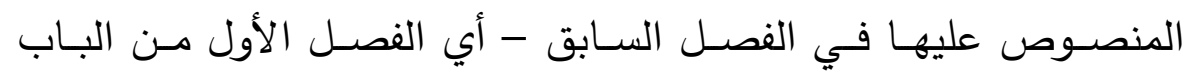

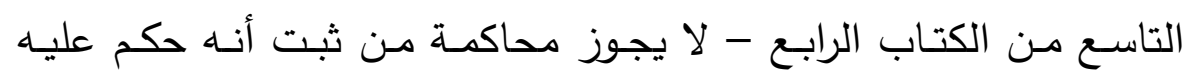

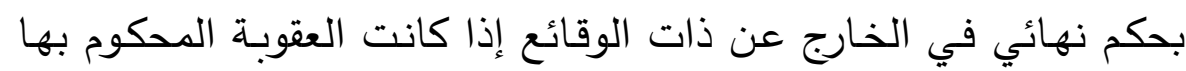

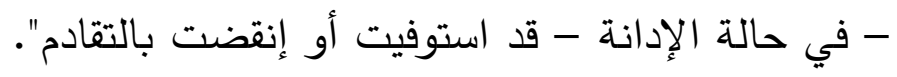
ومن هذه النصـوص يتضـح أن المشرع في البلدين لم يضـف الحجيـة

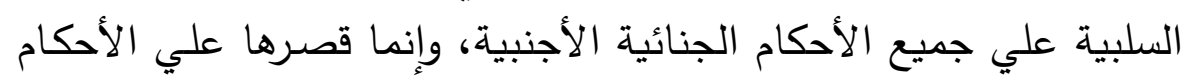

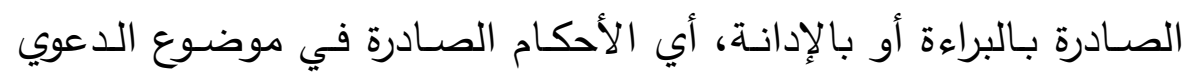
الجنائية. إلا أننا نري أنه لا يكفي توافر هذا الإدة الشرط في الحي الحكم الجنائي

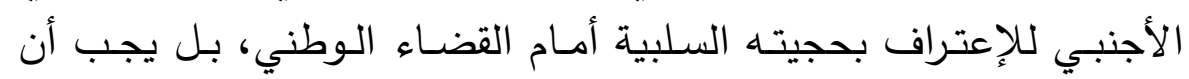

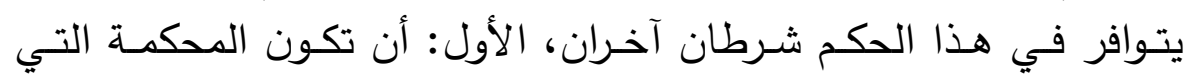
أصدرته مختصـة وفقاً لقواعد الإختصاص الدولي المعترف بهان الدران، الاول: والثاني: 
وحدة الـدعوي التي صـدر فيهـا الحكم البـات، والـدعوي المرفوعـة أمسام القضاء الوطني والتي يراد فيها التمسك بالحجية السلبية لهذا الحكم. ويبين مما سبق أن هناك ثلاثة شروط يجب توافرها في الحكم الجنائي الأجنبي للإعتراف بحجيته السلبية أمام القضاء المصري أو الفرنسي. الأول: ولاية المحكمة التي أصدرته. الثاني: أن يكون الحكم فاصلاً في موضوع الدعوي الجنائية. الثالث: وحدة الدعوي. وترتيباً علي ذلك نقسم هذا الفصل إلي ثلاثة مباحث: المبحث الأول: ولاية المحكمة الأجنبية بمحاكمة المتهم. المبحث الثاني: صدور حكم فاصل في موضوع الدعوي الجنائية. المبحث الثالث: وحدة الدعوي. 


\section{المبحث الأول \\ ولاية المحكمة الأجنبية بمحاكمة المتهم}

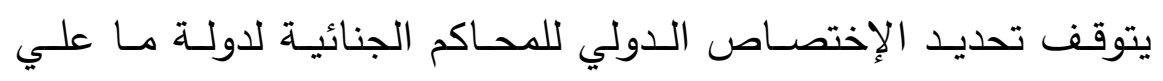

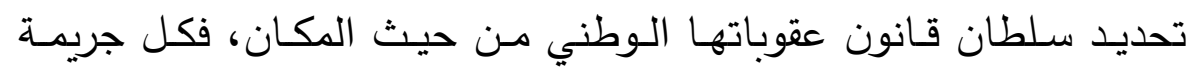

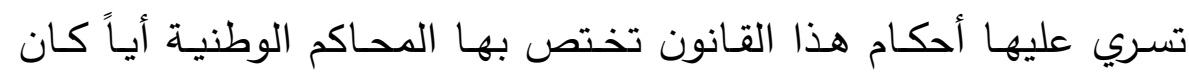
مكان وقوعها.

وفي ضـوء هذا التحديد، يستتد الإختصـاص الدولي للمحاكم الجنائيـة

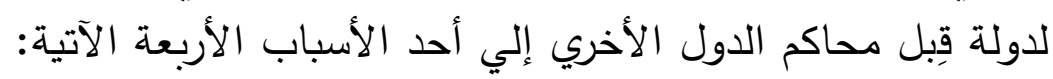
ا - أن تقع الجريمة في إقليم الدولة التي يتبعها القاضي، فيختص هذا

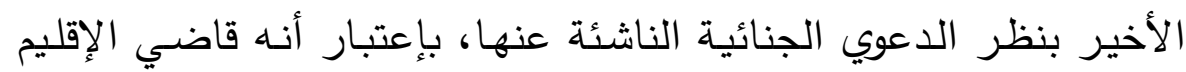

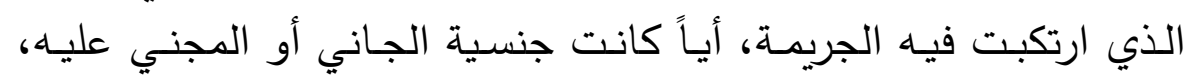
وهو ما يمكن أن نطلق عليها "الولاية القضائية الإقليمية".

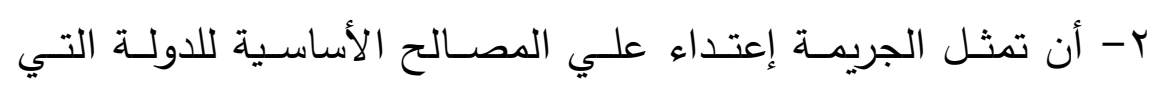
يتبعها القاضـي، فيختص هذا الأخيـر بنظـر الـدعوي الجنائيـة الناشـئة

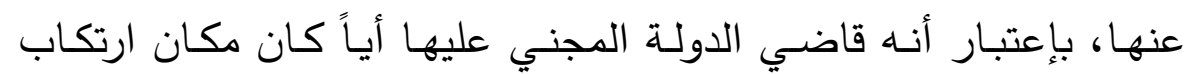

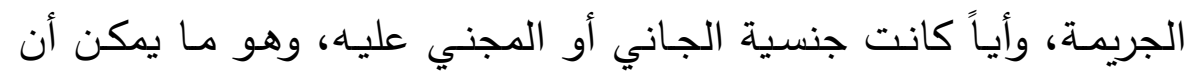
نطلق عليها "الولاية القضائية المؤسسة علي مبدأ العينية".

ب- أن يكـون الجـاني أو المجني عليـه مـن رعايـا الدولـة التي يتبعها

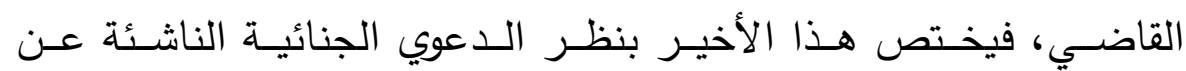
الجريمة علي إعتبار أنه قاضي دولة الجاني أو دولة المجني عليه، وهو

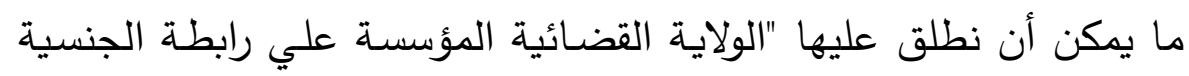
أو "الولاية القضائية المؤسسة علي علي مبدأ الثخصية".

ع- أن يتم القبض علي الجاني في دولة غير التي اقترف فيها جريمته أو غير المجني عليها أو ينتمي هو أو المجني عليه إليهان إنيا، فيحاكم أمام

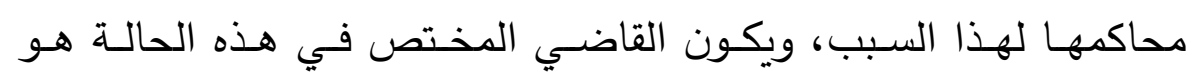


قاضـي الدولـة التي قبض عليـه فيها، وهو مـا يطلق عليه "الإختصـاص القضائي العالمي".

وفي ضـوء هذا التحديد، تختص المحاكم المصرية بمحاكمـة كل مـن ارتكب جريمـة في مصـر ، بغض النظر عن جنسية الجـاني أو جنسية

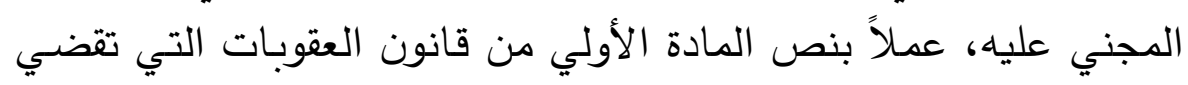
بأن "تسري أحكام هذا القانون علي كل من يرتكب في القطر المصري

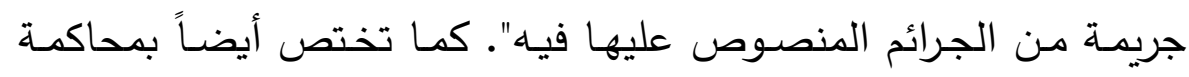

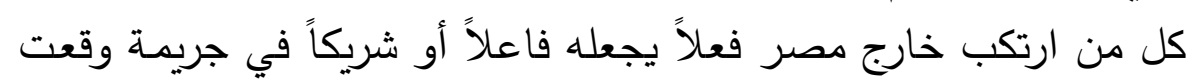

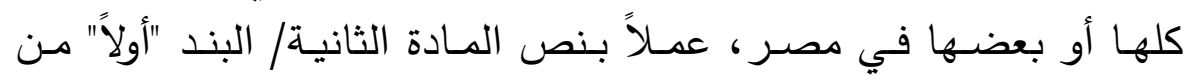

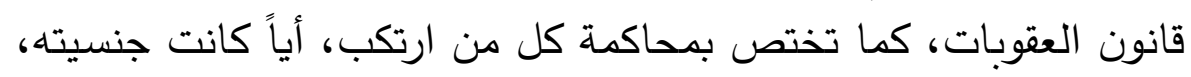

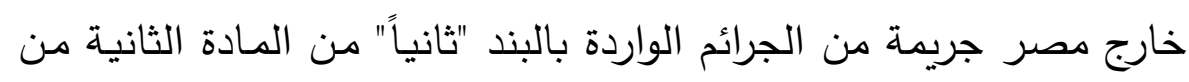

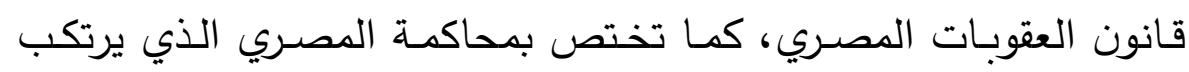

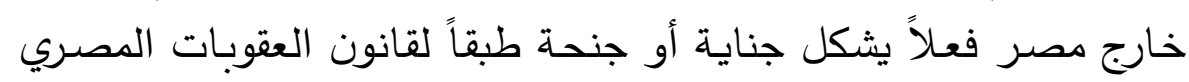

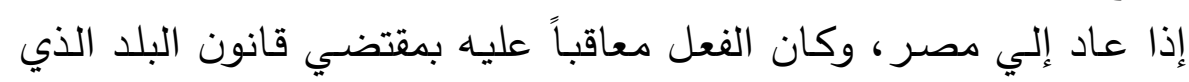
ارتكبت فيه، عملاً بنص المادة الثالثة من قانون العقوبات.

وبالنظر إلي نص المادة الرابعة من قانون العقوبات نجد أنها لم تشترط

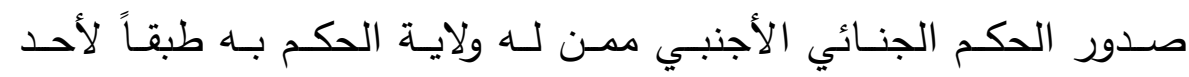

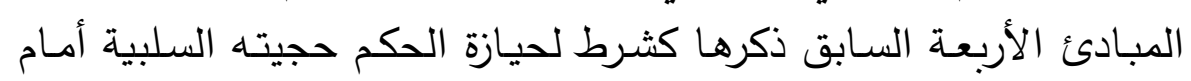
المحاكم المصرية. ولكن هذا القصور لم يمنع الفقه(1) من إشتراطه.

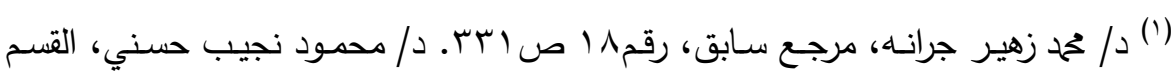

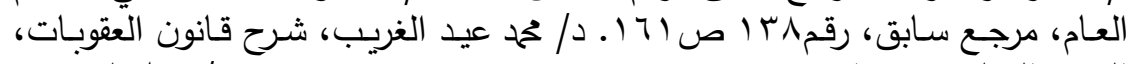

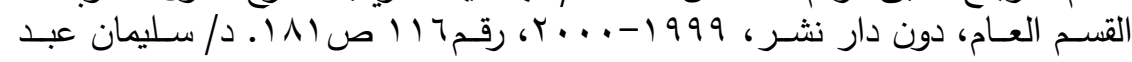

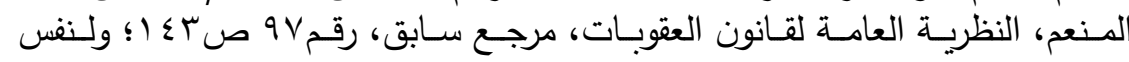

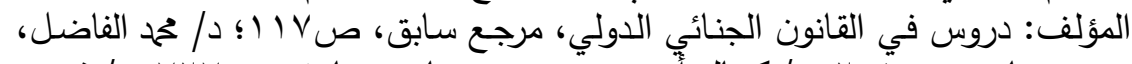

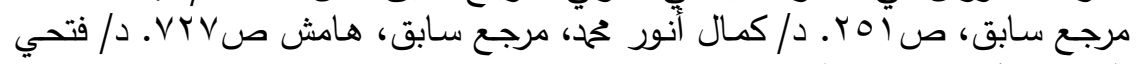

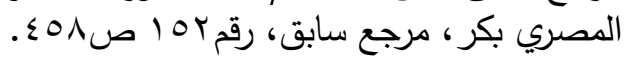

Huet (A.) et Koering-Joulin (R.): op.cit. n ${ }^{0} 10 \leqslant$, p. $r \leqslant 7$; Lombois (C.): op.cit. $n^{0} \leqslant \cdots-\varepsilon \cdot 1, p .{ }^{0 \cdot v}$; Donnedieu de vabres (H.): Les principes modernes du droit pénal international, op.cit. p. ${ }^{\top} 7$. Voir En juris: Aix, $r \leq$ mars $1 \wedge \wedge r$, JDI, $1 \wedge \wedge 0$, r^т. 
بـل ذهب رأي إلي أبعد مـن ذلك(') واشترط أن يكون الحكم الأجنبي صـادراً مـن محكمـة تفضـل فهي ولايتهـا العامـة ولايـة المحساكم المصـريـة.

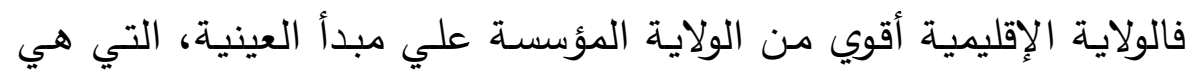

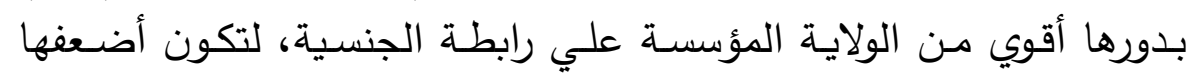

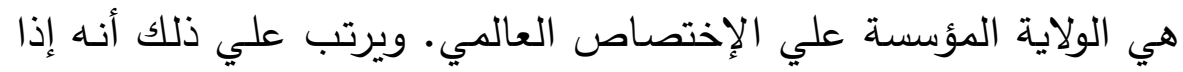
كان الحكم صـادراً في الخـارج ضـد أجنبي مـن قاضسي جنسيته، وكانـت الإهي

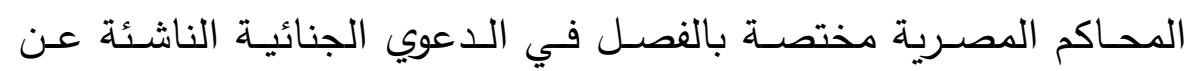
الجريمـة لكونها وقعـت كلها أو بعضـها في مصـر (المسادة الثانية/البند

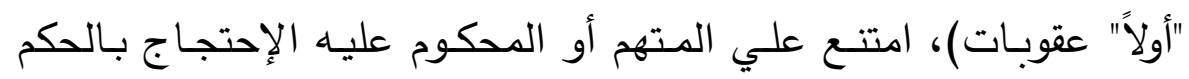

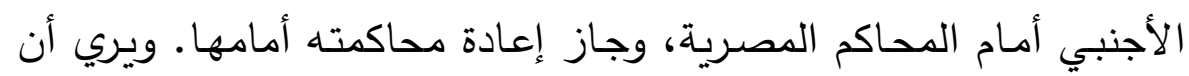

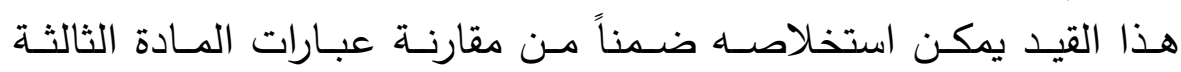
عقوبـات بالمـادة الرابعـة. فالمـادة الثالثة تثـترط لمعاقبـة المصـري العائدـ

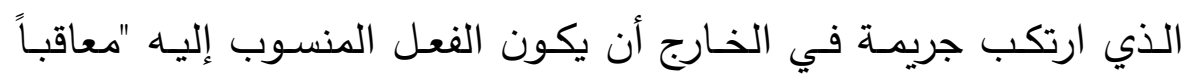

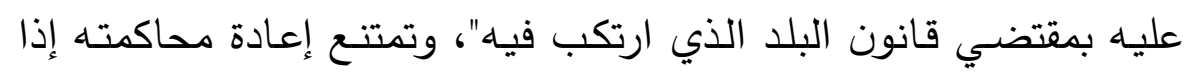

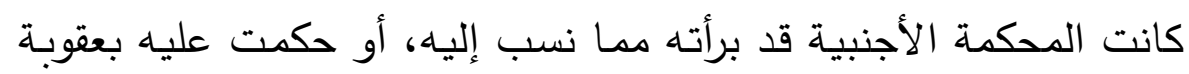

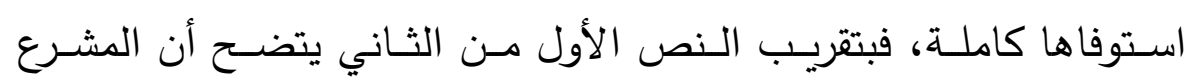

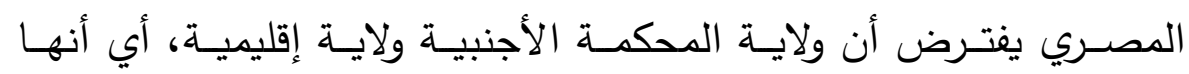
مستندة إلي أقوي سبب يمكن أن تقوم عليه، في حين أن ولايـة المحاكم

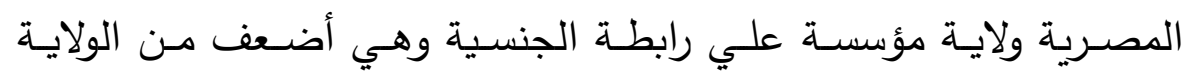

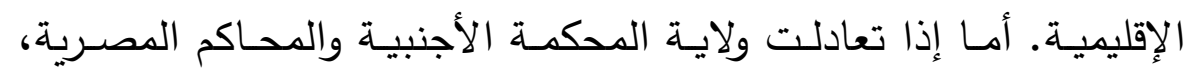

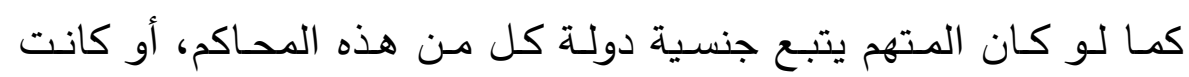
الجريمة المنسوبة إليه وقعت في الخارج وفي مصر ، فإن الحكم الأجنبي

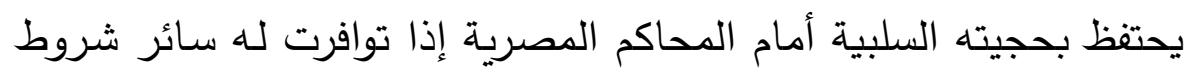

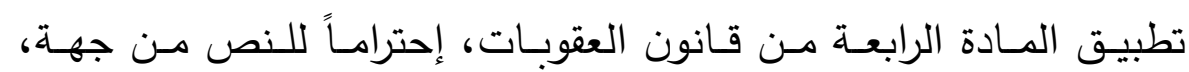

ومراعاة لعدالة مبدأ عدم جواز محاكمة المتهج عن فعل واحد مرتين.

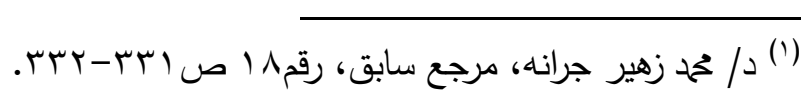


ونـري أن أسس الإختصـاص الدولي للمحساكم الجنائيـة السـابق ذكرهـا

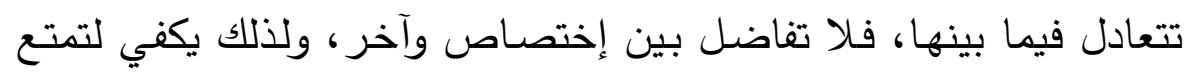

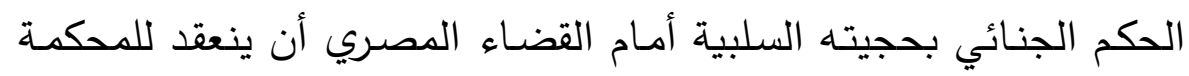

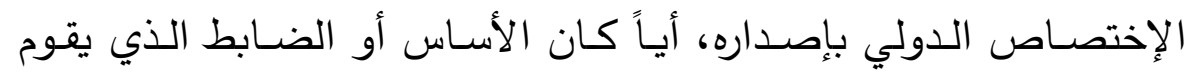
عليه هذا الإختصاص متي توافرت الثروط المنصوص عليها في المادة الثاني الرابعة من قانون العقوبات.

ومـن المتفـق عليـه(1)، أن تقصـي المحساكم المصـرية لولايـة المحكمـة الأجنبية التي أصدرت الحكم، يقتصر علي تقصي الإختصساص الدولي

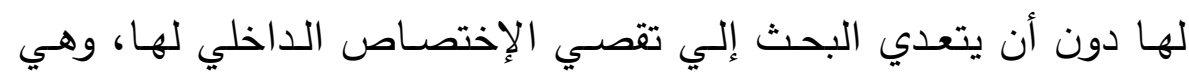

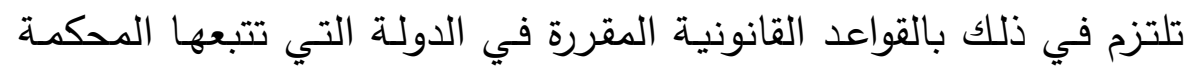

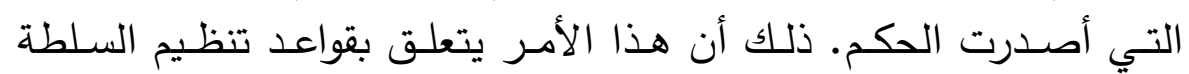

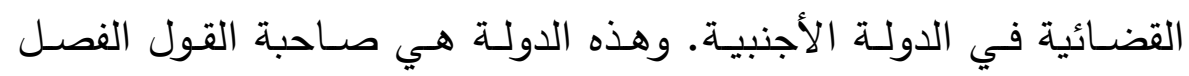

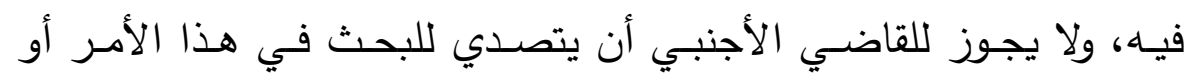

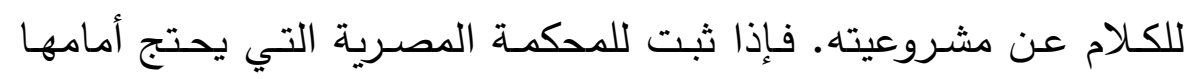

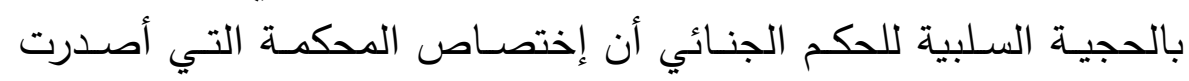

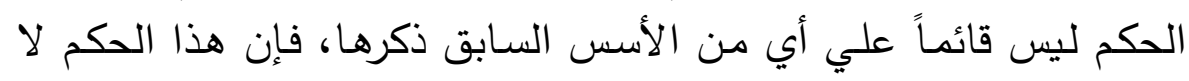
يعتد بـه.

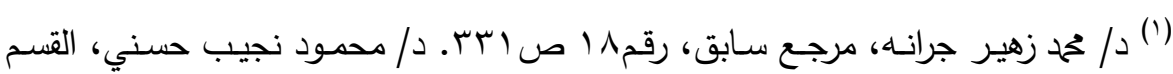

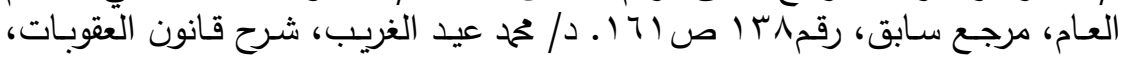

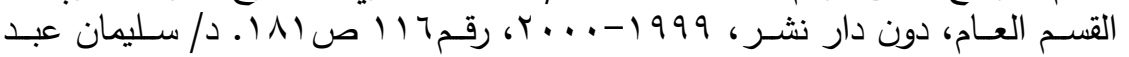

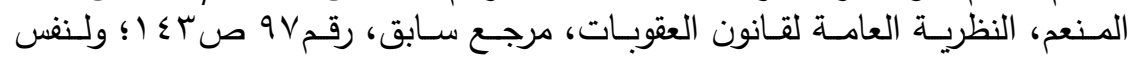

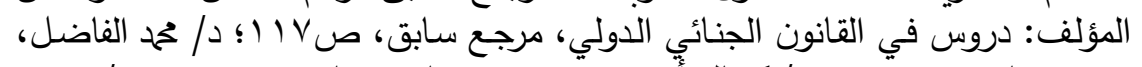

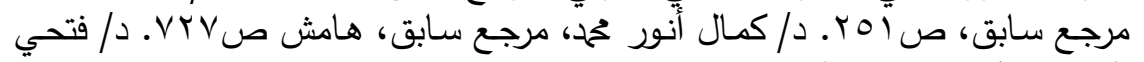

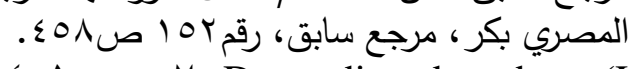

Lombois (C.): op.cit. $n^{0} \varepsilon \cdots-\varepsilon \cdot 1$, p. ${ }^{\circ} \cdot v_{\text {; }}$ Donnedieu de vabres (H.): Les principes modernes du droit pénal international, op.cit. p. ${ }^{1} 7$; Huet (A.) et Koering-Joulin (R.): op.cit. $n^{0} 10 \leqslant$, p. $r \leqslant 7$; contra. Travers (M.): Traité de droit pénal international, Paris, $19 r \cdot-19 r$ r, t. III, p.sir. 


\section{المبحث الثاني}

\section{صدور حكم فاصل في موضوع الدعوي الجنائية}

ليست كل الأحكام الجنائية الأجنبية تتمتع بحجية سلبية أمام القضـاء

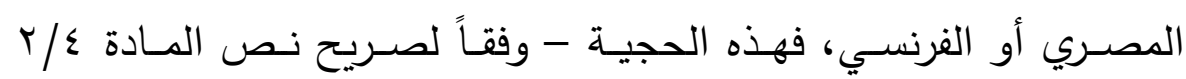

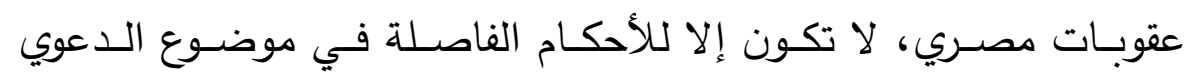

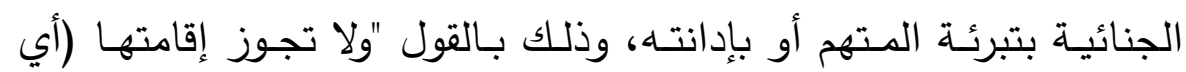

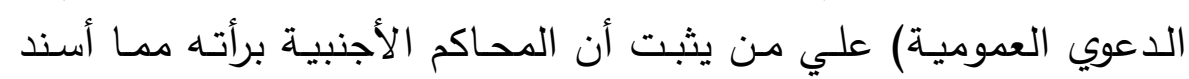

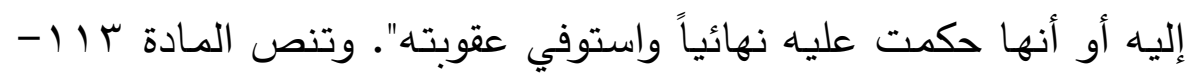

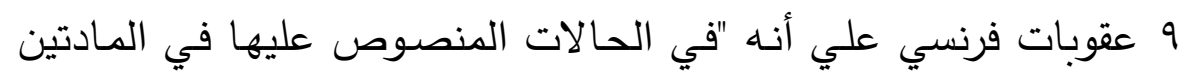

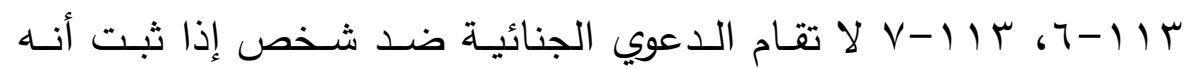

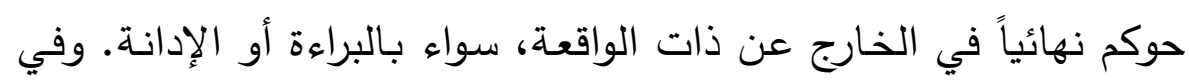

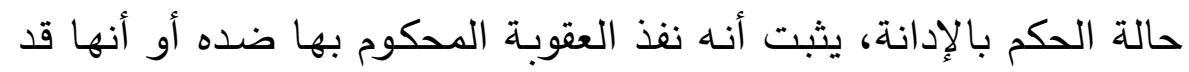
سقطت بالتقادم". فواضـح من هذين النصين أن الحكم الجنائي الأجنبي

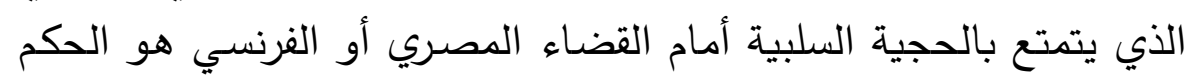

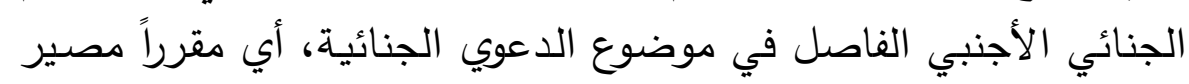

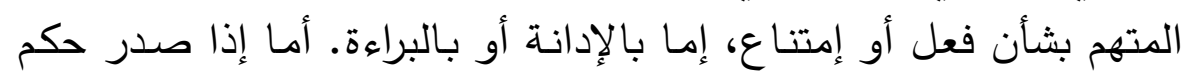

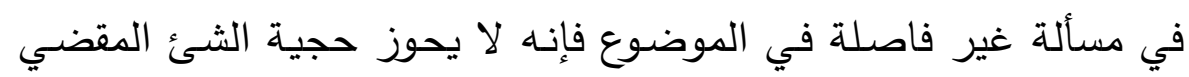

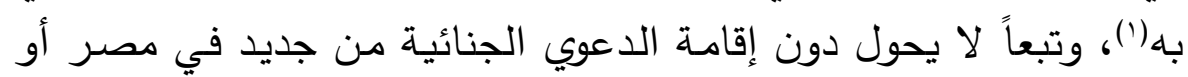

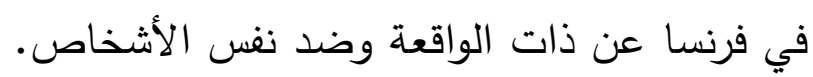

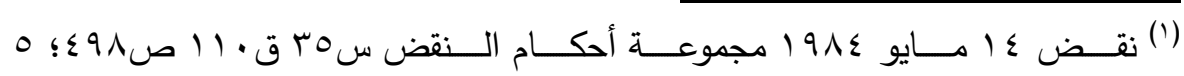

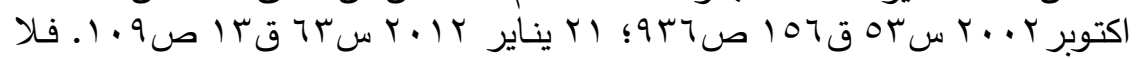

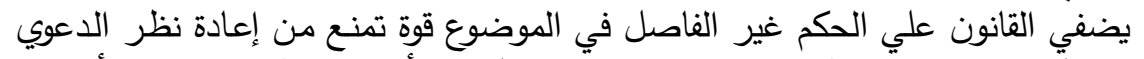

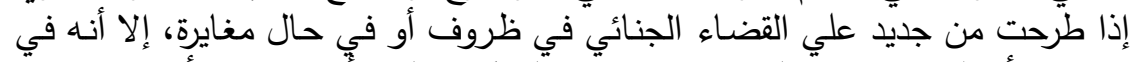

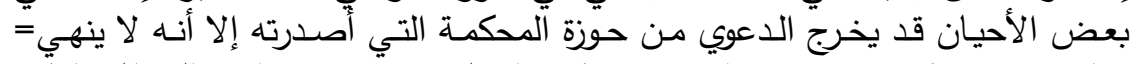

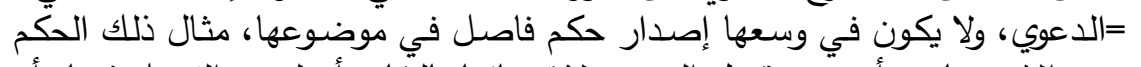

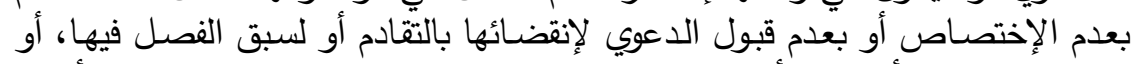

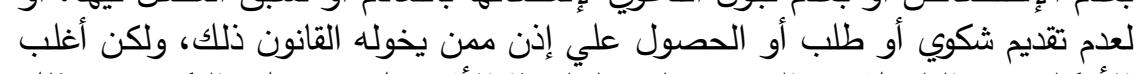

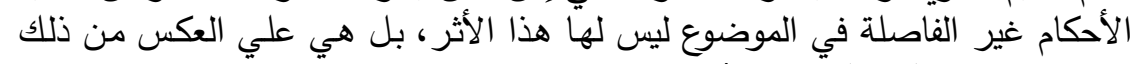

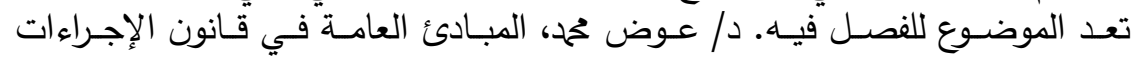


الحكم الفاصل في الموضوع وإنهاء الدعوي الجنائية:

الأحكام الجنائية متعددة الأنواع، وهي محل لتقسيمات كثيرة، ويعتمد كل تقسيم منها علي ضابط خاص. وتنقسم الأحكام الجنائيسة من حيث فصلها في موضـوع الدعوي، إلي أحكام فاصلة في الموضوع، وأحكام غير فاصلة في الموضوع.

وتتميز الأحكام الفاصلة في الموضسوع بكونها تطبق قواعد موضوعية

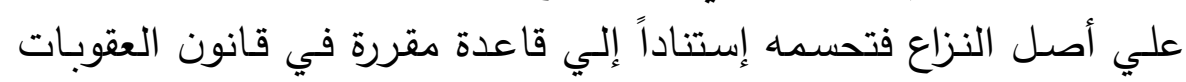

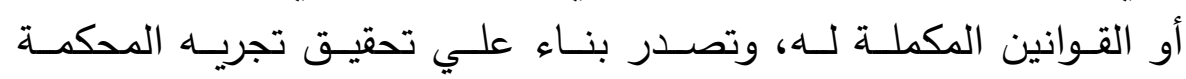

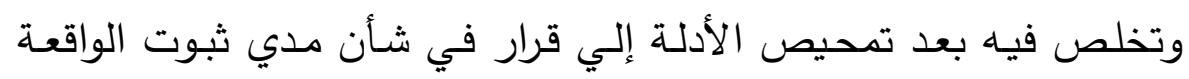

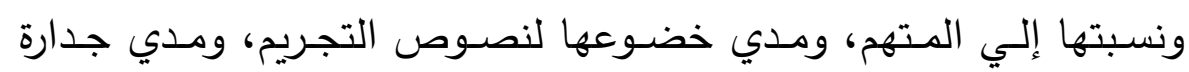
المتهم بالعقاب، وهذا الحكم إما أن يكون قاضياً بالبراءة أو بالإدانة('). أمسا الأحكـام غير الفاصلـة في الموضـوع فتطبـق قواعد إجرائيـة علي

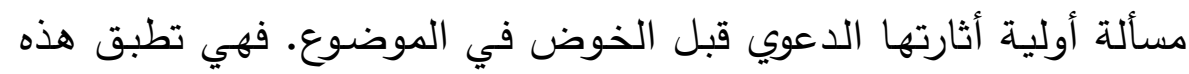

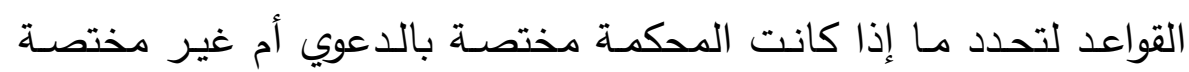

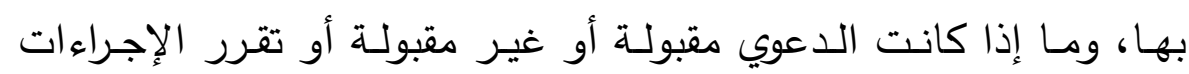

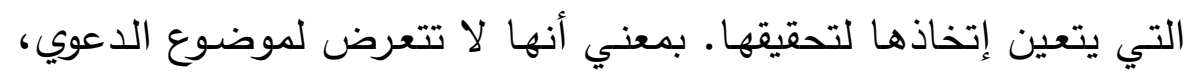

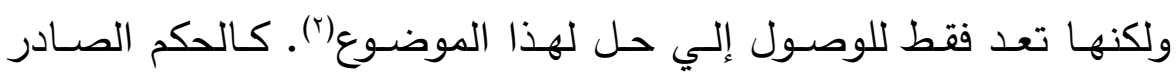

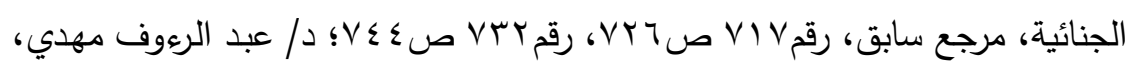

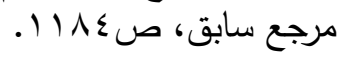

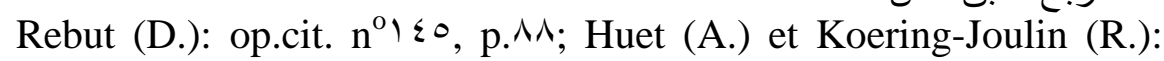

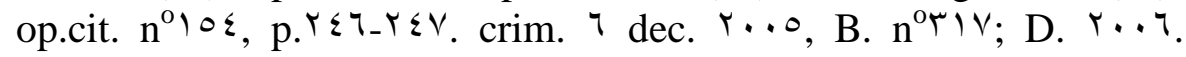
Somm. Tr, obs. J. Pradel; R.S.C. Y.. T. T.V , obs. G. Vermelle.

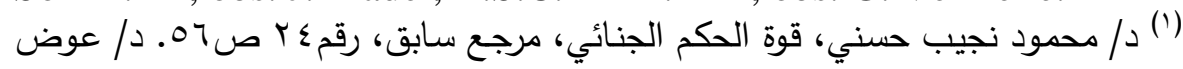

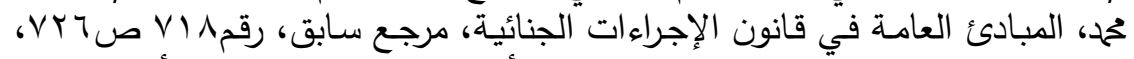

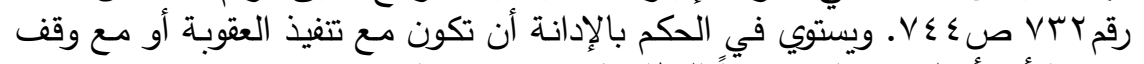

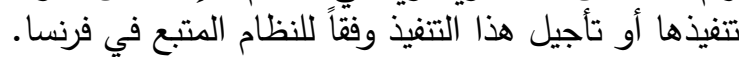

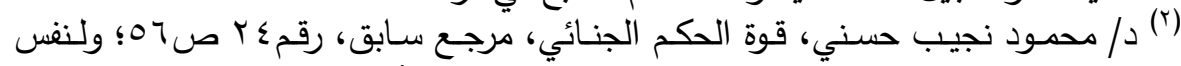

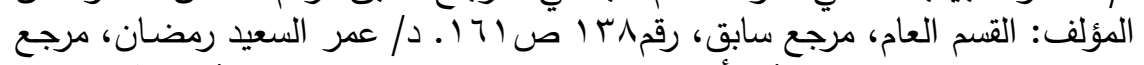

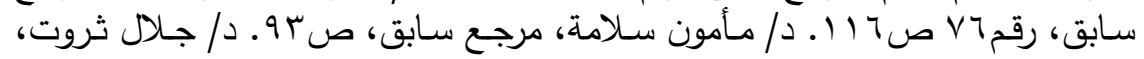

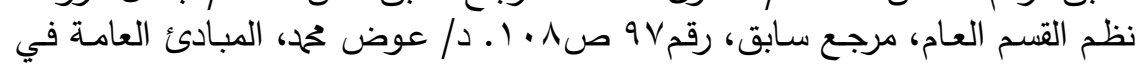


بعدم جواز نظر الدعوي لسبق الفصل فيها، والحكم القاضسي بعدم قبولها

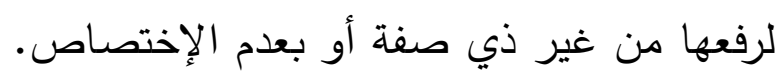

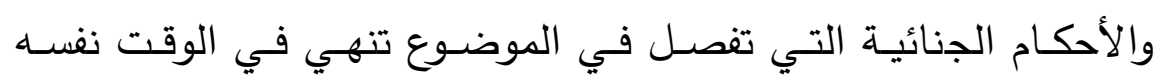

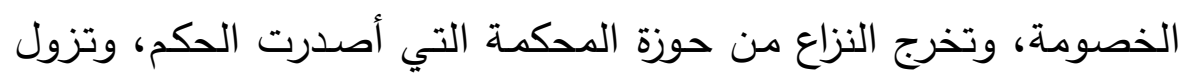

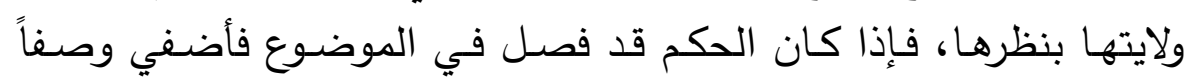

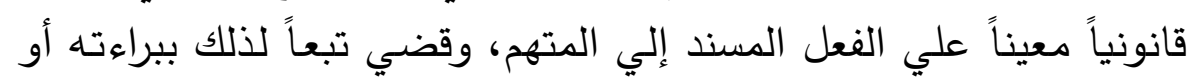

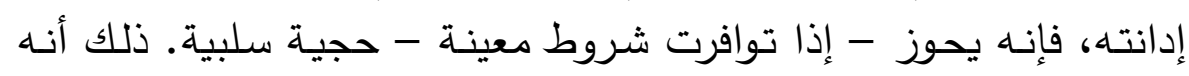

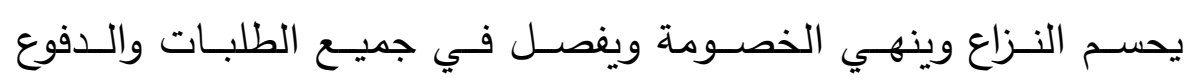

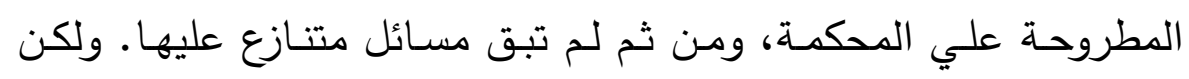
إنتهاء الدعوي الجنائية بصدور الحكم الفاصل في موضوعها هو إنتهاء

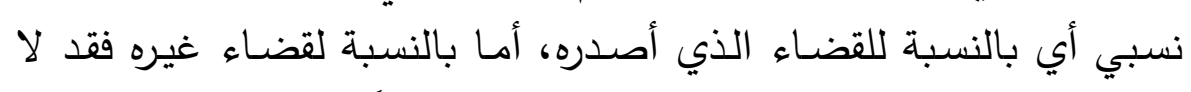

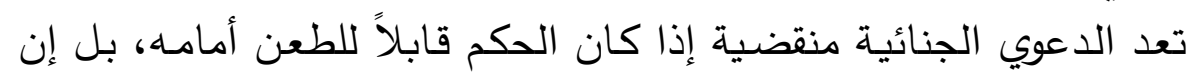

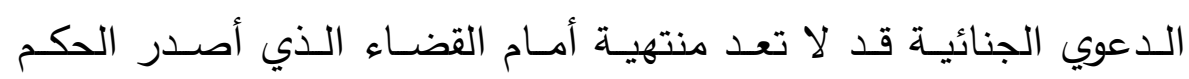

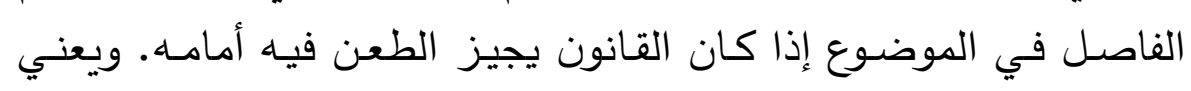

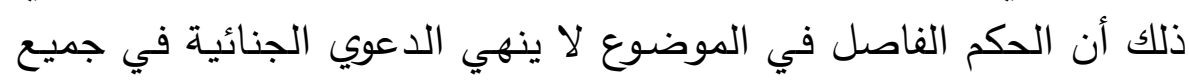

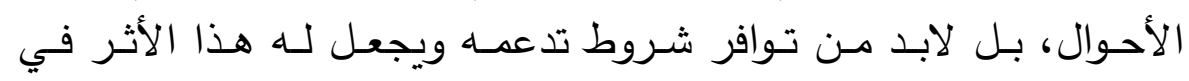

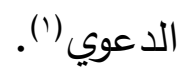

تقسيم:

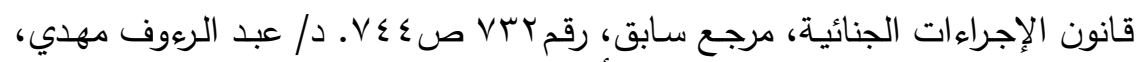

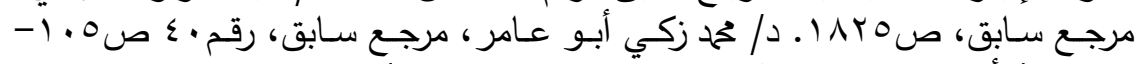

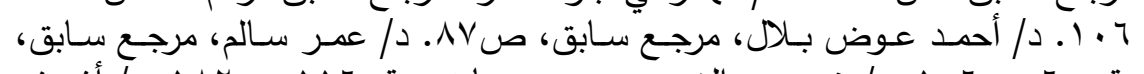

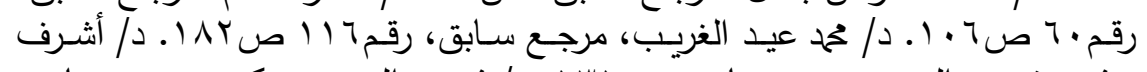

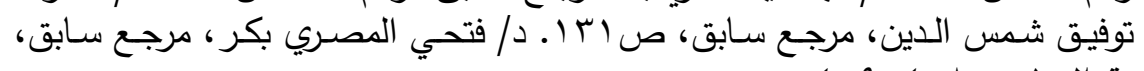

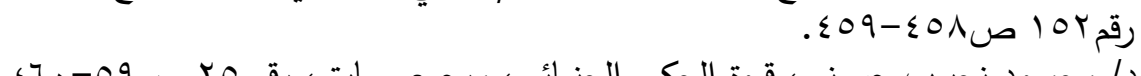

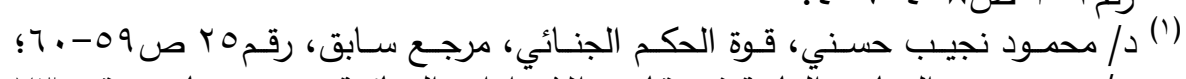

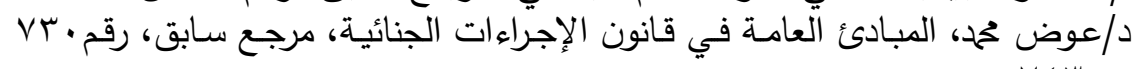
ص صن 
تنص الفقرة الثانية من المادة الرابعة من قانون العقوبات علي أنه "ولا تجوز إقامتها (اي الدعوي العمومية) علي من يثبت أن المحاكم الأجنبية

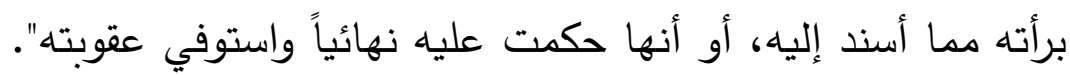

وواضـح مـن هـا الـص أن المشـرع المصـري لـم يغفـل حجيـة الحكم

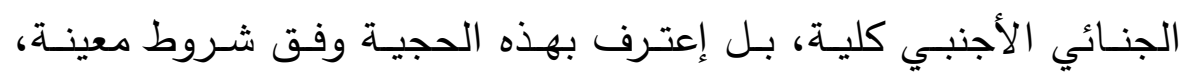

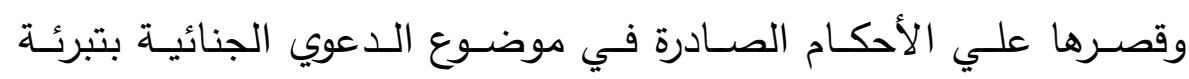
المتهح إو بإدانته نهائياً واستيفائه العقوبة كاملة.

وفي فرنسـا، فيمـا يتعلـق بـالجرائم المرتكبـة في الخـارج طبقـاً لمبـدأ

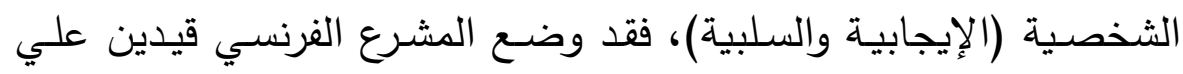
الدعوي الجنائية المتعلقة بها.

القيـد الأول: لا ترفـع الـدعوي الجنائيـة إلا بطلب مـن النيابـة العامـة،

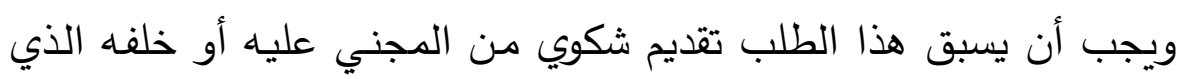

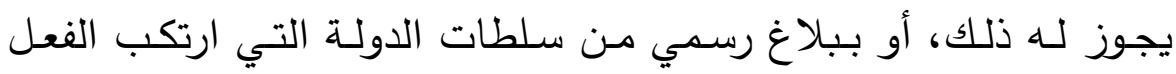

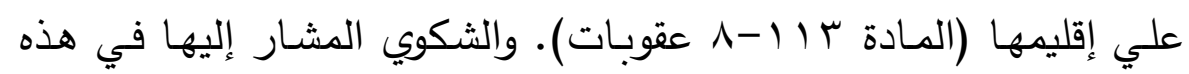

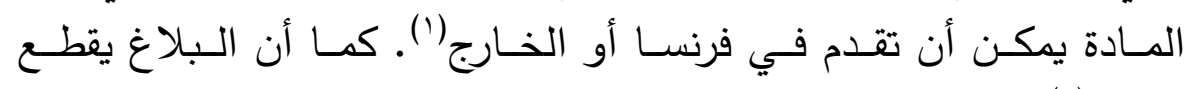

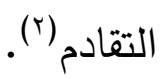
القيد الثاني: عدم جواز إقامة الدعوي الجنائية ضد شخص إذا ثبت أنه إنه

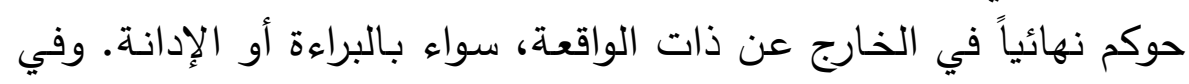

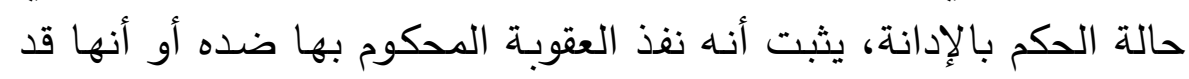

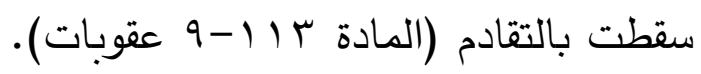

(1) crim. $r \leq$ nov. 1991, B. n $n^{\circ} r 1 r$.

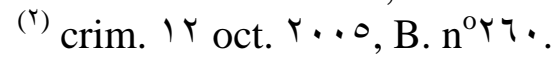

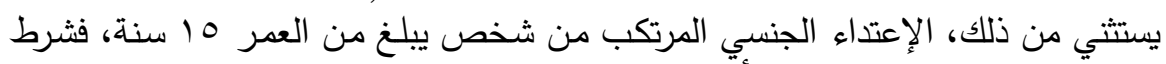

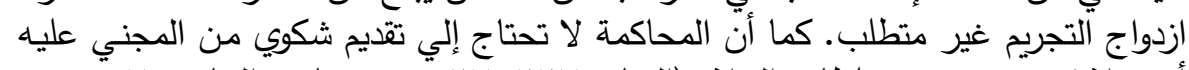

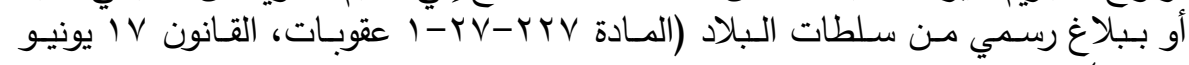

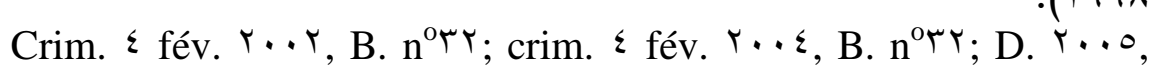
p. ${ }^{\text {T I }}$, note V. Malabat. 
أما بالنسبة للجرائم المرتكبة في الخارج طبقاً لمبدأ العالمية والتي تأخذ

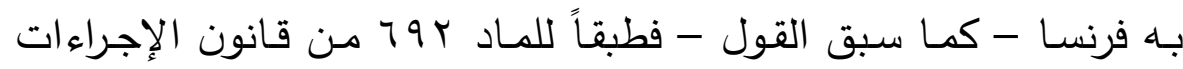
الجنائية لا يجوز محاكمة من ثبت أنه حكم بحكم نهائي عليه في الخارج عن ذات الوقائع إذا كانت العقوبة المحكوم بها - في حالة الإدانة - قداند

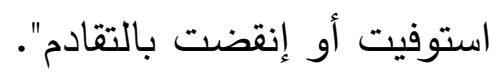

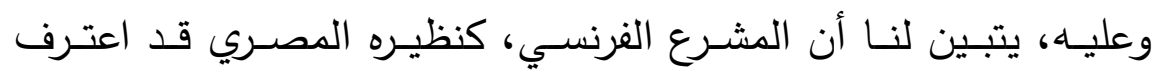

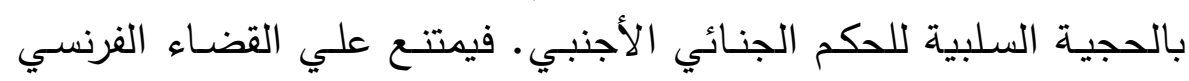

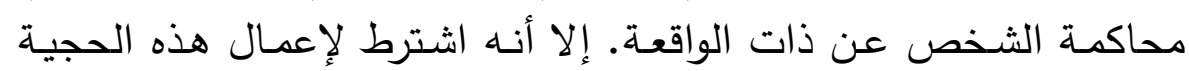

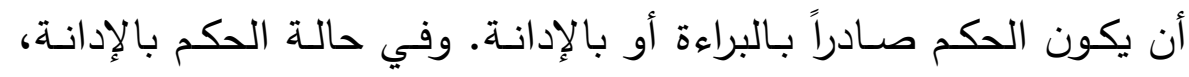

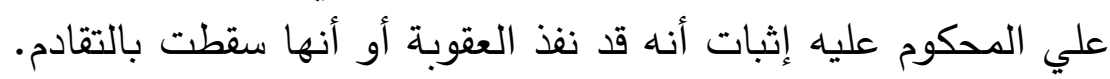
ونعرض للفرضين كل في مطلب مستقل. 


\section{المطلب الأول \\ الحكم بالبراءة}

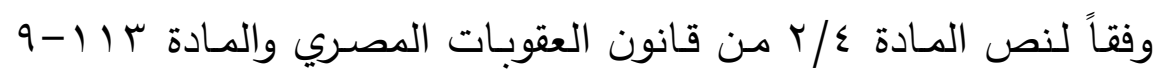

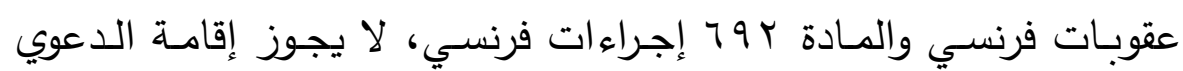
الجنائية علي من يثبت أن المحاكم الأجنبية برأته مما أسند إليه.

ويثير تطبيق هذين النصين المسائل الآتية:

المسألة الأولي: سبب البراءة :

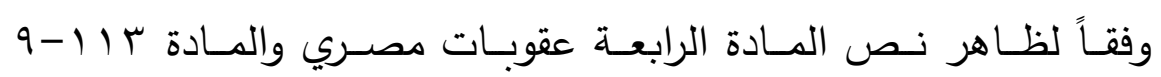

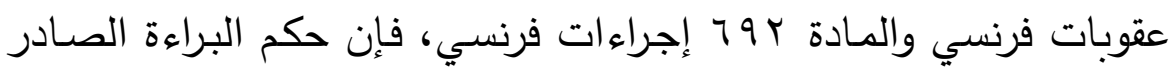
من محكمة أجنبية يتمتع بالحجية السلبية أمام القضاء الوطني مما يحول فأنساء

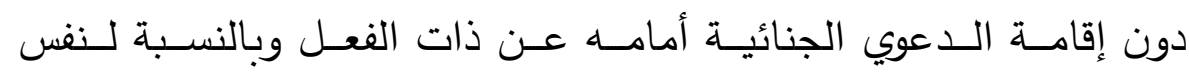

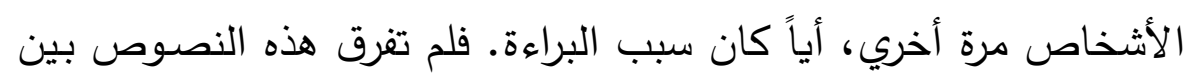

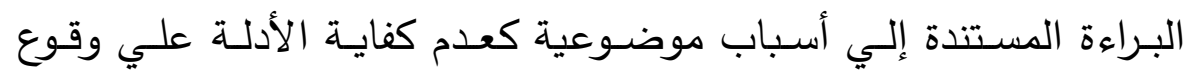

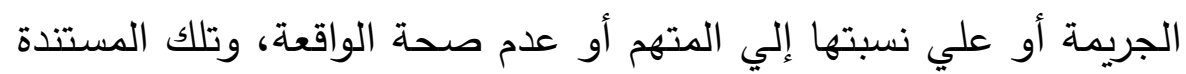

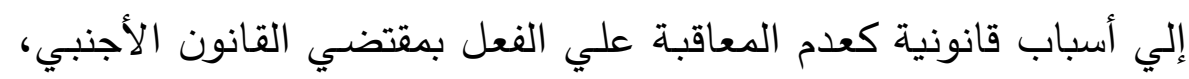
أو وجود سبب من أسباب الإباحة أو مانع من موانع المسؤولية الجنائية. إلا أن الفقه() في البلدين يذهب إلي أن الأمر في حاجة إلي تفرقة بين

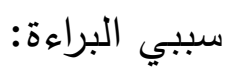

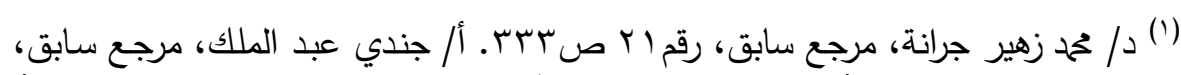

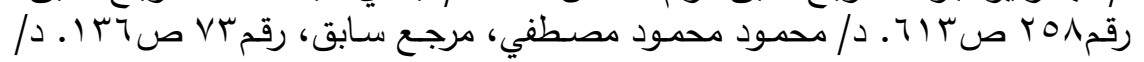

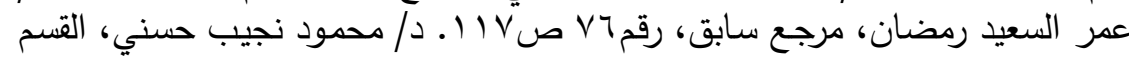

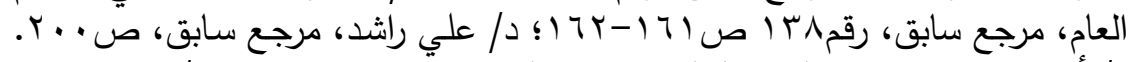

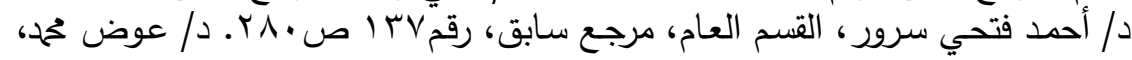

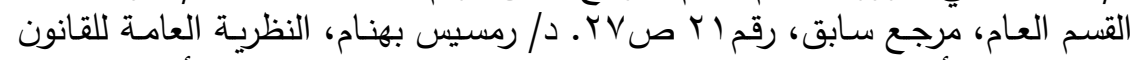

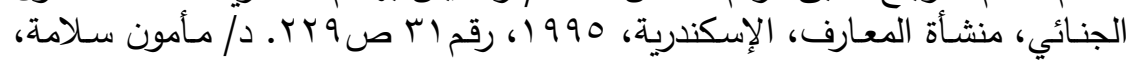

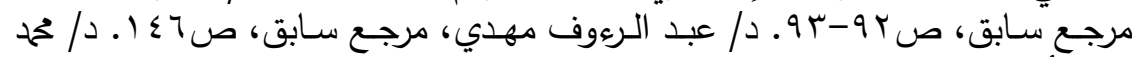

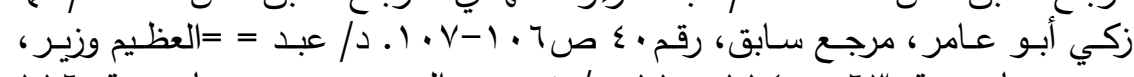

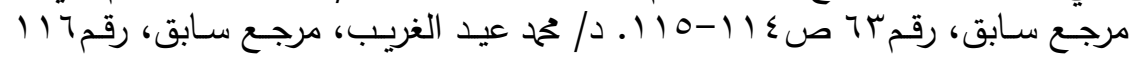


1- إذا استند حكم البراءة علي أسباب موضوعية، كعدم كفايـة الأدلة

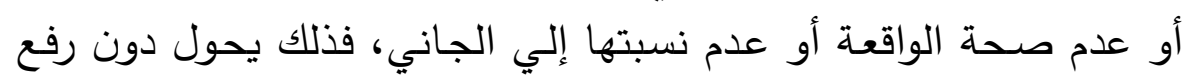

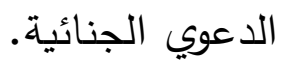

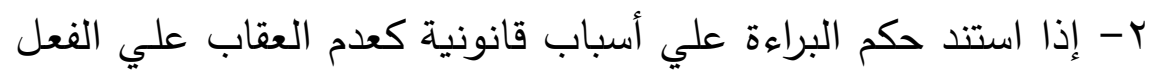

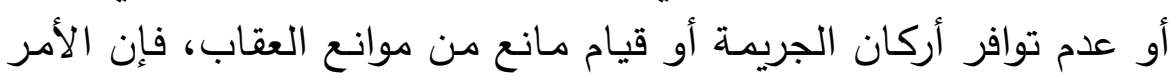

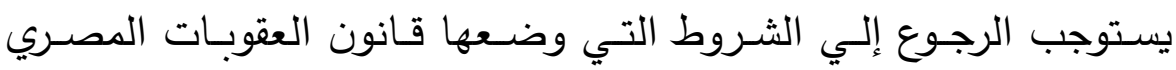

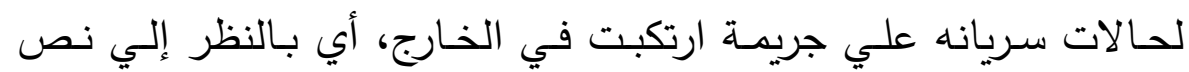

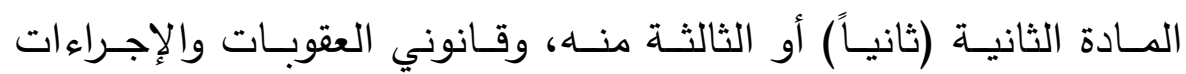
الجنائية الفرنسيين في هذا الثأن.

$$
\text { أ- الوضع في مصر: }
$$

إذا نظرنـا إلي نص المـادة الثالثة - والذي يستند إلي مبدأ الثخصية

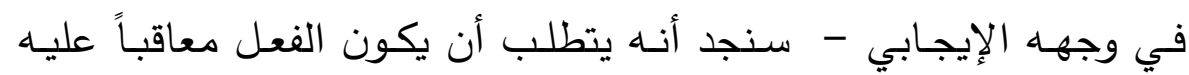

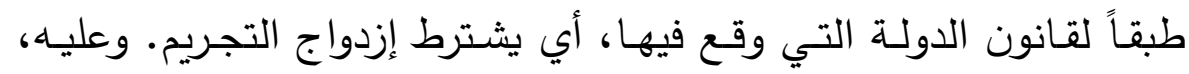

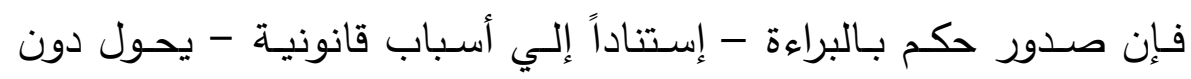

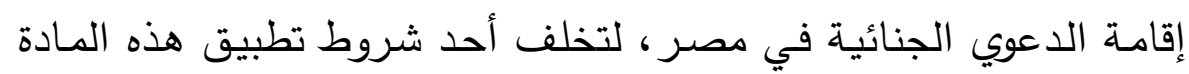

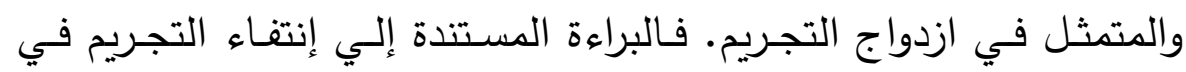

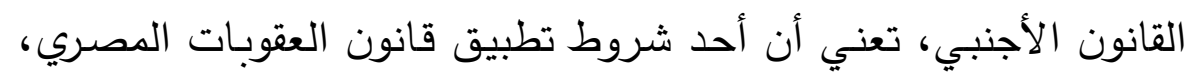
قد انتفت.

أما إذا كان الإختصاص وفقاً لمبدأ العينية، أي يستند إلي نص المادة

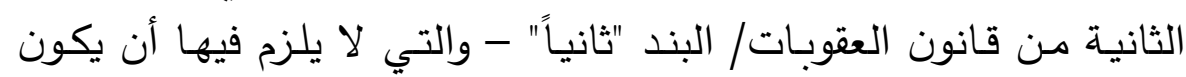

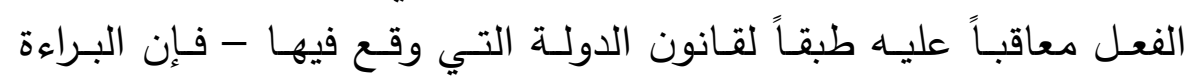

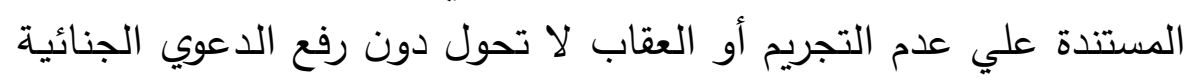

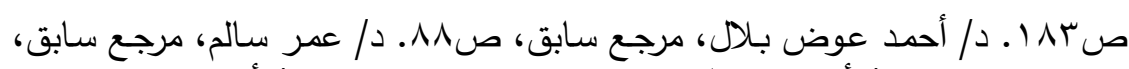

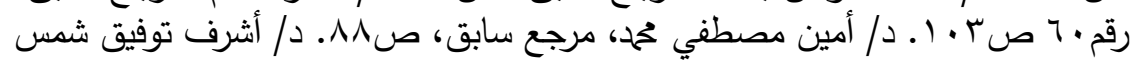

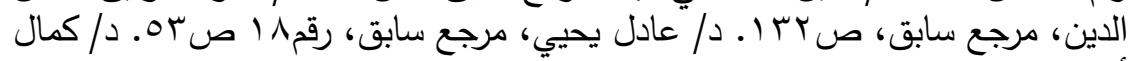

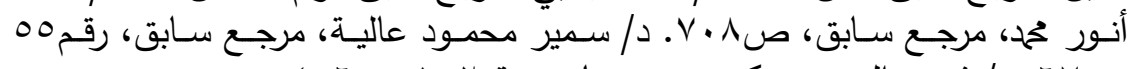

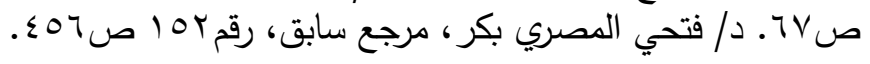


في مصر من جديد، وتجوز إعادة محاكمة المتهم بالرغم صدور الحكم الأجنبي بالبراءة. ذلك أن القول بغير ذلك فيه تعطيل لحكم المادة الثانية بغير سند قانوني أو مسوغ لمنطق تفسير النصوص. نظراً لأن الجرائم

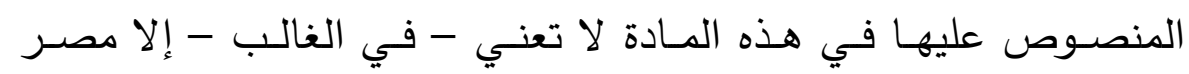

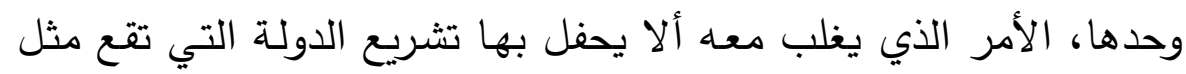

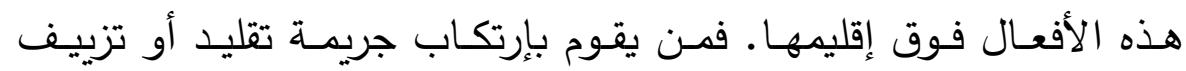

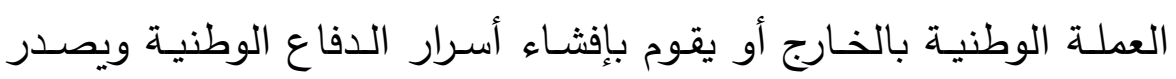

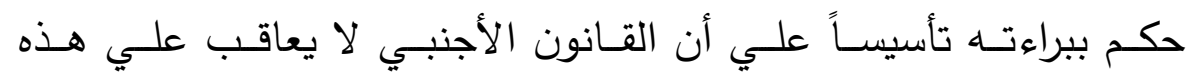

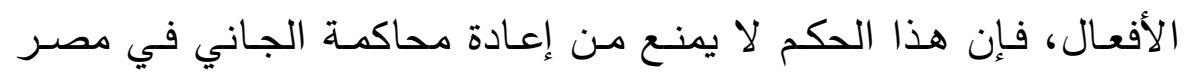

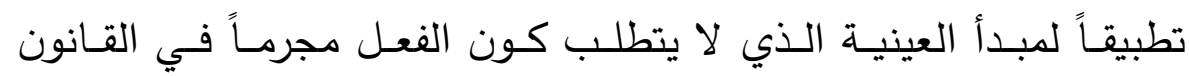
الأجنبي.

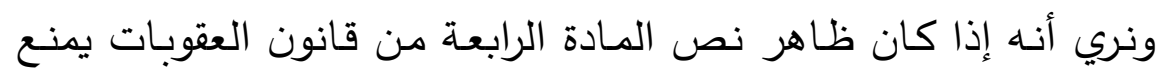

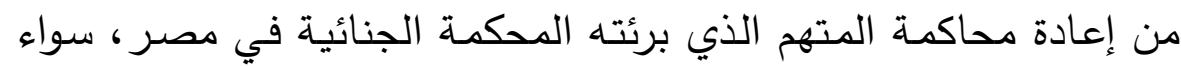

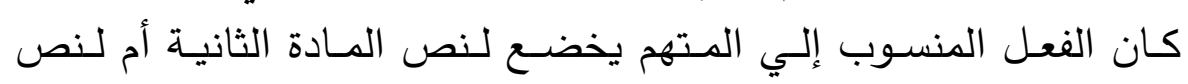

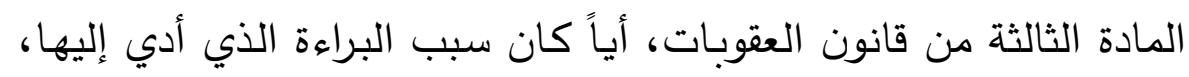

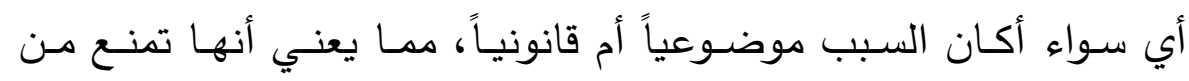

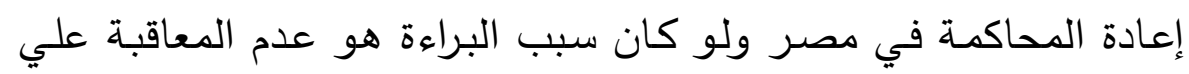

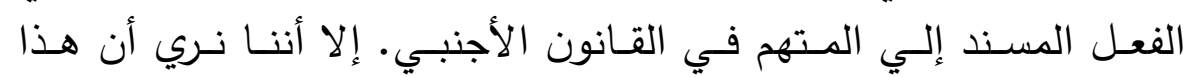

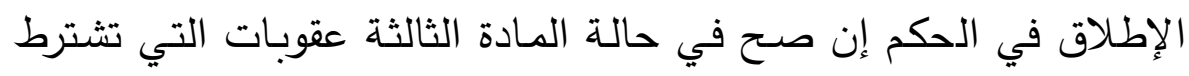
لمحاكمة المصري العائد أن يكون الفعل الذي ارتكبه في في الخارج معاقباً

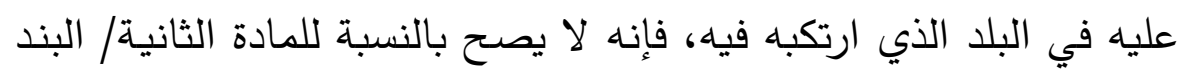

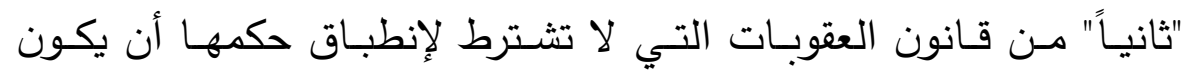

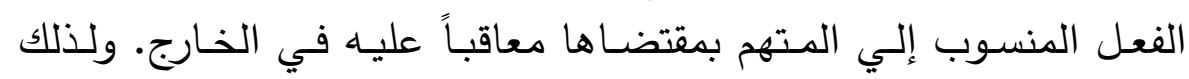
نري أن البراءة المؤسسة علي عدم وجود نص تجريم في قانون المحكمة الأجنبية التي أصدرت الحكم لا يحتج بها في مصر في شـأن الجرائم

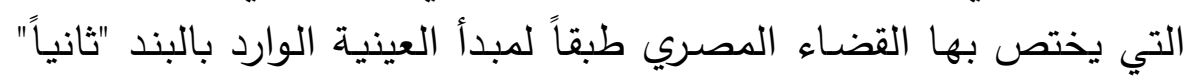

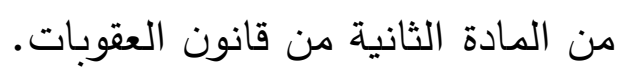




\section{ب- الوضع في فرنسا:}

يمتنع علي القضاء الجنائي الفرنسي محاكمة الثخص مرتكب الجريمـة

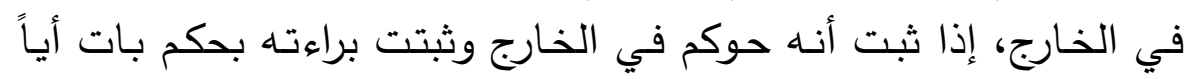

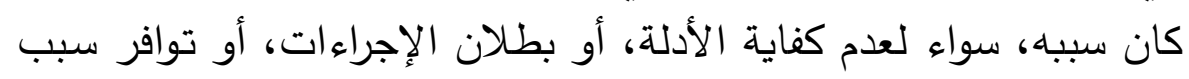

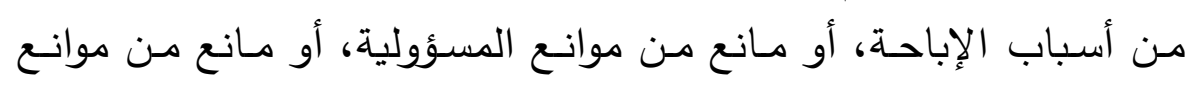
العقاب.

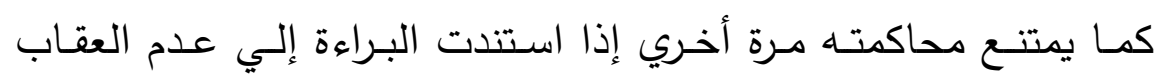

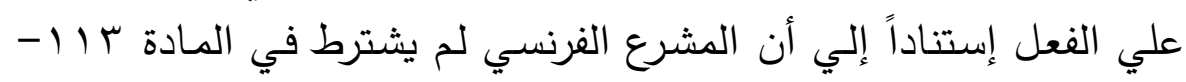

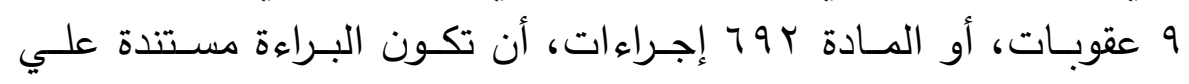
سبب دون آخر • فمتي توافرت الشروط الواجب توافرها في الحكم الجنائي الأجنبي، فيجب الإعتداد به، أياً كان سببها.

\section{المسألة الثانية: صدور قرار بحفظ التحقيق:}

ممـا لاشـك فيـه أنـه طبقاً لنص المـادة الرابعـة مـن قـانون العقوبـات

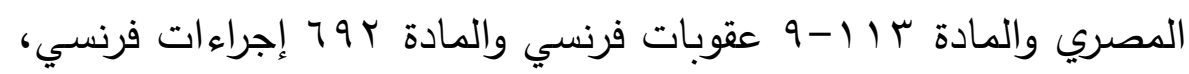

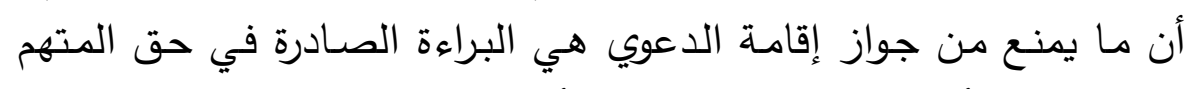

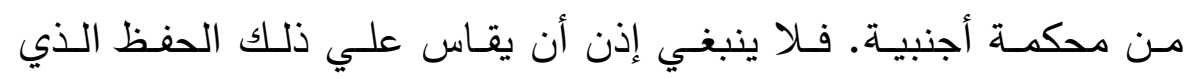

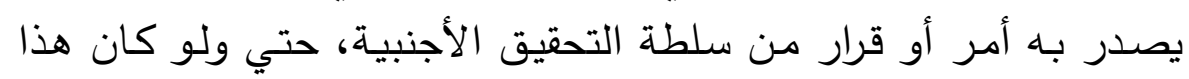

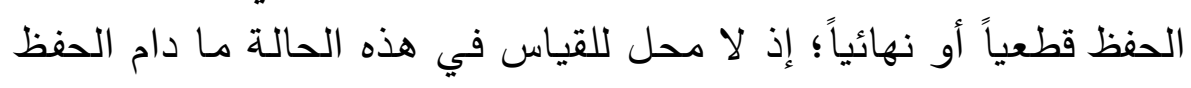

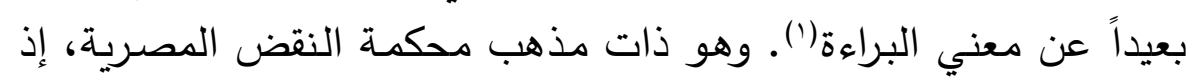

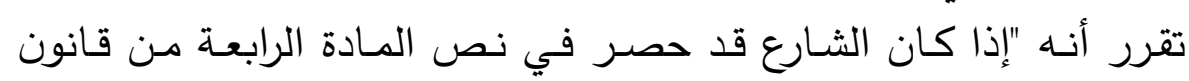
العقوبات القيود المانعة من تحريك الدعوي ضد المتهم في حالتي البراءة

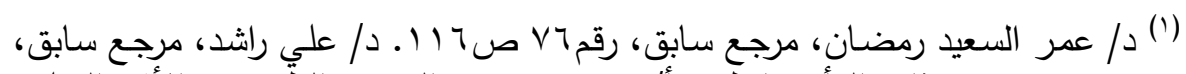

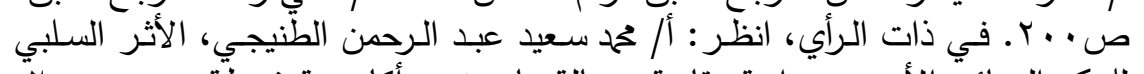

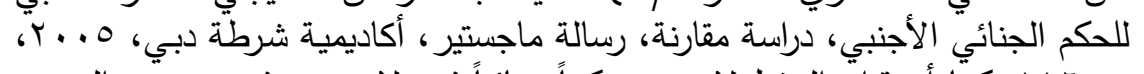

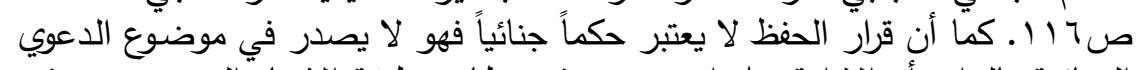

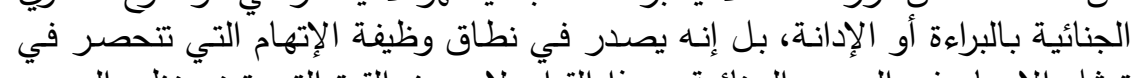

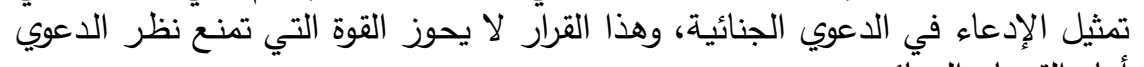
أمام القضاء الجنّائي. 
أو الإدانة المتبوعة بتنفيذ العقوبة، فإن ذلك يعني إستبعاد ما عداهما من

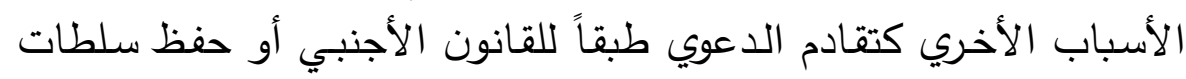

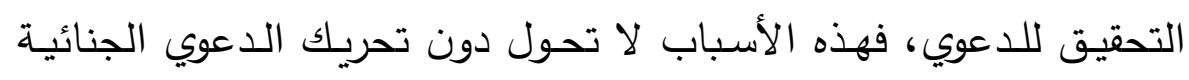

في مصر "(') - (1)

المسألة الثالثة: صدور أمر بألا وجه لإقامة الدعوي الجنائية:

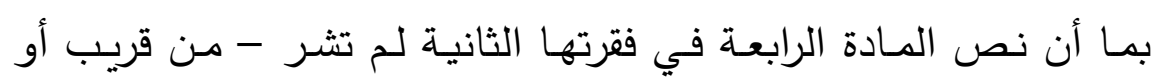

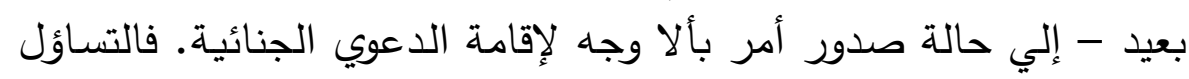
أثير حول مدي إعتباره في حكم البراءة التي تنص عليها المادة الرابعة

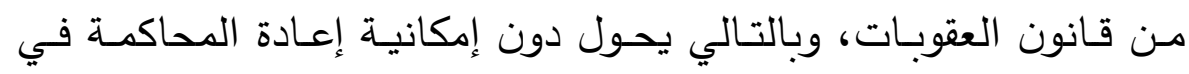
مصر من جديد؟

يري البعض(r) أن صدور أمر بألا وجه لإقامة الدعوي الجنائية وكان

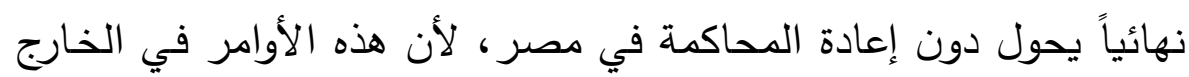

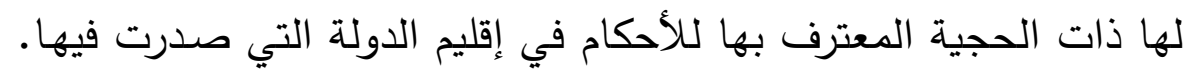
ولم يسلم أغلب الفقه(r) بهذا الرأي، ويري أن صدور أمر بألا وجه لإقامـة

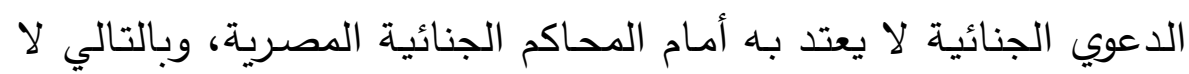

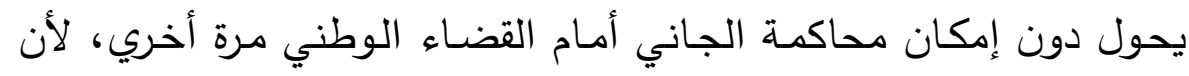

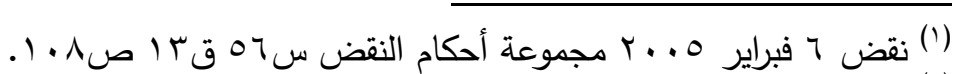

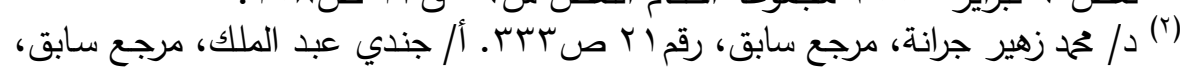

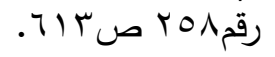

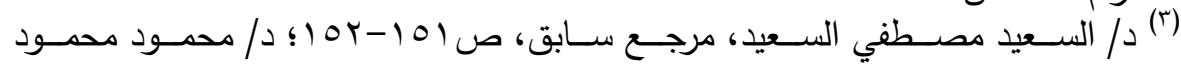

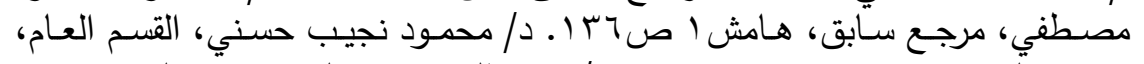

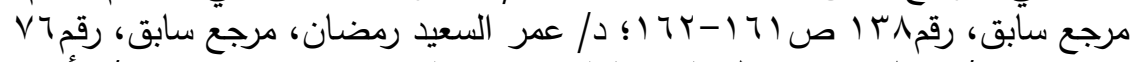

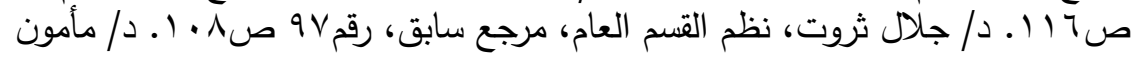

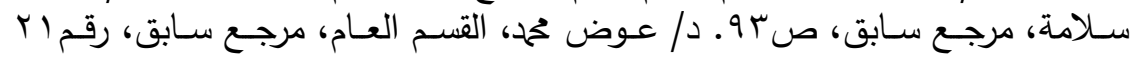

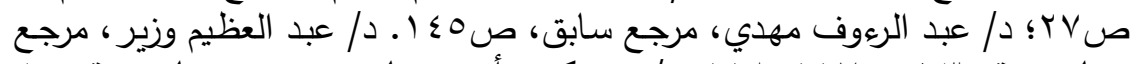

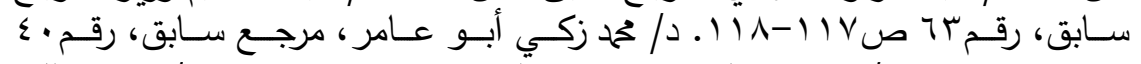

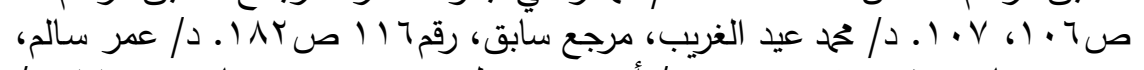

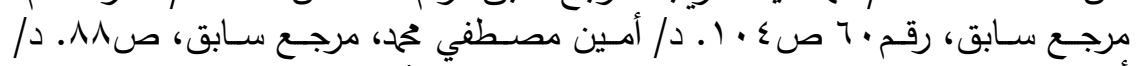

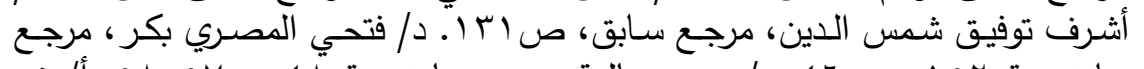

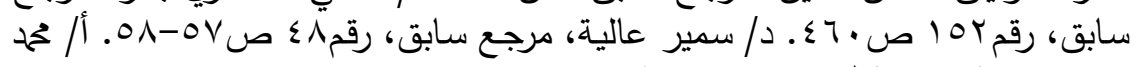

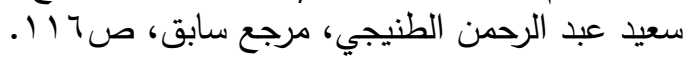


الأمـر بألا وجـه لإقامـة الدعوي لا يرقي إلـي مرتبـة الحكم بـالبراءة الذي الذي

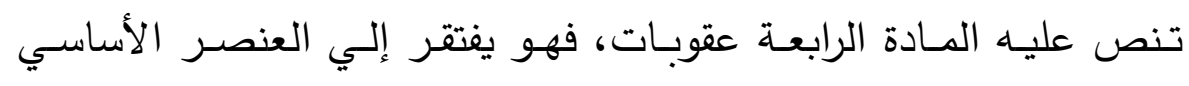

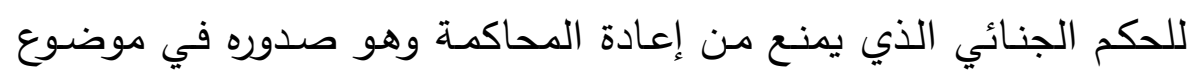

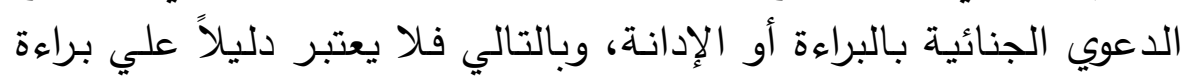

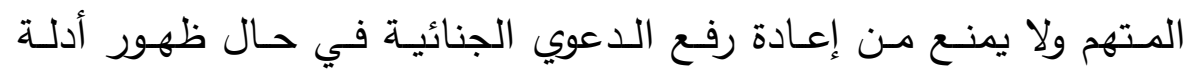

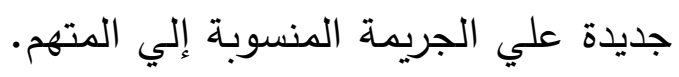
ونـري أنها إذا كـان نص المـادة الرابعـة مـن قانون العقوبـات قد حصر

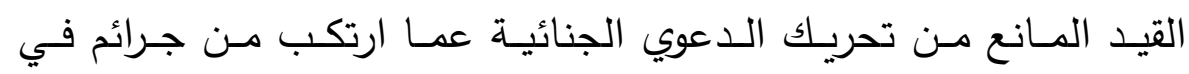

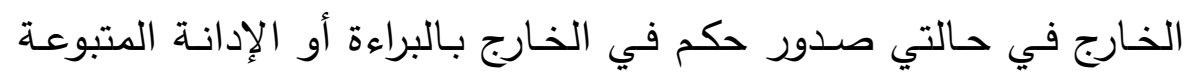

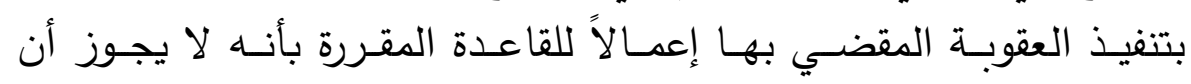

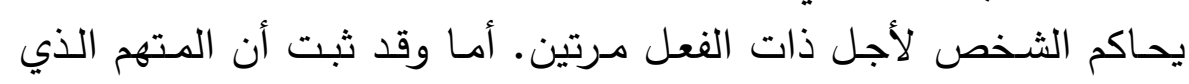
صدر في حقه الأمر بألا وجه لإقامـة الدعوي الجنائية لـ يحاكم أساساً

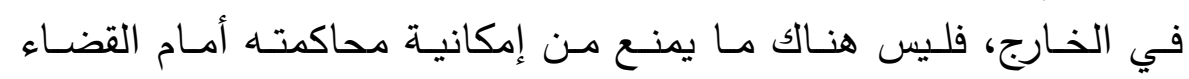

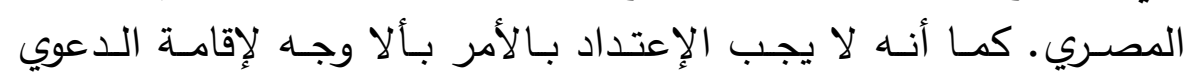
الجنائية الصادر من جهة التحقيق الأجنبية، فهذا الأمر قد يكون صـادراً

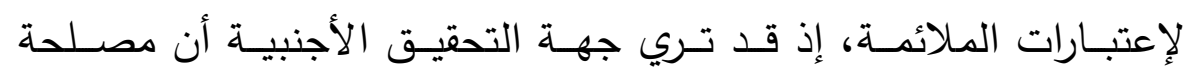

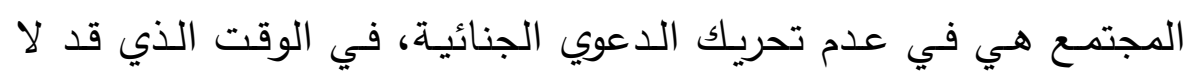

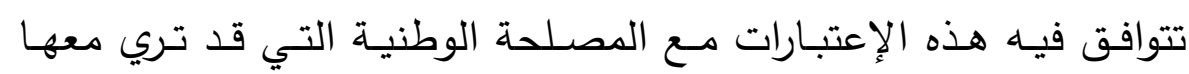

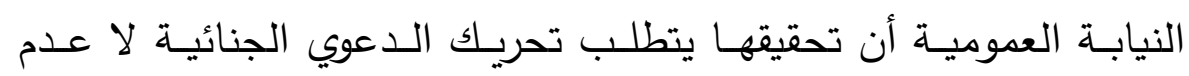
تحريكها.

علي أن عدم الإعتداد بمثل هذه الأوامر لاينكر مـا لهذه الأوامر من أنس

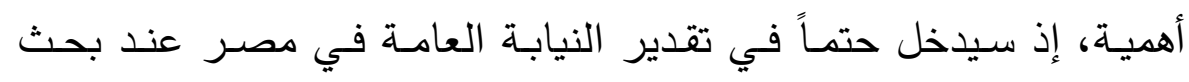

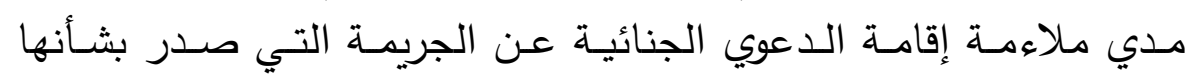

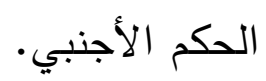

وفي فرنسا ذهبت محكمة النقض إلي أن الأمر بألاوجه لإقامة الدعوي

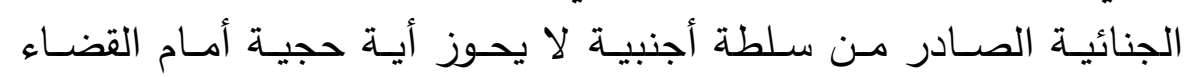


الفرنسـي. وعليـه، يجـوز للقضـاء الفرنسـي محاكمـة الثـص مـرة أخـري

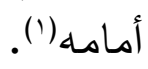

إلا أن البعض(؟) ذهـب عكس ذلك، ويـري الإعتـداد بـالأمر بـألا وجـه لإقامة الدعوي الجنائية الصادر من سلطة أجنبية سبباً للدفع بعدم جواز الإندان

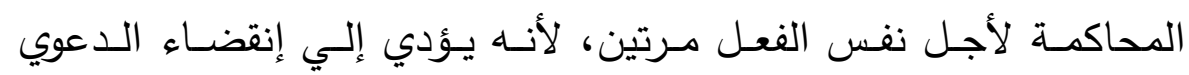

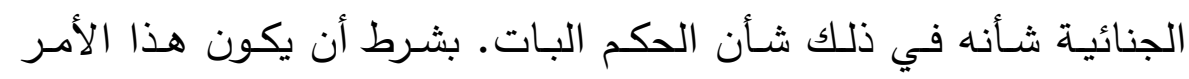

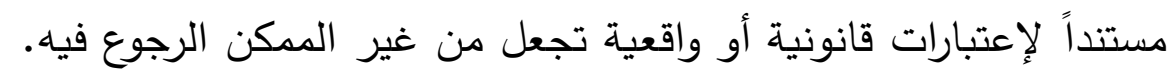
المسألة الرابعة: إنقضاء الدعوي الجنائية بمضي المدة:

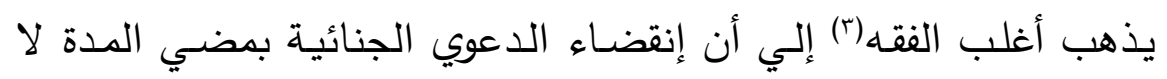

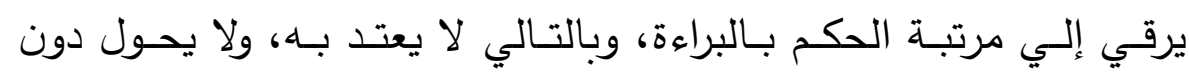

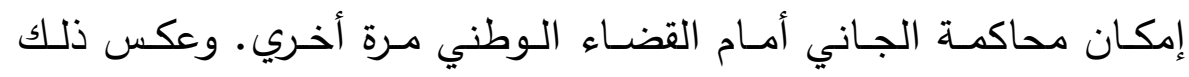

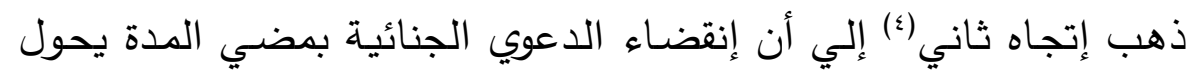
دون إمكان محاكمة الجاني أمام القضاء الوطني مرة أخري، إستناداً إلي لئي

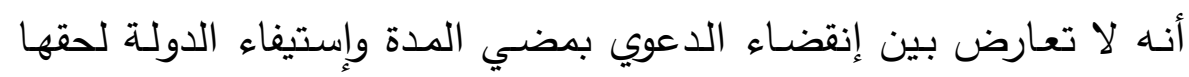

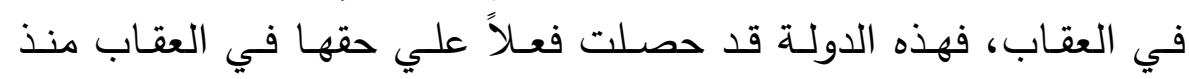

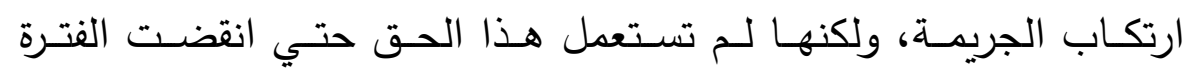

(') crim. 1 · août 19.0, B. $n^{\circ} \varepsilon \cdot 1$; Trib. Corr. Seine, $r$ l fev. 19.r, JDI, $19 . \varepsilon, 9.0$; crim. ${ }^{r}$ sép. $r \cdots v, B . n^{0} r$ r .

(ॅ) Donnedieu De Vabres (H.): Les principes modernes du droit pénal international, op.cit. p. ${ }^{\mu r}$. Lombois (C.): op.cit. $n^{0} 9 \wedge$, p. 0.7 .

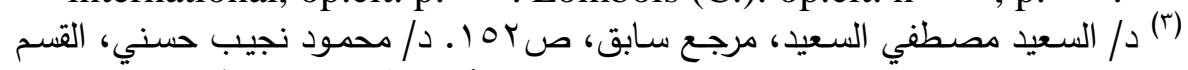

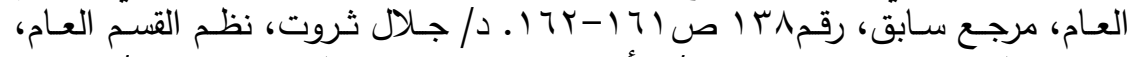

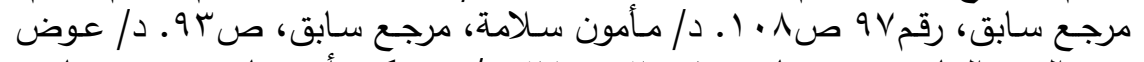

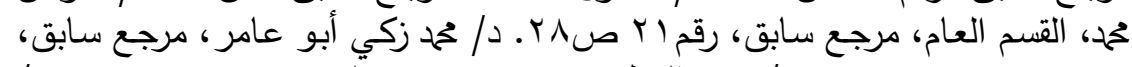

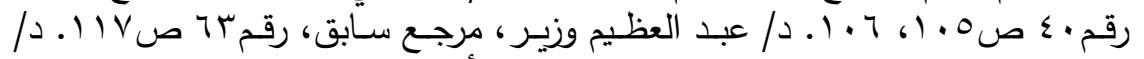

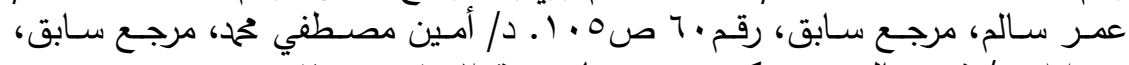

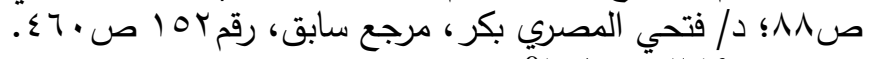

Huet (A.) et Koering-Joulin (R.): op.cit. $n^{0107}$, p. sq $^{\circ}$; Lombois (C.): op.cit. $n^{0} \uparrow \wedge \cdot$ et $\Sigma \cdot r$, p. $\leqslant \wedge \vee$.

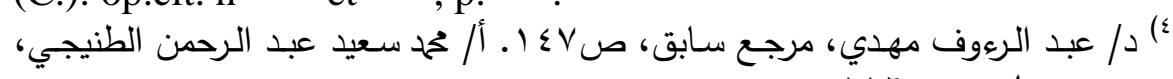

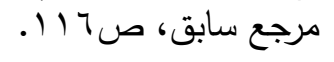


المحددة لـه وهـي انقضــاء الـدعوي بالتقـادم، حيـث تتحقـق بعدم عقـاب الجاني مصلحة قانونية أولي بالإعتبار من المصلحة في عقابه. بينما ذهب إتجاه ثالث(') - وبحق - إلي أن تقادم الدعوي يحول دون

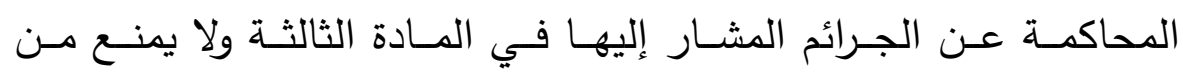

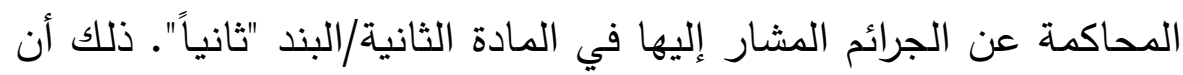

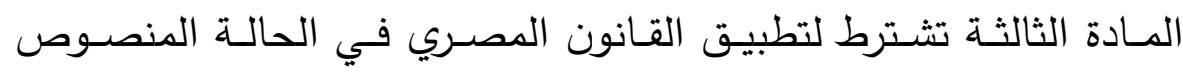

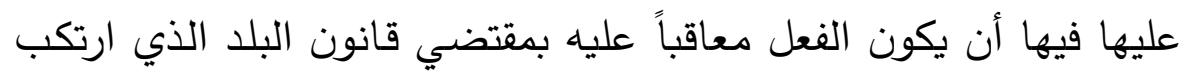

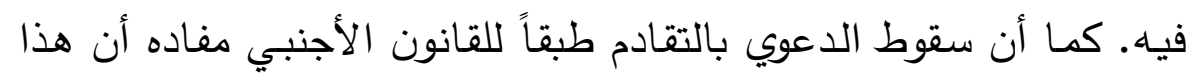

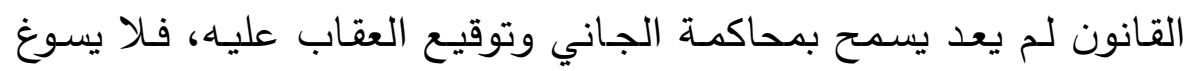

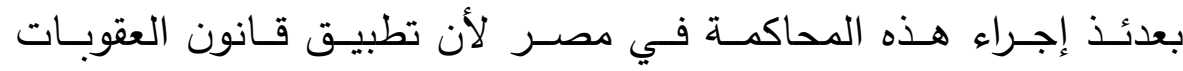

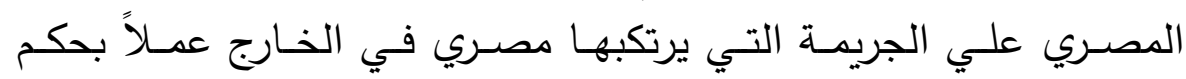

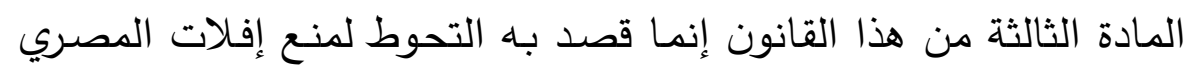

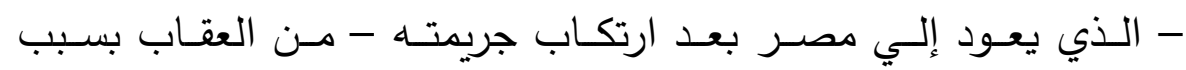

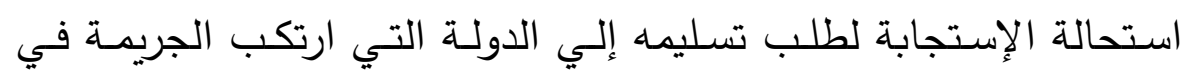
إقليمها والحرص علي تجنيب السلطات الوطنية الظهور بمظهر المتستر عليه، وهذه المعاني غير متحققة فيما يتعلق بالجرائم الواردة في المـادة

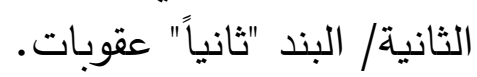

المسألة الخامسة: العفو عن الجريمة (العفو الثامل): قد يصـدر عفـو عـن الجريمـة (عفو شـامل) ممـن يملك إصـداره في

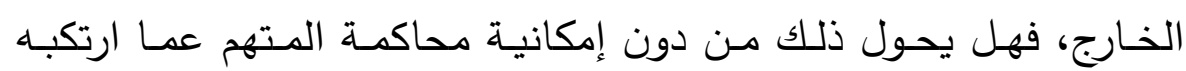
أمام القضاء الوطني؟

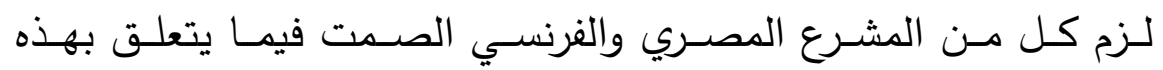

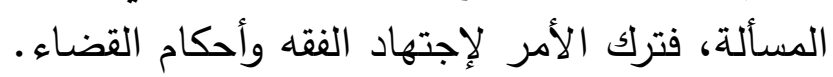

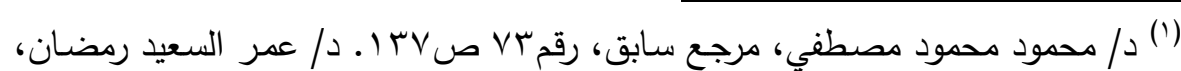

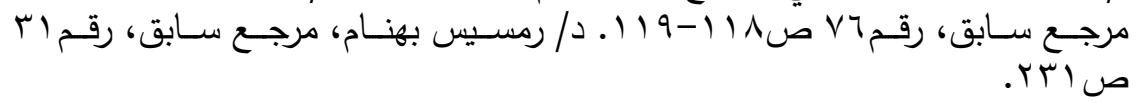


ففـي مصـر ، ذهـب الـبعض(') إلـي أن العفـو الثــامل لا يحـول دون

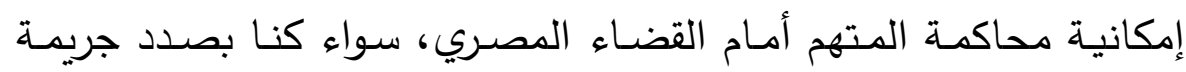

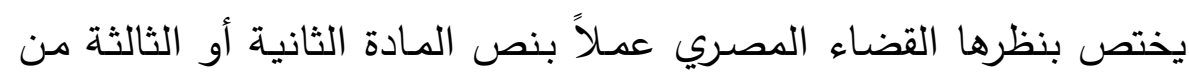
قانون العقوبات، فالعفو الشامل لا يرقي إلي مرتبة الحكم بالبراءة. إلا أننا نري مع البعض الآخر (r) من الفقه إلي أن العفو الشامل يحول

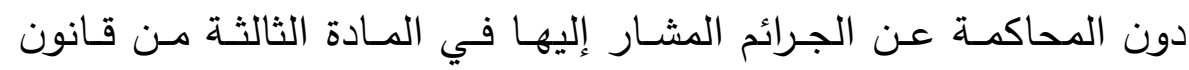

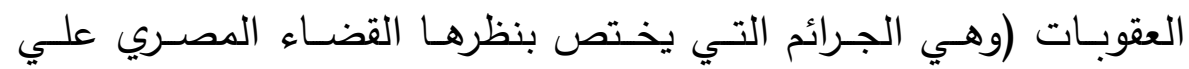

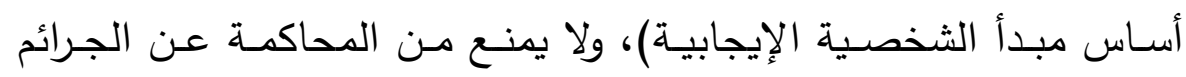

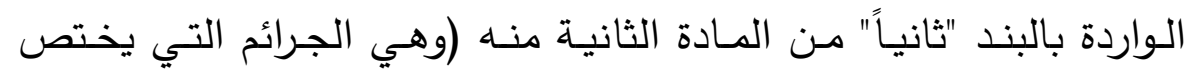

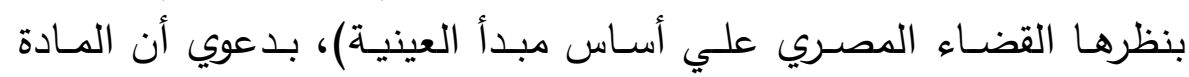

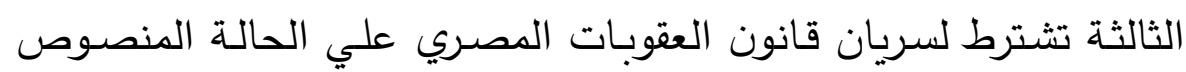

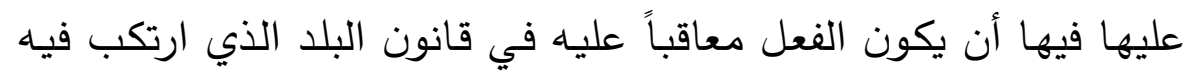

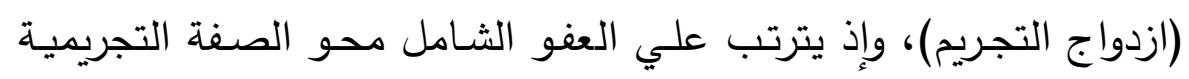
عن الفعل الذي ارتكبه المتهم ينتفي الثرط المذكور ولا سبيل لمحاكمته المته أمام القضاء المصري.

ولا يعتـد القضــاء الفرنسـي بقـانون العفـو الثـامل الصـادر مـن الدولــة

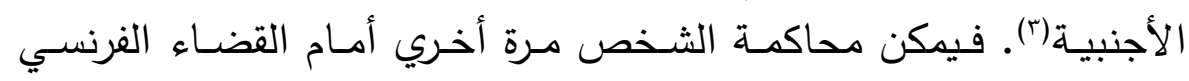

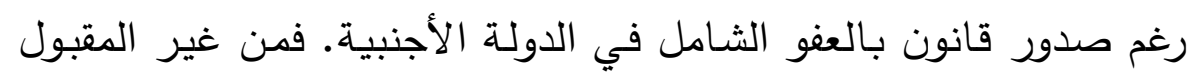

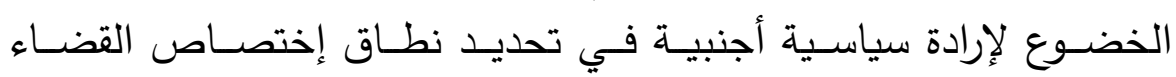

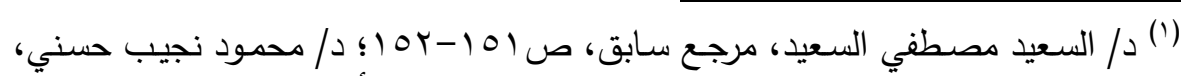

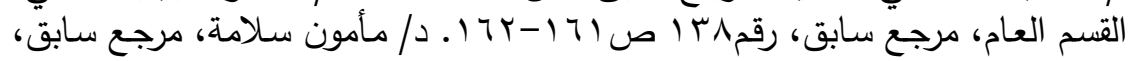

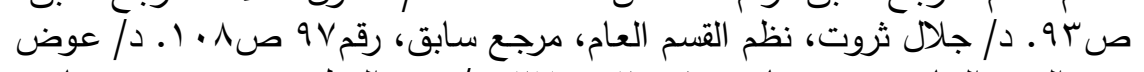

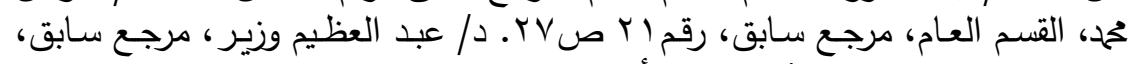

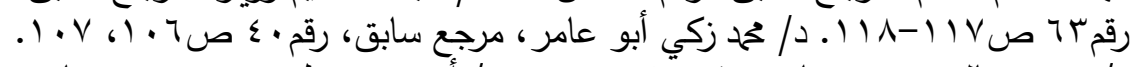

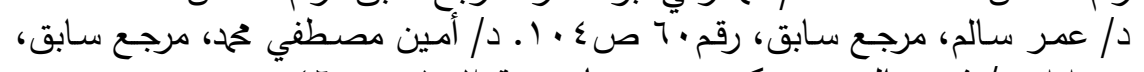

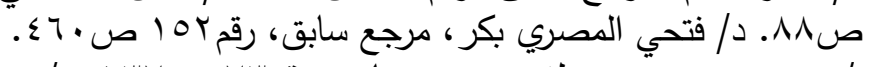

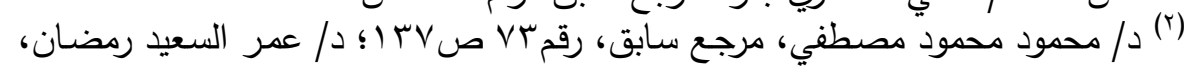

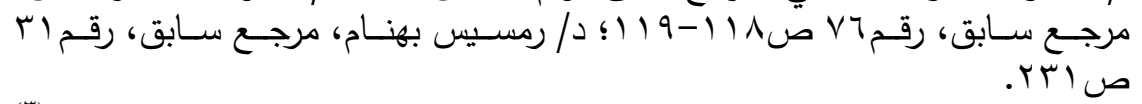
${ }^{(r)}$ crim. $r$ oct. $r \cdots r, B \cdot n^{0} 190$. 
الفرنسي، ذلك أن العفو يمكن أن يصـدر لأسـباب سياسـية أكثر منهـا

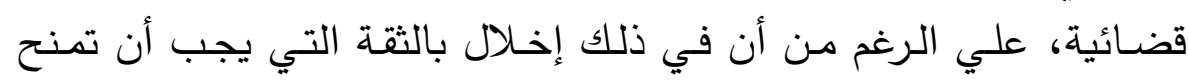

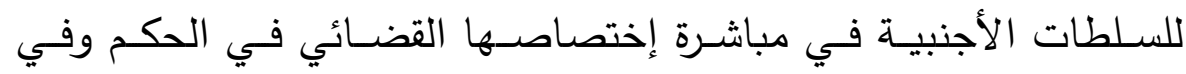
التنفيذ(')

\section{هل يشترط أن يكون الحكم الصادر بالبراءة باتاً:}

اشترط نص المادة الرابعة من قانون العقوبات أن يكون الحكم الأجنبي

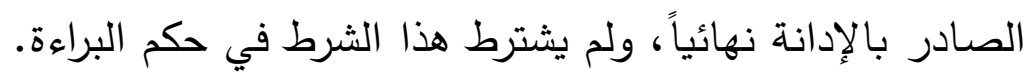

ونـري مـع أغلب الفتهـ(r) إلـي أن ذلك كـان مـن بـاب السـهو لأن هـا

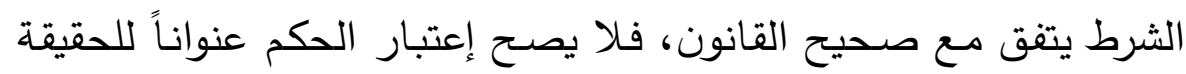

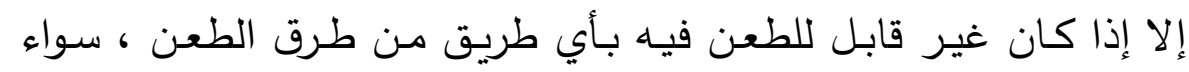

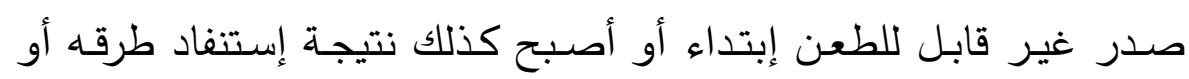

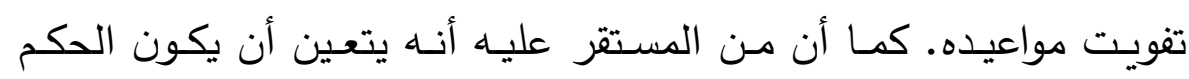

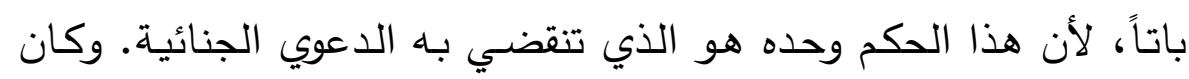

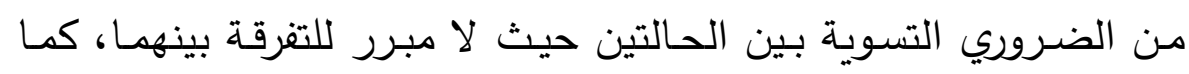

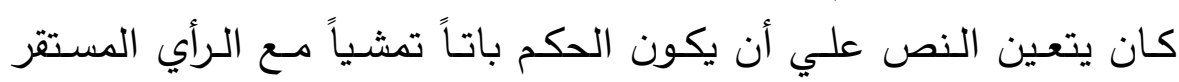

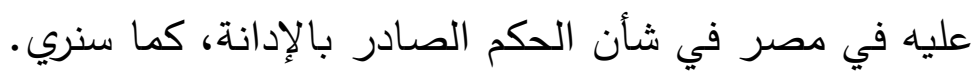

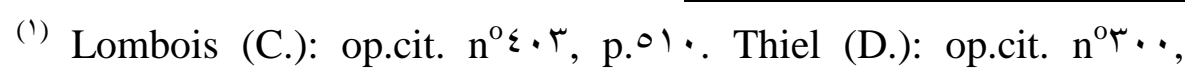
p. $r \leq \tau_{-} r \leqslant \vee$; Huet (A.) et Koering-Joulin (R.): op.cit. $n^{0} 100$, p. $r \leqslant \Lambda_{-}$ $r \leqslant 9$; Pralus (M.): op.cit. p. $07 r$.

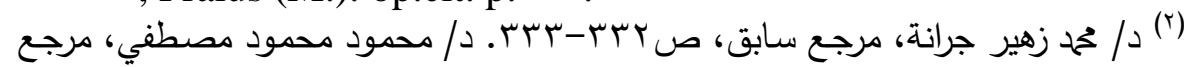

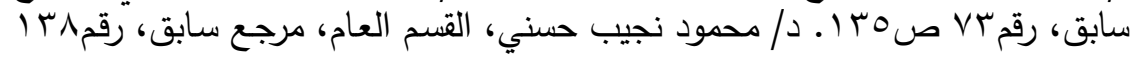

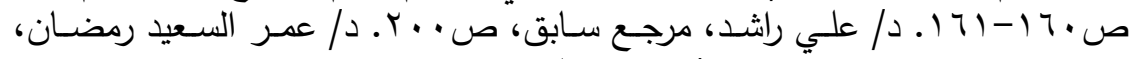

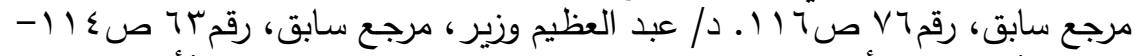

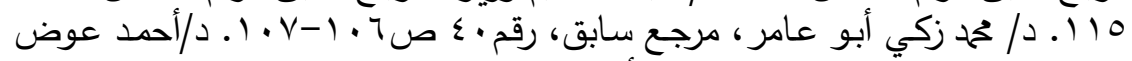

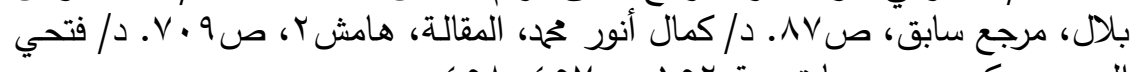

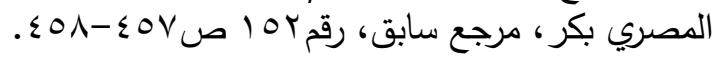




\section{المطلب الثاني \\ الحكم بالإدانة}

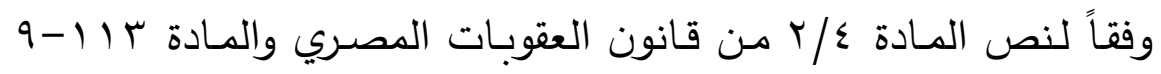

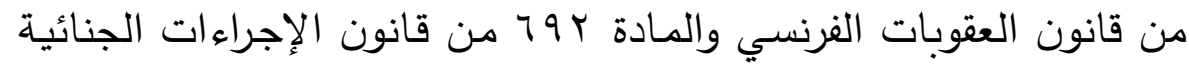

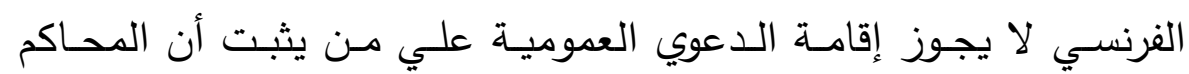
الأجنبية .... حكمت عليه نهائياً واستوفي عقوبته".

فالمشرع، في فرنسـا ومصر استلزم للإعتداد بالحكم الجنـائي الأجنبي

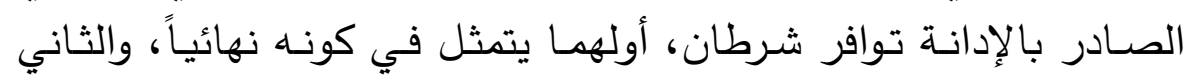

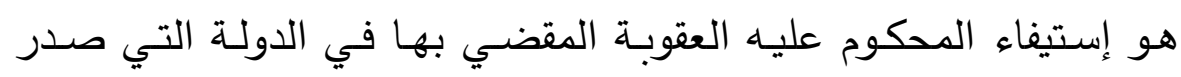
فيها هذا الحكم. ونتناول كل شرط في فرع مستقل. 


\section{الفرع الأول \\ نهائية الحكم}

اشترطت المـادة الرابعة من قانون العقوبـات المصـري والمـادة س | (-9

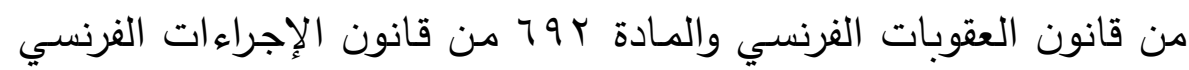
في الحكم الأجنبي الصـادر بالإدانـة حتي يتمتع بالحجيـة السـلبية أمسام المحاكم الوطنية أن يكون "نهائياً".

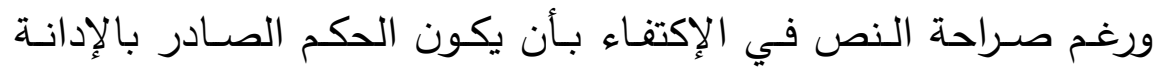

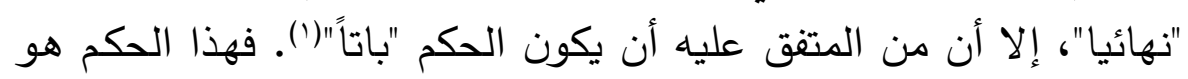
وحده عنوان الحقيقة وتنقضسي بـه الدعوي الجنائية ولا يجيز الرجوع إلي لياني موضوع الدعوي مرة أخري.

والغالب أن معظم التشريعات تعتبر الحكم "باتاً" إذا لم يكن من الجائز

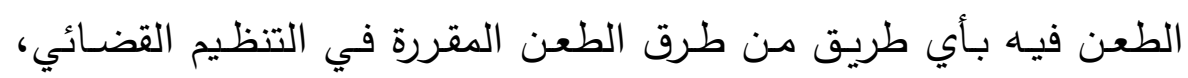

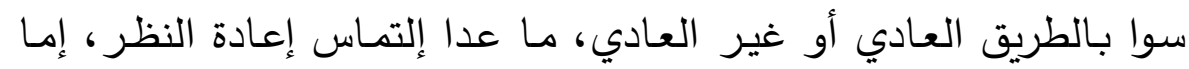

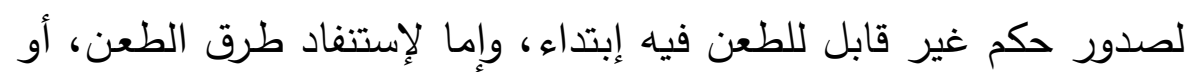

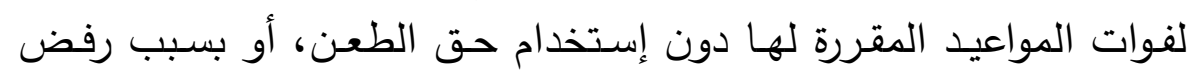

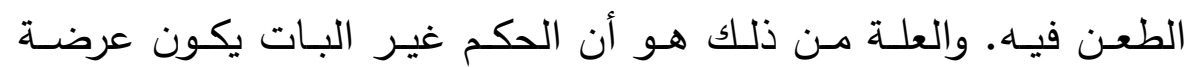
للإلغاء بسبب الطعن فيه.

أما إذا كان ميعاد الطعن مفتوحاً أو كان قد طعن فيه ومازال الطعن

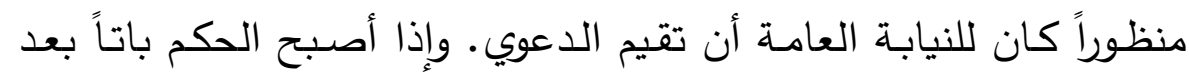

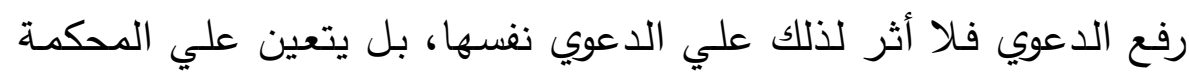

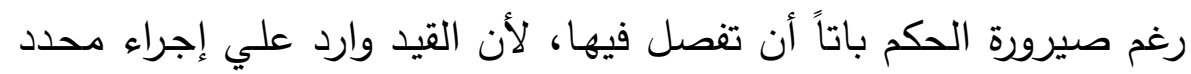
وهو رفع الدعوي دون سواه(r).

V)

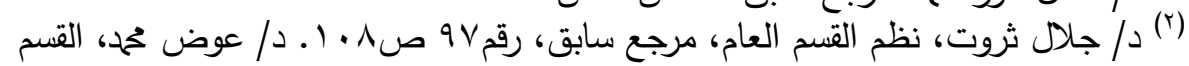

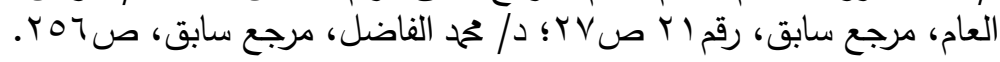




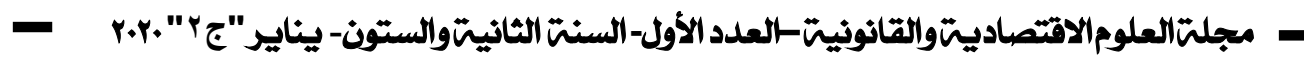

والفصل فيما إذا كان الحكم باتاً أو غير بات إنما يكون بالرجوع إلي قانون الدولة التي أصدرت محاكمها الحكم) (').

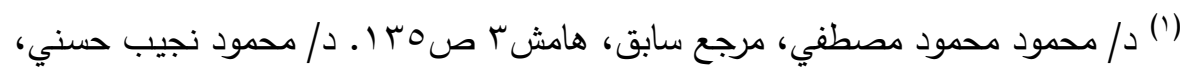

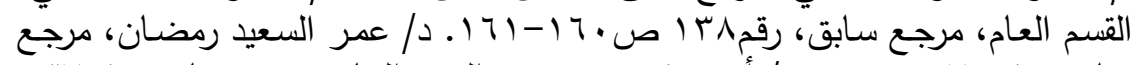

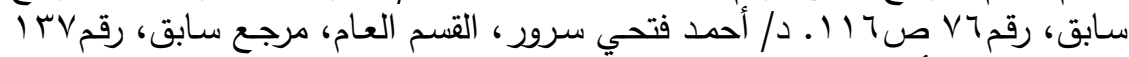

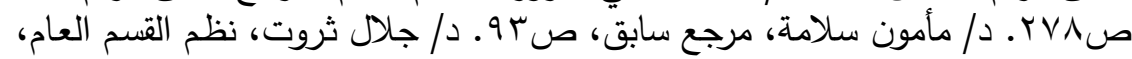

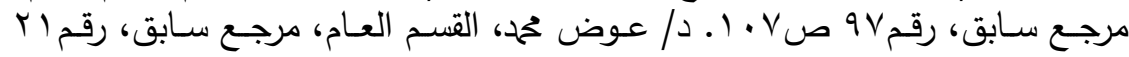

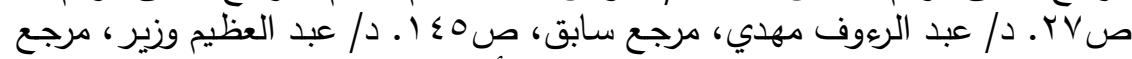

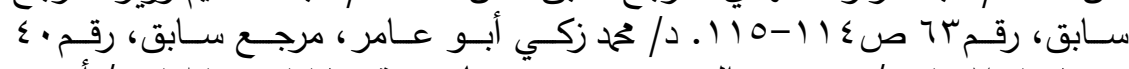

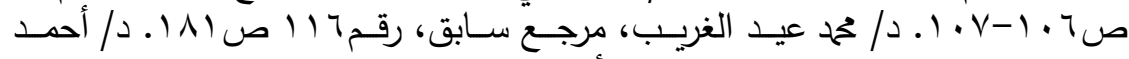

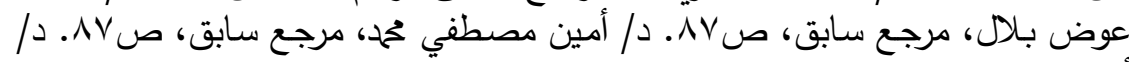

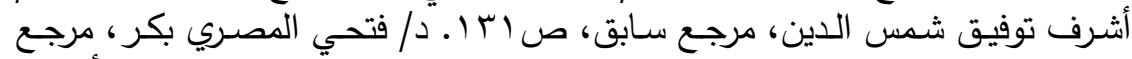

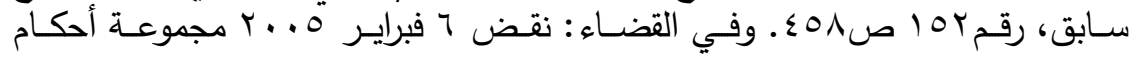

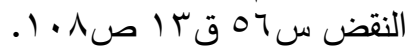

Lombois (C.): op.cit. $n^{\circ} \uparrow 9 \wedge$, p. ${ }^{\circ} \vee$. En juris.: cour d'appel de Paris, 19 avr. 1971, Gaz.Pal. 1971, II, p. $1 \vee 9$; Huet (A.) et Koering-Joulin (R.): op.cit. $\mathrm{n}^{0} 10 \leqslant$, p. $Y \leqslant \vee$. cour d'appel de Nïmes 1. nov. 197v, D. 1971, p. IIr. 


\section{الفرع الثاني}

\section{إستيفاء العقوبة}

لم يكتف المشرع، في فرنسـا أو في مصر ، للإعتداد بالحكم الجنائي

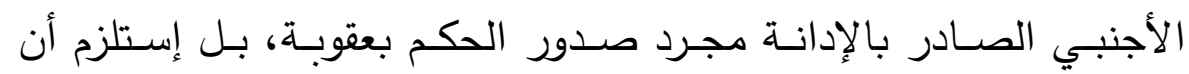

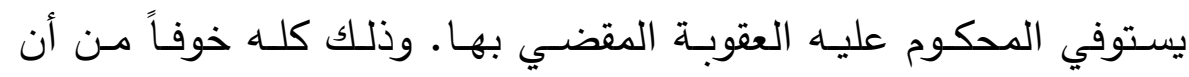
يكون المحكوم عليه قد فر - بعد صدور الحكم وقبل إستيفاء العقوبـة،

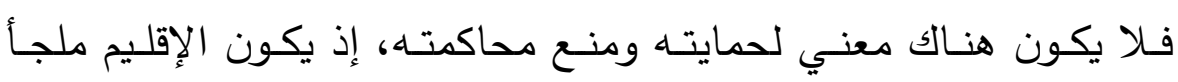

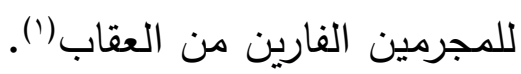

فمـا المقصود بإستيفاء العقوبـة؟ وهل يمكن لترتيب هذه الحجيـة للحكم الجنائي الأجنبي أن نساوي بين تنفيذ العقوبة والحالات التي لاءئين ينفذ فيهاء

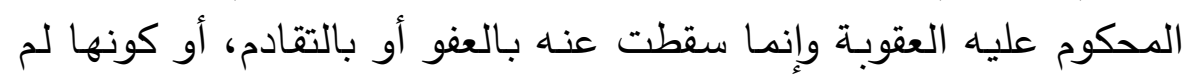

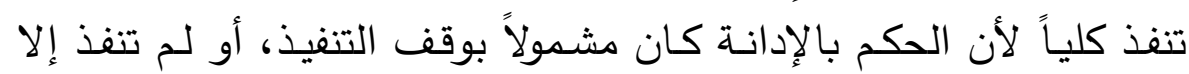

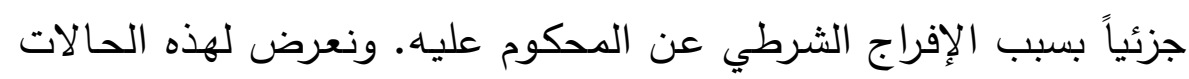
تباعاً.

\section{أولاً: تنفيذ العقوبة:}

طبقاً لنص المادة الرابعة من قانون العقوبات المصري والمادة ب | 1-9

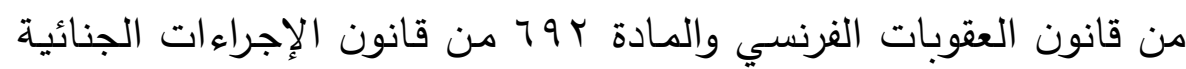
الفرنسي يجب في حالة الحكم بالإدانة أن تكون العقوبة قد تم إستيفائها. ويثير هذا الشرط مسألتين: أ- المقصود بالعقوبة الواجب تنفيذها:

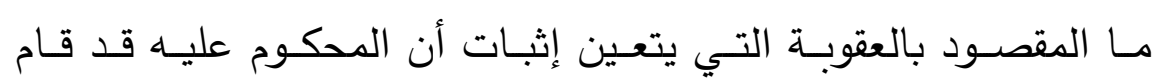
بتنفيذها؟

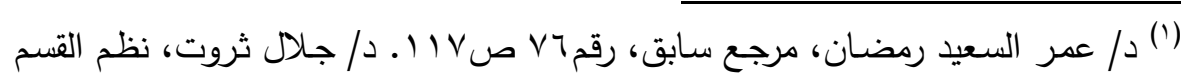

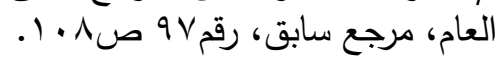


ذهب رأي في الفقه المصري(') إلي وجوب إستيفاء المحكوم عليه جميع

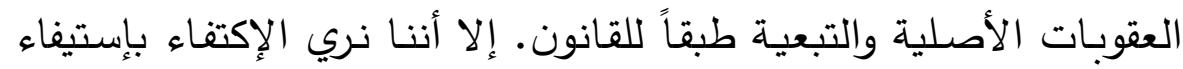

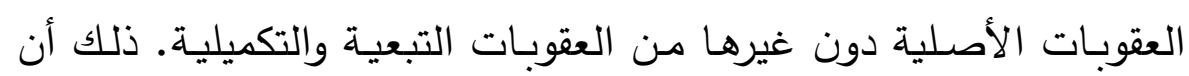
هذه العقوبات الأخيرة تتسم بطول مدة تنفيذها، واشتراط تنفيذها سيؤدي

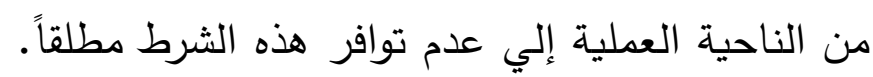
ب- التنفيذ الجزئي للعقوبة:

اشترطت الفقرة الثانيـة مـن المـادة الرابعـة مـن قـانون العقوبـات والمـادة

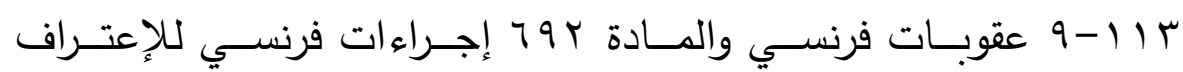
بالحجية السلبية للحكم الجنائي الصـادر بالإدانة أن يكون المحكوم عليه

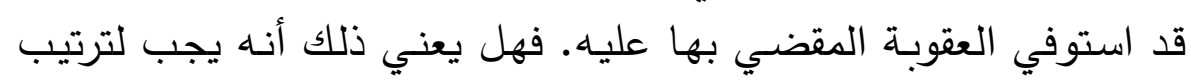

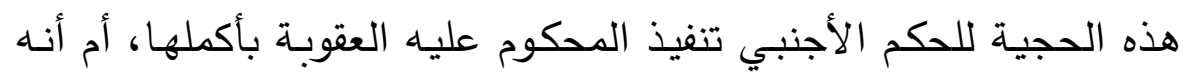
يكفيه تنفيذ قدر من العقوبة لكي تمتنع محاكمة الشخص مرة أخري؟

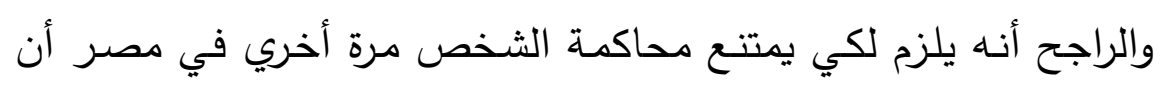

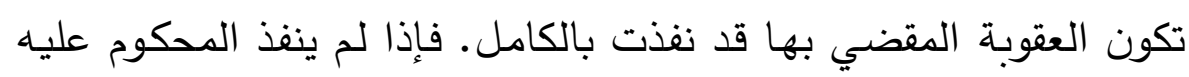

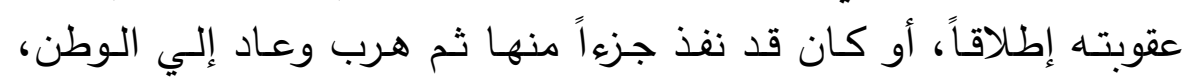

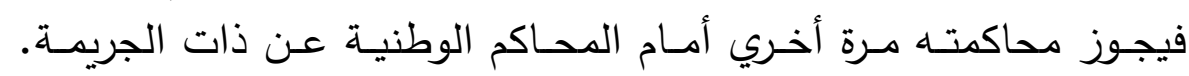
والقول بغير ذلك يعني حماية المتهم ومنع محاكمته، فيكون الإقليم ملجأ للمجرمين الفارين من العقاب(؟).

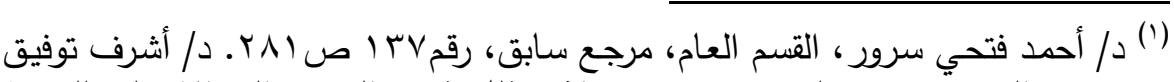

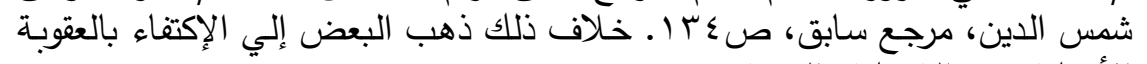
الأصلية دون التكميلية والتبعية. مرن.

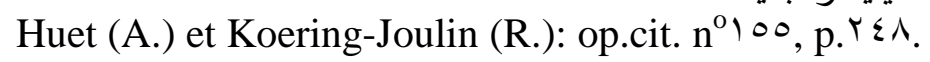

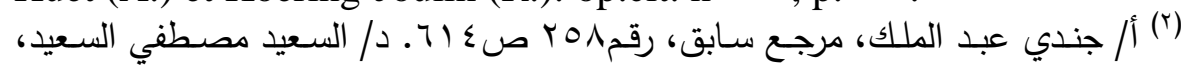

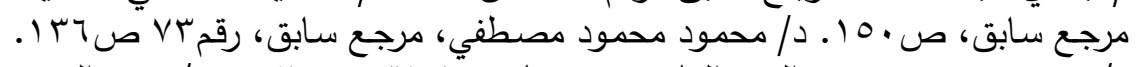

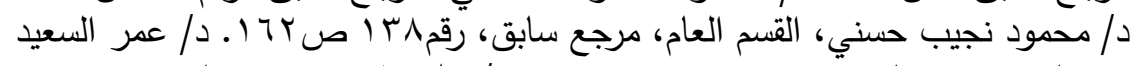

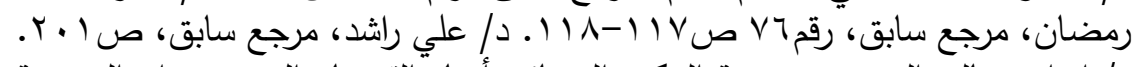

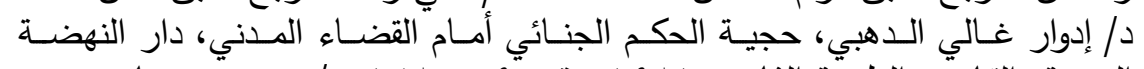

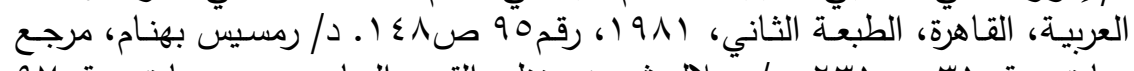

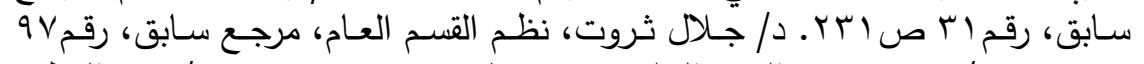

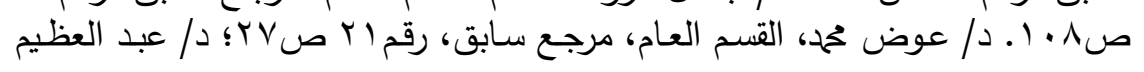


وتقدير ما إذا كان المتهم قد استوفي العقوبة أم لا، يكون وفقاً للقانون

الذي صدرت العقوبة ونفذت بالتطبيق لأحكامه(').

ويؤخذ علي نص المـادة الرابعـة من قانون العقوبـات أن القاضـي غير

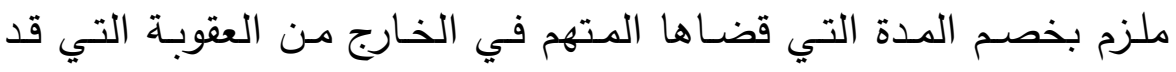
يقضي عليه بها عند إعادة محاكمته في مصر ، بل لـه أن يسقطها كلية

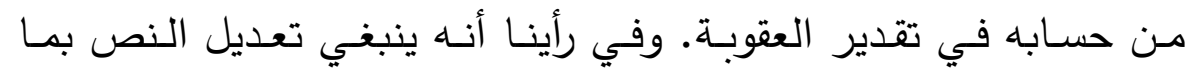

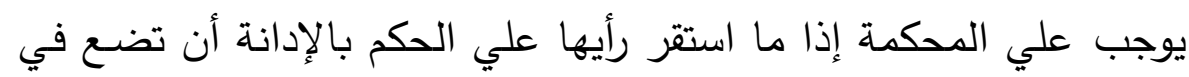

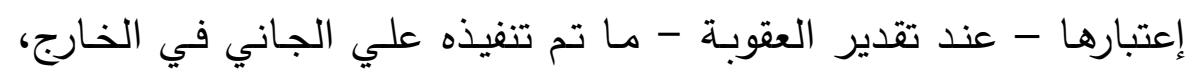

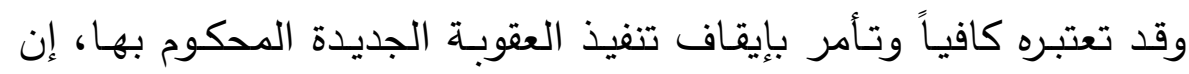

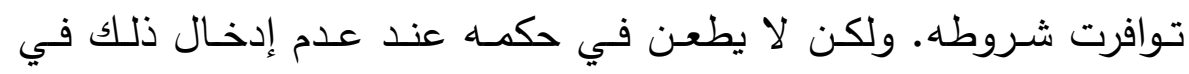

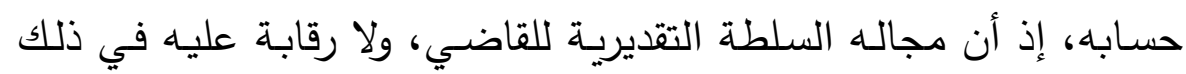

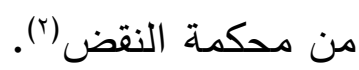

ويتضـح من نص المـادة ب | 1-9 عقوبـات أن المشرع الفرنسي يشترط

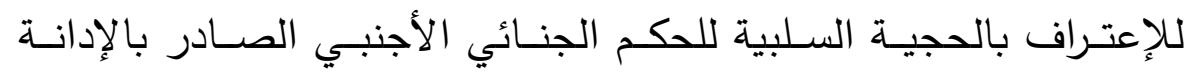

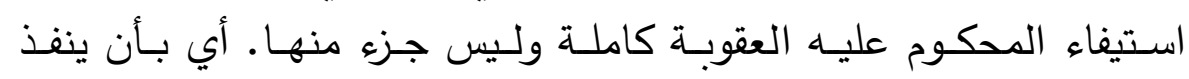

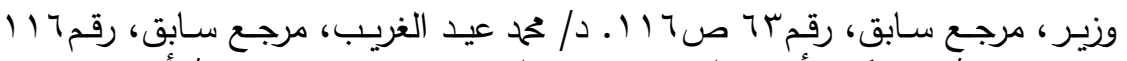

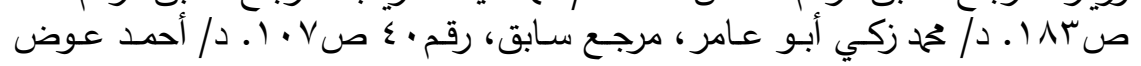

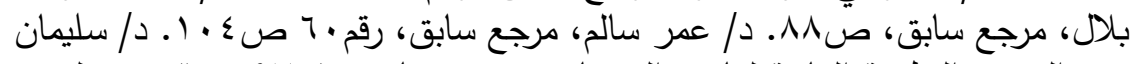

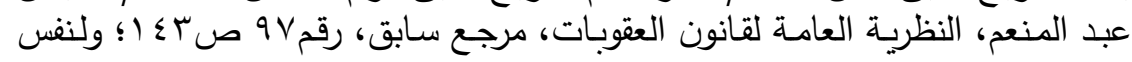

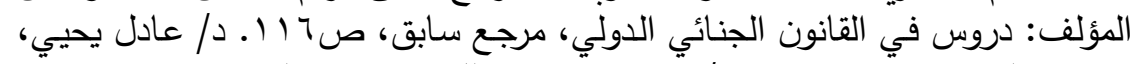

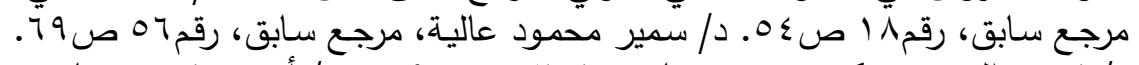

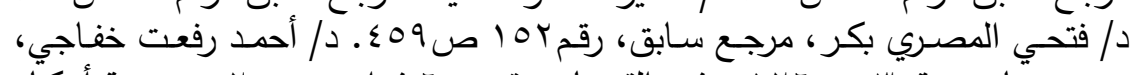

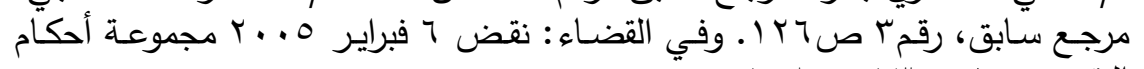

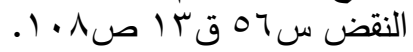

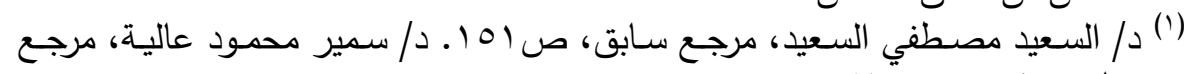

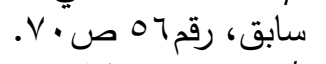

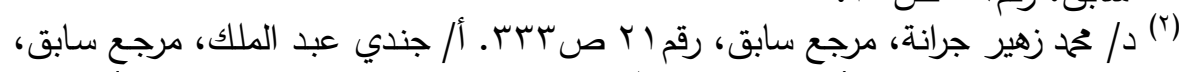

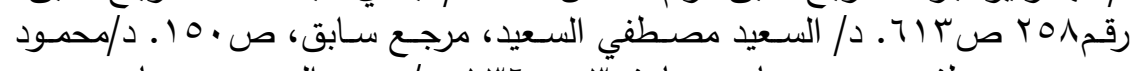

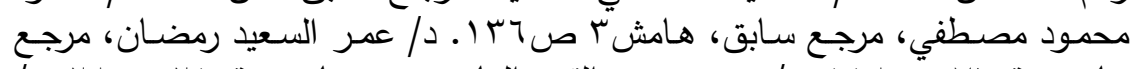

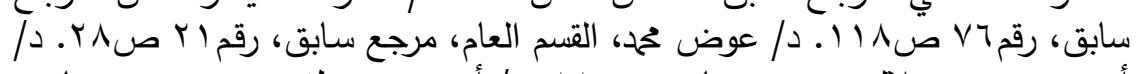

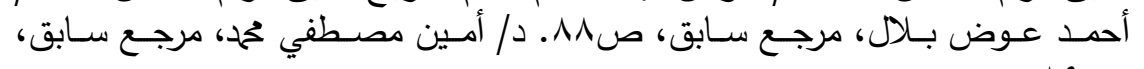
ص صو. 19. 
العقوبـة كاملـة داخل المؤسسـة العقابيـة أو أن يدفع الغرامـة المحكوم بهـا كلها.

أما إذا هرب المحكوم عليه من التنفيذ كلياً أو نفذ جزء من العقوبـة فقط

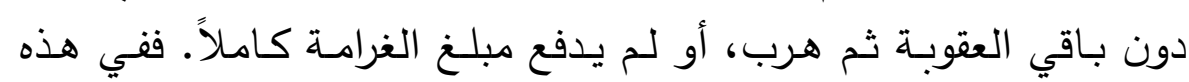

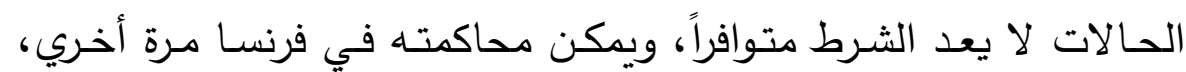

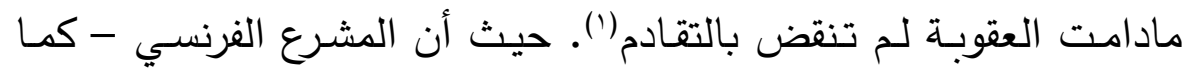

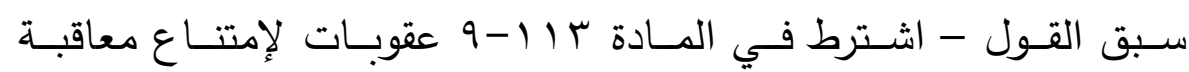
الفرنسي مرة أخري عن نفس الوقائع أن يثبت أنه استوفي العقوبـة كاملة

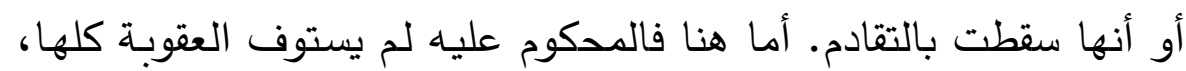

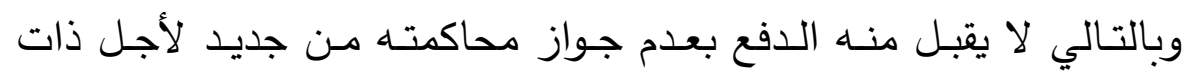

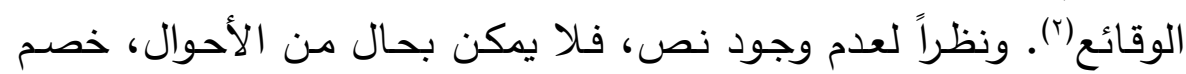

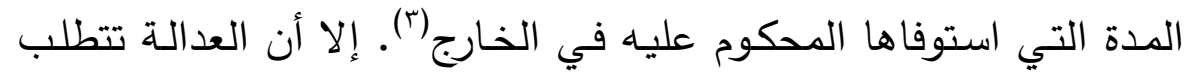
أنه في حالة الحكم بالإدانة عليه في فرنسا يتم خصم المدة التي قضـاها

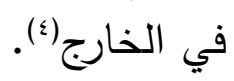

ثانياً: سقوط العقوبة بالعفو عنها أو بمضي المدة:

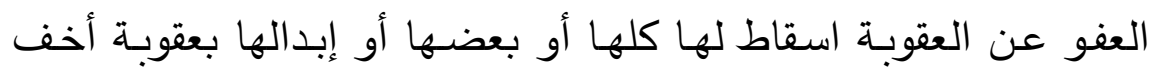

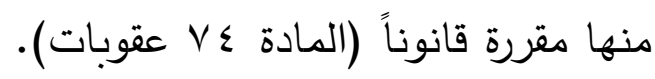
وبهذا يتضح أن للعفو عن العقوبة ثلاث صور (॰):

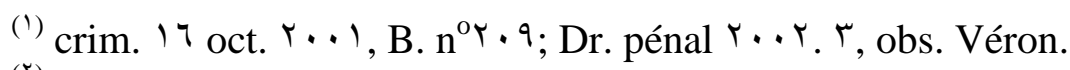

(`) crim. ₹ mars $19 \leqslant \wedge$, B. $n \vee r$. Thiel (D.): op.cit. $n^{\circ} \vee \wedge$, p. ${ }^{\top} \vee$.

(r) crim. $r$ mars 1971, B. $n^{0} 1 r^{4}$; crim. 11 juin 1914, B. $n^{0} r \cdot r$;

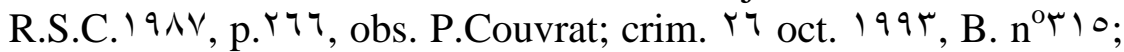
crim. Y oct. 199V, B. $n^{\circ}$ Y $\varepsilon$.

(₹) Lombois (C.): op.cit. $n^{0} \xi \cdot r$, p. ${ }^{0.9}$; Kunter (N.): op.cit. $n^{0} 11$, p. ${ }^{\top} \cdot$. Thiel (D.): op.cit. $n^{0} \vee 9$, p. 71 .

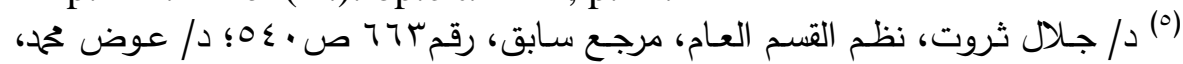

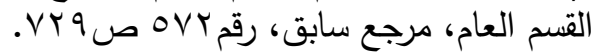




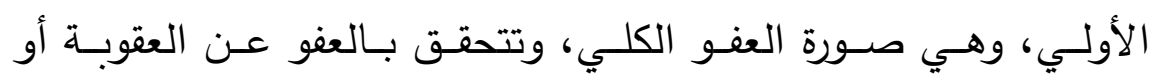

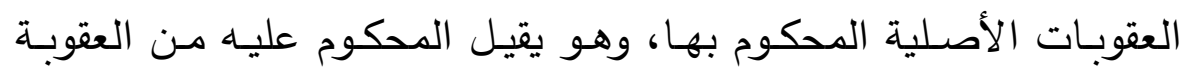
نهائياً.

الثانيـة، وهي صورة العفو الجزئي، وتتحقق بالعفو عن بعض العقوبـة

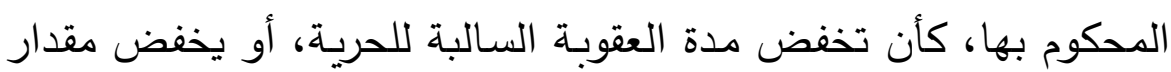

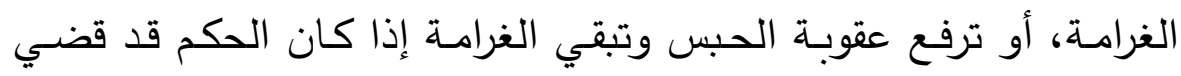

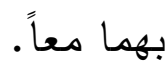

الثالثة، وهي صـورة العفو البدلي، وهو إستبدال العقوبـة المحكوم بها بعقوبة أخف منها مقررة قانوناً.

أما تقادم العقوبة فمعناه مضي مدة زمنية تبدأ من تاريخ صدور الحكم البات أو صيرورته كذلك وحتي تاريخ إنتهاء المدة كما يحددها القانون،

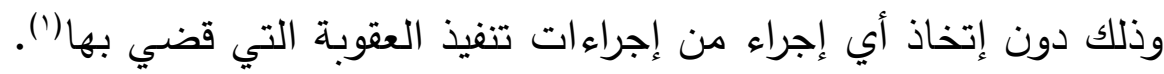
والتساؤل الآن يثور في حالة ما إذا صدر عفو عن العقوبة التي قضت التصات

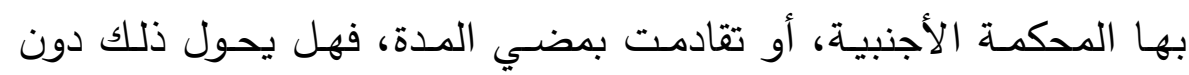

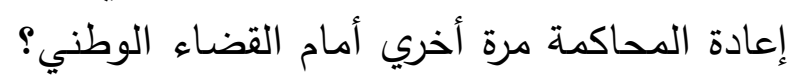
اختلف موقف المشرع المصري عن نظيره الفرنسي في الإجابة علي

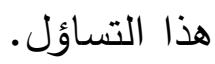
أ- موقف المشرع المصري: لم ينص المشرع المصري علي سقوط العقوبة المحكوم بها في الخارج

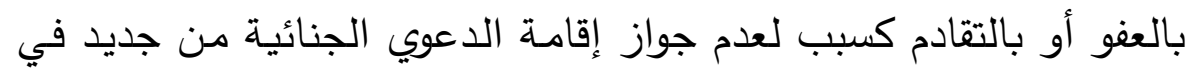
مصر، مما آثار خلافاً في الفقه.

إذ ذهب البعض(') إلي أن صدور عفو عن العقوبـة أو تقادمها بمضـي

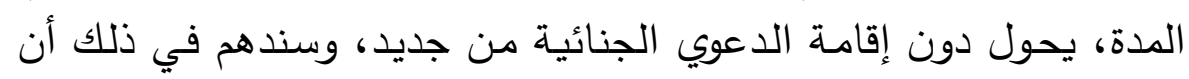

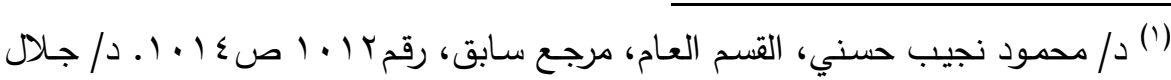

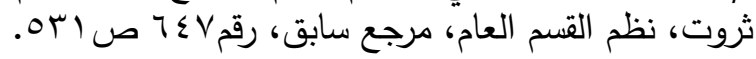


المشرع قد ذكر إستيفاء العقوبـة، والإستيفاء قد يكون حقيقياً أو حكمياً،

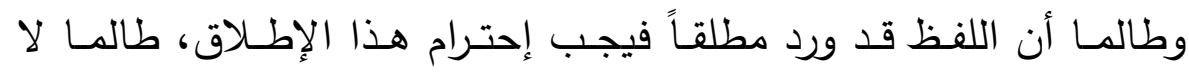

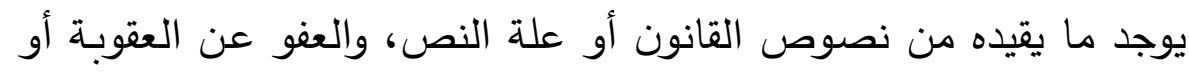

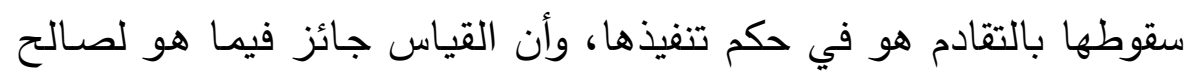

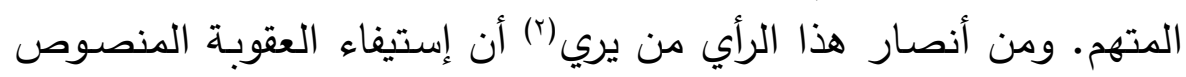

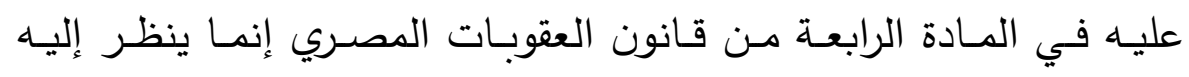

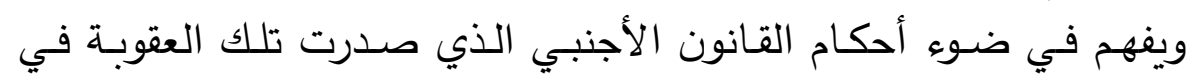

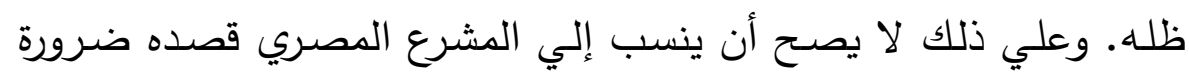

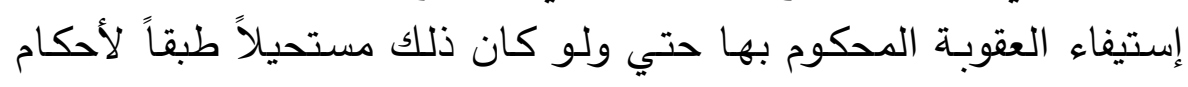

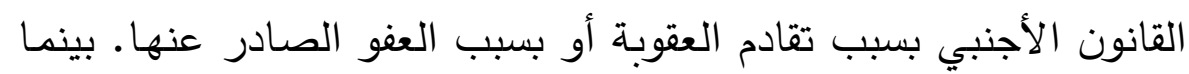

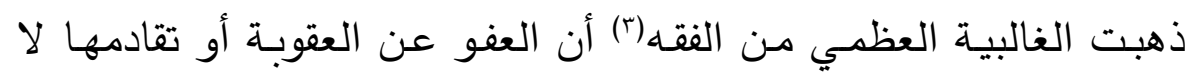

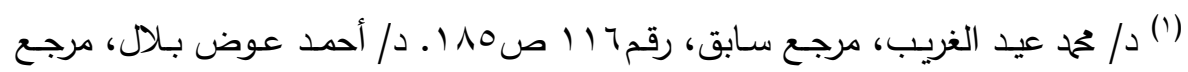

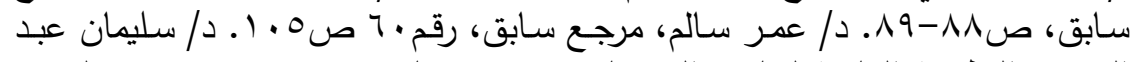

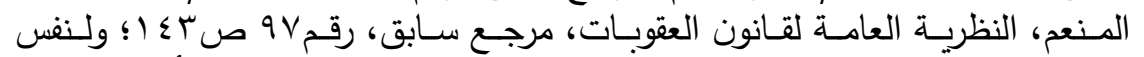

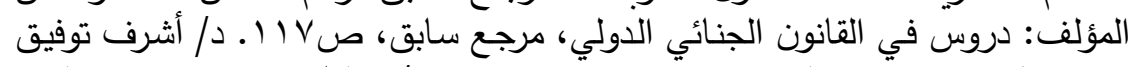

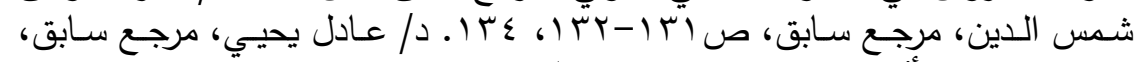

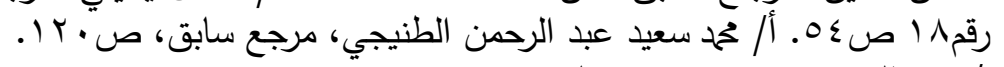

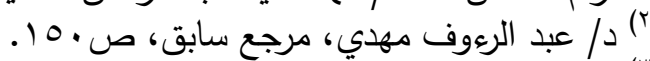

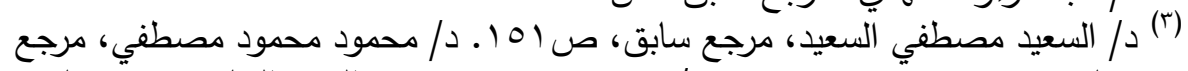

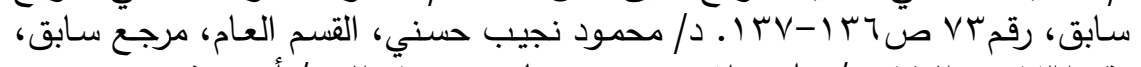

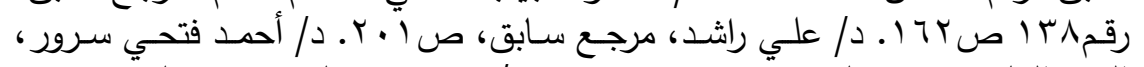

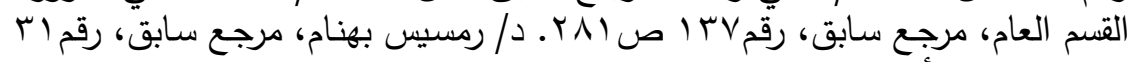

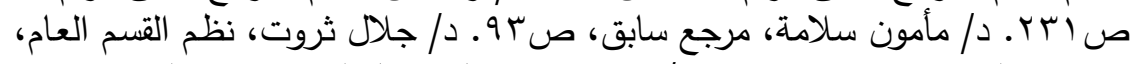

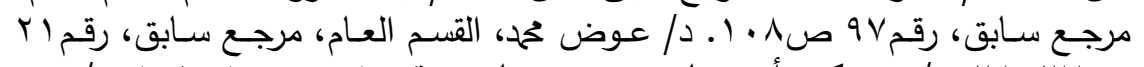

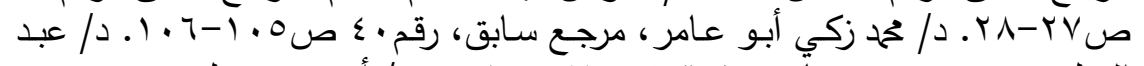

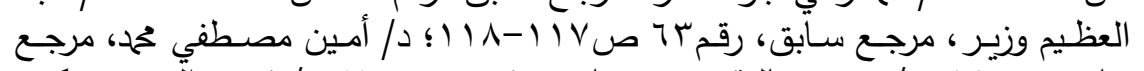

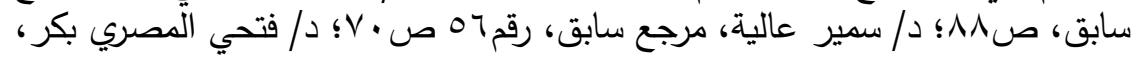

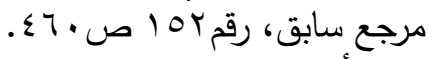

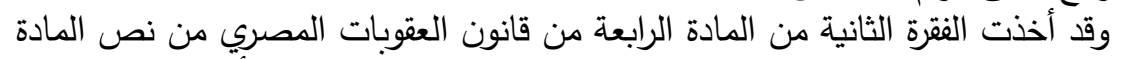

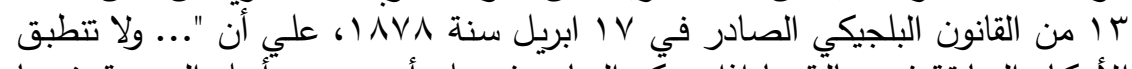

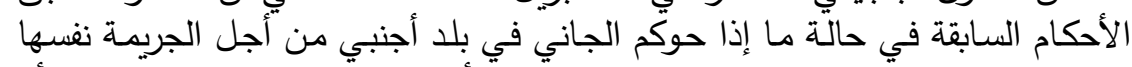

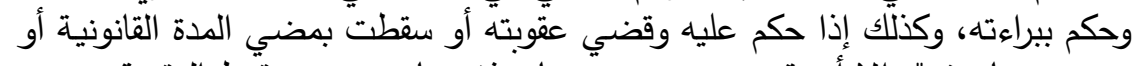

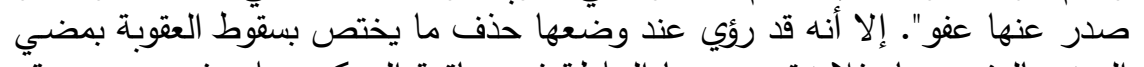

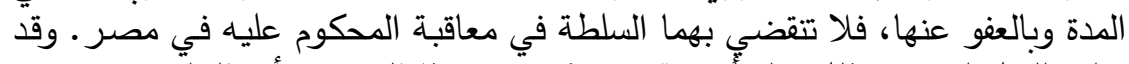

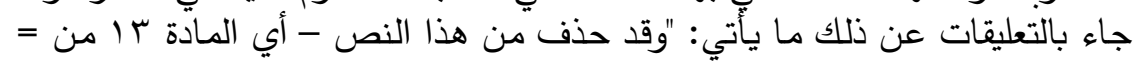


يحول دون إمكان محاكمة الجاني أمام القضاء المصري مرة أخري، وهذا

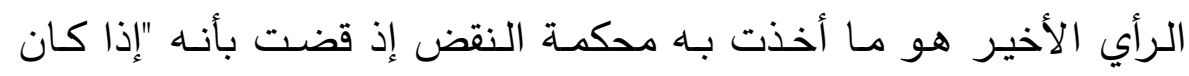

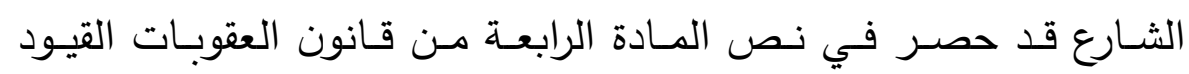
المانعة من إعادة تحريك الدعوي ضد المتهم في حالتي البراءة أو الإدانة

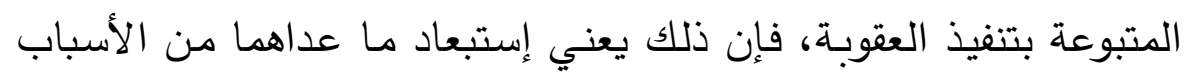

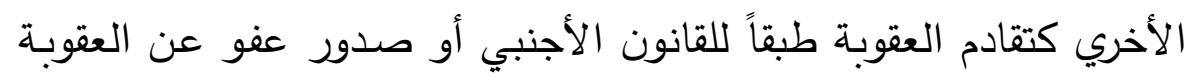

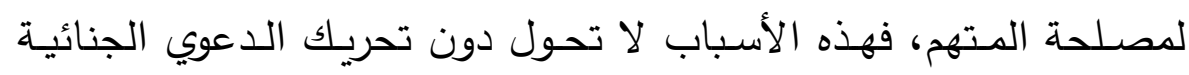

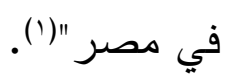

ونري أنه من الصعب قبول إستبعاد العفو عن العقوبـة في هذه الحالة.

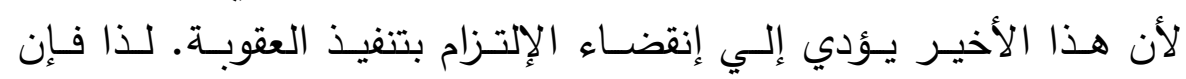

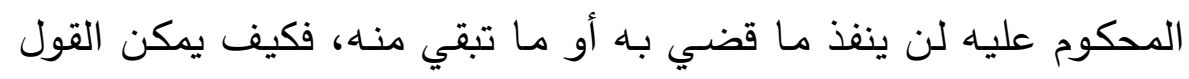

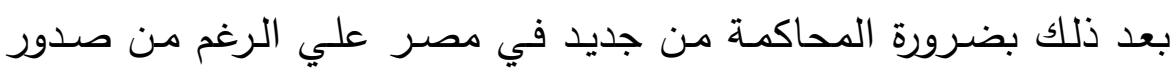

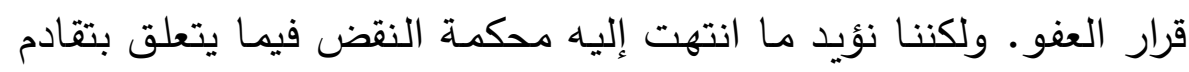

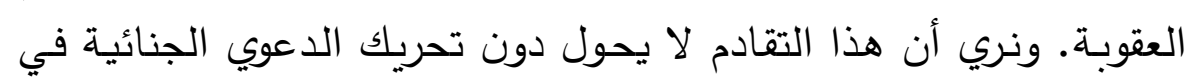
مصر إحتراماً لصريح نص المادة الرابعة من قانون العقوبات.

$$
\text { ب- موقف المشرع الفرنسي: }
$$

لم ينص المشرع الفرنسي علي العفو عن العقوبـة كسبب من أسباب

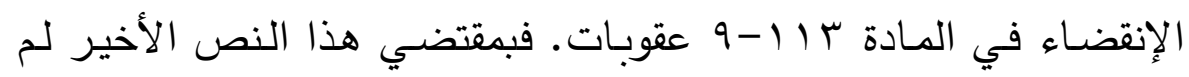

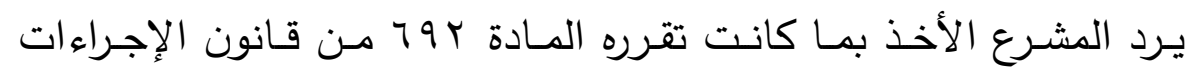

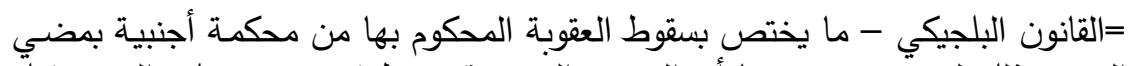

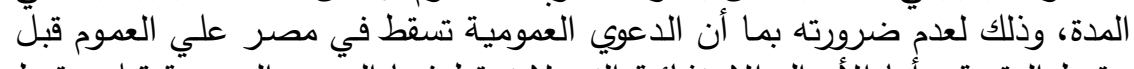

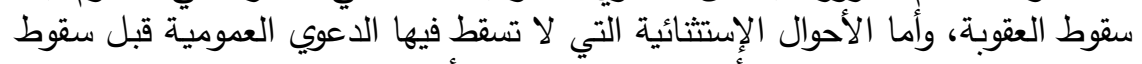

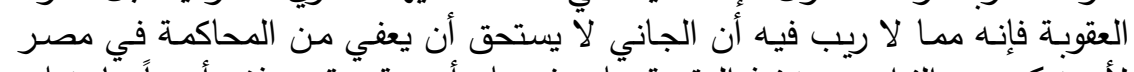

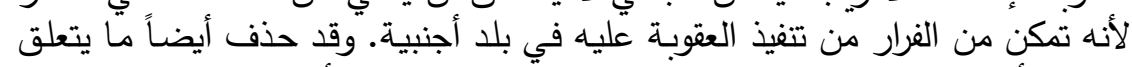

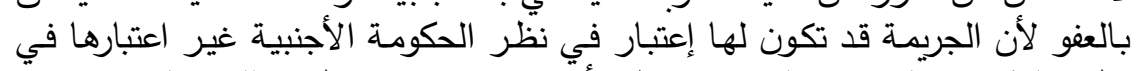

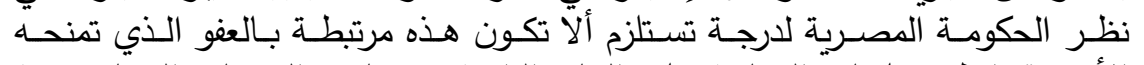

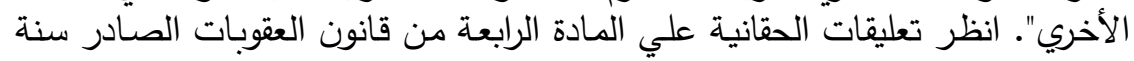

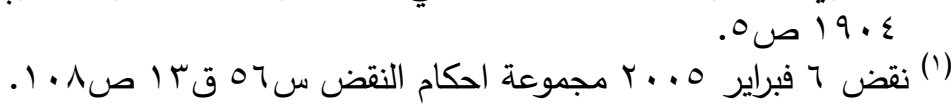


الجنائية قبل تعديلها(')، من عدم جواز إعادة محاكمـة الجاني مرة أخري

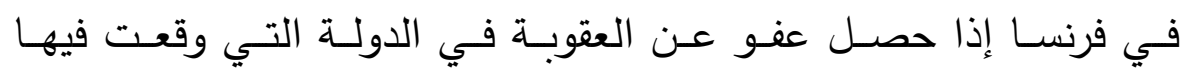

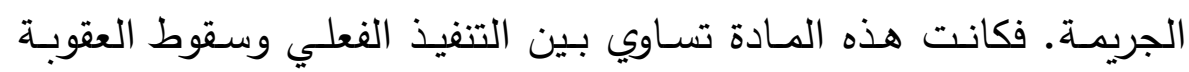
بالتقادم والعفو. والسبب في ذلك في رأي الفقه يرجع إلي أن هذا العفو

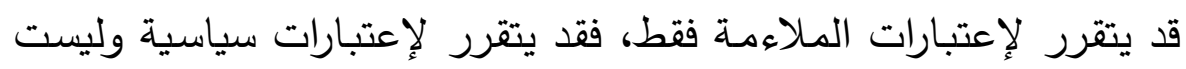

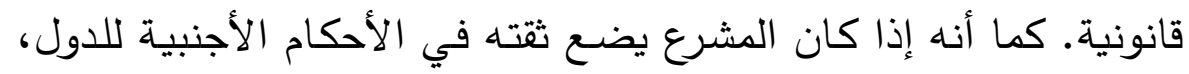

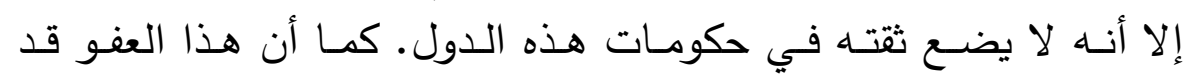

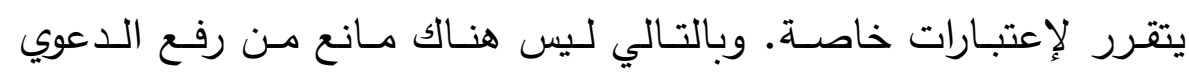
الجنائية ضد المتهم مرة أخري في فرنساعاتهات.

وإذا كانت العقوبـة المقضـي بهـا في الخـارج قد سقطت بالتقادم، فهل يعتبر هذا السقوط في حكم تنفيذها أم لا؟ أجابت المادة بر 11 -9 عقوبات صراحة علي هذه المسألة. وإعتبرت أن

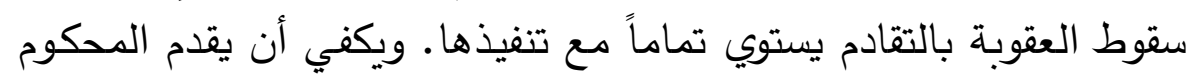

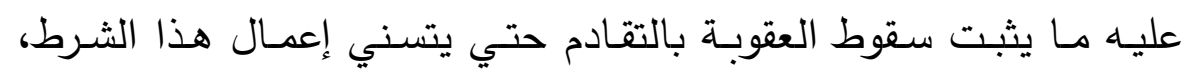

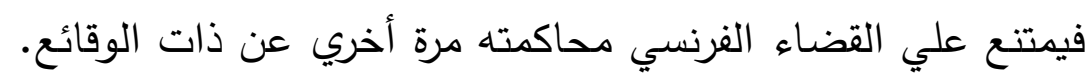
ثالثاً: صدور الحكم مشمولاً بوقف التنفيذ:

إذا صدر حكم من المحكمة الأجنبية بالإدانة مـع إيقاف التنفيذ، فهل

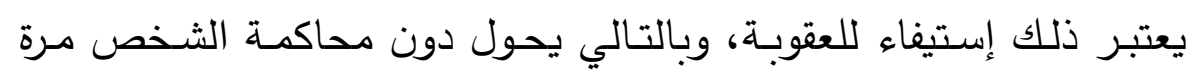

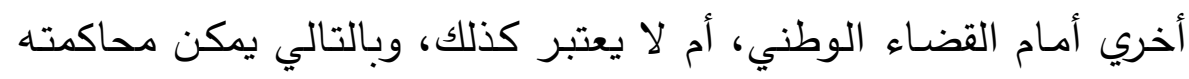

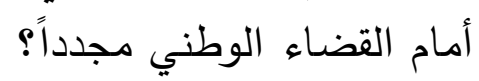

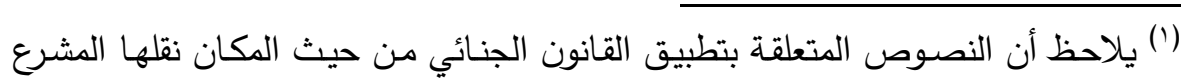

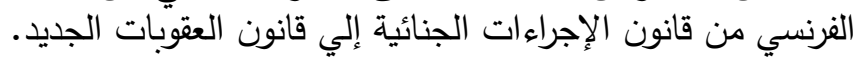

(r) Desportes (F.) et Le Gunehec (F.): Présentation des dispositions du

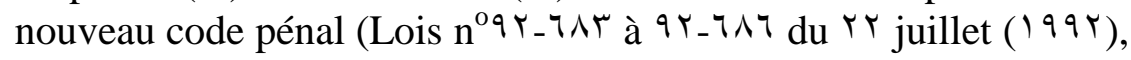
J.C.P. 199r, $n^{\circ} \leqslant 1, I, r 710, n^{\circ} r$, p. $\leqslant 11$. Thiel (D.): op.cit. $n^{\circ} \backslash \leqslant r$, p. $117, n^{\circ} r \cdots$, p. $r \leq 7$. Huet (A.) et Koering- Joulin (R.): op.cit.

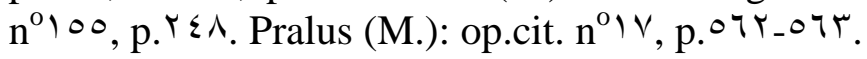


ذهب رأي في الفقه(') إلي أن صدور حكم بالإدانة مع إيقاف التنفيذ لا

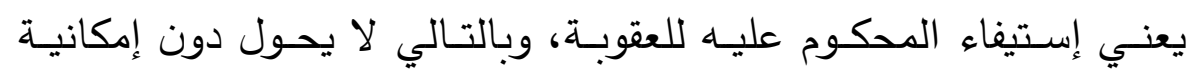

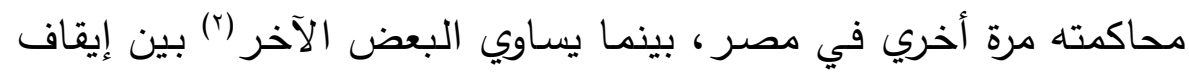

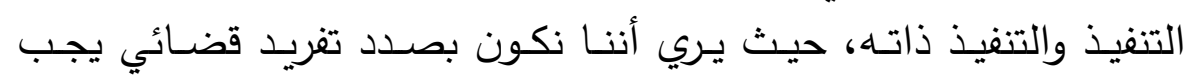

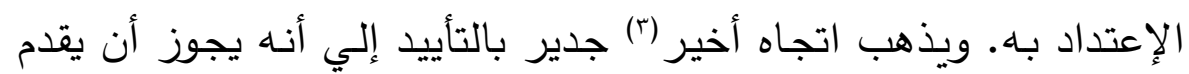

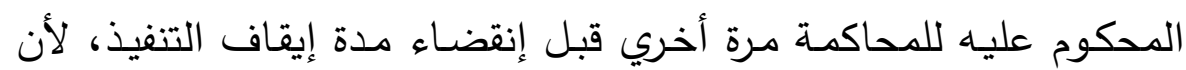

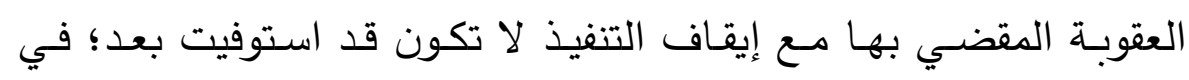
حين لا يجوز تقديم المحكوم عليه للمحاكمة مرة أخري عن ذات الجئ الجريمة

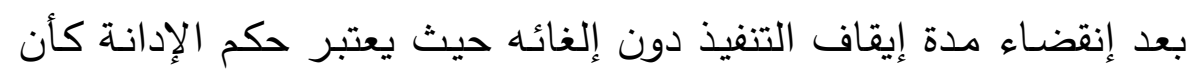
لم يكن، مما يجب معسه قياسه علي حكم البراءة، وهو قياس جائز مادام

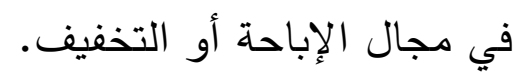

\section{رابعاً: الإفراج الشرطي:}

قد ينفذ المحكوم عليه في الخارج جزءاً من العقوبة، ثم يتم الإفراج عنهـ

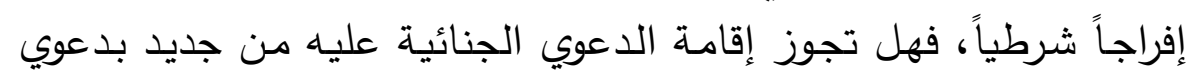

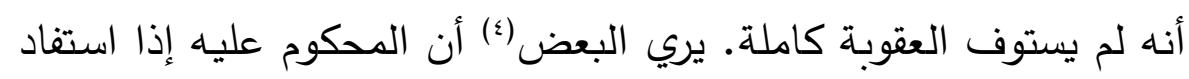

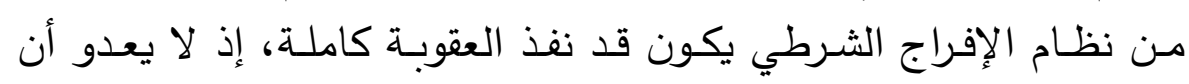

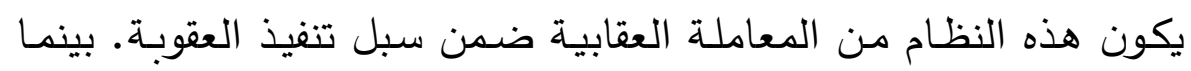

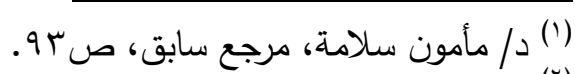

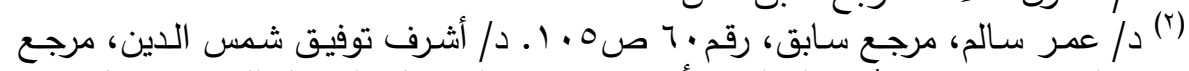

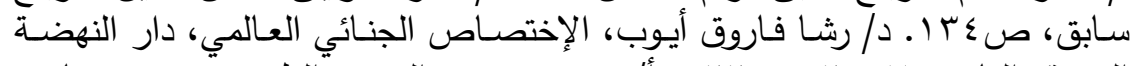

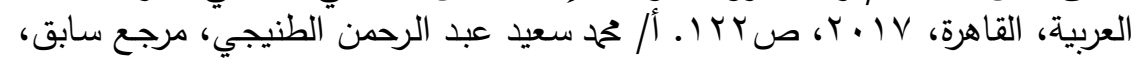

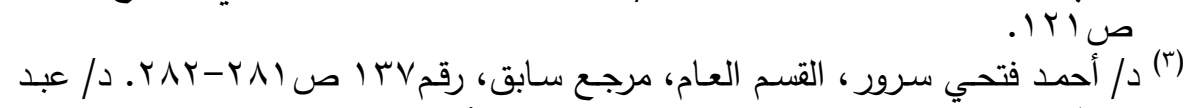

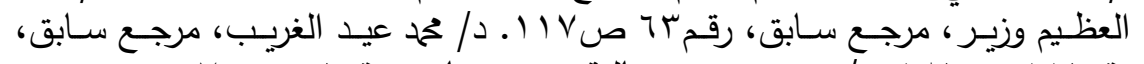

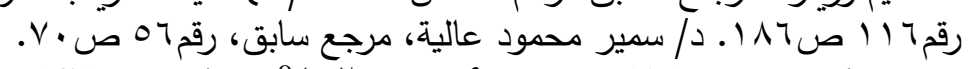

Lombois (C.): op.cit. $\mathrm{n}^{\mathrm{O}} \varepsilon \cdot \mathrm{r}$, p. ${ }^{0.9}$; Huet (A.) et Koering-Joulin (R.): op.cit. $n^{0} 100$, p. $r \leq \Lambda$.

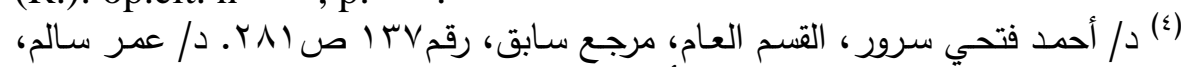

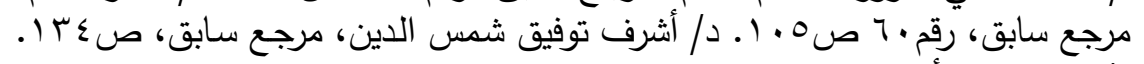

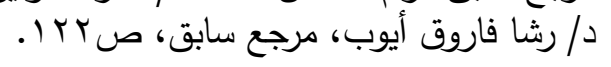




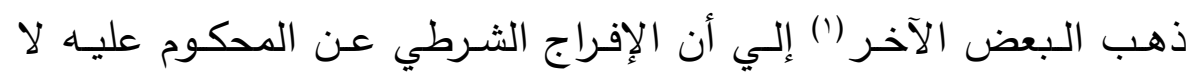
ينهي تنفيذ العقوبـة طوال مدة الإفراج. ذلك أن العقوبـة أثناء مدة الإفراج

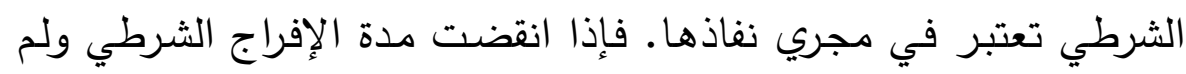

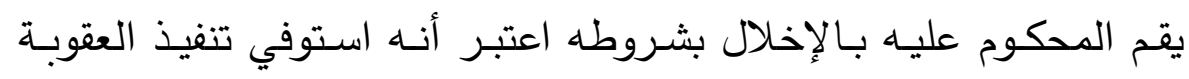

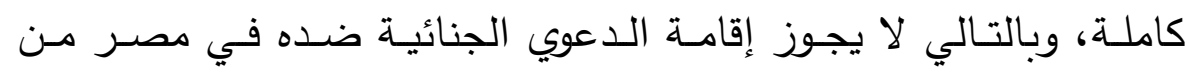

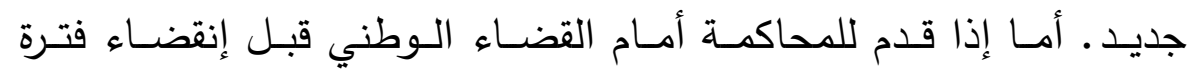
الإفـراج الشـرطي جـازت محاكمتـهـ لعـدم تحقـق شـرط الإسـتيفاء الكلـي للعقوبة، وهو ما نميل إليه.

ويميـل الفتـه الفرنسـي إلـي القول بأنـهـ إذا أفرج عـن الثـخص إفراجـاً

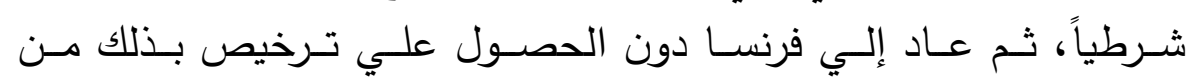

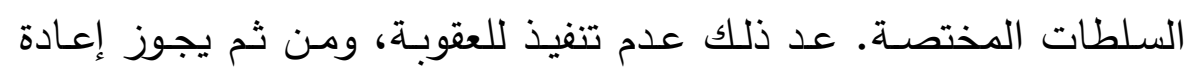

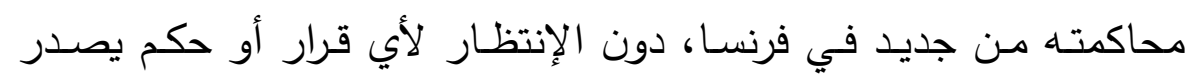

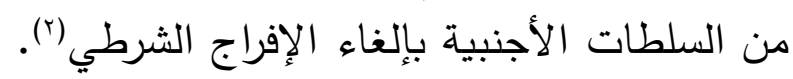
وفي كل الحسالات السـابقة، فـإن هنـاك سـلطة تقديريـة للنيابـة العامـة،

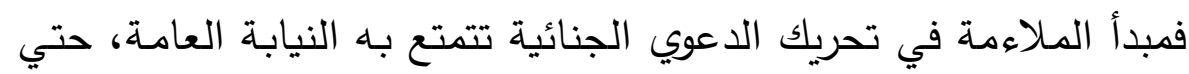

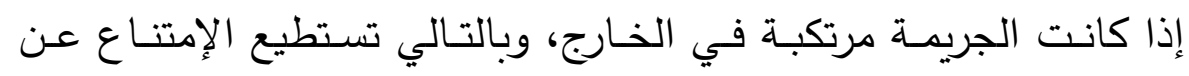

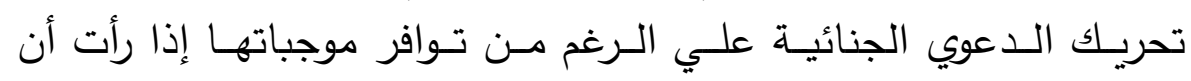
مصلحة المجتمع تقتضي ذلك.

إختلاف وصف الجريمـة أو مقدار العقوبـة في القـانون المصري عن

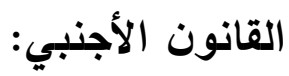
يتبين لنـا من نص المـادة الرابعـة أن المشرع إستلزم في حالة صدور

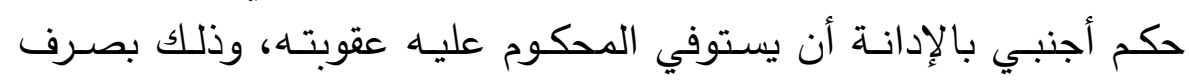

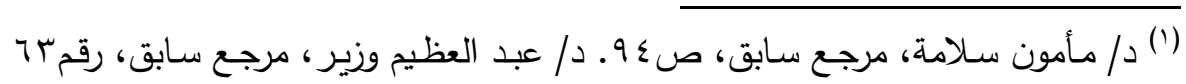

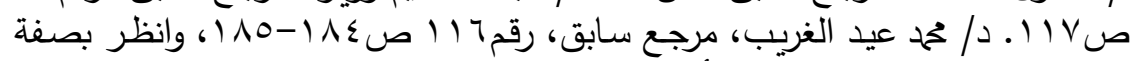

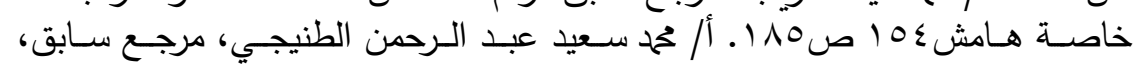

(r) Lombois (C.): op.cit. $n^{0} \varepsilon \cdot r$, p. ${ }^{0.9}$; Huet (A.) et Koering-Joulin (R.): op.cit. $n^{0} 100$, p. $r \leqslant \wedge$. 
النظر عما إذا كان وصف الجريمـة في القانون الأجنبي أقل من وصفها

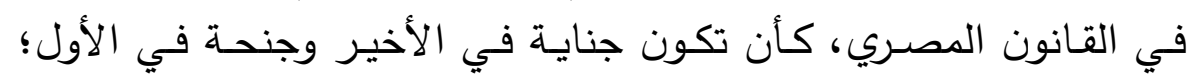

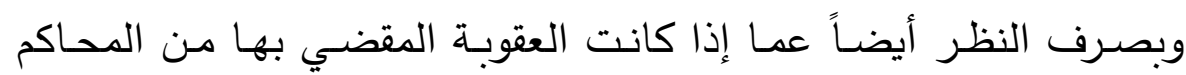

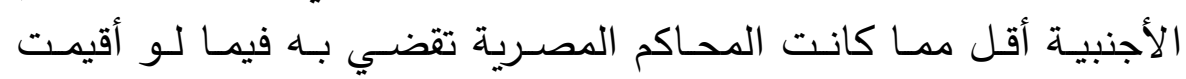
الدعوي أمامها، فقد يقضـي بالغرامـة علي المـتهم، بينمـا العقوبـة المقررة

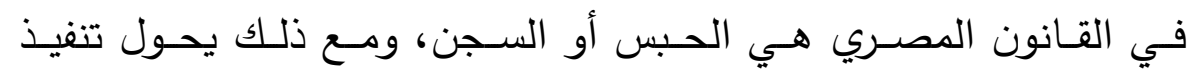

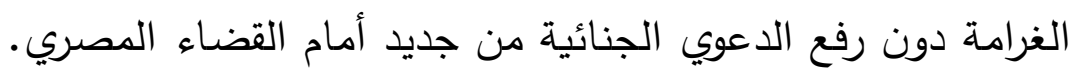

عدم أهمية معرفة القانون المصري بالعقوبة المحكوم بها في الخارج أو طريقة تنفيذها: لا يشترط أن تكون العقوبـة المقضي بها في الخارج مما يعرفه القانون

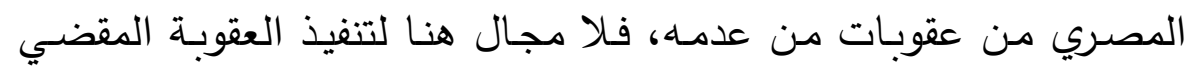
بها في الخـارج والتي لـم تنفذ، ولكن بصـد عند إقامـة دعـوي عـن الجـرائم المرتكبة في الخارج، ولو تم تنفيذ عقوبتها كاملة. كما لا يهم طريقـة تنفيذ العقوبـة، سواء كانت داخل إحدي المؤسسات

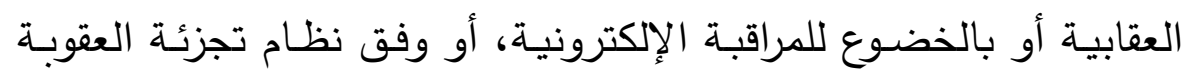

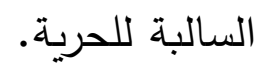




\section{المبحث الثالث}

\section{وحدة الد عوي}

القاعدة أنها إذا حاز حكم في ذاته قوة إنهاء الدعوي فكان فاصـلاً في

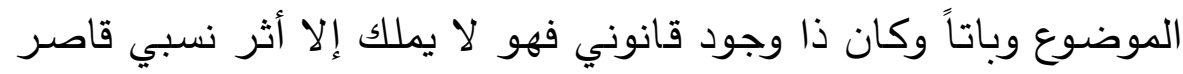

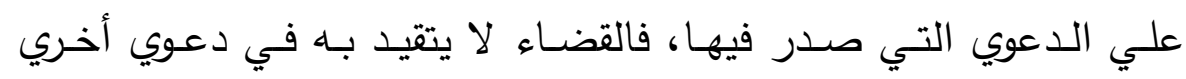

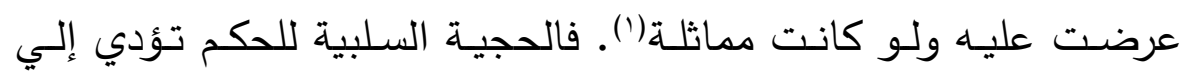

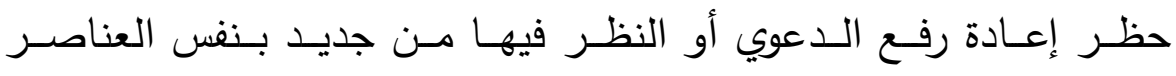

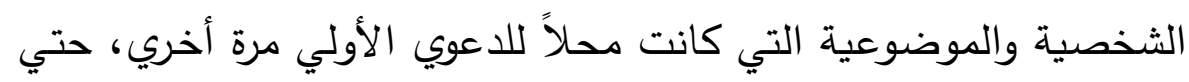

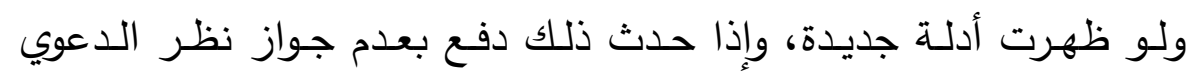

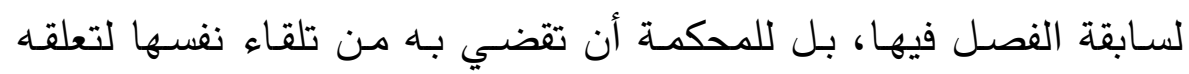

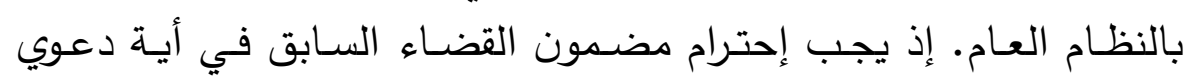

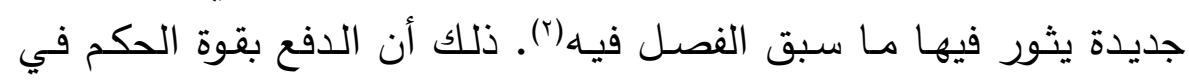
إنهاء الـدعوي هو دفع بعـدم قبولهـا لسبق الفصـل فيها، ومـن ثم كـان

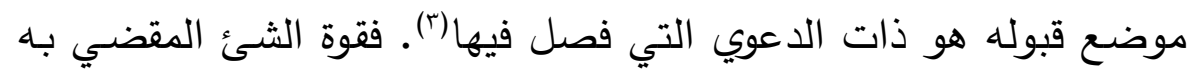

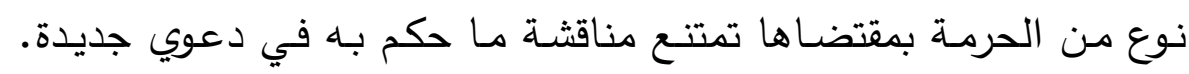

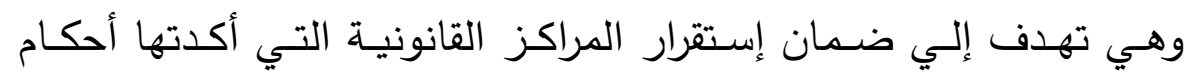

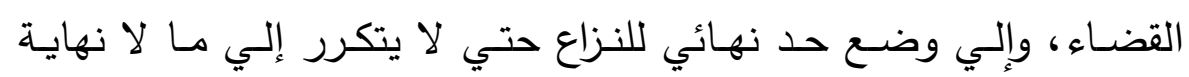

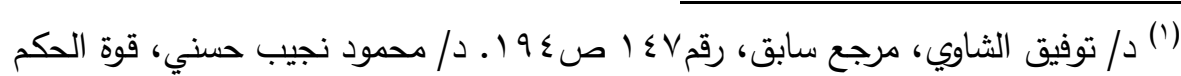

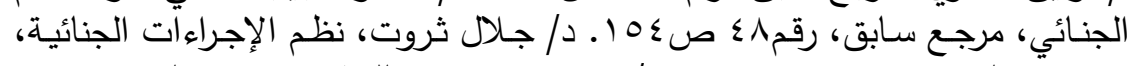

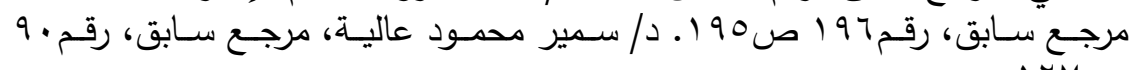
صVIT

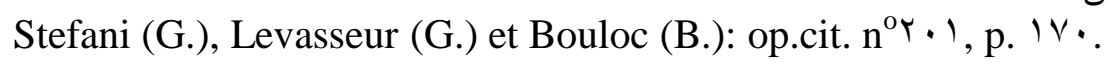

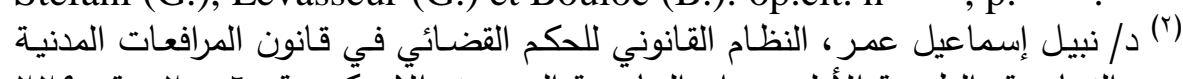

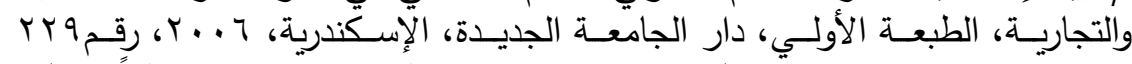

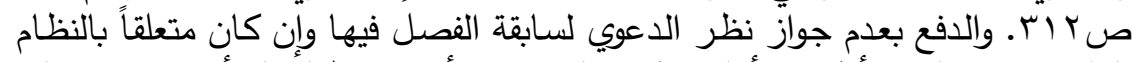

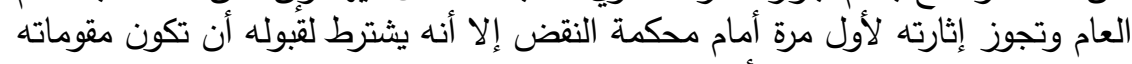

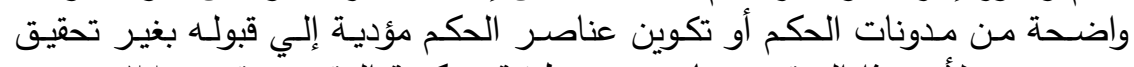

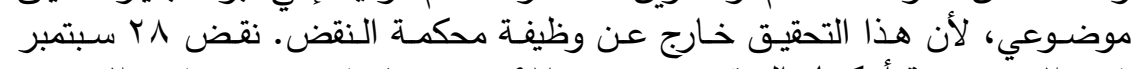

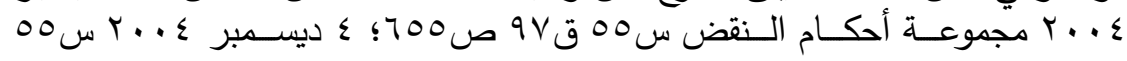
ق11)

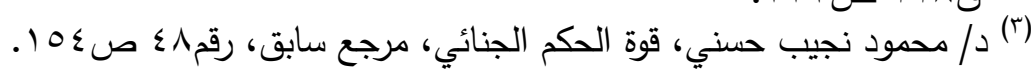


وإلـي تفـادي صدور أحكام متعارضــة. وهذه هـي الحجيـة السلبية للحكم الجنائي ومقتضاه أنه إذا طرحت دعوي جديدة مبتدأة أمام نفس المحكمة التي أصدرت حكماً سـابقاً في ذات هذه الدعوي موضوعاً وسبباً وأطرافاً

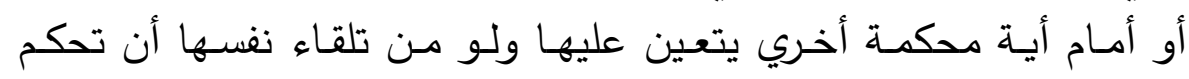

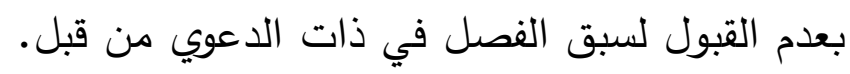

فشروط الدفع بقوة الحكم الجنائي في إنهاء الدعوي الجنائية تدور حول

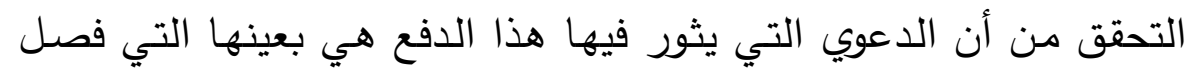

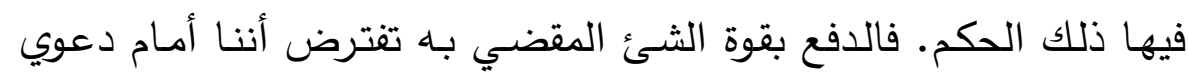
جديدة متحدة في جميع عناصرها مع الدعوي الأولي الصـادر فيها الحكم

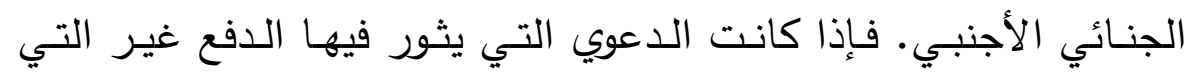
فصل فيها الحكم فليس لهذا الدفع محل' ('). ومن المتفق عليه فقهاً()( وقضـاءً(r) أن عناصر الدعوي ثلاثثة: أطرافها

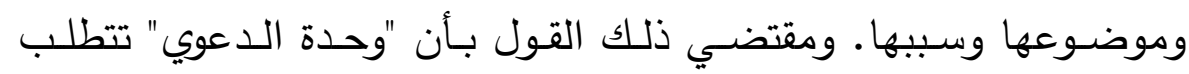

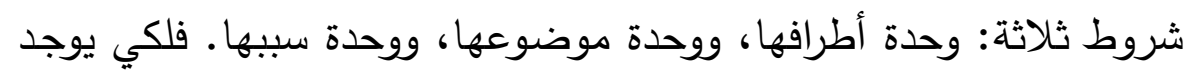

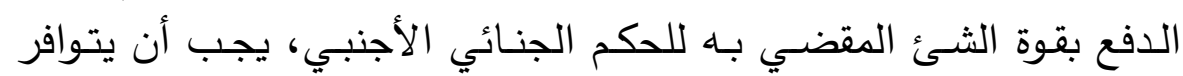
اتحاد الأشخاص والموضوع والسبب في الدعويين الأولي والثانية(؛).

(1) (1) (1) (نفس الموضع السابق.

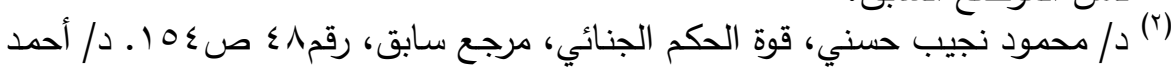

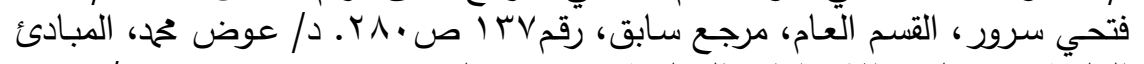

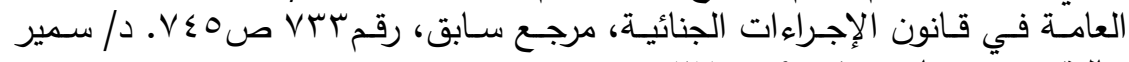

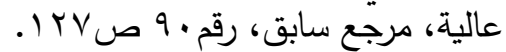

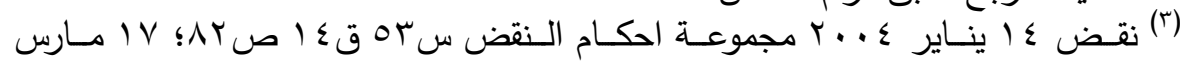

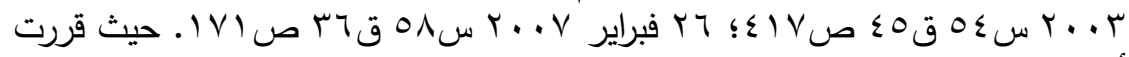

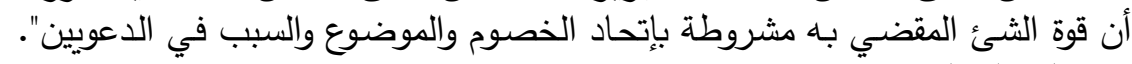
Crim. $r$ avr. $199 \cdot$, B. $n^{\circ} 1$ ا1.

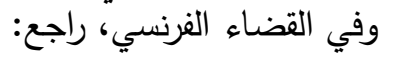

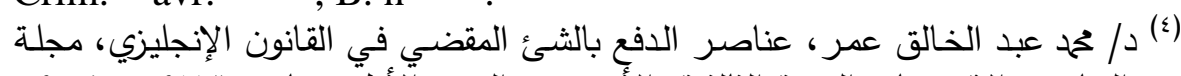

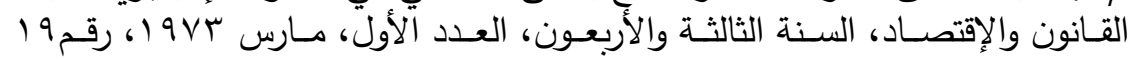


وتنص المـادة ؟0؛ مـن قانون الإجراءات الجنائيسة علـي أن "تنقضـي الدعوي الجنائية بالنسبة للمتهم المرفوعة عليه والوقائع المسندة فيها إليه

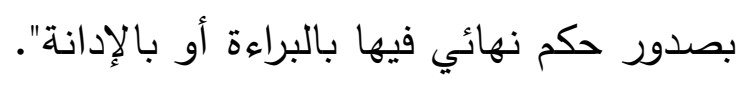

ويقرر هذا النص أن الدعوي الجنائية بصدور حكم نهائي فيها بالبراءة

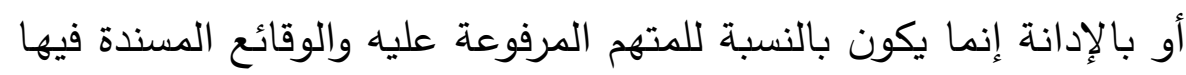

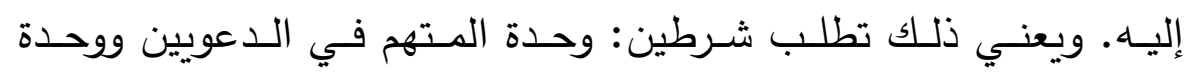

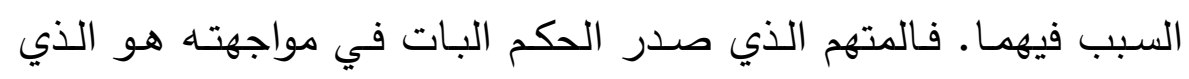

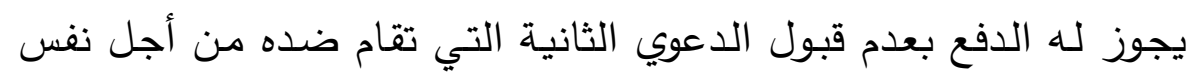

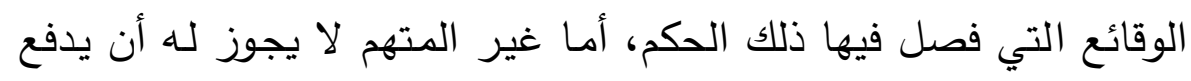

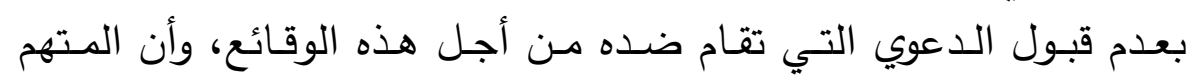

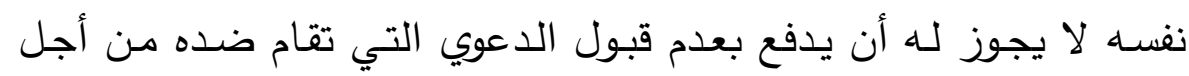

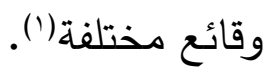
ويضيف القضساء شرطاً ثالثاً هو وحدة الموضوع في الدعويين، أي أن يكون المطلوب الحكم به في الدعويين واحداً(r).

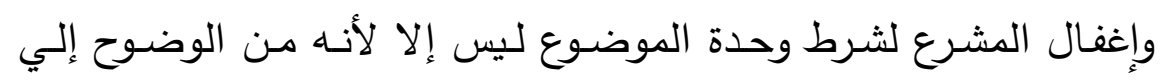

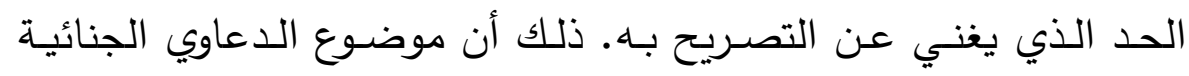

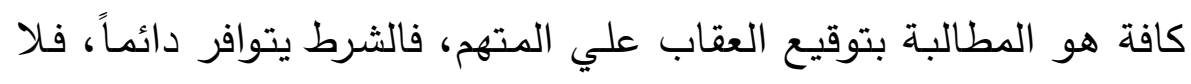

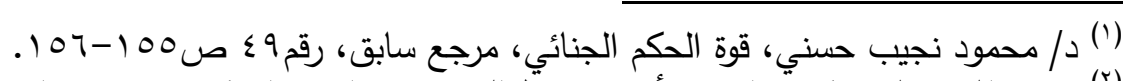

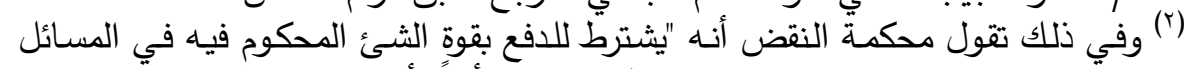

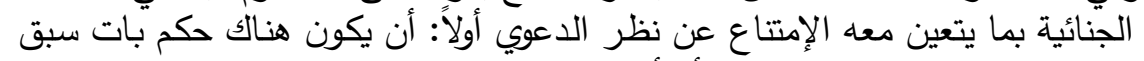

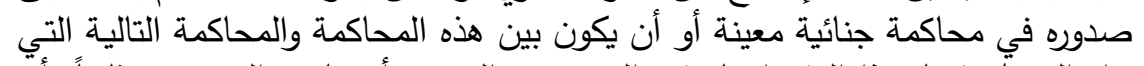

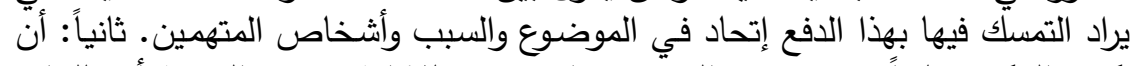

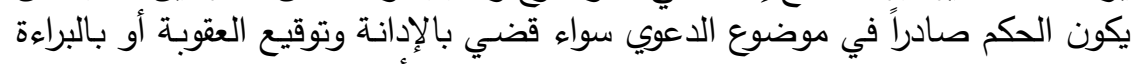

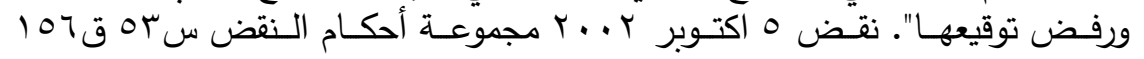

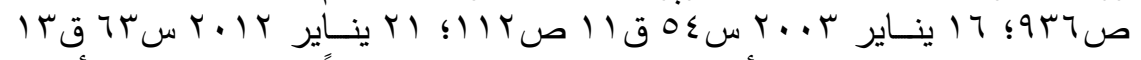

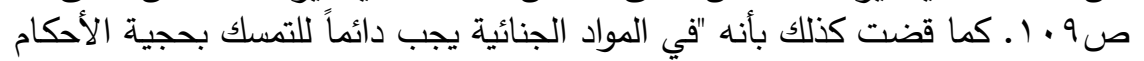

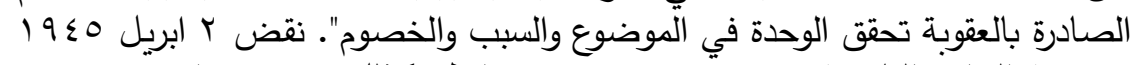

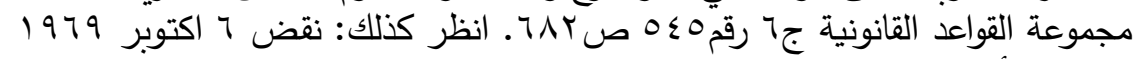

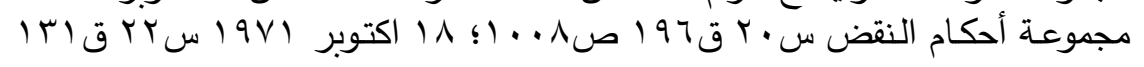

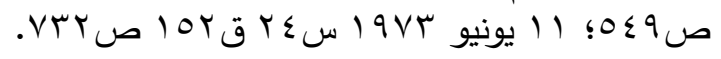


حاجة إلي نص يشير إليه خاصة('). فإن كان موضوع الدعوي غير ذلك لم نكن أمام دعوي جنائية أصلاً.

ونلقي بعض الضوء علي الشروط السابقة:

\section{الشرط الأول: وحدة الخصوم:}

الخصوم في الدعوي الجنائية هم النيابة العامـة والمتهم. والنيابة العامـة

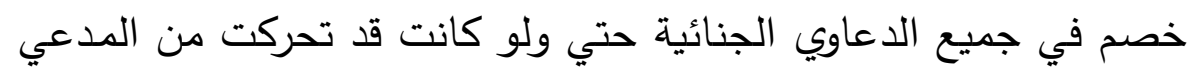

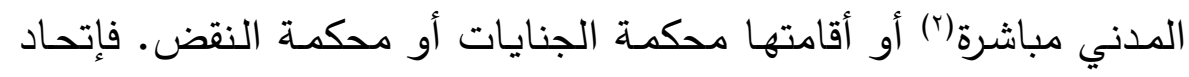

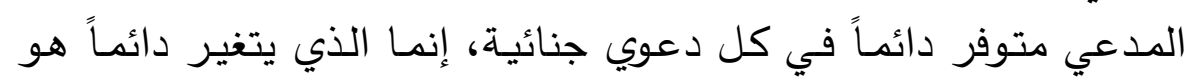

$$
\text { المدعي عليه أي المتهم ("). }
$$

ويتعين أن يكون المتهم في الدعوي التي صدر فيها الحكم الأجنبي

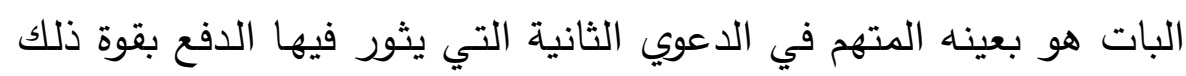

$$
\text { الحكم في إنهاء الدعوي الجنائية(أ). }
$$

فإذا إنتفت هذه الوحدة فإن الحكم الأجنبي البات الصسادر في الدعوي

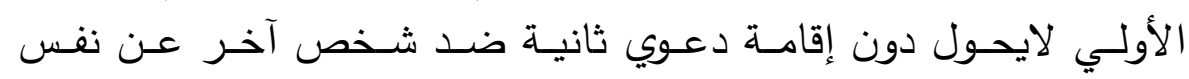

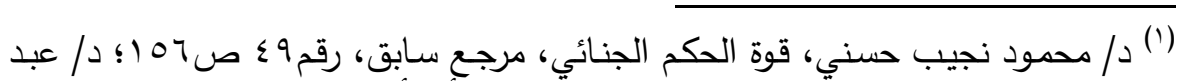

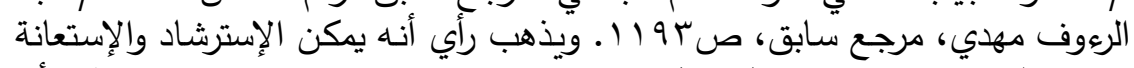

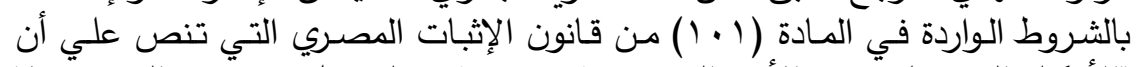

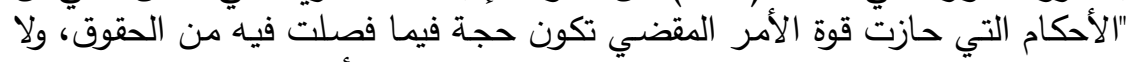

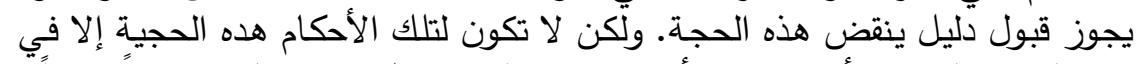

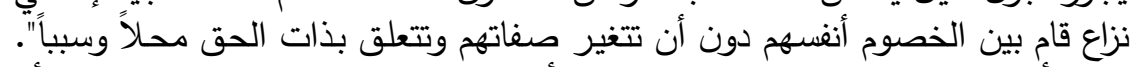

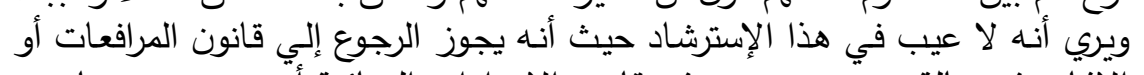

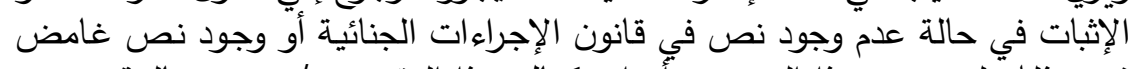

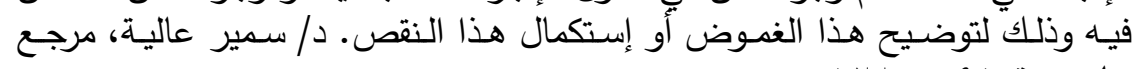

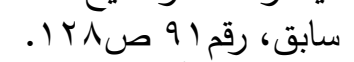

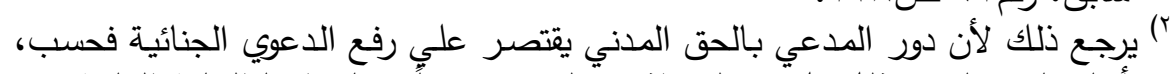

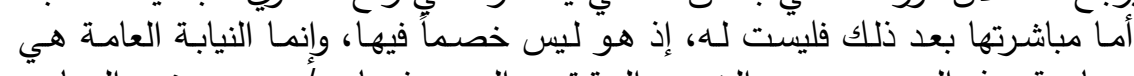

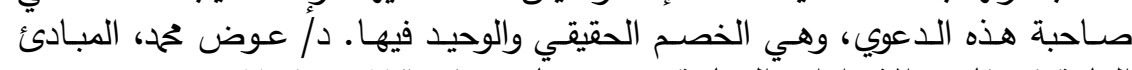

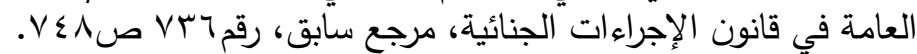

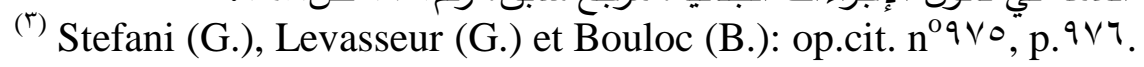

(घ) crim. O fév. 1910, B. nº9.

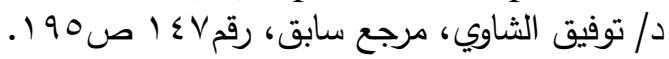


الوقائع، فالدعويان مختلفتان، فإن كانت الأولي قد انقضت بذلك الحكم في مواجهة المتهم المرفوعة عليه الدعوي، فالثانية لم تنقض بعد لإندان بالنسبة

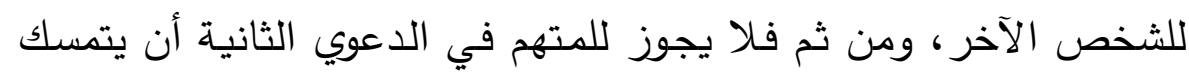

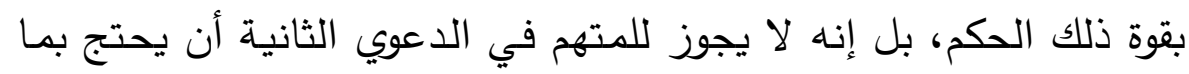

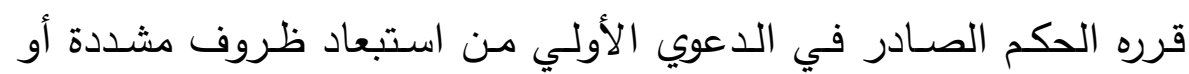
ظروف مخففة أو إقرار وصف قانوني معين (').

والقانون الجنائي يعنيه شخص المتهح لا صفته(؟). ويراد بصفة المتهم

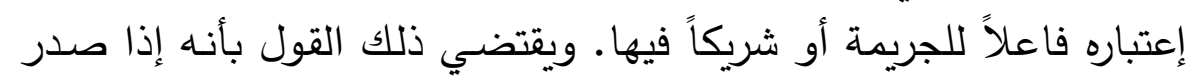

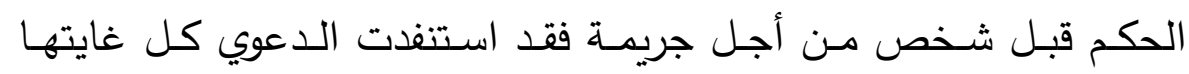

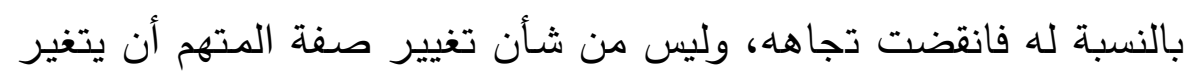

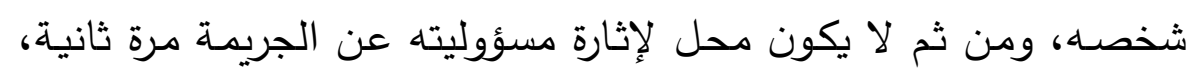
فقد فُصل فيها علي نحو بات حكم سابق. وإطـلاق هذا القول يعني أنه

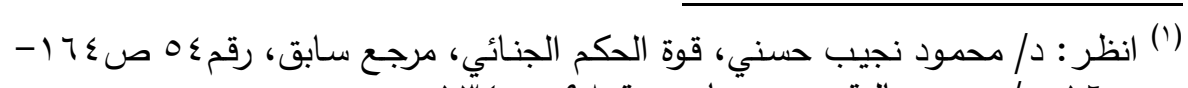

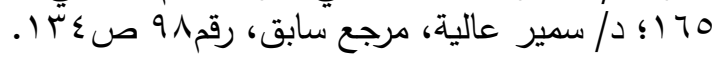

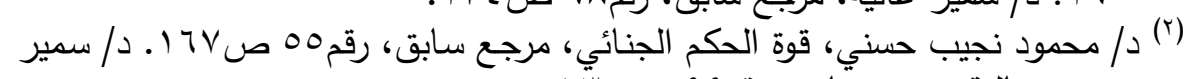

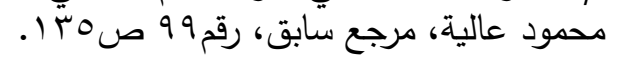

Crim. Y^ fév. 190r, S. 190r, 1. 1 1 1, note Légal; crim. r fév. 1907 , D. 1907.0 .1 , note M. R.-M. P., J.C.P. 1907. II. 90V \&, note Larguier; crim. 10 nov. 197r, D. 197r. Somm., p. ${ }^{9}$; crim. 1 nov. 197r, B.

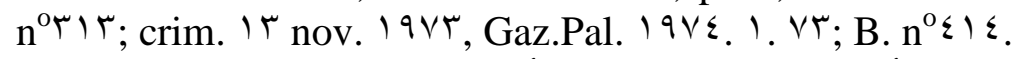

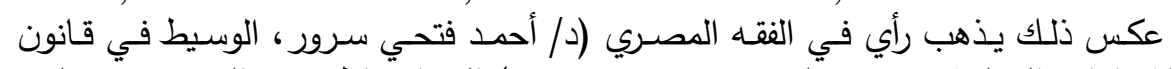

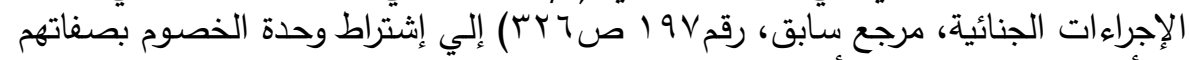

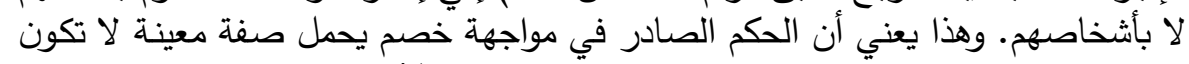

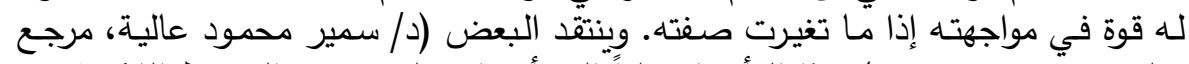

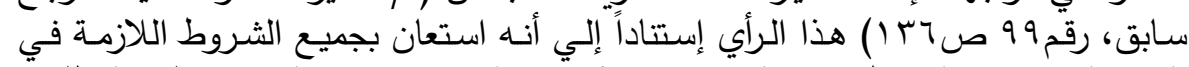

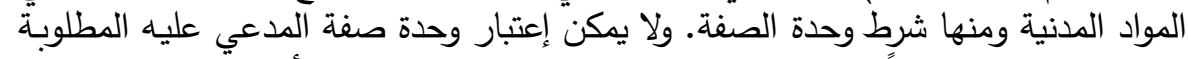

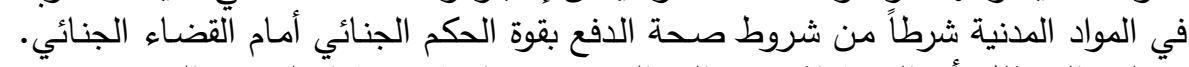

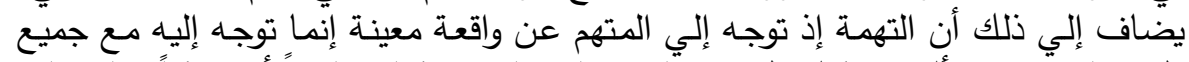

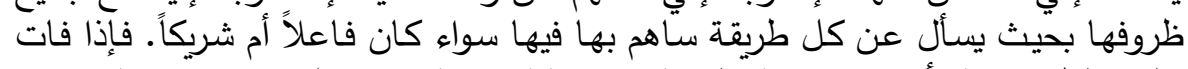

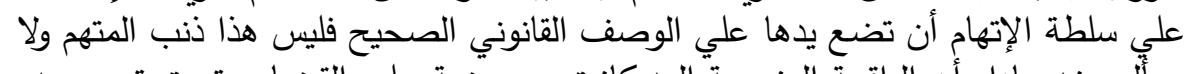

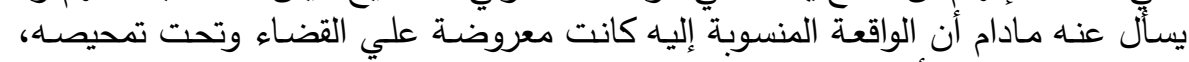

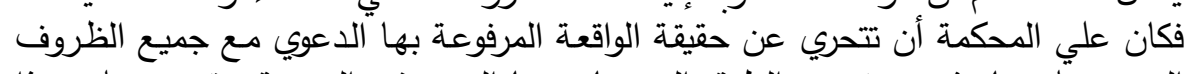

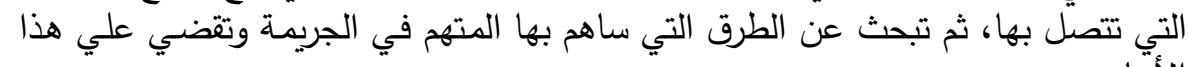
الأسناس. تصن. 
إذا أقيمت الدعوي الجنائية ضد شخص بإعتباره شريكاً في جريمة وصـار

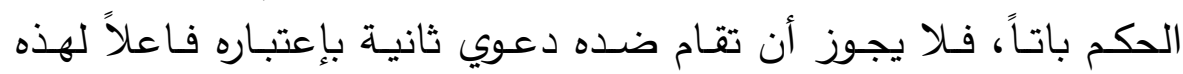
الجريمة.

\section{الشرط الثاني: وحدة الموضوع}

لا يقبل الدفع بقوة الحكم الجنائي الأجنبي في إنهاء الدعوي الجنائية

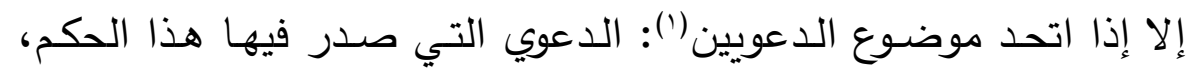
والدعوي المرفوعة أمام القضساء الوطني والتي يراد فيها التمسك بالحجية

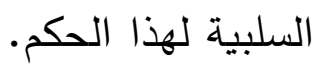

وموضوع الدعوي - أياً كان نوعها - هو ما يطالب بـه المدعي ويزعم أن لله حقاً في إقتضائه.

وموضـوع الدعوي الجنائية هو المطالبـة بحق الدولة في توقيع الجزاء

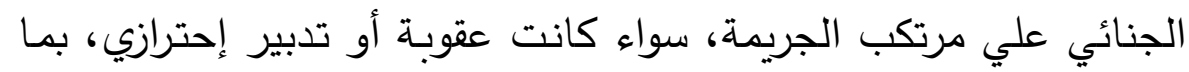

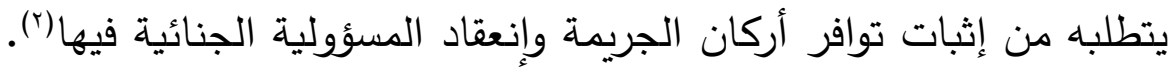
ويتضـح بـلك أن الجريمـة ليست موضـوع الدعوي الجنائية، وإنمـا هي

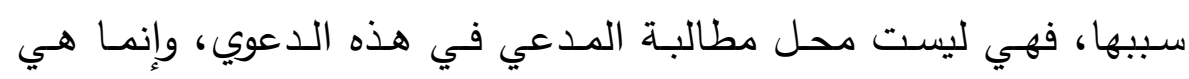
سـنده فيمـا يطالب بـه ممثل الإدعـاء مـن توقيع العقوبـة علـي المـتهم.

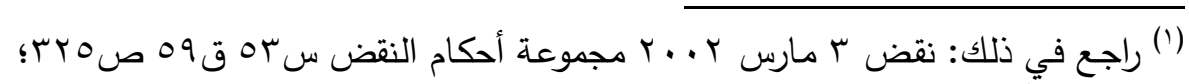

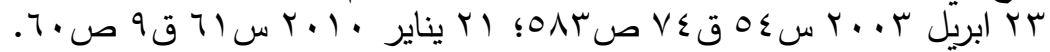

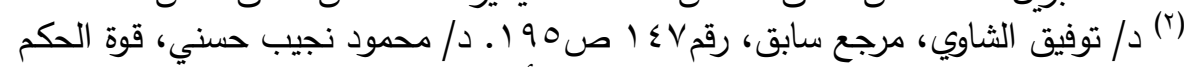

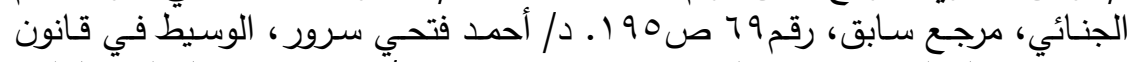

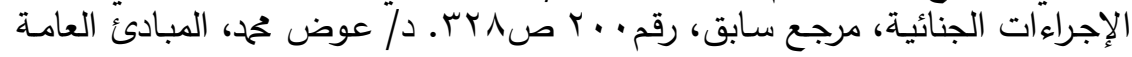

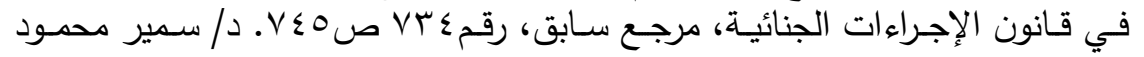

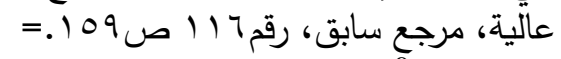
$=$ Stefani (G.), Levasseur (G.) et Bouloc (B.): op.cit. n ${ }^{\circ} 9 \vee \varepsilon, p .9 \vee 0$. Comp. crim. ${ }^{\circ}$ oct. $19 \vee r$, B. n ${ }^{\circ} Y \vee \cdot ;$ D. $19 \vee \varepsilon .11 \%$, note Robert; crim. $r$ janv. $191 \cdot$, B. $n^{\circ}$. 
وتحديـد موضـوع الـدعوي الجنائية يتكفـل بـه نـص القـانون الذي ينطبق

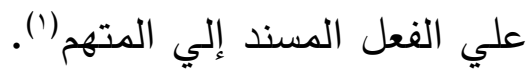
ويترتب علي هذا التحديد لموضوع الدعوي الجنائية نتيجة هامـة: هي

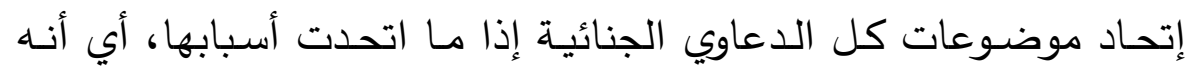
إذا كانت الواقعة واحدة في دعويين جنائيتين، فالجزاء الذي يقرره القانون

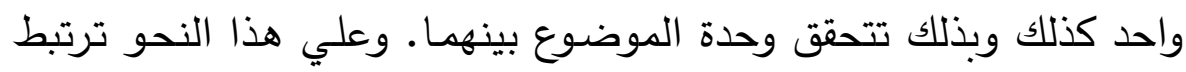

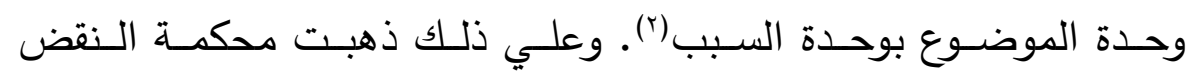

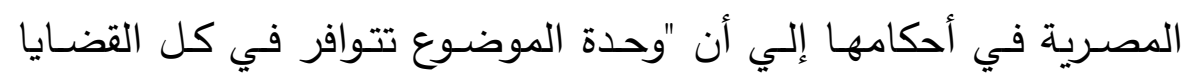
الجنائية لأن الموضوع في كل قضية هو طلب عقاب المتهم أو المتهمين

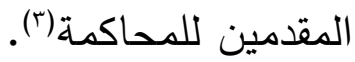

\section{الثرط الثالث: وحدة السبب:}

إذا كانت العقوبة المقررة في القانون هي موضوع الدعوي الجنائية فإن

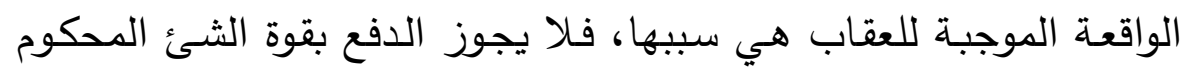

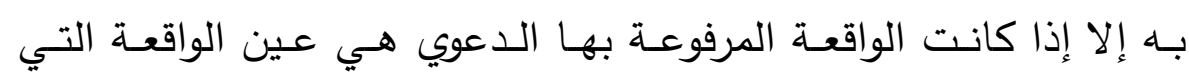

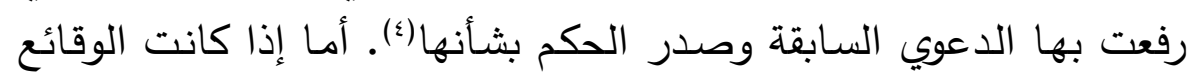

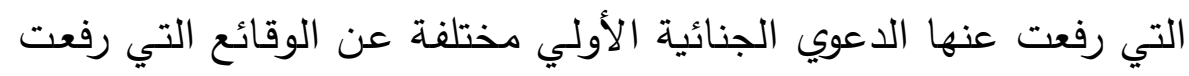

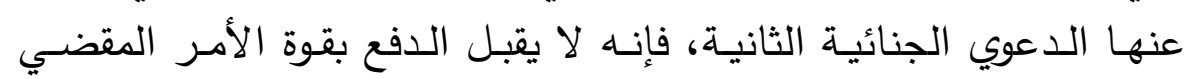
لإنهاء الدعوي الثانية(ه).

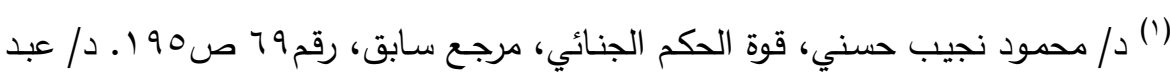

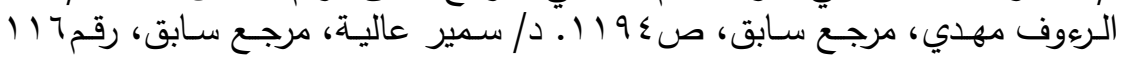

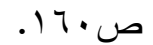

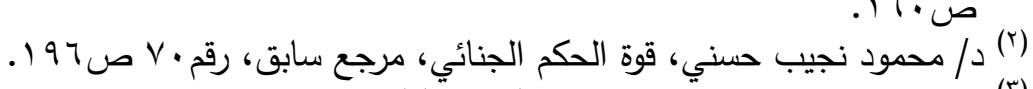

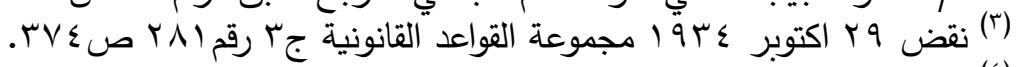

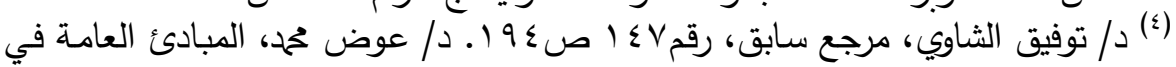

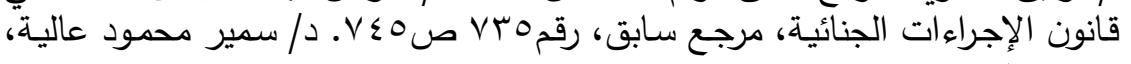

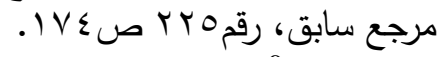

Stefani (G.), Levasseur (G.) et Bouloc (B.): op.cit. n ${ }^{0} 9 \vee 7$, p. $9 \vee{ }_{\text {_ }}$

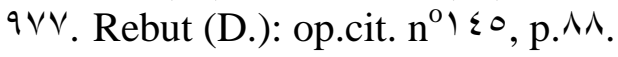

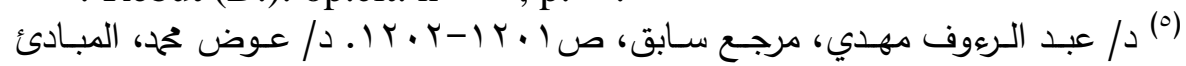

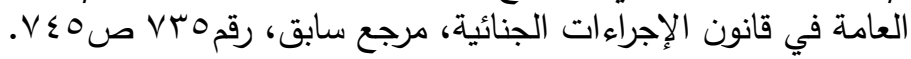


ولا يقبـل الدفع بقوة الحكم الجنائي في إنهاء الدعوي الجنائيـة إلا إذا

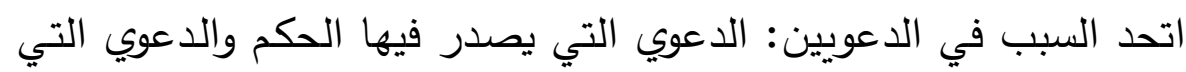

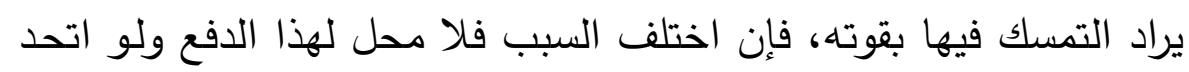

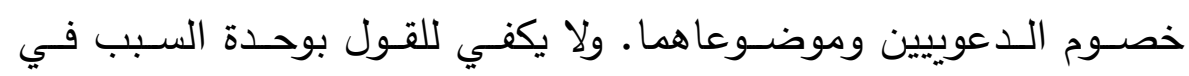

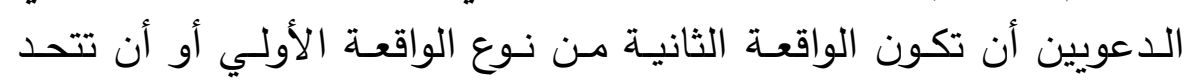

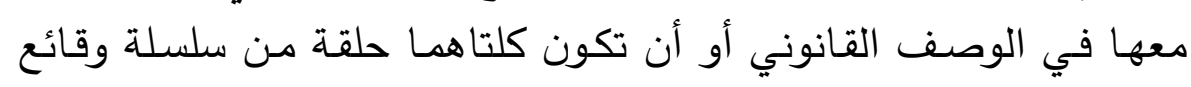

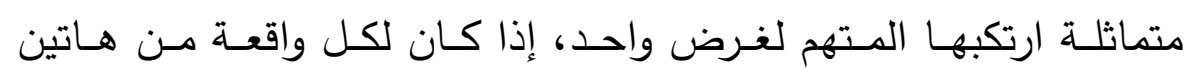

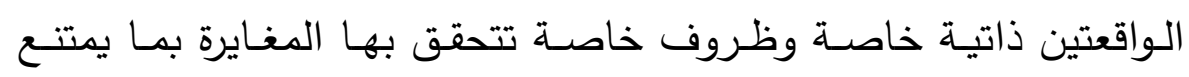

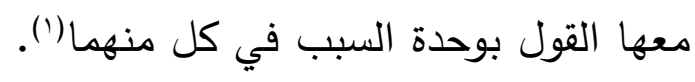
مدي تعلق الدفع بعدم جـواز إقامـة الدعوي الجنائيـة لسـابقة الفصل

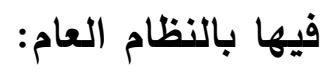

إذا كانت القاعدة بالنسبة للأحكام الجنائية الوطنية أن الدفع بعدم جواز

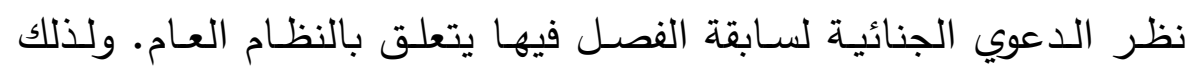
يجـوز الدفع بـه في أيـة حالـة كانـت عليهـا الداعوي ولـو لأول مـرة أمسام

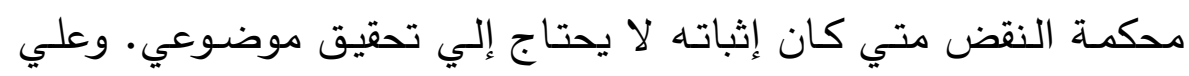

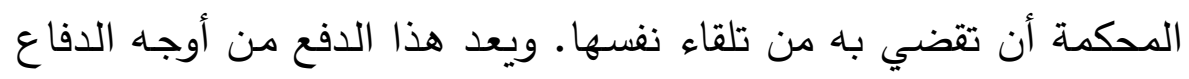

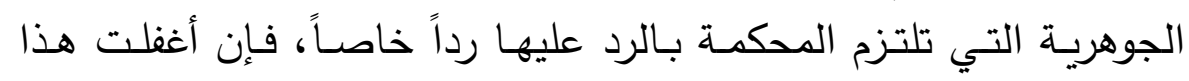

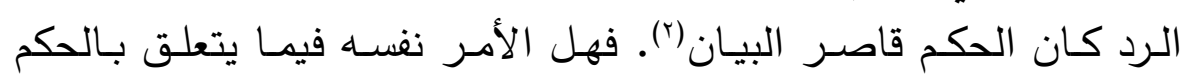

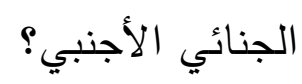

ولذلك قضت محكمة النقض الفرنسية أن الحكم بالإدانة عن قتل خطأ لا يشكل عقبة أمام المحاكمة اللاحقة عن قتل عمد عن عن ذات الفئ الواقعة.

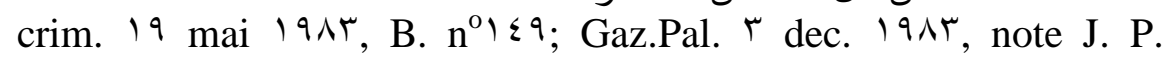

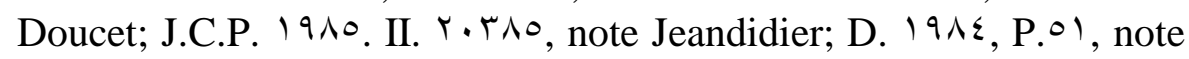
Chapar; crim. rr mai 1990, B. $n^{0} 19$. . Voir aussi: Stefani (G.), Levasseur (G.) et Bouloc (B.): procedure pénale, op.cit. $n^{0} 9 \vee 7, p .9 \vee \vee$.

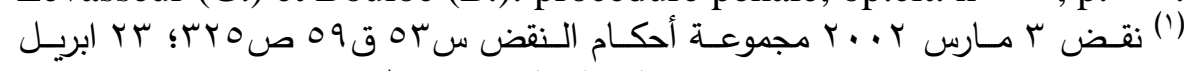
rr nov. I $9 V r$, B. n $n^{\circ} \leqslant r \varepsilon$.

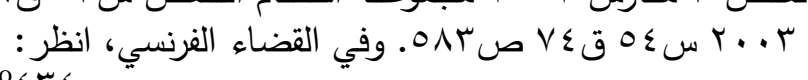

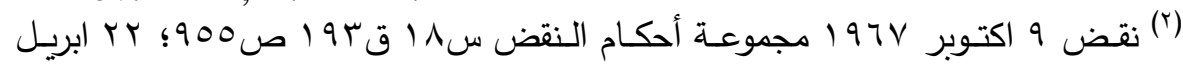

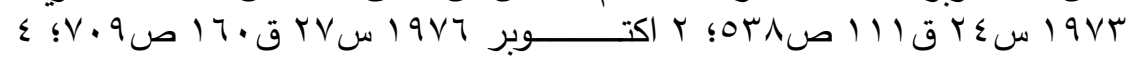


أجاب البعض علي هذا التساؤل بالإيجاب('). وهو ما أخذت به محكمة

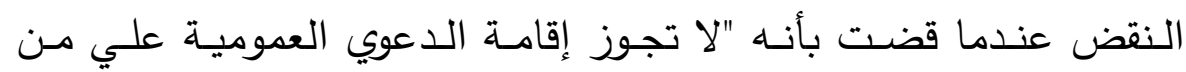

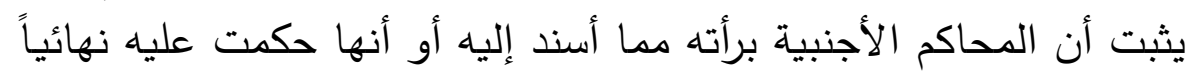

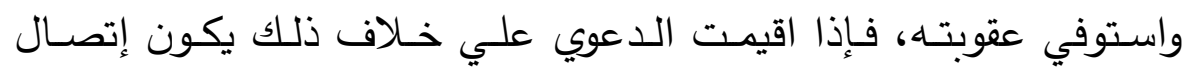

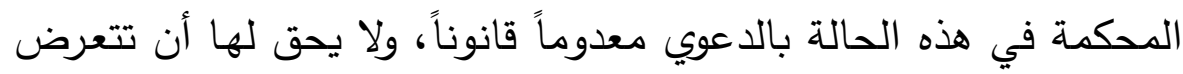

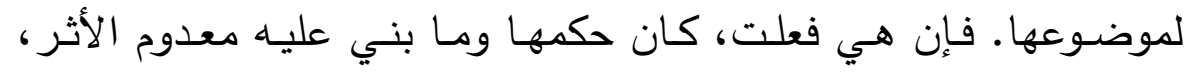

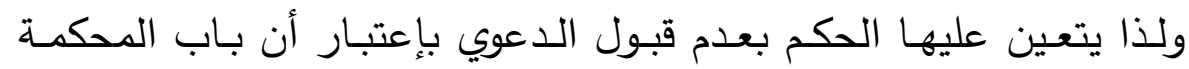

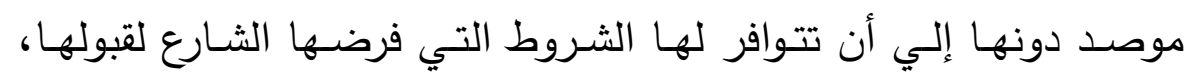

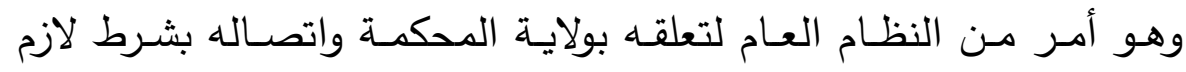
لتحريك الدعوي الجنائية ويقيد اتصال المحكمة بالواقعة"(r). ويكاد يجمع الفقه الفرنسي(r) علي أنه خلافاً للأحكام الجنائية الفرنسية،

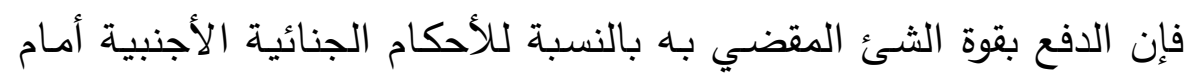

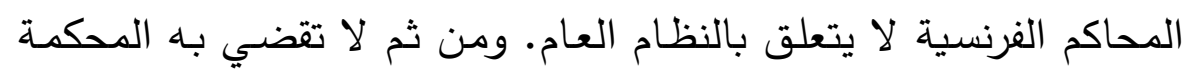

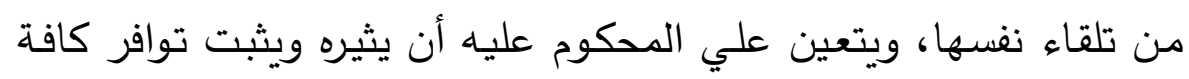
الشـروط اللازمـة لإعماله، بأن يقيم الدليل علي صلي صدور الحكم الجنـائي

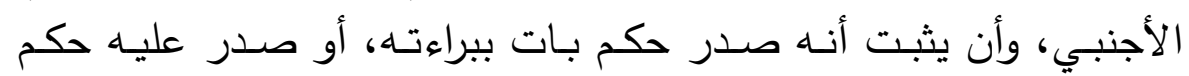

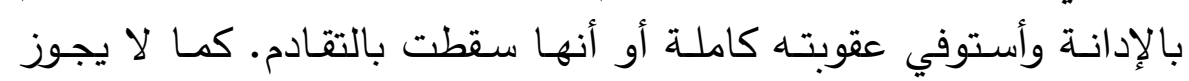

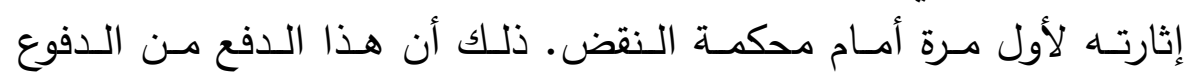

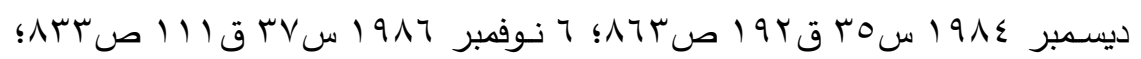

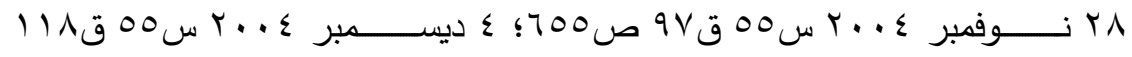
ص صY

Pradel (J.): Droit pénal, Tome II, procedure pénale, op.cit. ${ }^{\circ} 700$, p. $ง$ 7. Lombois (C.): op.cit. n ${ }^{\circ} 9 \vee$, p. ${ }^{0.7}$. En juris: Paris 17 mars

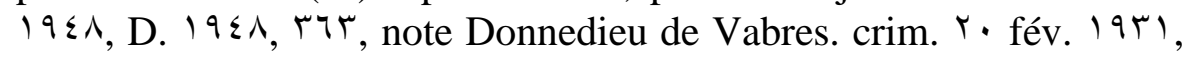
Gaz.Pal. 19r1, I, 799 ; crim. $r$ mai 1971 , motifs, B. $n^{\circ} r \cdot r$; crim. $r \uparrow$ juill. 19V1, J.C.P. 19V1, IV, r.r.

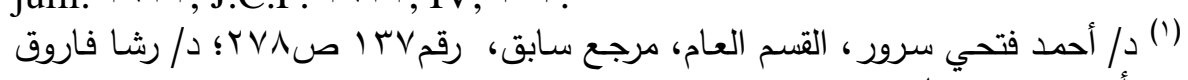

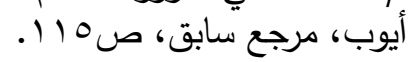

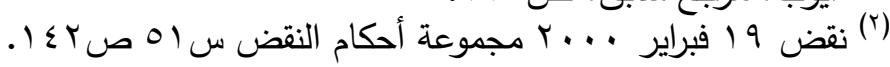

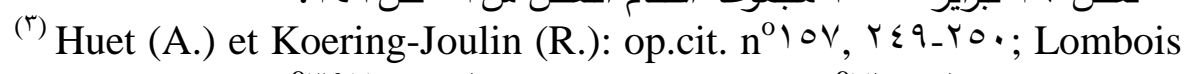
(C.): op.cit. $n^{0} \uparrow q \vee$, p. ${ }^{0.7}$; Thiel (D.): op.cit. $n^{0} \vee 4$, p. ${ }^{70}$. 
الموضـوعية التهي تـدخل فـي إختصــاص قاضـي الموضـوع، حيـث أنـهـ يستلزم إثارة بعض الموضوعات المتعلقة بالقانون الأجنبي.

وقد أيد البعض من الفقه المصري(') - وبحق - مذهب الفقه الفرنسي،

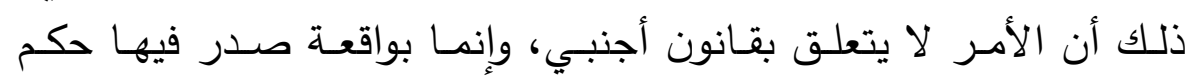

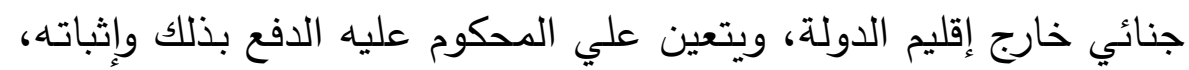

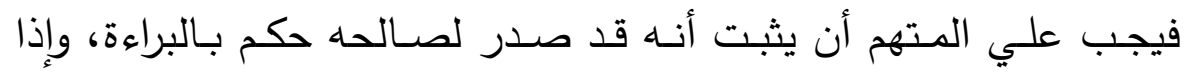
كان صادراً بالإدانة فيتعين عليه أن يثبت أنه قد استوفي عقوبته. ويبرز

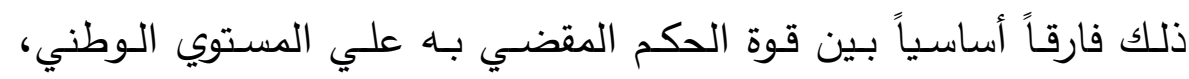

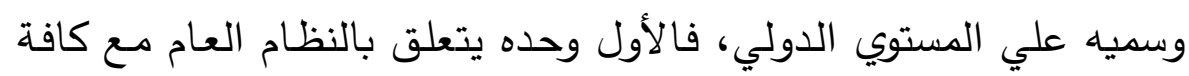
الآثار المترتبة عليه، دون الثاني.

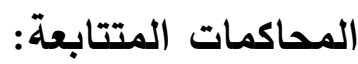

لم يعالج المشرع - سواء في فرنسـا أو في مصر - حالة مـا إذا قدم

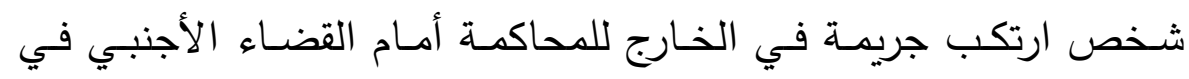

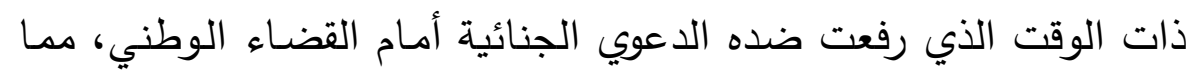

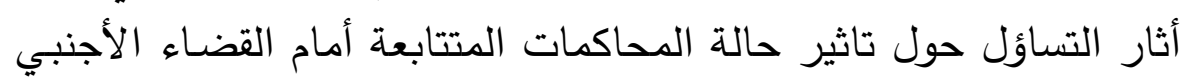
وأمام القضاء الوطني. فنظراً لعدم وجود نص خاص في هذه التهأل المسألة(r).

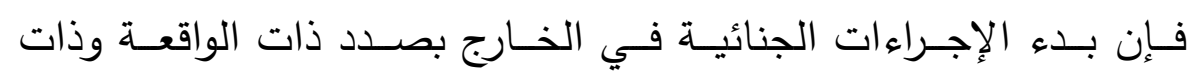

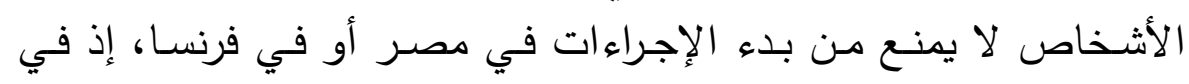

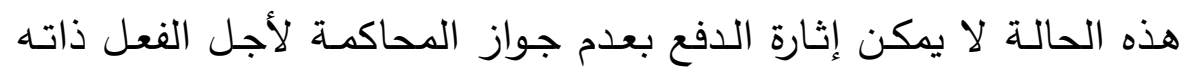

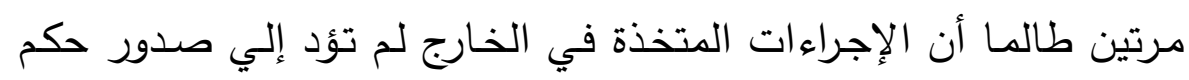
بات في الموضوع بالبراءة أو الإدانة، إذ يمكن إثارة هذا الدفع هنا فئ فقط.

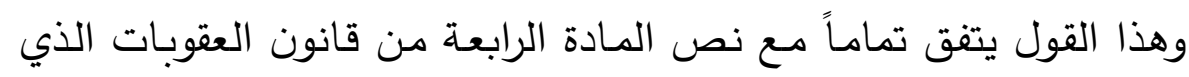

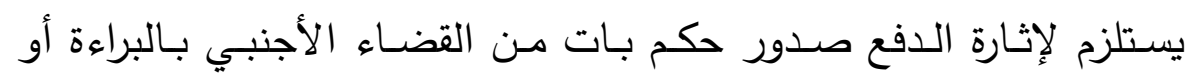

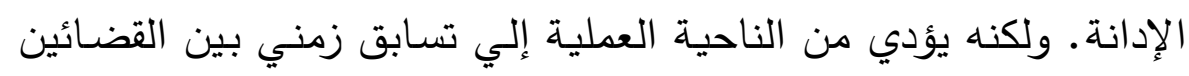

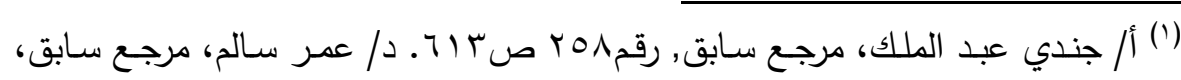

(ऍ) crim. I $\vee$ mars 1999, B. $n^{\circ} \leqslant \varepsilon$. رقم.7 صات •1. 


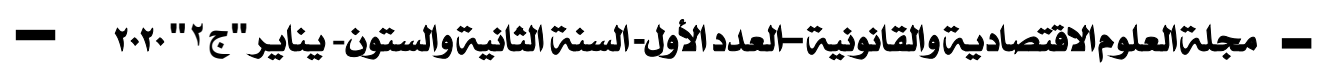

الوطني والأجنبي في سبيل الوصول إلي حكم بات قبل القضـاء الآخر ،

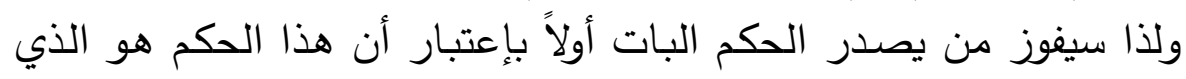
سيعتد به في الدولة الأخري(').

(') Lombois (C.): op.cit. $\mathrm{n}^{\mathrm{o}} \varepsilon \cdot 0, \mathrm{p} .011$.

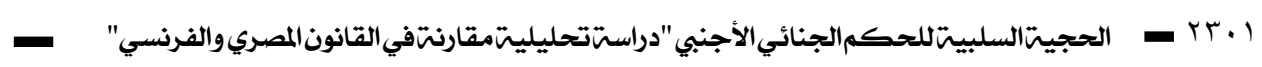




\section{خاتمة}

ترتـب علـي تخلـي التشـريعات الجنائيـة الوطنيـة عـن مبـدأ الإقليميـة

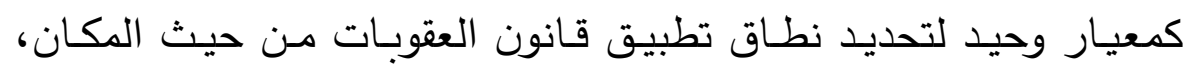

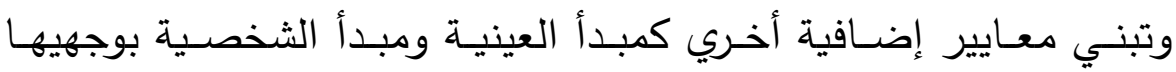

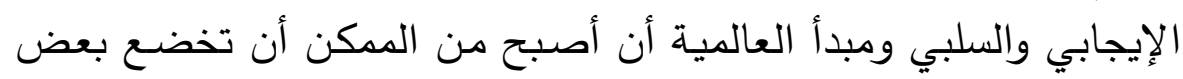
الجرائم التي ترتكب خارج إقليم الدولة لقانون العقوبات الوطني.

ونظراً إلي أن هناك ارتباط وثيق بين سريان قانون العقوبات المصري

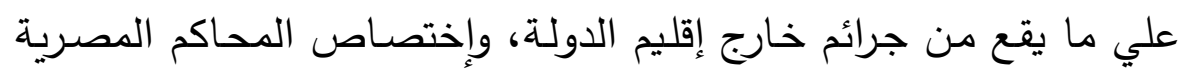

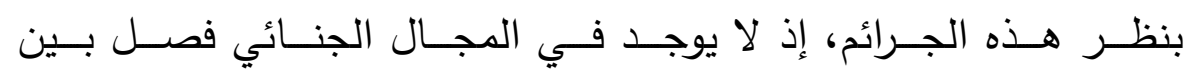

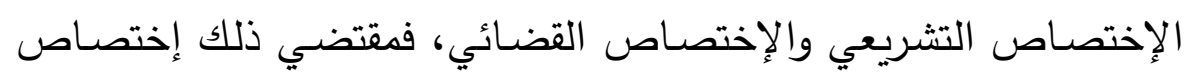
المحاكم المصرية بنظر الجرائم التي تقع في الخارج والتي يسري عليها قانون العقوبات المصري بالتطبيق لنص المادتين الثانية والثالثة منه. وهـو مـا يمكن معسه إمكانيـة انعقـاد الإختصـاص بنظـر الجريمــة التي

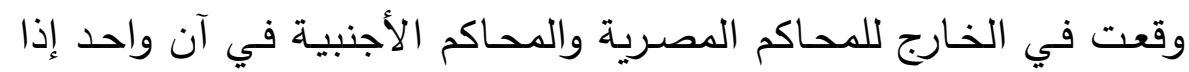

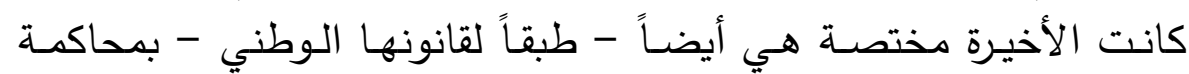

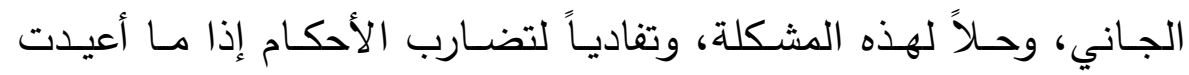

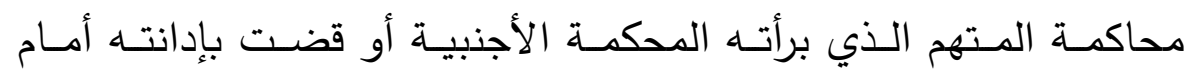

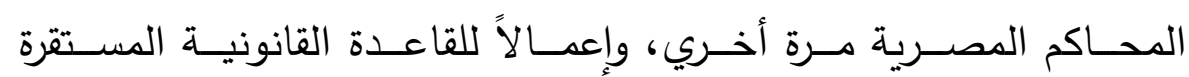

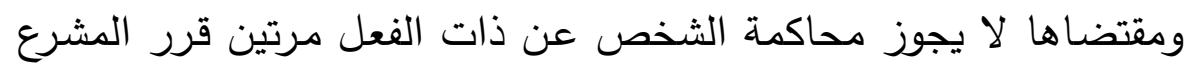

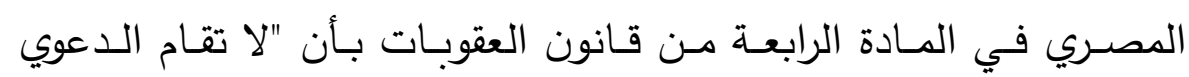

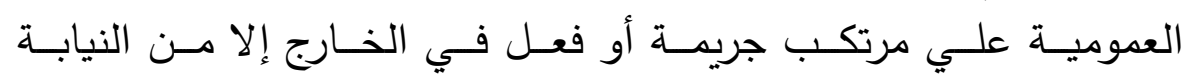

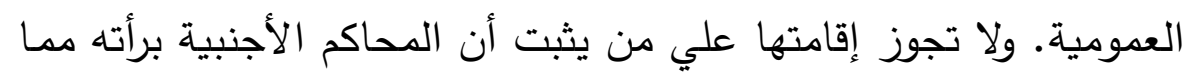
أسند إليه أو أنها حكمت عليه نهائياً واستوفي عقوبته".

فمحاكمة المتهم في مصر عما ارتكب من جرائم أو أفعال في الخارج

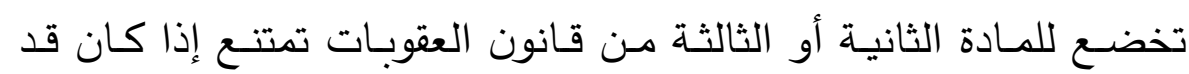

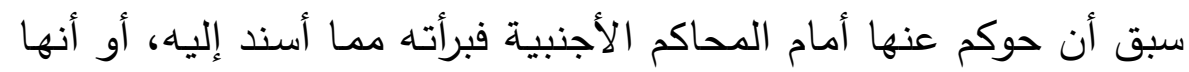


حكمت عليه نهائياً بالإدانة واستوفي عقوبته. وهو ما يعبر عنهـ بالحجية

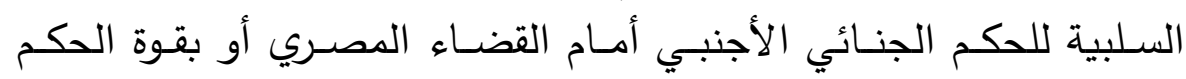
الجنائي الأجنبي في إنهاء الدعوي الجنائية.

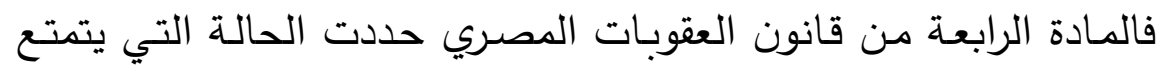

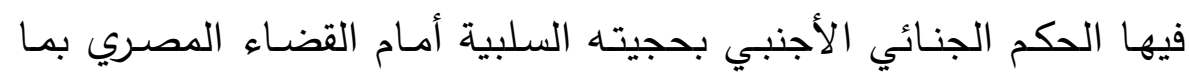
يقع من جرائم في الخارج تدخل في إختصـاص القضاء المصري إستناداً

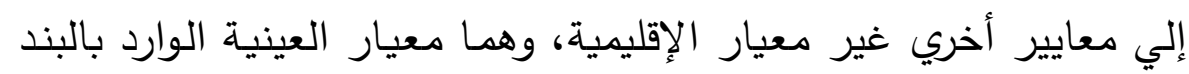

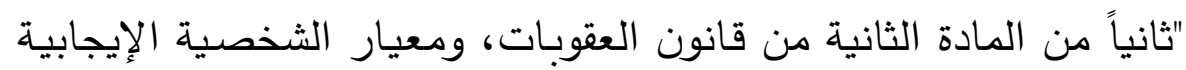

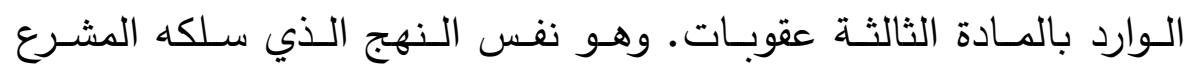

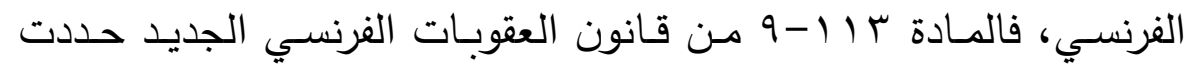

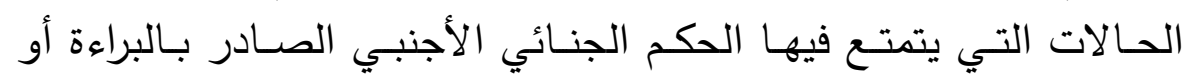

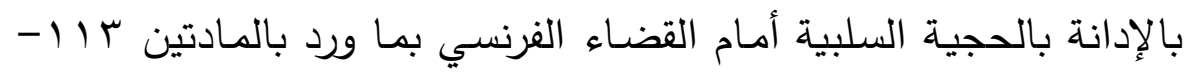

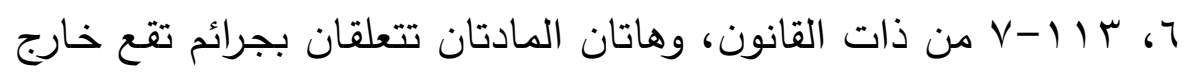

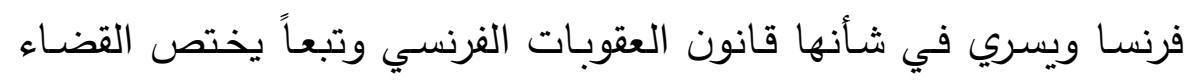
الفرنسي بنظرها إستناداً إلي معايير أخري غير فير فعيات فيار الإقليمية، فأولاهما

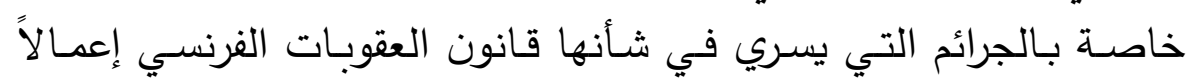

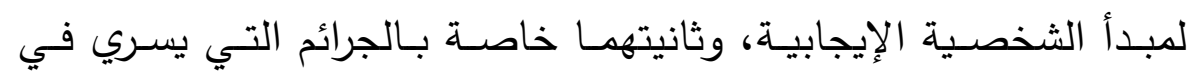

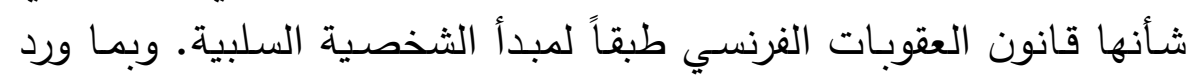

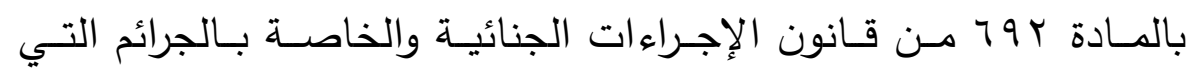
يختص بها القضاء الفرنسي طبقاً لمبدأ العالمية.

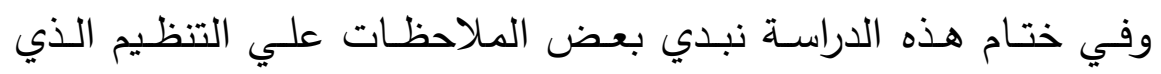

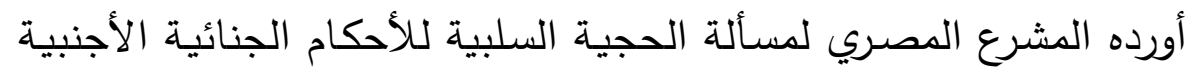
أمام القضاء المصري في المادة الرابعة من قانون العقوبات وهي:

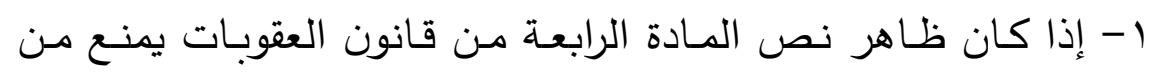

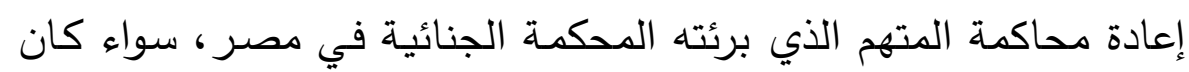

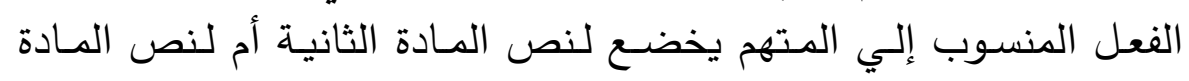

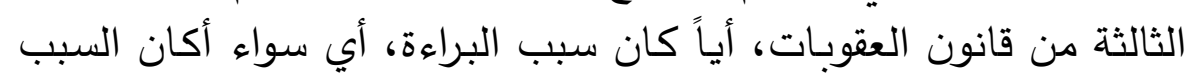




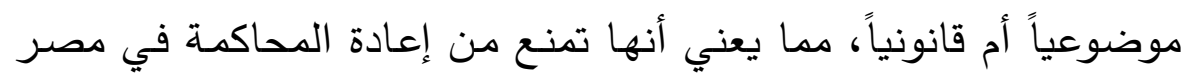

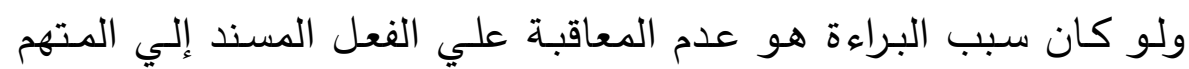

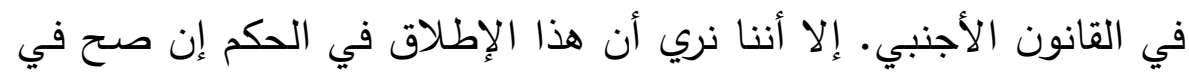

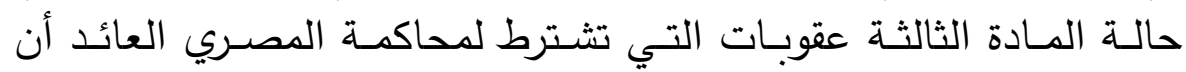

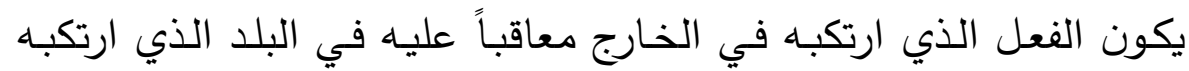

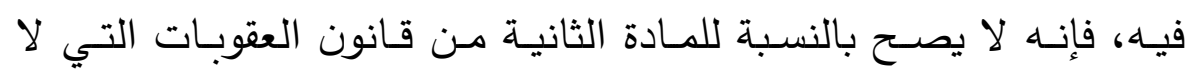

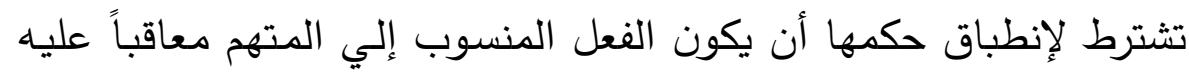

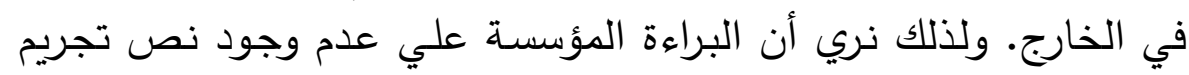

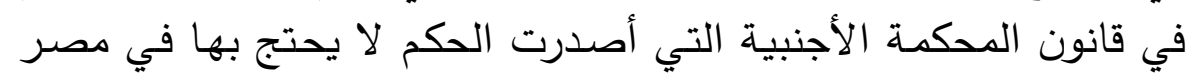

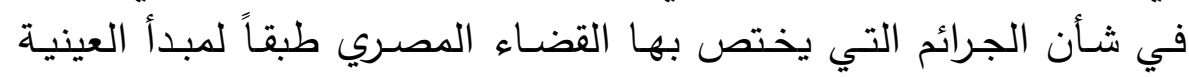
الواردة بالبند "ثانياً" من المادة الثانية من قانون لخدي العقوبات.

r- اشـترط نـص المـادة الرابعـة مـن قـانون العقوبـات أن يكـون الحكم

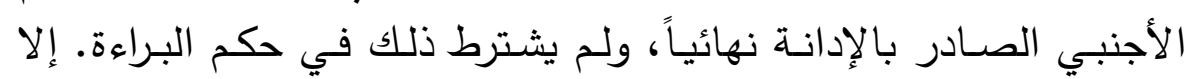

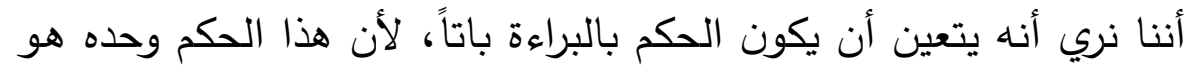

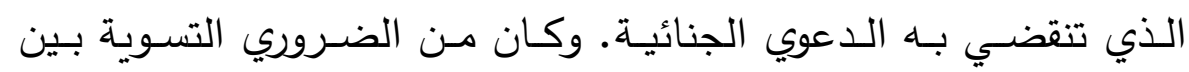

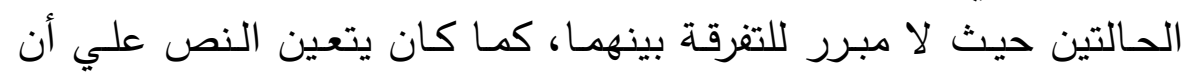
يكون الحكم باتاً تمشياً مع الرأي المستقر عليه في مصر في شأن الحكم الصادر بالإدانة.

r - يؤخذ علي نص المادة الرابعة من قانون العقوبات أن القاضي غير

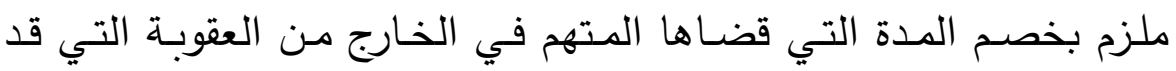

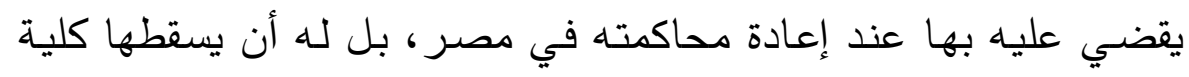

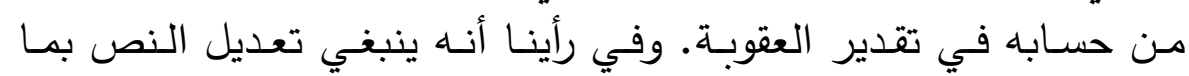

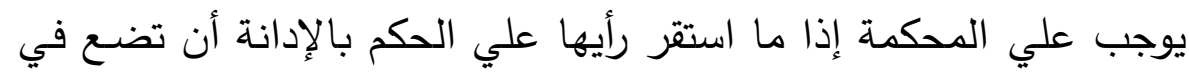

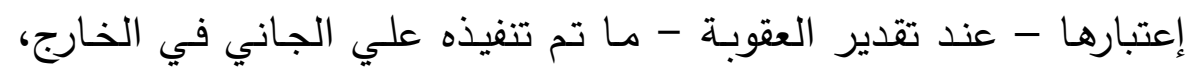

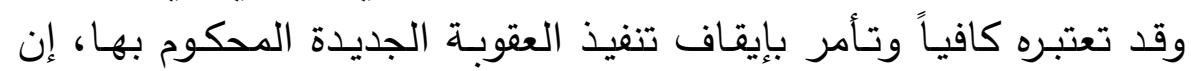
توافرت شروطه.

تم بحمد الله وتوفيقه،، 


\section{قائمة المراجع}

أولاً: المراجع العربية:

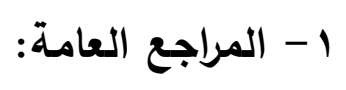

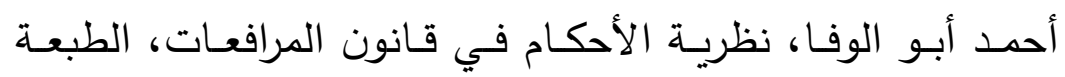

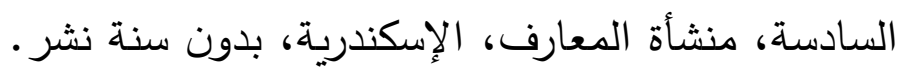

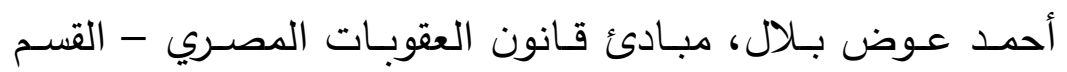

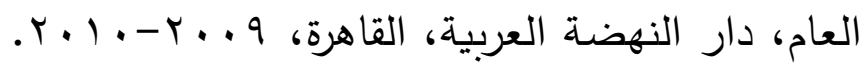

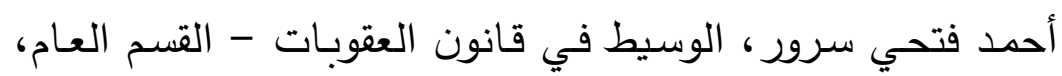

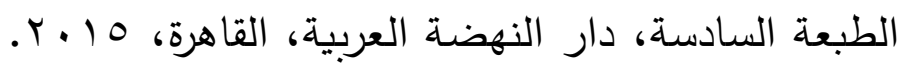

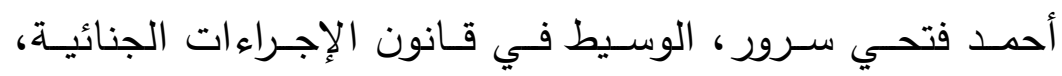

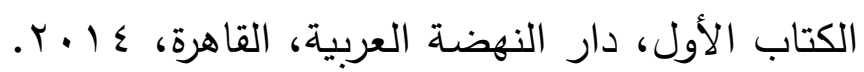

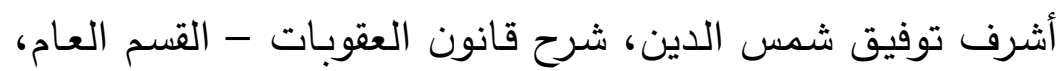

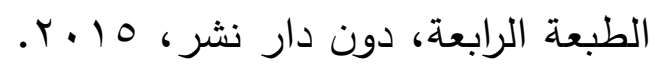

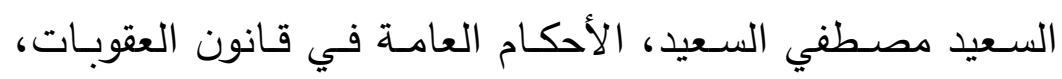

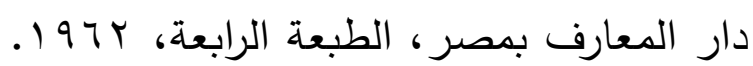

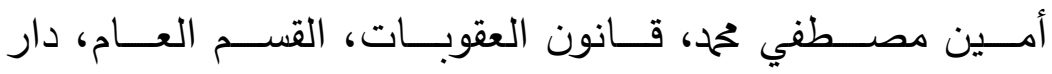

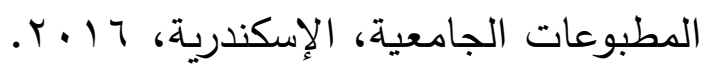

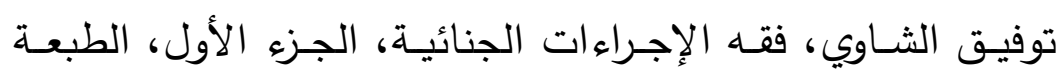

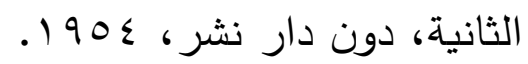

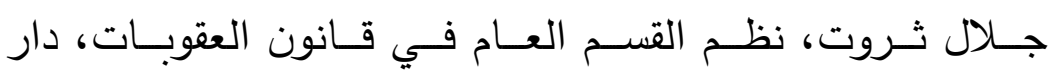

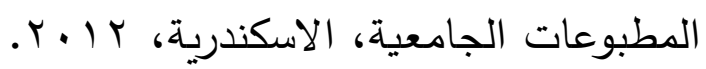

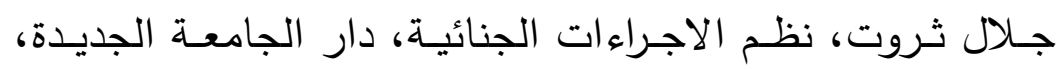

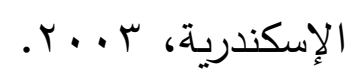

جندي عبد الملك، الموسـوعة الجنائيـة، جه، دار إحيـاء التراث

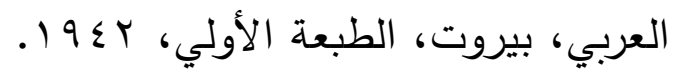

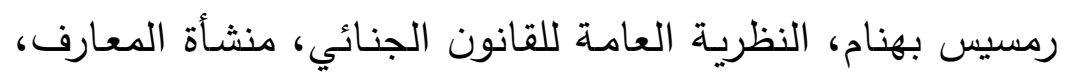




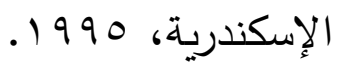

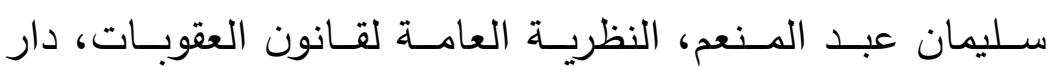

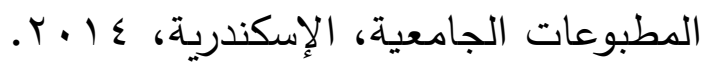

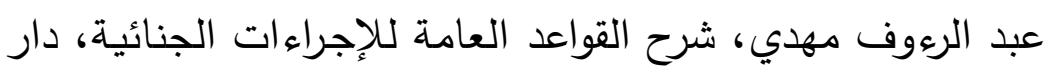

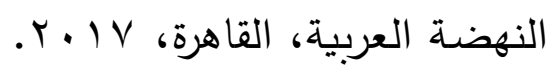

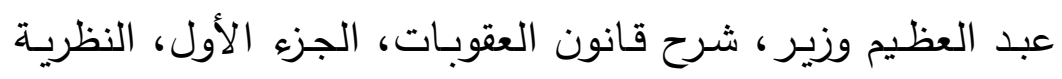

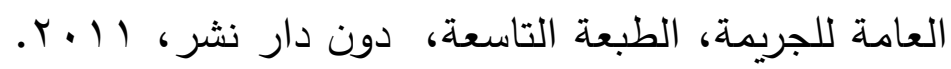

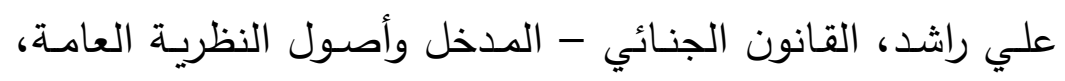

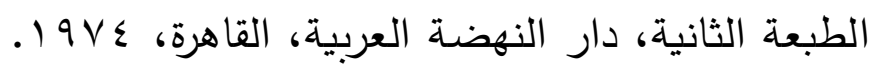

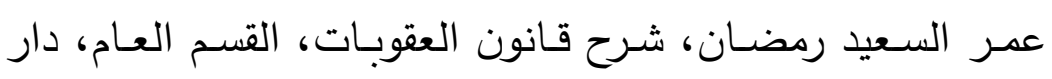

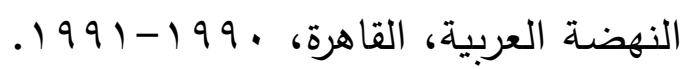

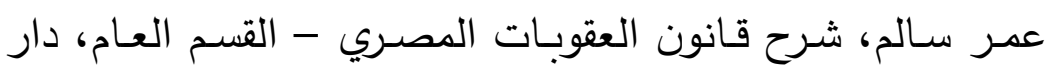

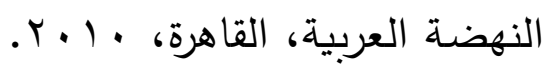

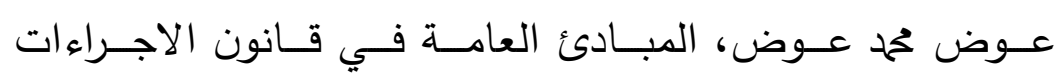

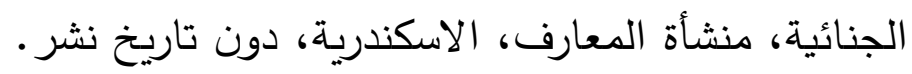

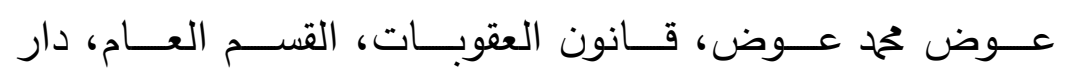

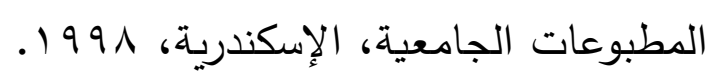

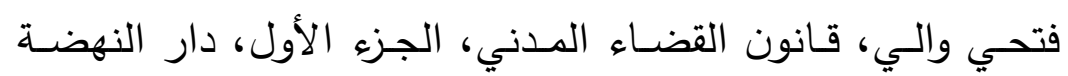

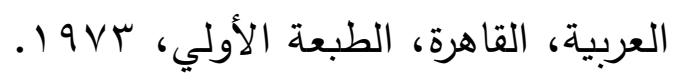

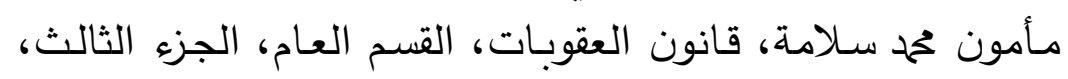

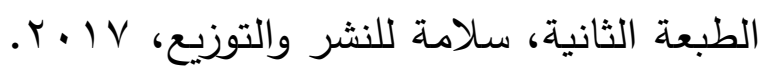

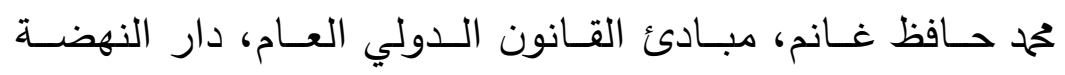

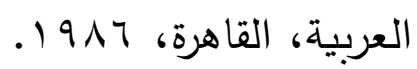

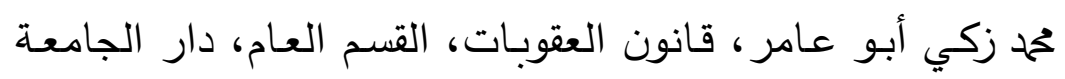

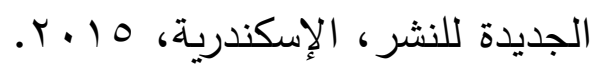

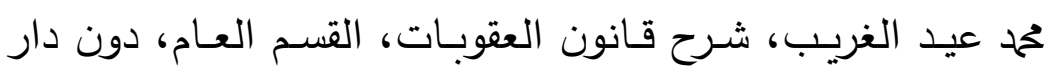

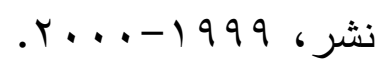




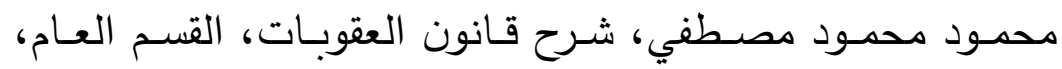

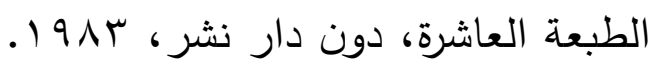

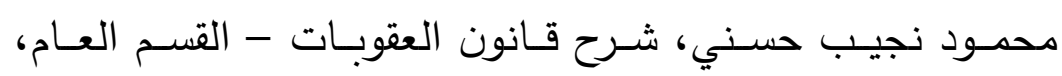

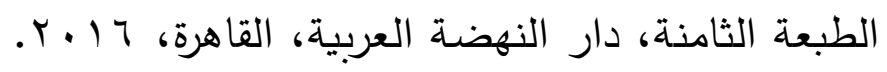

r - ب - المراجع المتخصصة:

إدوار غالي الدهبي، إعادة النظر في الأحكام الجنائية، دار الفكر العربي،

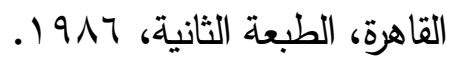
إدوار غالي الدهبي، حجية الحكم الجنائي أمام القضاء المدني، دار النهضة

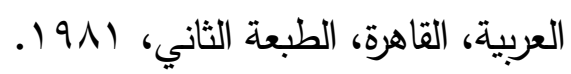

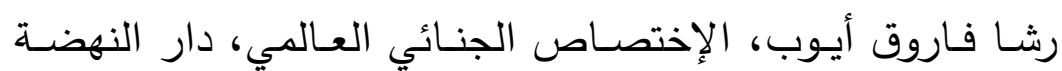

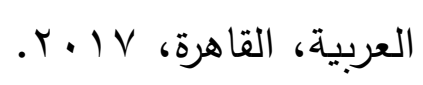

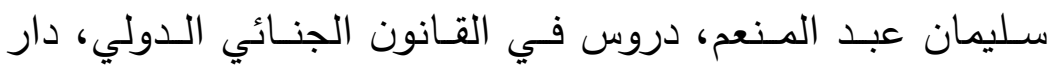

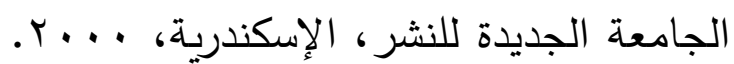

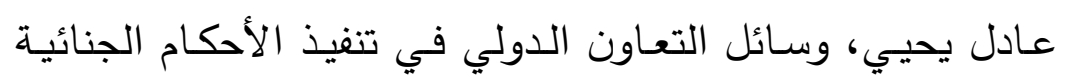
الأجنبية، الطبعة الأولي، دار النهضة العربية، القاهرة، دون سنة التعاونة نشر . محمد الفاضل، التعاون الدولي في مكافحة الإجرام، دون دار نشر، دون سنة نشر • محمـود نجيـب حسـني، قـوة الحكـم الجنـائي في إنهـاء الـدعوي

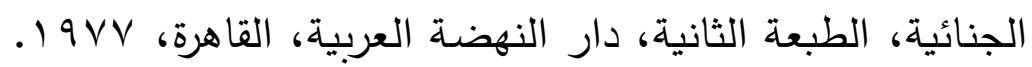

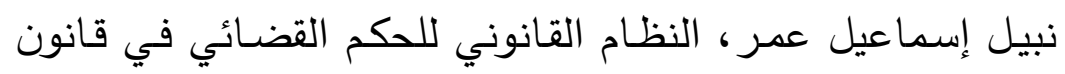

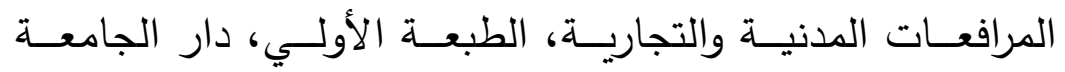

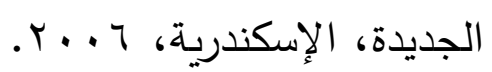




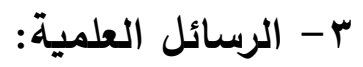

سمير محمود عالية، قوة الحكم الجنائي أمام القضـاء الجنائي - دائية

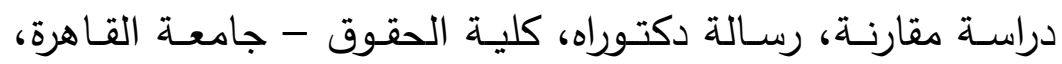
$.19 \vee 0$

فتحي المصري بكر، قوة الثـئ المقضي بـه في المجال الجنائي، ركأ

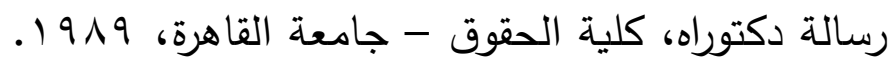

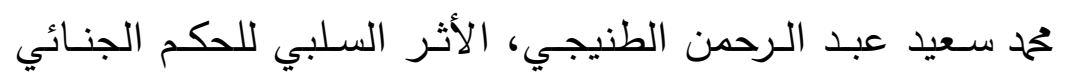

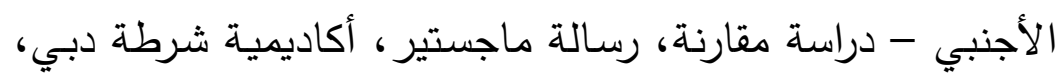
. . . O צ - المقالات:

أحمد رفعت خفاجي، أثر الأحكام الجنائية الأجنبية، دراسة فقهية

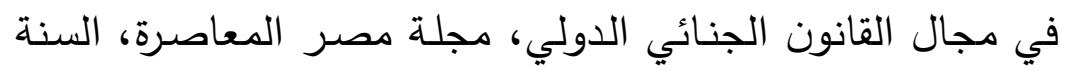

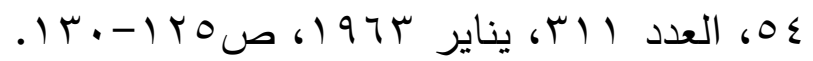

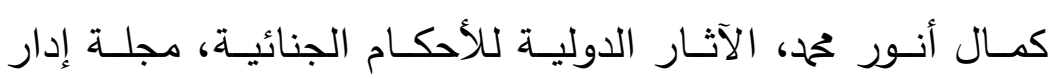

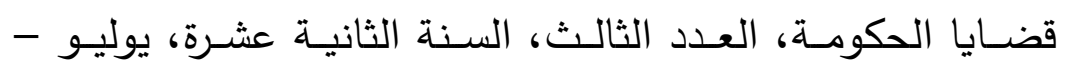
سبتمبر

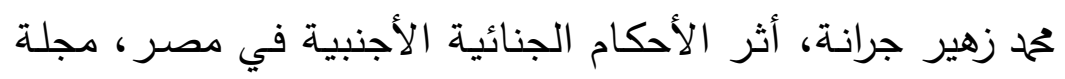

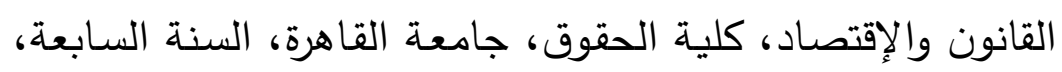

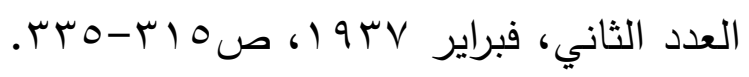

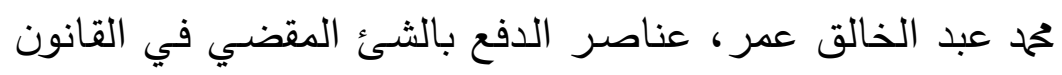

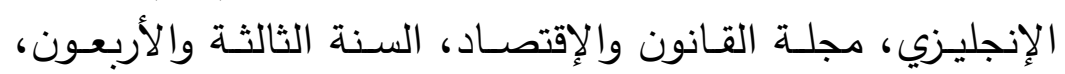

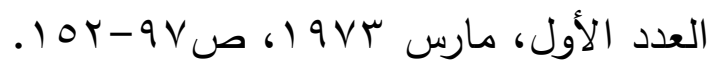

$$
\begin{aligned}
& \text { ثانياً: المراجِع الأحنبية: }
\end{aligned}
$$

\section{1- Ouvrages:}

- Barbe (E.): Une présentation du projet de décision cadre rélative à la reconnaissance des 
décision de gel des avoirs et des preuves, In. "La reconnaissance mutuelle des décisions judiciaires pénales dans l'union europénne, ouvrage collectif, Bruxelles, r..'.

- Bouloc (Bernard): Droit pénal général, Dalloz, Paris, $Y^{\mathrm{e}}$ édition, $Y$. 9 .

- Donnedieu de vabres (Henri): Traité de droit criminal et de législation pénal comparée, Recueil Sirey, $19 \leqslant \vee$.

- Donnedieu de vabres (Henri): Les principes modernes du droit pénal international, Paris, 1941.

- Huet (André) et Koering-Joulin (Renée): Droit pénal international, presses universitaires de France, Thémes, Paris, $199 \varepsilon$.

- Jeandidier (Wilfrid): Droit pénal général, Montchrestien, Paris, Y ${ }^{\mathrm{e}}$ éd. 1991.

- Lombois (Claude): Droit pénal international, Deuxième édition, Dalloz, Paris, । १४१.

- Pradel (Jean): Droit pénal, Tome I, Introduction générale, Droit pénal général, Édition Cujas, Paris, 19^1.

- Jean Pradel: Droit penal, Tome II, procedure pénale, Édition Cujas, Paris, Deuxième édition, 1911.

- Rebut (Didier): Droit penal international, Dalloz, $r \cdot 1 r$. 
- Stefani (Gaston), Levasseur (Georges) et Bouloc (Bernard): procedure pénale, Dalloz, Paris, Y $)^{\mathrm{e}}$ édition, $r . \wedge$.

- Travers (Maurice): Traité de droit pénal international, t. III, Paris, $19 r \cdot-19 r$ r.

\section{r-Articles:}

- Bigay (Jacques): Les dispositions nouvelles de compétence des juridictions francaises à l'égard des infractions commises à l'étranger, D. I $9 \vee 7$, chronique p.01_or.

- Breukelaar (W.): La reconnaissance des Jugements répressifs étrangères, R.I.D.P. numéro spécial, । $9 \vee \varepsilon, \varepsilon 0^{\mathrm{e}}$ année, $\mathrm{n}^{\mathrm{o}}$ et $\varepsilon, \mathrm{P} .070_{-} 0 \wedge \varepsilon$.

- David (F.): De la reconnaissance des sentence pénale étrangèrs en France, au point de vue de la recedive et du sursis, R.I.D.P. $n^{\circ} \mid r, 10^{\mathrm{e}}$ année, ו 9 r , p.rr।-ro.

- Desessard (L.): France, Les competences criminelles concurrentes nationales et internationals et le principe non bis in idem, R.I.D.P. r. r/r, vol. $\vee r, p . q) q_{-} q \varepsilon \cdot$

- Desportes (F.) et Le Gunehec (F.): Présentation des dispositions du nouveau code pénal (Lois

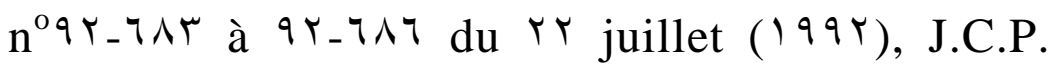
199r, $n^{\circ} \varepsilon 1, I, r 410$,

- Fayard (Marie-Claude): La localisation international de l'infraction (Etude de 


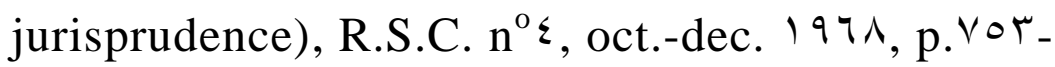
$\vee \vee 9$.

- Fournier (Alain): Complicité internationale et compétence des juridictions répressives françaises, Rev. crit. DIP 1911, doctrine et chroniques, p. r I $-V Y$.

- Jofé: De l'application par le juge d'un Etat des lois penales étrangères, Revue de droit penal et

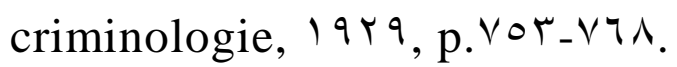

- Kunter (Nurullah): La valeur européennes des jugements répressifs au point de vue des conséquences occasionnelles, R.I.D.P. 197V, no11, p.190-rr1.

- Le Calvez (Jacques): Compétence legislative et competence judiciaire en droit penal, seconde partie, R.S.C. 191।, $n^{\circ}$ r avril - juin, 19^., p.rTV_rvT.

- Massé (Michel): La competence pénale francaise dans l'espace depuis l'entrée en vigueur du nouveau code penal, R.S.C. oct.-dec. 1990,

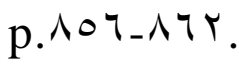

- Pradel (Jean): Le nouveau code penal (partie generale) (loi $n^{0} 9 r_{-} \uparrow \wedge r$ du $r$ juillet $\left.199 r\right)$, ALD 1994 ,

- Pralus (Michel): Etude en droit penal international et en droit communautaire d'un 
aspect du principe non bis in idem: non bis, R.S.C. ( $\left.{ }^{r}\right)$, juill.-sep. 1997, p.001: 0V 1 .

- Ropers (Jean-Louis): Le marché commun et les effets internationaux des jugements répressifs, J.C.P. $197 \%$, doctrine, $\left.n^{\circ}\right) \vee 9 \vee$.

- Schultz (Hans): Compétence des juridictions pénales pour les infractions commises à l'étranger, R.S.C. $197 \mathrm{~V}$, p.r।・-rr^.

- Zlataric (Bogdan): Droit pénal international, Revue al Qanoun wal Iqtisad, Le caire, juin 1979 , $n^{\circ}$ r, $q_{\text {année, }}$ p. $\leqslant q_{-} \wedge$ ०.

\section{r. Thèses:}

- Canonne (G.): Essai de droit pénal international; L'affaire du "lotus", thèse, Toulouse, 19 9 9 .

- Colombini (J.-L.): La prise en considération du droit étranger (penal et extra penal) dans le jugement penal, thèse, université de Lausanne, 19人r.

- Koering Joulin (R.): L'article 79r CPP et la localisation internationale de l'infraction, thèse, Strasbourg, $19 \vee r$.

- Moulier: La compétence universelle en droit international T.I, Thèse, Paris I, Y . ..

- Thiel (D.): Conflits positifs et conflits négatives en droit penal international, thèse, université de Metz, r... 
- Tsarpalas: Le moment et la durée dans les infractions pénales, thèse, Paris, $197 \mathrm{~V}$.

\section{\& - Mélanges:}

- Carreau (Dominique): La compétence universelle au regard du droit international, in. Les droits et le droit, Mélanges dédiés à Bernard Bouloc, vol. ', Paris, Dalloz, ץ.. .

- Fournier (A.): Aperçu critique du principe de double incrimination en droit pénal international, in. Les droits et le droit, Mélanges dédiés à Bernard Bouloc, vol.', Paris, Dalloz, Y..v.

- Legeais: L'évolution des solutions francaises de conflits de lois en matière pénale, Mélanges Savatier, $197 \varepsilon$. 


\section{قائمة المختصرات}

Liste des abréviations

\begin{tabular}{|c|c|}
\hline AJ.Penal & Actualité juridique penal (Dalloz) \\
\hline ALD & $\begin{array}{l}\text { Actualité Législative Dalloz (à partir } \\
\text { de (৭৭ґ) }\end{array}$ \\
\hline Art. & Article \\
\hline B. & $\begin{array}{l}\text { Bulletin des arrets de la chambre } \\
\text { criminelle de la cour de cassation }\end{array}$ \\
\hline Chron. & Chronique \\
\hline Comm. & commentaires \\
\hline Comp. & Comparer \\
\hline C.P.J.I. & $\begin{array}{l}\text { Cour permanente de justice } \\
\text { internationale }\end{array}$ \\
\hline CPP. & Code de procédure pénale \\
\hline Crim. & $\begin{array}{l}\text { Chambre criminelle de la cour de } \\
\text { cassation }\end{array}$ \\
\hline D. & Recueil Dalloz \\
\hline DH. & $\begin{array}{l}\text { Recueil hebdomadaire de jurisprudence } \\
\text { Dalloz (années antérieures à } \ 9 \text { १) }\end{array}$ \\
\hline DP. & $\begin{array}{l}\text { Recueil périodique et critique mensuel } \\
\text { Dalloz (années antérieures à } 19 \text { ।) }\end{array}$ \\
\hline Dr. Pen. & Revue Droit pénal (éd. techniques) \\
\hline Éd. & Édition \\
\hline Gaz.Pal. & Gazette du Palais \\
\hline
\end{tabular}




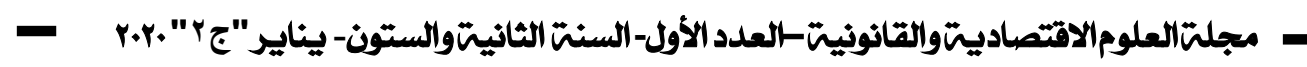

\begin{tabular}{|c|c|}
\hline in & Dans l'ouvrage suivant \\
\hline IR & $\begin{array}{l}\text { Informations rapides du Recueil } \\
\text { Dalloz }\end{array}$ \\
\hline J.C.P. & $\begin{array}{l}\text { Juris-Classeur périodique (sémaine } \\
\text { juridique) }\end{array}$ \\
\hline Juris. & Jurisprudence \\
\hline Litec & Librairies techniques \\
\hline $\mathrm{n}^{\mathrm{o}}$ & Numéro \\
\hline Op.cit. & opere citato (ouvrage précité) \\
\hline $\mathrm{P}$. & Pages \\
\hline R.D.I.P. & $\begin{array}{l}\text { Revue générale de droit international } \\
\text { public }\end{array}$ \\
\hline Rev. crit. DIP & $\begin{array}{l}\text { Revue critique de droit international } \\
\text { privé (Dalloz) }\end{array}$ \\
\hline R.I.D.P. & Revue international de droit pénal \\
\hline R.S.C. & $\begin{array}{l}\text { Revue de science criminelle et de droit } \\
\text { pénal comparé (Dalloz) }\end{array}$ \\
\hline S. & Et Suivants \\
\hline S. & Recueil Sirey \\
\hline Somm. & Sommaire \\
\hline $\mathrm{T}$. & Tome \\
\hline Trib.corr. & Tribunal, chambre correctionnelle \\
\hline
\end{tabular}

